


\title{
Patched-assoziierte Tumoren: \\ Modifikatorgene und Pathogenese
}

\author{
Dissertation \\ zur Erlangung des Doktorgrades \\ der Mathematisch-Naturwissenschaftlichen Fakultäten \\ der Georg-August-Universität zu Göttingen
}

vorgelegt von

Frauke Nitzki

aus Hannover

Göttingen 2008 
Referent:

Korreferent:

Tag der mündlichen Prüfung:
Prof Dr. W. Engel

Prof. Dr. R. Hardeland 
Die vorliegende Arbeit wurde in der Zeit von Juli 2003 bis März 2008 im Institut für Humangenetik der Universität Göttingen angefertigt.

Teile dieser Arbeit wurden veröffentlicht:

Hahn H, Nitzki F, Schorban T, Hemmerlein B, Threadgill D und Rosemann M. Genetic mapping of a Ptch1-associated rhabdomyosarcoma susceptibility locus on mouse chromosome 2. Genomics. 2004 Nov;84(5):853-8.

Nitzki F, Kruger A, Reifenberg K, Wojnowski L und Hahn H. Identification of a genetic contamination in a commercial mouse strain using two panels of polymorphic markers. Lab Anim. 2007 Apr;41(2):218-28.

Uhmann A, Dittmann K, Nitzki F, Dressel R, Koleva M, Frommhold A, Zibat A, Binder C, Adham I, Nitsche M, Heller T, Armstrong V, Schulz-Schaeffer W, Wienands J und Hahn $\mathrm{H}$. The hedgehog receptor patched controls lymphoid lineage commitment. Blood. 2007 Sep 15;110(6):1814-23. 
$1 \quad$ Einleitung

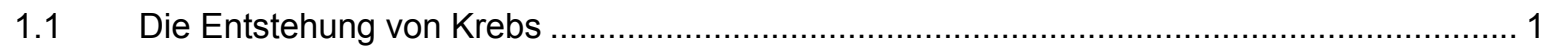

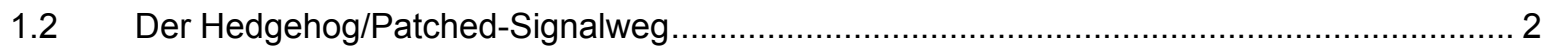

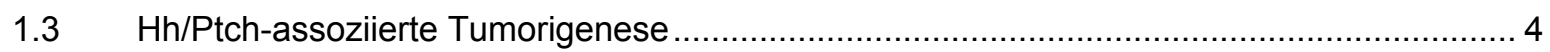

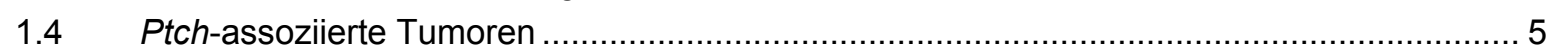

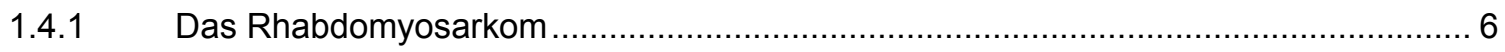

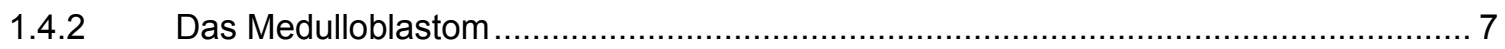

1.4.3 Modifikatorgene bei Ptch-assoziierten RMS und MB .......................................... 7

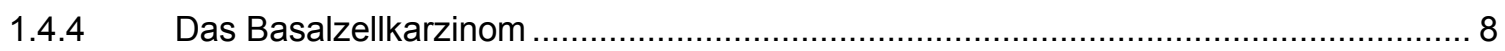

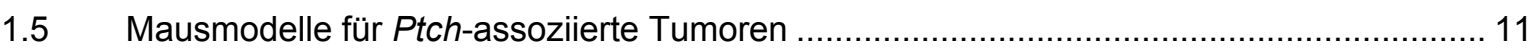

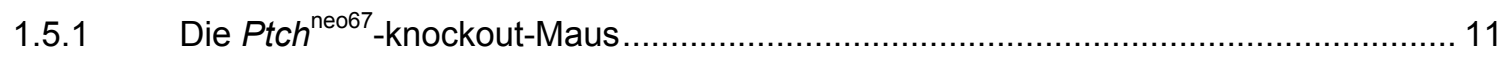

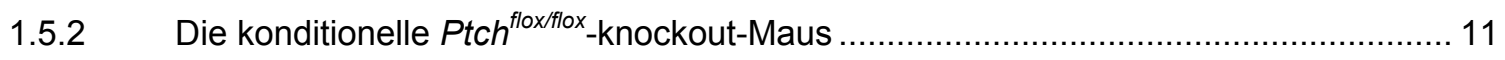

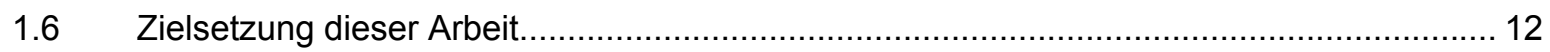

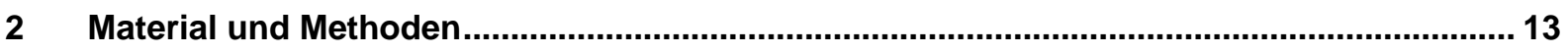

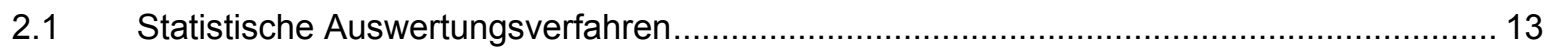

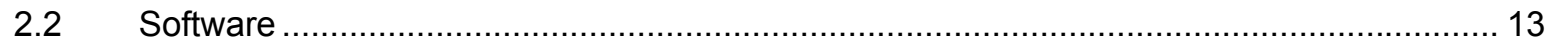

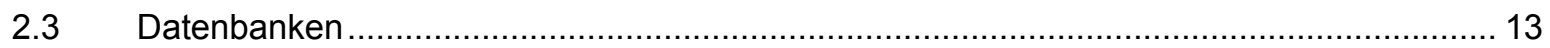

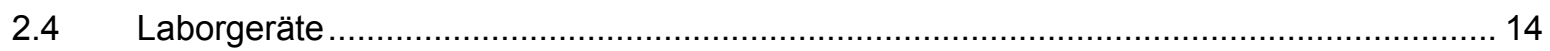

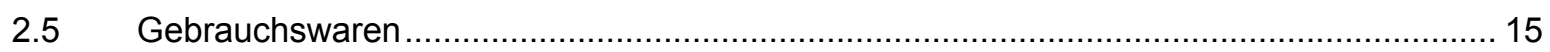

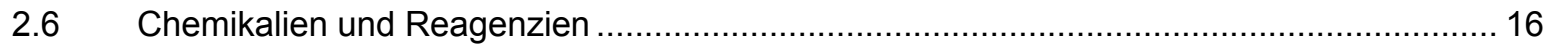

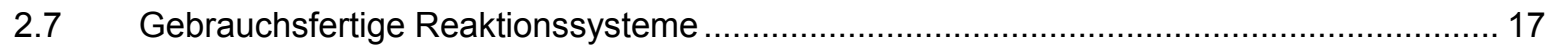

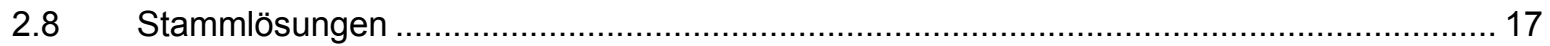

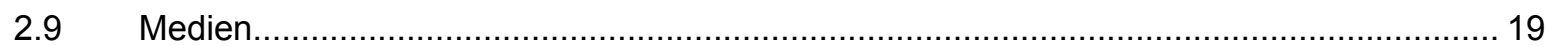

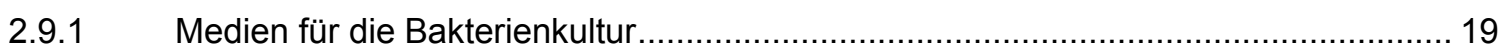

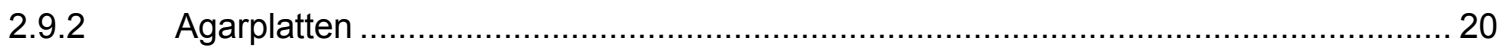

2.9.3 Medien für die Kultur eukaryontischer Zellen ......................................................... 20

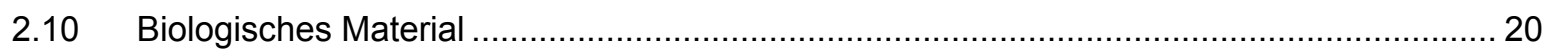

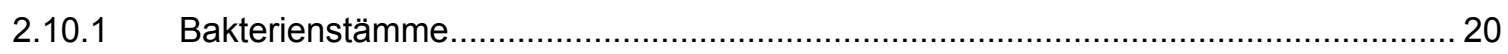

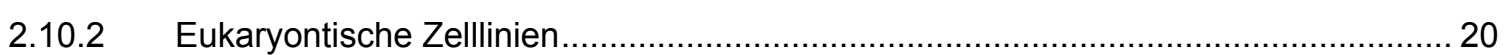

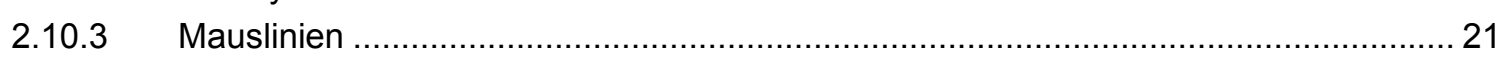

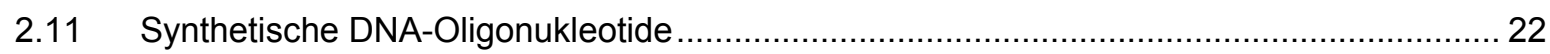

2.11.1 DNA-Oligonukleotide zur Genotypisierung von Mäusen............................................ 22

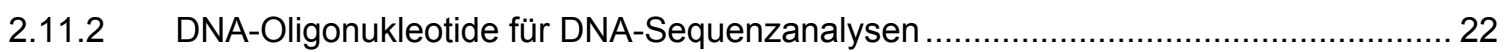

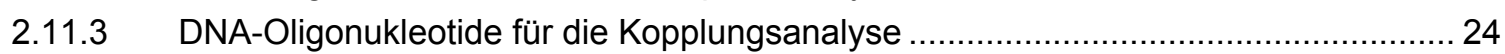

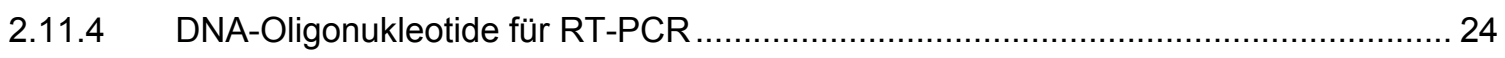

2.11.5 DNA-Oligonukleotide für die quantitative real time PCR ............................................... 25

2.11.5.1 DNA-Oligonukleotide für die quantitative real time PCR an cDNA..................... 25

2.11.5.2 DNA-Oligonukleotide für TaqMan-Analysen an gDNA ..................................... 26

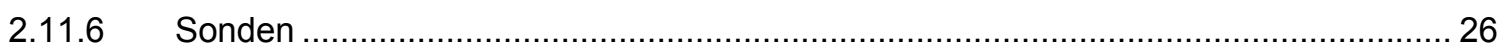

2.12 Gebrauchsfertige TaqMan Assays für Genexpressionsanalysen ..................................... 27

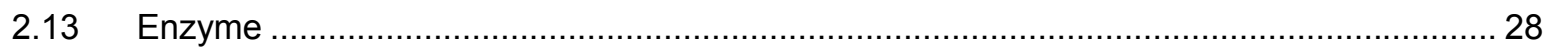

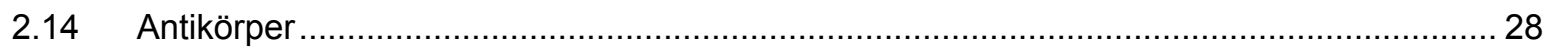

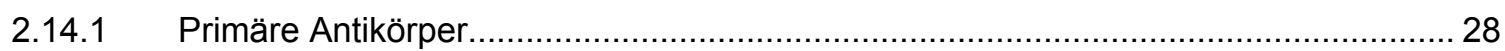

2.14.2 Sekundäre Antikörper und Alkalische Phosphatase-gekoppelte Streptavidin

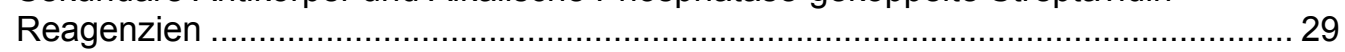

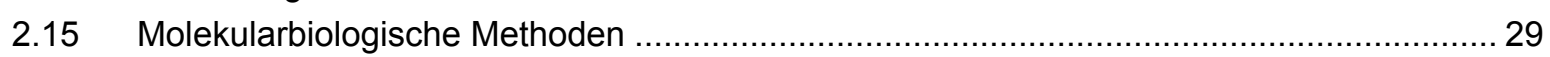

2.15.1 Präparative und analytische Arbeiten mit Nukleinsäuren......................................... 29

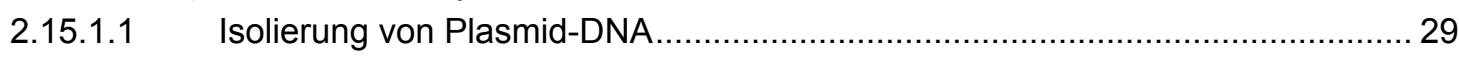

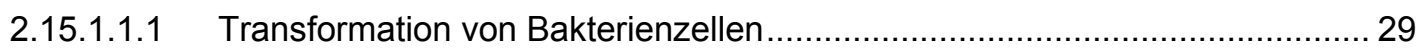




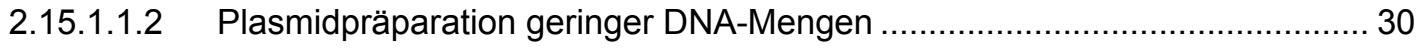

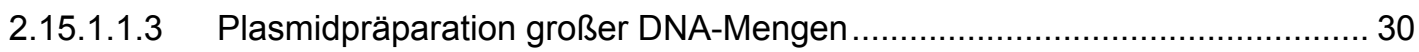

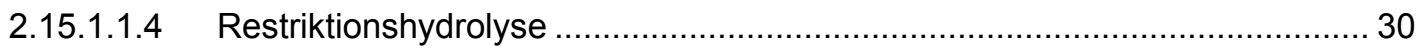

2.15.1.2 Phenol/Chloroform-Aufreinigung von Nukleinsäuren .................................... 31

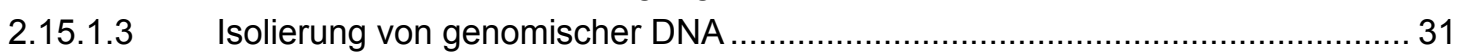

2.15.1.3.1 Isolierung von genomischer DNA aus eukaryontischen Zellen..................... 31

2.15.1.3.2 Isolierung von genomischer DNA aus Gewebe für Genotypisierungen......... 31

2.15.1.3.3 Isolierung von genomischer DNA aus Gewebe für Southern Blot-Analysen . 32

2.15.1.4 Isolierung von Gesamt-RNA ..................................................................... 32

2.15.1.4.1 Isolierung von Gesamt-RNA aus eukaryontischer Zellkultur ........................ 32

2.15.1.4.2 Isolierung von Gesamt-RNA aus Gewebe ............................................. 32

2.15.1.5 Konzentrationsbestimmung von Nukleinsäuren ............................................. 33

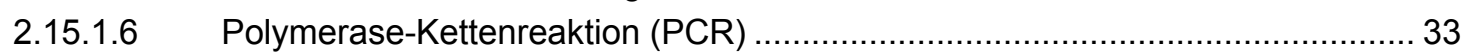

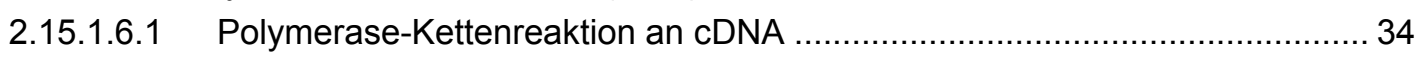

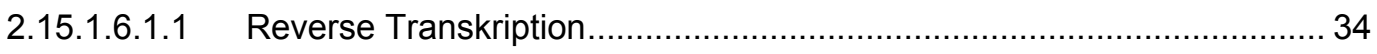

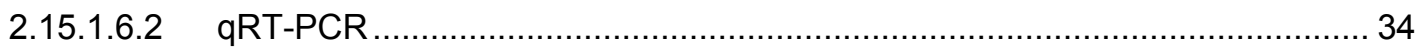

2.15.1.6.2.1 Durchführung und Aufbau der TaqMan-Analyse zur Quantifizierung der Rekombinationseffizienz nach Aktivierung der Cre-Rekombinase.......... 35

2.15.1.6.2.2 Durchführung und Aufbau der gebrauchsfertigen TaqMan Assays ....... 35

2.15.1.6.2.3 Durchführung und Aufbau der qRT-PCR mit SYBR Green ................... 36

2.15.1.6.2.4 Auswertung nach der Standardkurvenmethode ...................................... 37

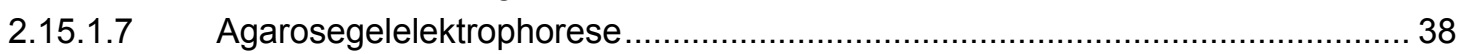

2.15.1.8 Southern Blot-Analyse zur Detektion der homologen Rekombination des Vektors

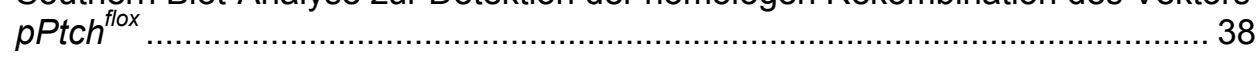

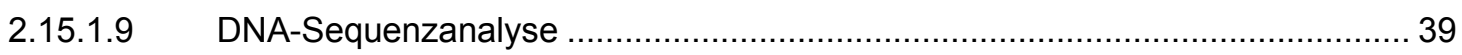

2.15.1.9.1 Isolierung und Aufreinigung von DNA-Fragmenten aus Agarosegelen ......... 40

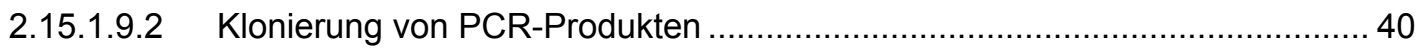

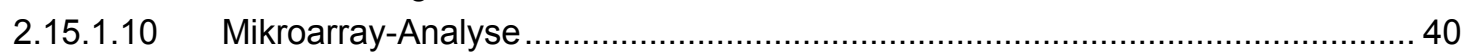

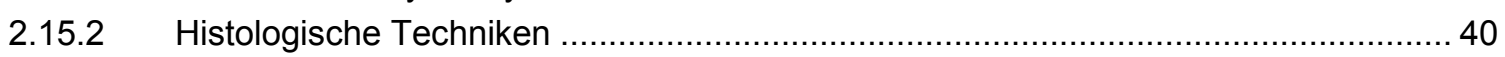

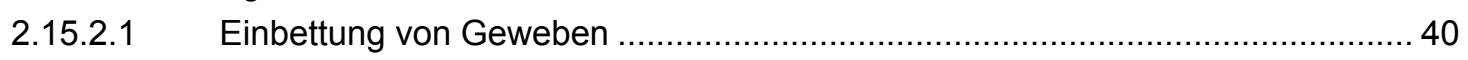

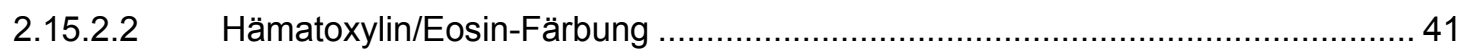

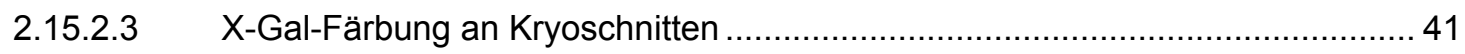

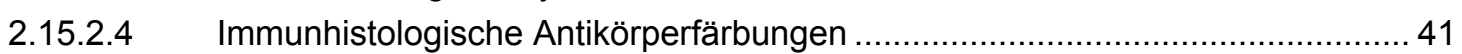

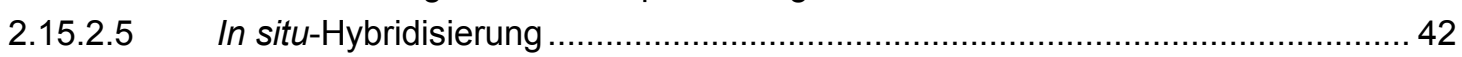

2.15.2.5.1 Herstellung Digoxigenin-markierter Sonden für in situ-Hybridisierung .......... 43

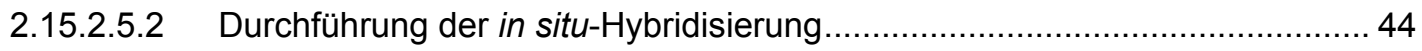

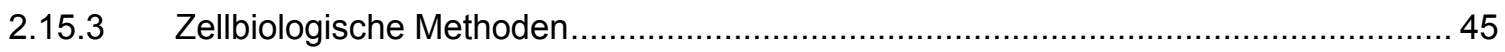

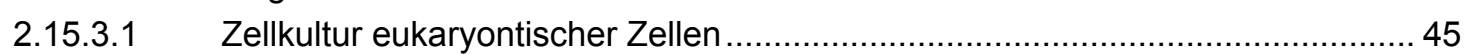

2.15.3.2 Kryokonservierung eukaryontischer Zellen .................................................. 46

2.15.3.3 Isolierung und Kultivierung adulter muriner Fibroblasten .................................. 46

2.15.3.4 Aktivierung der Cre-Rekombinase in $\mathrm{Ptch}^{\text {floxflox }} \mathrm{ERT2}^{+/}$-Zellen durch Tamoxifen ..

2.15.3.5 Herstellung von Shh-konditioniertem Medium ........................................... 47

2.15.3.6 Stimulation des Hh/Ptch-Signalweges durch konditioniertes Shh Medium ........ 47

2.15.3.7 Blockade des Hh/Ptch-Signalweges durch Cyclopamin..................................... 47

2.15.3.8 Bestimmung der Zellproliferationsrate mittels Inkorporation von 5-Bromo-2-

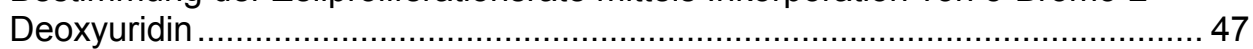

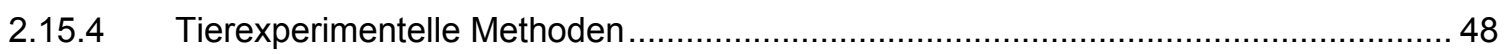

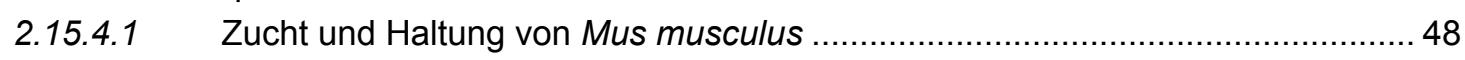

2.15.4.1.1 Schwanzbiopsie und Ohrlochmarkierung............................................. 48 


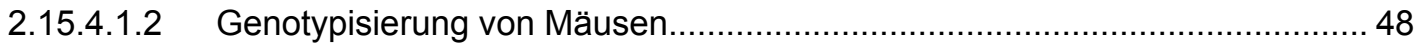

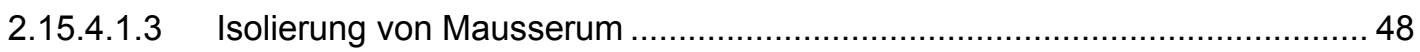

2.15.4.1.4 Bestimmung des Kopulationszeitpunktes und der Trächtigkeit sowie Isolierung

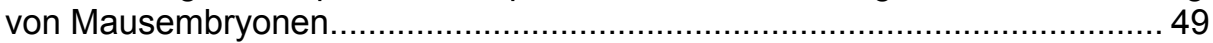

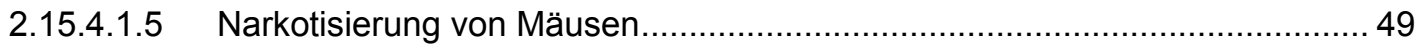

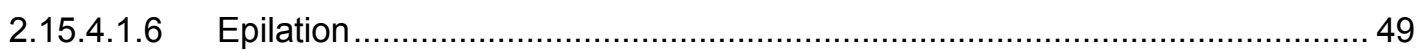

2.15.4.1.6.1 Lokale Applikation von Tamoxifen auf die epilierte Haut........................ 50

2.15.4.1.7 Intraperitoneale und intramuskuläre Injektion von Tamoxifen ....................... 50

2.15.4.1.8 Perfusion von Mäusen mit Paraformaldehyd ............................................. 50

2.15.4.1.9 Sichtung und Präparation von Tumoren ................................................... 51

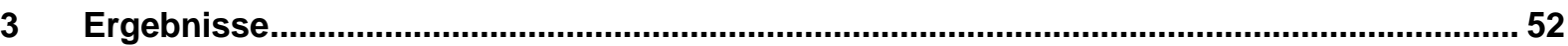

3.1 Abhängigkeit der Tumorinzidenz vom genetischen Hintergrund bei Ptch ${ }^{\text {neo67/+ }}$-Mäusen .... 52

3.1.1 Detektion des RMS-Suszeptibilitätslokus Parms1 auf Chromosom 2 ........................55

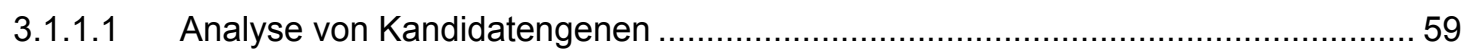

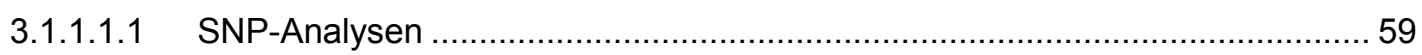

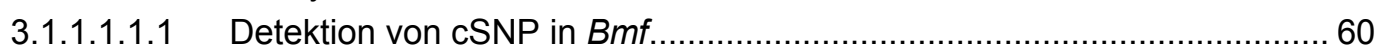

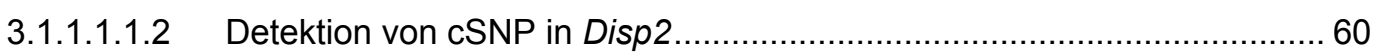

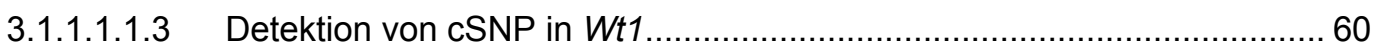

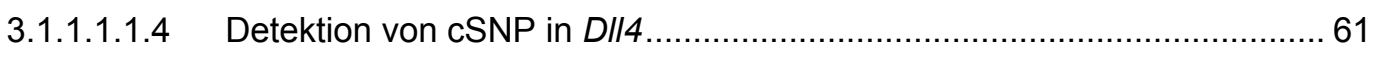

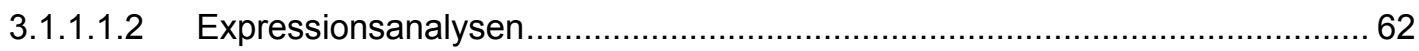

3.1.1.2 Etablierung einer neuen N2-Mauskolonie zur Eingrenzung von Parms1 ............... 62

3.1.1.3 Detektion einer genetischen Kontamination im Mausstamm B6 ........................... 63

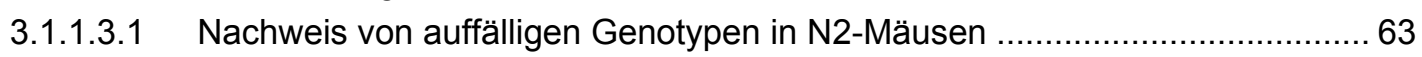

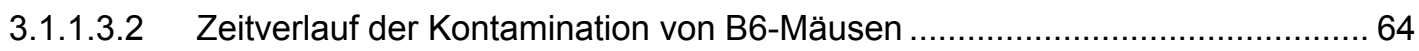

3.1.1.3.3 Identifikation der kontaminierenden Mauslinie ...............................................6 66

3.1.2 Entwicklung von RMS in Ptch $^{\text {neo67/t }}$-Mäusen mit 50 \% DBA2J-, 129Sv- und FVB/N-

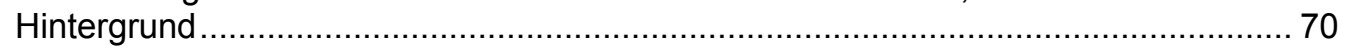

3.1.3 Zusammenfassung der Ergebnisse des Kartierungsprojektes ................................ 72

3.1.4 Mikroarray-basierte Genexpressionsanalysen von RMS aus CD1Ptch ${ }^{\text {neo67/+ }}$ - und (BALBxB6)Ptch ${ }^{\text {neo67// }}$-Mäusen ............................................................................. 73

3.2 Analyse von konditionellen $\operatorname{Ptch}^{\text {flox }}$-knockout-Mäusen: Allgemeine Charakterisierung und

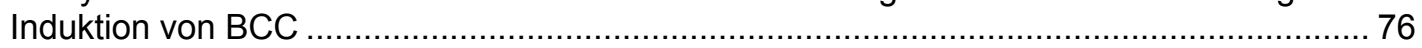

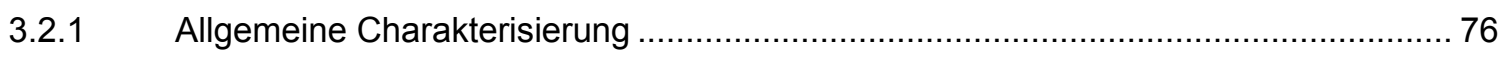

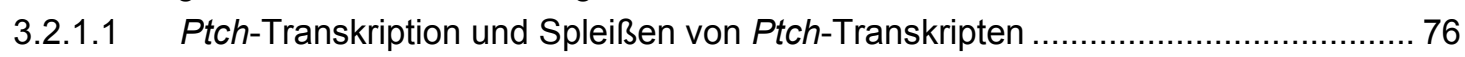

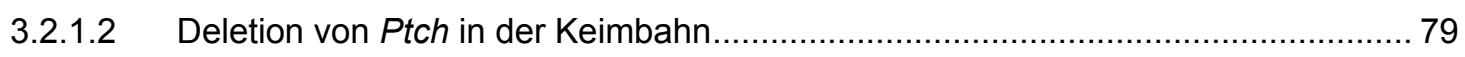

3.2.1.3 Deletion von Ptch in adulten $P t c h{ }^{f l o x}$-Mäusen und Induktion von

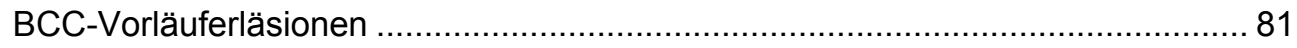

3.2.1.3.1 Deletion von Ptch durch i.p. Gabe von $5 \mathrm{mg}$ Tamoxifen ............................... 81

3.2.1.3.2 BCC-Vorläuferläsionen und andere Anomalien in $\mathrm{tPtch}{ }^{-/}$-Mäusen ................... 82

3.2.2 Induktion von BCC durch i.m. Gabe von $100 \mu \mathrm{g}$ Tamoxifen .................................... 85

3.2.2.1 In vivo-Analyse der Tamoxifen-induzierten Aktivität der Cre-ERT2 in ROSA26-R-

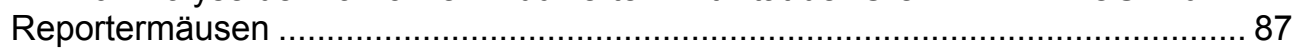

3.2.2.2 Entstehung von BCC aus Basalzellen und der äußeren Wurzelscheide................. 89

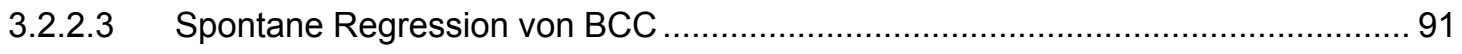

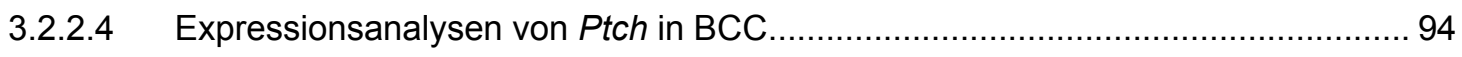

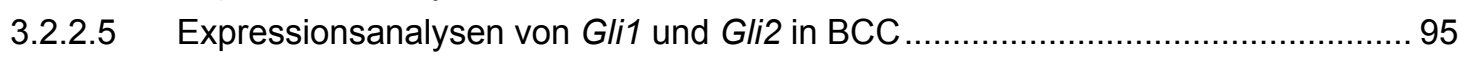

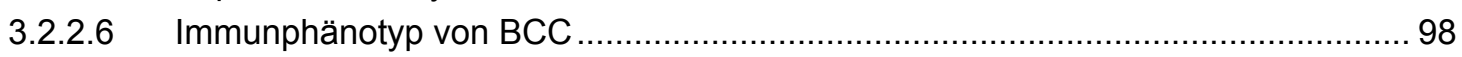

3.2.2.7 Analyse der kanonischen Wnt-Signalkaskade in BCC ..................................... 99

3.2.2.8 Expressionsanalysen von Differenzierungsmarkern in regredienten BCC ............. 99

3.2.2.9 Zusammenfassung der Charakteristika der induzierten BCC............................. 101 
3.2.3 Induktion von BCC in unterschiedlichen Phasen des Haarzyklus .......................... 102

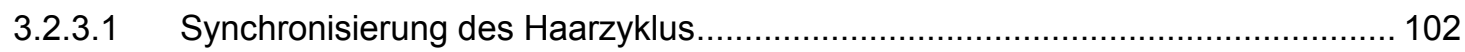

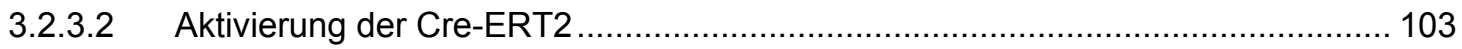

3.2.3.3 Induktion von BCC in unterschiedlichen Haarzyklusphasen .............................. 103

3.2.4 Etablierung stabiler Ptch floxfllox $_{-}$, Ptch $^{\text {floxflox }} E R T 2^{+/}$- und Ptch $^{-/}$-Zelllinien.................... 105

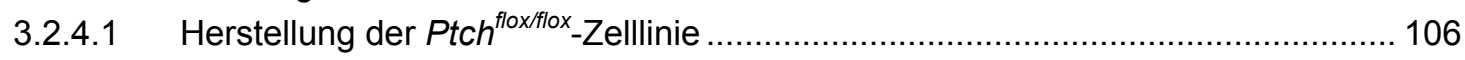

3.2.4.2 Herstellung von fünf monoklonalen Ptch $^{\text {floxfllox }} E R T 2^{+/}$-Zelllinien............................ 106

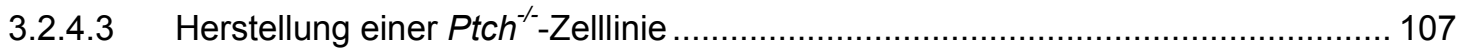

3.2.4.4 Charakterisierung der Ptch ${ }^{\text {flox/flox }}$ ERT2 ${ }^{+/}$-Fibroblasten (B9) ................................ 108

3.2.4.4.1 Aktivierung der Hh/Ptch-Signalkaskade durch Tamoxifen ............................ 108

3.2.4.4.1.1 Untersuchung der Rekombinationseffizienz am Ptch ${ }^{\text {flox }}$-Lokus .............. 108

3.2.4.4.1.2 Untersuchung der Aktivität des Hh/Ptch-Signalweges ......................... 110

3.2.4.4.2 Untersuchung der Aktivität des Hh/Ptch-Signalweges in Abhängigkeit von der

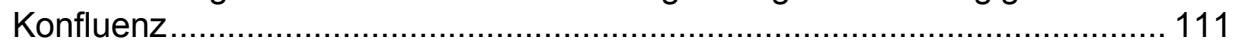

3.2.4.4.3 Blockade der Hh/Ptch-Signalkaskade durch Cyclopamin ............................. 112

3.2.4.4.4 Aktivierung der Hh/Ptch-Signalkaskade durch Shh....................................... 114

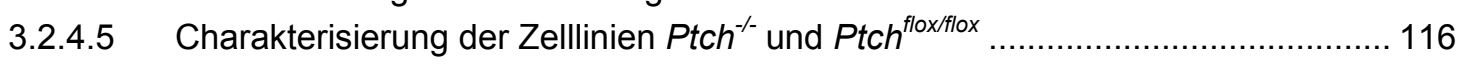

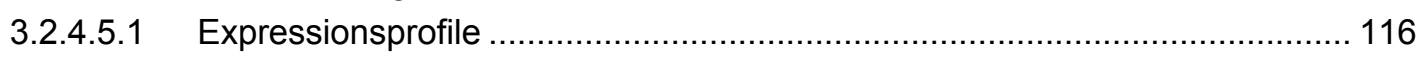

3.2.4.5.2 Untersuchung der Proliferationsraten................................................... 118

3.2.4.6 Zusammenfassung der Zellkulturexperimente.............................................. 119

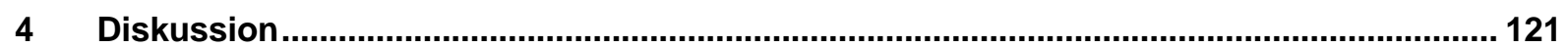

4.1 BALB-Allele des Lokus Parms1 vermitteln Suszeptibilität für RMS ................................. 121

4.1.1 Analyse von potenziellen RMS-modifizierenden Genen im Lokus Parms1 ............. 122

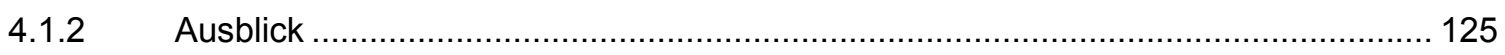

4.2 Detektion und Charakterisierung der genetischen Kontamination im Mausstamm B6 ..... 126

4.2.1 Identifikation von DBA-Inzuchtlinien als Ursprung der Kontamination...................... 127

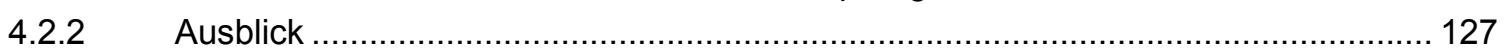

4.3 Unterschiedliche Expressionsmuster von RMS aus CD1Ptch ${ }^{\text {neo67/+ }}$ - und

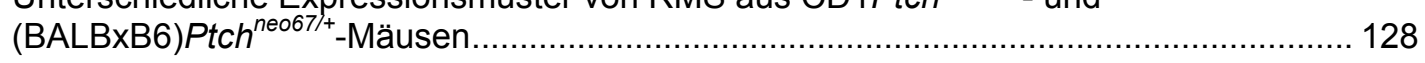

4.4 Charakterisierung der $P t c h^{\text {flox }}$-knockout-Maus und Induktion von BCC........................... 128

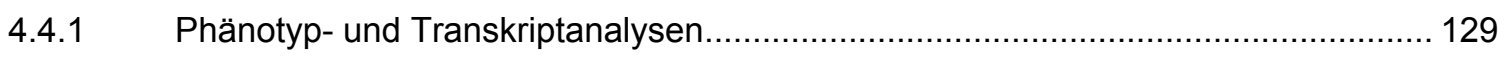

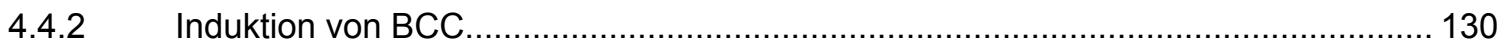

4.4.2.1 Entstehung von BCC nach i.m. Applikation von $100 \mu \mathrm{g}$ Tamoxifen ..................... 130

4.4.2.2 Initiation und Progression von BCC ........................................................... 132

4.4.2.3 Spontane Regression und Differenzierung von BCC ...................................... 133

4.4.3 Entstehung von BCC möglicherweise unabhängig vom Haarzyklus ........................ 137

4.4.4 Etablierung stabiler Zelllinien für in vitro-Analysen der Ptch-Funktion...................... 138

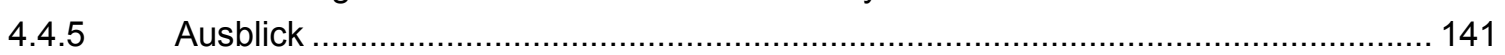

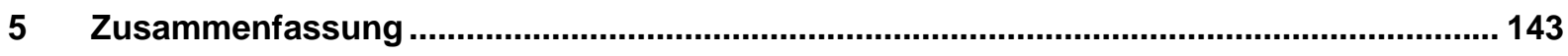

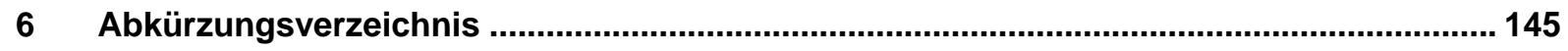

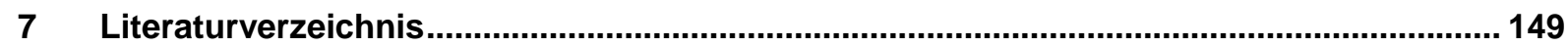

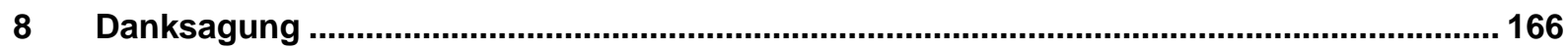

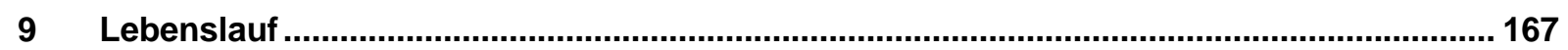




\section{$1 \quad$ Einleitung}

\subsection{Die Entstehung von Krebs}

Der Begriff Krebs wurde vermutlich erstmalig im 5. Jahrhundert v. Chr. vom griechischen Arzt Hippokrates verwendet (karkinos [griech.] - Krebs). Damit wurden nicht heilende Geschwüre bezeichnet, die von erweiterten Blutgefäßen umgeben sind. Man nahm damals an, dass Krebs durch Melancholie entstehe, wenn Organismus und Seele durch ein Überwiegen der schwarzen Galle vergiftet werden. Heute weiß man, dass Krebserkrankungen entstehen, wenn die Regulation des Zellwachstums gestört ist und die entsprechenden Kontrollmechanismen nicht mehr funktionieren. So kann durch Veränderungen der DNA (Mutationen) aus einem Proto-Onkogenen ein Onkogen entstehen oder die Funktion von Tumorsuppressorgenen gestört werden.

Protoonkogene, die unter anderem für Transkriptionsfaktoren, Wachstumsfaktoren oder Proteinkinasen kodieren, kontrollieren Zellwachstum, Zellteilung und Differenzierung. Aktivierende Mutationen in diesen Genen führen daher zu Tumoren (D Hanahan und RA Weinberg, 2000). Tumorsuppressorgene dagegen verhindern normalerweise unkontrolliertes Zellwachstum, indem sie den Zellzyklus oder die Apoptose regulieren. Inaktivierende Mutationen und der Funktionsverlust eines Tumorsuppressorgens können daher ebenfalls zu Krebs führen. Nach Knudsons „zwei Treffer“-Hypothese erfordert die Entstehung von Tumoren durch Mutationen in Tumorsuppressorgenen eine Inaktivierung beider Allele des entsprechenden Gens (AG Knudson, Jr., 1971). Bei krebsprädisponierenden Erbkrankheiten kann die Mutation eines Allels des Tumorsuppressorgens vererbt werden, während ein zweites somatisches Ereignis zur Mutation des zweiten Allels führt. Häufig geht hierbei das zweite Allel verloren, was mit einem Verlust der Heterozygotie (aus dem Engl:: Loss of Heterozygosity - LOH) einhergehen kann. Natürlich können auch zwei somatische Mutationen auftreten. Dieses Ereignis findet sich bei sporadischen Tumoren. Hierbei ist häufig ein Allel des Tumorsuppressorgens mutiert und das andere verloren gegangen, epigenetisch abgschaltet oder ebenfalls mutiert. Somit muss ein kompletter Funktionsverlust des Tumorsuppressorgens vorliegen, um die Entstehung von Tumoren zu bewirken.

Zu den Tumorsuppressorgenen gehört Patched (Ptch), das eine essentielle Komponente der Hedgehog/Ptch-Signalkaskade ist. 


\subsection{Der Hedgehog/Patched-Signalweg}

Der Hedgehog (Hh)/Ptch-Signalweg spielt eine bedeutende Rolle bei der Embryonalentwicklung verschiedener Gewebe und Organe, da er das Überleben, die Proliferation und Differenzierung von Zellen sowie die Musterbildung reguliert (JE Hooper und MP Scott, 2005). Dieser in Abbildung 1 dargestellte Signalweg ist zwischen Vertebraten und Invertebraten stark konserviert (LV Goodrich et al., 1997; A Ruiz i Altaba, 1999).

Bereits 1980 wurden die wesentlichen Komponenten des Signalweges, Hh und Ptc, bei Drosophila melanogaster identifiziert (C Nusslein-Volhard und E Wieschaus, 1980). Ptc ist der Rezeptor für den Liganden $\mathrm{Hh}$ und vermittelt durch einen komplexen Mechanismus das Signal unter anderem über das Protein Cubitus interruptus $(\mathrm{Ci})$ ins Zellinnere.

Im Gegensatz zu D. melanogaster wurden in Vertebraten bisher mehrere Ptc-Homologe identifiziert. Dazu gehört neben Ptch auch Ptch2 (I Smyth et al., 1999; L Frohlich et al., 2002). Weiterhin existieren in Vertebraten mehrere Hh-Homologe, die als Sonic hedgehog (Shh), Desert hedgehog und Indian hedgehog bezeichnet werden (Y Echelard et al., 1993). Auch bei den Gli-Proteinen, die ortholog zu Ci aus D. melanogaster sind, liegen in Vertebraten mehrere Homologe vor (JE Hooper und MP Scott, 2005). Sie werden Gli1, Gli2 und Gli3 genannt.

Ist der Hh/Ptch-Signalweg inaktiv, verbleiben die Gli-Transkriptionsfaktoren bzw. Ci im Zytoplasma, da sie an einen Proteinkomplex gebunden sind. Dieser Proteinkomplex besteht aus den zytoplasmatischen Proteinen Fused (Fu), Suppressor of Fused (Sufu) sowie Costal-2 (D. melanogaster) bzw. bei Vertebraten wahrscheinlich dem Costal-2-Homolog Kinesin family member 7 (Kif7) (Y Katoh und M Katoh, 2004; D Huangfu und KV Anderson, 2006). Die Freisetzung der Gli-Transkriptionsfaktoren erfolgt erst nach der Aktivierung des Signalweges durch Hh (PW Ingham und AP McMahon, 2001).

Shh, das wichtigste der Hh-Homologe, wird in Vertebraten in einer Signal sendenden Zelle synthetisiert. Wichtig für seine Funktion sind nach einer autokatalytischen Spaltung die Palmitylierung der aminoterminalen (N-terminalen) Region sowie die Bindung von Cholesterol an die carboxyterminale (C-terminale) Domäne. Durch das Transmembranprotein Dispatched Homolog 1 (Disp1), welches Homologie zu Ptch zeigt, erfolgt möglicherweise der Transport des modifizierten Liganden in den Interzellularraum (T Kawakami et al., 2002; H Tian et al., 2005).

Ptch kodiert für ein Membranprotein aus zwölf transmembranen Domänen, zwei hydrophilen extrazellulären Schleifen, einer intrazellulären Schleife sowie C- und 
N-terminalen intrazellulären Regionen. Die so genannte „sterol sensing domain“ (SSD), die für die Aktivität von Ptch notwendig ist, umfasst die Region zwischen der zweiten und sechsten transmembranen Domäne (PE Kuwabara und M Labouesse, 2002). Obwohl die genaue Funktion der SSD unklar ist, wird eine Rolle in der Bindung von Hh angenommen (R Burke et al., 1999). Anderen Vermutungen zufolge könnte die SSD eine Funktion in der Regulation des Transports und der Degradation von Smoothened (Smo), dem Signalpartner von Ptch, besitzen (H Strutt et al., 2001).

Smo besteht aus sieben transmembranen Domänen und besitzt eine den G-Protein-gekoppelten Rezeptoren ähnliche Struktur (J Alcedo et al., 1996). Normalerweise wird die Aktivität von Smo durch Ptch blockiert. Diese Blockade erfolgt wahrscheinlich nicht durch eine direkte Interaktion zwischen Ptch und Smo, sondern durch die Sekretion eines Smo-inhibitorischen Moleküls durch Ptch (JK Chen et al., 2002).

Durch die Bindung des Liganden Hh an die extrazellulären Schleifen von Ptch (V Marigo et al., 1996a) wird die Inhibition von Smo aufgehoben (LV Goodrich und MP Scott, 1998). Hierdurch wird die Aktivierung der Signalkaskade ausgelöst, da Smo die Aktivität weiterer Komponenten des Signalweges bewirkt.

Die Aktivität des Signalweges wird vor allem durch die Transkriptionsfaktoren der Gli-Familie vermittelt. Im inaktiven Zustand des Signalweges werden die Gli-Transkriptionsfaktoren normalerweise von einem Proteinkomplex im Zytoplasma gehalten (MM Cohen, Jr., 2003). Im aktiven Zustand werden die Gli-Proteine aus dem zytoplasmatischen Proteinkomplex entlassen und gelangen in den Nukleus. Dort bewirken sie die Transkription ihrer Zielgene (K Nybakken und N Perrimon, 2002).

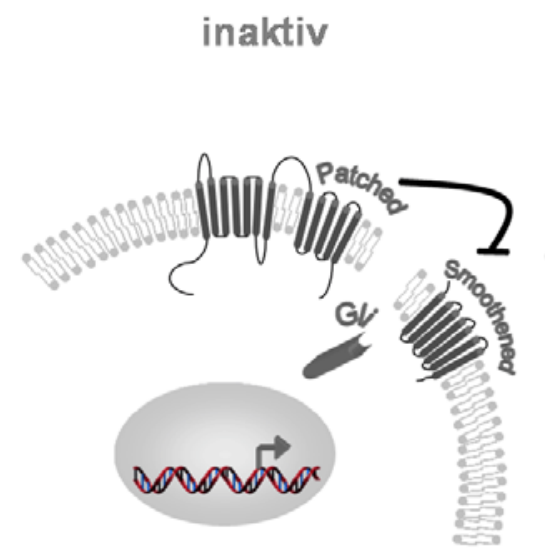

\section{physiologisch aktiviert}

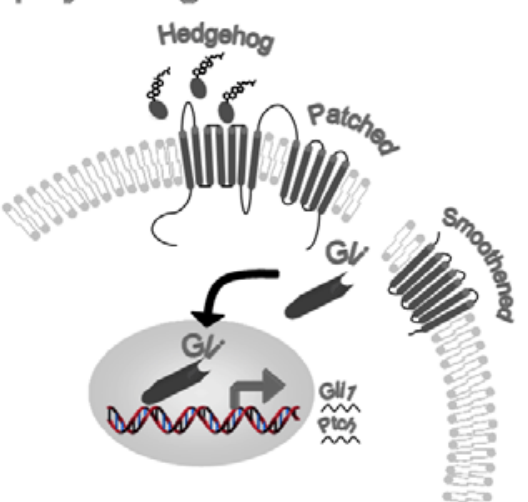

pathologisch aktiviert

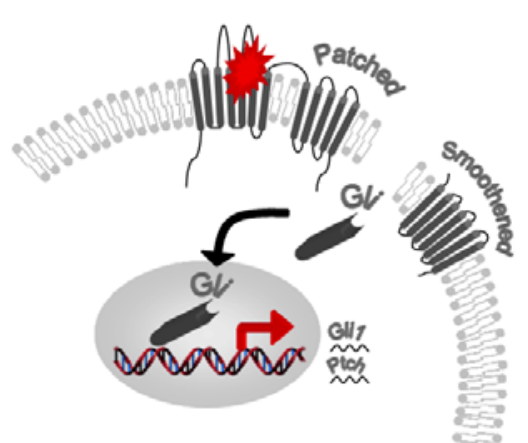

Abbildung 1: Schematische Darstellung des inaktiven, physiologisch und pathologisch aktivierten Hh/Ptch-Signalweges. Gezeigt ist der inaktive (links) und durch die Bindung des Liganden Hh physiologisch aktivierte Hh/Ptch-Signalweg (Mitte) einer normalen somatischen Zelle im Gegensatz zu einer Zelle mit einem pathologisch aktivierten Signalweg (rechts). Die pathologische Aktivierung kann durch eine inaktivierende Ptch-Mutation (roter Stern) verursacht werden. 
Der inaktive Zustand der Signalkaskade beruht auf der Inhibition der Aktivität von Smo durch Ptch. Ausgelöst durch die Bindung des Liganden $\mathrm{Hh}$ an Ptch oder durch eine inaktivierende Ptch-Mutation vermittelt Smo die Translokation von Gli1 und weiteren Gli-Transkriptionsfaktoren in den Nukleus. Dort wird die Transkription von Zielgenen, darunter Ptch und Gli1, ausgelöst.

Bei Säugern fungieren Gli1 und Gli2 als hauptsächliche Aktivatoren der Hh/PtchSignalkaskade. Gli3 hingegen übt eine repressorische Aktivität auf die Kaskade aus, die durch das Hh-Signal aufgehoben wird. Interessanterweise wird hierbei im Rahmen eines positiven Rückkoppelungsmechanimus die Gli1-Transkription aktiviert. Dafür werden funktionelle Gli2- und Gli3-Proteine benötigt (M Kasper et al., 2006). Die Expression von Gli1 ist folglich ein zuverlässiger Marker für den Aktivitätszustand der $\mathrm{Hh} / \mathrm{Ptch}$ Signalkaskade (M Kasper et al., 2006). Da Gli-Proteine wiederum die Ptch-Transkription stimulieren, gehört neben Gli1 auch Ptch zu den heute bekannten Zielgenen der aktivierten Hh/Ptch-Signalkaskade (Y Katoh und M Katoh, 2006) (siehe Abbildung 1).

Die Hh/Ptch-Signalkaskade ist unter anderem an der Regulation des Zellzyklus beteiligt. So wurde bereits 1999 gezeigt, dass Shh einen terminalen Zellzyklus-Arrest verhindert (H Fan und PA Khavari, 1999). Weiterhin wurde ein Zusammenhang zwischen der zellulären Lokalisierung von Cyclin B1 und Ptch nachgewiesen (EA Barnes et al., 2001). Erst durch die nukleäre Translokation kann Cyclin B1 den Beginn der Mitose (M-Phase) bewirken (J Li et al., 1997). Die nukleäre Translokation von Cyclin B1 wird jedoch durch eine Bindung an die intrazelluläre Schleife des Ptch-Proteins verhindert. Shh stört die Interaktion von Ptch mit Cyclin B1 und ermöglicht so die nukleäre Lokalisierung des letzteren Proteins (EA Barnes et al., 2001). Diese Daten zeigen, dass Ptch den Zellzyklus inhibieren kann, was wahrscheinlich zusätzlich zur Blockade der M-Phase auch durch eine Blockade der Synthesephase (S-Phase) hervorgerufen wird (C Adolphe et al., 2006).

Die Hh/Ptch-Signalkaskade hat deshalb eine essentielle Funktion in der Regulation des Zellzyklus. Eine Deregulation der Kaskade, z. B. durch inaktivierende Ptch-Mutationen, kann daher gravierende Folgen auf die Proliferation von Zellen haben.

\subsection{Hh/Ptch-assoziierte Tumorigenese}

Durch Überexpression von $\mathrm{Hh}$, durch eine inaktivierende Ptch-Mutation oder auch durch aktivierende Smo- oder Gli-Mutationen wird der Hh/Ptch-Signalweg pathologisch aktiviert (siehe Abbildung 1).

Aufgrund der wichtigen Funktionen des Signalweges in der Kontrolle von Zellproliferation und -differenzierung führt eine pathologische Aktivierung, die durch Mutationen einzelner 
Komponenten hervorgerufen wird, zur Entstehung von Krebs. Je nach der Rolle der betreffenden Komponenten kann eine Klassifizierung in Proto-Onkogene und Tumorsuppressorgene vorgenommen werden. In Aktivatoren des Signalweges wie Hh, Smo und Gli zeigten sich in Tumoren vereinzelt aktivierende Mutationen (s. u.). Diese

Proteine besitzen demnach onkogenes Potenzial. Dagegen wurden in Tumoren inaktivierende Mutationen in Ptch, das eine inhibitorische Wirkung auf den Signalweg hat, festgestellt (H Hahn et al., 1999). Daher wird Ptch als Tumorsuppressorgen eingestuft.

Das Tumorspektrum, das durch eine pathologische Aktivierung der Signalkaskade hervorgerufen wird, ist sehr breit. Eine Deregulation des Signalweges wurde bei Tumoren des Verdauungstrakts, des Pankreas, der Lunge, der Harnblase und des Ovars festgestellt (DM Berman et al., 2003; SP Thayer et al., 2003; DN Watkins et al., 2003; S Hamed et al., 2004; X Chen et al., 2007). Weiterhin wurden aktivierende SmoMutationen in Haut- und neuroektodermalen Tumoren (I Vorechovsky et al., 1997a; J Reifenberger et al., 1998; J Xie et al., 1998; CW Lam et al., 1999) sowie die Überexpression von Gli1 in Hauttumoren, Schwannomen, Chondrosarkomen und Leberzellkarzinomen festgestellt (N Dahmane et al., 1997; H Endo et al., 2004; S Huang et al., 2006; TD Tiet et al., 2006).

Die Aktivierung der Hh/Ptch-Signalkaskade kann durch Cyclopamin verhindert werden. Cyclopamin ist ein Pflanzenalkaloid aus der Pflanze Veratrum californicum (Kalifornischer Germer), das bei Vertebraten zu Holoprosenzephalie und Zyklopie führen kann (S Coventry et al., 1998). Dies wurde zunächst bei Lämmern festgestellt, deren Mütter während der Trächtigkeit den Kalifornischen Germer verzehrt hatten (MA McFerren, 2006). Heute weiß man, dass diese Entwicklungsdefekte auf eine Inhibition der Hh/Ptch-Signalkaskade während der Embryonalentwicklung zurückzuführen sind (J Taipale et al., 2000). Aufgrund seiner inhibierenden Wirkung auf den Hh/Ptch-Signalweg wird Cyclopamin momentan in präklinischen Studien zur Therapie von Hh/Ptchassoziierten Tumoren eingesetzt (SP Thayer et al., 2003; SS Karhadkar et al., 2004; V Clement et al., 2007; G Feldmann et al., 2007).

\subsection{Ptch-assoziierte Tumoren}

Es ist bekannt, dass somatische Mutationen von Ptch zur Entstehung von Basalzellkarzinomen (engl.: „Basal Cell Carcinoma“ - BCC), Medulloblastomen (MB) und Rhabdomyosarkomen (RMS) führen (C Raffel et al., 1997; I Vorechovsky et al., 1997a; 
JA Bridge et al., 2000; H Zhang et al., 2001; J Reifenberger et al., 2005; U Tostar et al., 2006). Weiterhin werden Keimbahnmutationen in Ptch mit einer seltenen autosomal dominant vererbten Erkrankung, dem Gorlin-Goltz- oder Basalzellnävus-Syndrom (engl.: „Nevoid Basal Cell Carcinoma Syndrome“ - NBCCS), in Verbindung gebracht (RJ Gorlin, 1987; H Hahn et al., 1996; RL Johnson et al., 1996). Das NBCCS zeichnet sich durch verschiedene Entwicklungsdefekte sowie eine Prädisposition für die Bildung von Tumoren in einer Vielzahl von Geweben aus. Daran ist die duale Funktion des Hh/PtchSignalweges in der Embryogenese sowie der malignen Transformation erkennbar. Die Patienten erkranken überwiegend an $\mathrm{BCC}$, darüber hinaus entwickeln ca. $5 \%$ der Patienten MB (DG Evans et al., 1991; MR Gailani et al., 1992). Weiterhin wird das NBCCS mit anderen Tumoren, zu denen auch das RMS gehört, assoziiert (RJ Gorlin, 1987; U Tostar et al., 2006).

Ptch-Mutationen, die zur Entstehung von Tumoren führen, sind häufig in Regionen mit einer wichtigen Funktion in der Signaltransduktion lokalisiert. Sowohl Keimbahn- als auch sporadische Ptch-Mutationen sind häufig in den beiden extrazellulären Schleifen zu finden (E Lindstrom et al., 2006). Auch die N-terminale Region oder die intrazelluläre Schleife ist bei NBCCS-Patienten oftmals betroffen (E Lindstrom et al., 2006). Alle diese Mutationen rufen eine Inaktivierung von Ptch hervor. Weiterhin stören Mutationen, die zu einem verkürzten C-Terminus führen, die Inhibition von Smo (RL Johnson et al., 2000).

\subsubsection{Das Rhabdomyosarkom}

Wie unter 1.4 beschrieben, können RMS aufgrund somatischer Ptch-Mutationen entstehen (JA Bridge et al., 2000; U Tostar et al., 2006).

Beim RMS, einem Tumor des quer gestreiften Skelettmuskels, handelt es sich um das häufigste Weichteilsarkom bei Kindern. Die Histologie des malignen klein-, blau- und rundzelligen Tumors ähnelt dem fötalen Skelettmuskel. Meist treten RMS sporadisch auf. Man unterscheidet im Wesentlichen zwischen dem embryonalen (ERMS) und dem alveolären Subtyp (ARMS). ERMS zeichnen sich durch einen differenzierteren Phänotyp mit spindelförmigen Zellen aus, während für ARMS kleine, runde und dicht gelagerte Zellen typisch sind.

In spontanen RMS wurde neben LOH von Ptch zusätzlich auch LOH von SUFU beschrieben (U Tostar et al., 2006). Weiterhin wurde in RMS sowie in humanen RMS Zellinien auch die Amplifikation von Gli1 (WM Roberts et al., 1989; JW Yoon et al., 2002) oder der chromosomalen Region, in der das Gen lokalisiert ist, beschrieben (JA Bridge et al., 2002). Da auch NBCCS-Patienten eine Prädisposition für RMS zeigen (RJ 
Gorlin, 1987), beruht die Entstehung dieses Tumors vermutlich auf einer pathologischen Aktivierung der Hh/Ptch-Signalkaskade. Tatsächlich zeichnen sich RMS häufig durch eine erhöhte Expression der Zielgene des Hh/Ptch-Siganlweges, Ptch und Gli1 aus (U Tostar et al., 2006). Auch Ptch ${ }^{\text {neo67/+ }}$-Mäuse, die eine heterozygote Keimbahnmutation in Ptch tragen, entwickeln RMS (H Hahn et al., 1998; M Aszterbaum et al., 1999), die eine hohe Expression von Ptch und Gli1 aufweisen (H Hahn et al., 1998; R Kappler et al., 2003). Analysen dieser Mäuse zeigten weiterhin, dass der genetische Hintergrund der Tiere die RMS-Inzidenz stark beeinflusst. So entstehen keine RMS, wenn die Mutation auf dem Inzuchtstamm C57BL/6N (B6) propagiert wird. Dagegen entwickeln sich diese Tumoren in bis zu $15 \%$ der Ptch-heterozygoten knockout-Tiere des Auszuchtstammes CD1 (J Calzada-Wack et al., 2002). Diese Daten zeigen, dass es Modifikatorgene geben muss, die die Prädisposition zu RMS bei bestehender Ptch-Mutation beeinflussen.

\subsubsection{Das Medulloblastom}

Das MB, ein maligner embryonaler Tumor des Kleinhirns, ist mit einer Inzidenz von $20 \%$ einer der häufigsten bösartigen Hirntumoren bei Kindern. Die 5-Jahres-Überlebensrate von Patienten, die an diesem rasch proliferierenden Tumor erkrankt sind, liegt zwischen 55 und 80 \% (A Rossi et al., 2008). In 12 bis $18 \%$ sporadischer MB wurden somatische Ptch-Mutationen oder LOH am Ptch-Lokus detektiert (T Pietsch et al., 1997; M Wolter et al., 1997; J Xie et al., 1997; RH Zurawel et al., 2000a). In diesen Tumoren wurde eine Überexpression von Ptch und Gli1 nachgewiesen, was auf die Aktivierung der Hh/Ptch-Signalkaskade schließen lässt (RH Zurawel et al., 2000a; JI Pritchard und JM Olson, 2008). Die Fehlregulation des Hh/Ptch-Signalweges führt auch in etwa $5 \%$ der NBCCS-Patienten zur Entwicklung eines MB (DG Evans et al., 1991).

MB entwickeln sich auch in heterozygoten Ptch-knockout-Mäusen (LV Goodrich et al., 1997; H Hahn et al., 2000; C Wetmore et al., 2000; RH Zurawel et al., 2000b). Wie bereits für RMS beschrieben (siehe 1.4.1), ist auch die Entstehung von MB von Modifikatorgenen abhängig. Die Inzidenz für $\mathrm{MB}$ bei $\operatorname{Ptch}^{\text {neo67/+ }}$-Mäusen auf B6-Hintergrund ist mit 72 \% sehr hoch (H Hahn et al., 2004). Dagegen entstehen bei Ptch $^{\text {neo67/+ }}$-Mäusen auf CD1-Hintergrund nur zu 8 \% MB (S Pazzaglia et al., 2002).

\subsubsection{Modifikatorgene bei Ptch-assoziierten RMS und MB}

Wie schon erwähnt, entwickeln Ptch $^{\text {neo67/+ }}$-Mäuse Tumoren abhängig vom genetischen Hintergrund. Ptch ${ }^{\text {neo67/+ }}$-Mäuse auf B6-Hintergrund entwickeln keine RMS, wohingegen diese Tumoren in bis zu 15 \% auf CD1-Hintergrund anzutreffen sind (J Calzada-Wack et 
al., 2002). Dagegen prädisponiert der B6-Hintergrund zu MB, die bei mehr als $72 \%$ aller heterozygoten Ptch ${ }^{\text {neo67/+ }}$-Tiere innerhalb der ersten 300 Tage nach der Geburt auftreten ( $\mathrm{H}$ Hahn et al., 2004). Diese Daten zeigen, dass die Tumorfrequenz in Ptch $^{\text {neo67/+ }}$-Mäusen auch von anderen Genen als Ptch modifiziert wird. Eine Kartierung und Charakterisierung dieser Gene in der Maus sollte durchführbar sein. Die Identifizierung derjenigen Gene oder Genvarianten, welche die individuelle Suszeptibilität für Hh/Ptch-assoziierte MB und RMS beeinflussen, wird einen großen Beitrag zum besseren Verständnis der Funktion der Hh/Ptch-Signalkaskade leisten. Weiterhin sollte es möglich sein, diese Gene auf ihre Relevanz bei der Entstehung von menschlichen MB und RMS zu überprüfen. Das Wissen über einzelne oder additive Effekte von genetischen Polymorphismen und ihren Einfluss auf das individuelle Risiko von Kindern, an einem dieser beiden hochmalignen Tumoren zu erkranken, könnte einen Einfluss auf die frühzeitige Erkennung und dadurch eventuell auf die Heilungschancen haben.

\subsubsection{Das Basalzellkarzinom}

Mit einer Inzidenz, die sämtliche andere Tumorentitäten übertrifft, ist das BCC der häufigste Tumor des Menschen (AI Rubin et al., 2005). Jährlich sind allein in den USA mehr als 750.000 neue Fälle zu verzeichnen und die Rate der Neuerkrankungen ist weiter steigend (MR Karagas et al., 1992; DL Miller und MA Weinstock, 1994; E de Vries et al., 2005).

Das BCC ist ein langsam wachsender, semimaligner Tumor, der umliegendes Gewebe schädigen kann, jedoch äußerst selten metastasiert (JK Robinson und M Dahiya, 2003). Charakteristisch für die Histologie sind basaloid differenzierte Zellverbände, die von dermalem Stroma umgeben sind. Generell werden BCC in differenzierte und undifferenzierte bzw. solide BCC unterteilt (AN Crowson, 2006). Zu den differenzierten BCC gehören hauptsächlich der infundibulozystische, keratotische, follikuläre und pleomorphe Typ. Bei undifferenzierten BCC unterscheidet man zwischen indolenten und aggressiven Tumoren. Zum indolenten Typ gehören superfizielle und nodulläre BCC, zum aggressiven hingegen infiltrative und metatypische BCC (AN Crowson, 2006).

Die Behandlung von BCC kann durch Exzision, mikrographische Chirurgie nach Mohs, Kürettage, Laser- oder Kryochirurgie und Bestrahlung, aber auch mit Imiquimod, einem Immunmodulator, erfolgen (MP Bukhardt Perez et al., 2007). Aufgrund der Häufigkeit sind die Kosten für die Behandlung dieser Erkrankung durchaus relevant für das Gesundheitssystem. Durch alternative effektivere Therapien könnten die Kosten deutlich 
reduziert werden. Daher ist eine bessere Kenntnis der molekularen Grundlagen der Entstehung und Progression von BCC äußerst wichtig.

$\mathrm{Zu}$ den Risikofaktoren für BCC gehören neben heller Haut, UV-Licht und Immunsuppression auch die genetische Veranlagung (L Daya-Grosjean und S CouvePrivat, 2005). So wurden z. B. Mutationen des Gens p53 in BCC identifiziert (G GigliaMari und A Sarasin, 2003; J Reifenberger et al., 2005; T Mizuno et al., 2006). Auch Patienten mit der Erkrankung Xeroderma pigmentosum weisen eine erhöhte Inzidenz für die Entstehung von BCC auf (KH Kraemer et al., 1987; KH Kraemer et al., 1994). Das höchste Risiko für BCC mit über $90 \%$ iger Wahrscheinlichkeit haben hellhäutige Patienten mit NBCCS (VE Kimonis et al., 1997). Oft entwickeln Patienten bis zum 20. Lebensjahr bereits ein BCC, später können sie bis zu 1000 dieser Tumoren aufweisen (VE Kimonis et al., 1997).

Interessanterweise wurde in 60 bis $70 \%$ der sporadischen BCC LOH der Region 9q22, in der das Ptch-Gen lokalisiert ist, nachgewiesen (MR Gailani et al., 1996; AB Unden et al., 1997). Heute nimmt man an, dass der Funktionsverlust von Ptch eine Voraussetzung für die Entstehung von BCC darstellt (D Sidransky, 1996). Schon seit längerem wird spekuliert, ob Ptch als so genanntes „gatekeeper“-Gen fungiert (D Sidransky, 1996; I Vorechovsky et al., 1997b). Darunter versteht man Gene, die durch Mutationen unmittelbar die Entwicklung von Tumoren auslösen können.

Auch heterozygote Ptch-knockout-Mäuse können BCC entwickeln. Die Tumoren entstehen jedoch nicht per se, sondern erst nach Behandlung der Tiere mit ionisierender oder UV-Bestrahlung (M Aszterbaum et al., 1999; M Mancuso et al., 2004).

BCC entwickeln sich auch in anderen Tiermodellen, die mit einer Deregulation der $\mathrm{Hh} /$ Ptch-Signalkaskade einhergehen. So entstehen BCC in transgenen Mäusen, die durch die Verwendung des Keratin 5 (K5)-Promotors eine erhöhte Expression von Gli1 oder Gli2 in der Haut aufweisen (M Grachtchouk et al., 2000; M Nilsson et al., 2000; ME Hutchin et al., 2005). Ebenso entwickeln sich BCC durch die Expression von Shh unter der Kontrolle des Keratin 14 (K14)-Promotors (AE Oro et al., 1997).

Als Ursprungszellen für BCC kommen verschiedene Zellpopulationen, darunter die Basalzellen der interfollikulären Epidermis und Zellen des Haarfollikels, in Betracht (JP Lacour, 2002). In der Literatur finden sich jedoch kontroverse Angaben.

Haarfollikelzellen kommen für den BCC-Ursprung deshalb in Frage, weil die Entwicklung des Haarfollikels von der Hh/Ptch-Signalkaskade abhängig ist. Am Beginn der 
Entstehung des Haarfollikels steht die Ausbildung einer so genannten Haarplakode. Diese wird u. a. durch den Wnt-Signalweg (abgeleitet von: „Wingless“ und "Int-1“) hervorgerufen. Ausgehend von der Haarplakode wird die Entstehung eines dermalen Kondensats aus mesenchymalen Zellen induziert. An der Invagination der Haarplakode in die Dermis und bei der Ausbildung der dermalen Papille, die sich aus dem Kondensat mesenchymaler Zellen entwickelt, ist der $\mathrm{Hh} /$ Ptch-Signalweg beteiligt. Danach werden weitere Strukturen des Haarfollikels, wie z. B. die innere Wurzelscheide, gebildet (SE Millar, 2002). Diese Daten zeigen, dass für die Entwicklung des Haarfollikels ein intakter Hh/Ptch-Signalweg nötig ist. Unterstützt wird dies durch Untersuchungen von Shh-knockout-Mäusen. Bei diesen Tieren entstehen zwar die Haarplakode und das dermale Kondensat, jedoch kommt es nicht zur vollständigen Ausbildung des Haarfollikels (B St-Jacques et al., 1998; C Chiang et al., 1999).

Für den Ursprung von BCC aus Basalzellen spricht die basaloide Morphologie der Tumorzellen (ME Maloney, 1995). Weiterhin wurde gezeigt, dass BCC aus Basalzellen entstehen, die eine ektopische Expression von Gli1 aufweisen (N Dahmane et al., 1997). Daher scheinen sowohl der Haarfollikel als auch die interfollikuläre Epidermis als Ausgangsstruktur für BCC in Frage zu kommen.

Auch bei der Homöostase des Haarzyklus von adulten Haarfollikeln ist die Hh/Ptch-Signalkaskade essentiell (N Sato et al., 1999; LC Wang et al., 2000; RD Paladini et al., 2005). Der Haarzyklus besteht aus einer Wachstumsphase (Anagen), gefolgt von einer Übergangsphase (Katagen) und einer Ruhephase (Telogen), nach welcher das Haar ausfällt und wieder ein neuer Haarschaft gebildet wird (R Paus und G Cotsarelis, 1999). Bei der Maus umfasst der Haarzyklus nur 25 Tage, wobei das Anagen ca. 15 Tage einnimmt. Danach folgen Katagen und Telogen, bis am Tag 25 bzw. 0 erneut das Anagen einsetzt (S Muller-Rover et al., 2001).

Während des Anagens werden Shh und die Zielgene Ptch, Gli1 und Gli2 des Hh/Ptch-Signalweges im Haarfollikel exprimiert (VA Botchkarev et al., 2001; AE Oro und K Higgins, 2003; C Lo Celso et al., 2004). Befindet sich der Haarfollikel jedoch im Katagen oder Telogen, ist die Expression dieser Gene reduziert (AE Oro und K Higgins, 2003; RD Paladini et al., 2005). Somit ist der Hh/Ptch-Signalweg nur während der Wachstumsphase des Haarfollikels aktiv. 


\subsection{Mausmodelle für Ptch-assoziierte Tumoren}

\subsubsection{Die $P t c h^{\text {neo67 }}$-knockout-Maus}

Wie bereits erwähnt, entstehen in heterozygoten $P t c h^{\text {neo67 }}$ - oder Ptch ${ }^{\text {neo12 }}$-Mäusen vor allem MB und RMS (Goodrich et al 1997, Hahn et al 1998).

In der Ptch-kockout-Mauslinie Ptch ${ }^{n e 067}$, die in dieser Arbeit verwendet wurde, sind die Exone 6 und 7 eines Ptch-Allels durch eine Neomycin-Resistenzkassette ausgetauscht (Ptch ${ }^{\text {neo67}}$-Allel). In Abbildung 2 ist der $P t c h^{\text {neo67}}$-Lokus im Vergleich zum Wildtyp (wt) Ptch-Lokus der Ptch ${ }^{\text {neo67/+ }}$-Mauslinie dargestellt (H Hahn et al., 1998).

wt Ptch Allel

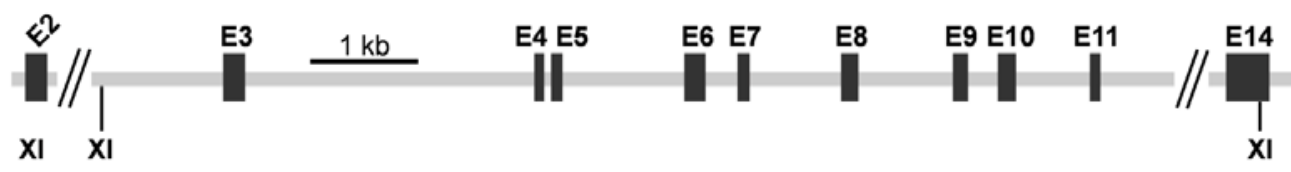

Ptch $^{\text {neo67 }}$ Allel

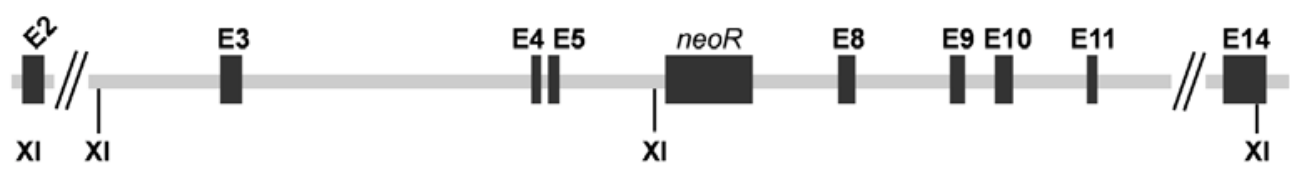

Abbildung 2: Schematische Darstellung des Ptch ${ }^{\text {neo67 }}$-Lokus. Dargestellt sind das wt Ptch- und das mutante Ptch ${ }^{\text {neo67 }}$-Allel von Ptch ${ }^{\text {neo67/+ }}$-Mäusen. Anstelle der Exone 6 und 7 enthält das $P t c h^{\text {neo67 }}$-Allel eine Neomycin-Resistenzkassette (neoR) (H Hahn et al., 1998). Abkürzungen: E, Exon; $\mathrm{XI}$, Xhol

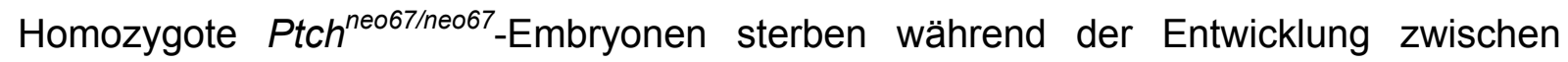
Tag 9 und 10,5 nach der Befruchtung in utero aufgrund von Neuralrohr- und Herzdefekten. Heterozygote Mäuse hingegen zeigen ähnliche Symptome wie NBCCS-Patienten. So treten bei $\mathrm{Ptch}^{\text {neo67/+}}$-Mäusen Großwuchs und Skelettanomalien auf, und die Tiere entwickeln RMS und MB (H Hahn et al., 1998; H Hahn et al., 2000). BCC entstehen erst nach Bestrahlung Ptch-heterozygoter Tiere mit UV- oder ionisierender Strahlung (M Mancuso et al., 2004).

Wie bereits unter 1.4 beschrieben, ist die Inzidenz von RMS und MB in Ptch $^{\text {neo67/+ }}$-Mäusen vom genetischen Hintergrund abhängig. Je nach genetischem Hintergrund können die Tumorinzidenzen für RMS zwischen 0 und $63 \%$ und für MB zwischen 8 und 72 \% liegen (H Hahn et al., 2004).

\subsubsection{Die konditionelle Ptch $^{\text {flox/flox }}$-knockout-Maus}

Neben den konventionellen Ptch ${ }^{\text {neo67/+ }}$-knockout-Tieren wurde in dieser Arbeit auch ein konditionelles Ptch-knockout-Mausmodell verwendet. Hierbei handelt es sich um die 
Mauslinie Ptch flox/flox, die von Mitarbeitern der AG Hahn etabliert wurde. Durch IoxP-Sequenzen in den Intronen 7-8 sowie 9-10 kann in diesen Mäusen durch die Aktivität einer Cre-Rekombinase eine Deletion der Exone 8 und 9 des Ptch-Gens induziert werden. Für eine genauere Darstellung des Ptch $^{\text {flox }}$-Lokus und zur Charakterisierung der Mauslinie, an der im Rahmen dieser Arbeit mitgewirkt wurde, siehe 3.2.1.

\subsection{Zielsetzung dieser Arbeit}

Mutationen im Tumorsuppressorgen Ptch, einer Komponente des Hh/Ptch-Signalweges, führen zur Entstehung von BCC, RMS und MB. Der häufigste Tumor des Menschen ist das BCC, während das RMS das häufigste Weichteilsarkom bei Kindern ist. Das MB, ein maligner, primitiver neuroektodermaler Tumor des Kleinhirns, ist für $20 \%$ aller pädiatrischen Hirntumoren verantwortlich (RP Humphreys, 1982).

Auch Ptch $^{\text {neo67/+ }}$-Mäuse entwickeln MB und RMS mit einer hohen Frequenz, wobei die Inzidenz beider Tumoren vom genetischen Hintergrund der Tiere abhängig ist $(\mathrm{H}$ Hahn et al., 1998). Ziel des Projektes war die Identifikation der tumormodifizierenden Gene für diese beiden Tumorentitäten. Hierzu wurden verschiedene Rückkreuzungen mit den genannten $\mathrm{Ptch}^{\text {neo67/+}}$-Mäusen für Hochdurchsatz-PCR-Verfahren und genomweite Kopplungsanalysen hergestellt. Weiterhin sollten identifizierte Lozi, die die Suszeptibilität für RMS oder MB beeinflussen, eingeengt und potenzielle tumormodifizierende Gene identifiziert werden.

Der zweite Aspekt dieser Arbeit beschäftigte sich mit der Generierung eines Modells, in dem sich durch die Induktion einer Ptch-Mutation einfach und zuverlässig BCC induzieren lassen. Ein solches Modell ist für eine bessere Kenntnis der Rolle des $\mathrm{Hh} /$ Ptch-Signalweges bei der Pathogenese von BCC und somit für die Etablierung neuer Therapien von essentieller Bedeutung. Zu Beginn dieser Arbeit existierte kein solches Tiermodell. In unserem Labor wurde jedoch ein konditionelles Ptch-knockout-Mausmodell etabliert. Nach einer allgemeinen Charakterisierung dieses Modells sollte versucht werden, BCC mittels einer ubiquitär exprimierten induzierbaren Cre-Rekombinase im adulten Tier zu induzieren und gegebenenfalls zu analysieren.

Des Weiteren wurden Zelllinien aus den konditionellen Ptch-knockout-Mäusen etabliert und charakterisiert. Diese Zelllinien sollen künftig als Modellsystem für die in vitro-Analyse der Funktion von Ptch eingesetzt werden. 


\title{
2 Material und Methoden
}

\subsection{Statistische Auswertungsverfahren}

Die Kopplungsanalyse zur Berechnung von LOD-Scores und der Permutationstest erfolgten durch Michael Rosemann, GSF Neuherberg, anhand der Software MapManager QTX.

Von Bettina Kulle, Department of Biostatistics \& Department of Mathematics, Oslo, Norwegen, wurde die Auswertung der Mikroarray-Analysen mit Hilfe der Software Bioconductor/R durchgeführt, für die Normalisierung wurde die RMA-Methode verwendet. Eine hierarchische Clusteranalyse erfolgte nach der höchsten t-Test Statistik zwischen verschiedenen genetischen Hintergründen.

Alle weiteren statistischen Auswertungen erfolgten mit Hilfe der Programme Excel bzw. Statistica (siehe 2.2).

\subsection{Software}

2100 Expert Software
ABI 3100 Genetic Analyser Data Collection 1.0
EXCEL
FreeHand MX
Intas GDS
Photoshop 6.0
SDS 2.1
Sequencher
Statistica
WORD

\author{
Agilent Technologies, Waldbronn \\ Applied Biosystems, Darmstadt \\ Microsoft Co., Redmont, USA \\ Adobe Systems Incorporated, San Jose, USA \\ Intas, Göttingen \\ Adobe Systems Incorporated, San Jose, USA \\ Applied Biosystems, Darmstadt \\ Applied Biosystems, Darmstadt \\ StatSoft GmbH, Hamburg \\ Microsoft Co., Redmont, USA
}

\subsection{Datenbanken}

MGI_3.54-Mouse Genome Informatics

Mouse Phenome Database

National Center for Biotechnology Information (NCBI)

Ensembl release 48 http://www.informatics.jax.org/

http://www.jax.org/phenome

http://www.ncni.nlm.nih.gov/

http://www.ensembl.org/index.html 


\subsection{Laborgeräte}

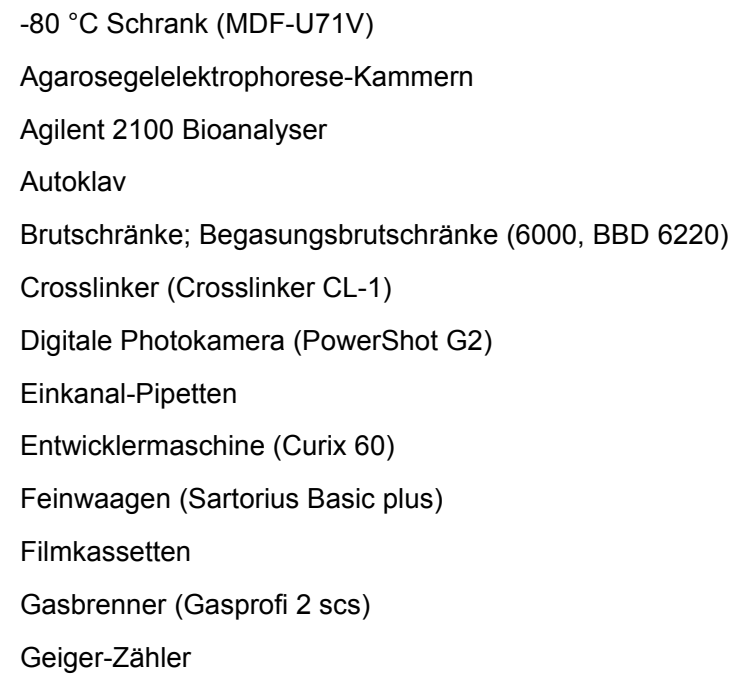

Sanyo Electric Co., Ltd., Japan

Peqlab Biotechnologie $\mathrm{GmbH}$, Erlangen

Agilent Technologies, Waldbronn

W. Krannich GmbH \& Co. K.G., Göttingen

Kendro Laboratory Products $\mathrm{GmbH}$, Hanau

Herolab $\mathrm{GmbH}$, Wiesloch

Canon Inc., Japan

Eppendorf, Hamburg

AGFA Deutschland Vertriebsgesellschaft mbH \& Co, Köln

Sartorius AG, Göttingen

Sigma-Aldrich Chemie $\mathrm{GmbH}$, Steinheim

WLD-TEC GmbH, Göttingen

Berthold detection systems $\mathrm{GmbH}$, Pforzheim

Leica Mikrosysteme Vertrieb $\mathrm{GmbH}$, Bensheim

Eppendorf, Hamburg

Heidolph Instruments, Schwabach

ART-moderne Labortechnik e.K., Müllheim

UVP, Inc., Upland, USA

Carl Zeiss Jena GmbH, Jena

Schott Glas, Mainz

Leica Microsysteme Vertrieb $\mathrm{GmbH}$, Bensheim

MembraPure $\mathrm{GmbH}$, Bodenheim

Carl Roth $\mathrm{GmbH}$, Karlsruhe

Eppendorf, Hamburg

Medite Medizintechnik $\mathrm{GmbH}$, Burgdorf

Eppendorf, Hamburg

MWG AG Biotech, Ebersberg

Stratagene, Amsterdam Zuidoost, Niederlande WTW GmbH, Wien, Österreich

Eppendorf, Hamburg

Brand GmbH \& Co. KG, Wertheim

OSRAM, München

Leica Microsysteme Vertrieb $\mathrm{GmbH}$, Bensheim

New Brunswick Scientific $\mathrm{GmbH}$, Nürtingen

GFL mbH, Burgwedel

Applied Biosystems, Darmstadt

Carl Zeiss Jena GmbH, Jena

Clean Air Techniek bv, Woerden, Niederlande

Peqlab Biotechnologie $\mathrm{GmbH}$, Erlangen

L'air liquide S.A., Paris Cedax, Frankreich

Applied Biosystems, Darmstadt

Mitsubishi, Ratingen 
UV-Transilluminator/Software

Vakuumpumpe

Vortexer (Vortex-Genie 2)

Wipp-Taumel-Tisch (Unimax 1010)

Zählkammer nach Neubauer (Assistent)

Zentrifugen (Biofuge pico, fresco, primo, Multifuge $3 L-R$ )

Zwölfkanal-Pipette

\subsection{Gebrauchswaren}

\author{
1,5 ml Reaktionsgefäße \\ $13 \mathrm{ml}$ Röhrchen \\ $15 \mathrm{ml}$ Röhrchen \\ 2,0 ml Reaktionsgefäße \\ $50 \mathrm{ml}$ Röhrchen \\ 6-Loch-Platten (Tissue Culture Plate 6-Well) \\ Aufreinigungsplatte 96-Loch (MAHVN45) \\ Blotting-Papier (GB 33 B003) \\ Deckgläser \\ Dispensionspipetten (Combitips plus) \\ ECL-Filme (Hyperfilm ECL) \\ Einwegspritzen (BD Plastipak) \\ Faltenfilter \\ Glaswaren \\ Kanülen (Sterican $\varnothing 0,45 \times 12 \mathrm{~mm}$ ) \\ Kryokonservierungsröhrchen (Cryo.s) \\ Küvetten (UVette) \\ Luminometer Messplatten (96 Well Assay Plate) \\ Nitrozellulosemembran (Hybond-XL) \\ Objektträger (SuperFrost Plus) \\ Objektträger-Kulturschalen (Culture Slides) \\ Pasteurpipetten
}

PCR-Reaktionsgefäße und Deckel (ThermoFast 96, nonskirted, natural domed cap strips, natural)

Petrischalen

Pipettenspitzen, gestopft $(10 \mu \mathrm{l}, 100 \mu \mathrm{l}, 200 \mu \mathrm{l}, 1000 \mu \mathrm{l})$

Pipettenspitzen, ungestopft ( $10 \mu \mathrm{l}, 200 \mu \mathrm{l})$

Pipettenspitzen, ungestopft (1000 $\mu \mathrm{l})$

Serologische Pipetten ( $5 \mathrm{ml}, 10 \mathrm{ml}, 25 \mathrm{ml}$ )

Skalpelle

Sterilfilter

TaqMan Platten und Folien (96-Well Optical Reaction Plate, 384-well Optical Reaction Plate, Optical Adhesive Covers)

Zellkulturschalen, 100 mm, 35 mm (Nunclon Surface)
Intas, Göttingen

Schütt Labortechnik, Göttingen

Scientific Industries, Inc., Bohemia, USA

Heidolph Instruments, Schwabach

Omnilab-Krannich, Göttingen

Kendro Laboratory Products $\mathrm{GmbH}$, Hanau

Eppendorf, Hamburg

Ochs $\mathrm{GmbH}$, Bovenden/Lenglern

Nunc GmbH \& Co.KG, Wiesbaden

Greiner Bio-One $\mathrm{GmbH}$, Frickenhausen

Sarstedt AG \& Co., Nürnberg

Sarstedt AG \& Co., Nürnberg

Sarstedt AG \& Co., Nürnberg

Amersham Biosciences Europe $\mathrm{GmbH}$, Freiburg

Heinemann Labortechnik GmbH, Duderstadt

Menzel GmbH \& Co.KG, Braunschweig

Eppendorf, Hamburg

Amersham Biosciences Europe $\mathrm{GmbH}$, Freiburg

BD GmbH, Heidelberg

Schleicher \& Schüll, Dassel

Schott AG, Mainz

B. Braun Medical AG, Emmenbrücke

Greiner Bio-One $\mathrm{GmbH}$, Frickenhausen

Eppendorf, Hamburg

Costar, Corning Incorporated, Corning, USA

Amersham Biosciences Europe $\mathrm{GmbH}$, Freiburg

Menzel GmbH \& Co.KG, Braunschweig

BD Falcon, Heidelberg

Brand GmbH \& Co.KG, Wertheim

Sarstedt AG \& Co., Nürnberg

Ochs $\mathrm{GmbH}$, Bovenden/Lenglern

G. Kisker GbR, Steinfurt

Ochs $\mathrm{GmbH}$, Bovenden/Lenglern

Sarstedt AG \& Co., Nürnberg

Sarstedt AG \& Co., Nürnberg

Aesculap AG \& Co.KG, Tuttlingen

Omnilab-Krannich, Göttingen

Applied Biosystems, Darmstadt

Nunc GmbH \& Co.KG, Wiesbaden 


\subsection{Chemikalien und Reagenzien}

Die im Folgenden nicht aufgelisteten Chemikalien wurden von der Firma Carl Roth $\mathrm{GmbH}$, Karlsruhe, und von der Firma Sigma-Aldrich Chemie $\mathrm{GmbH}$, Steinheim, bezogen.

$1 \mathrm{~kb}$ DNA, 50 bp und 100 bp DNA Ladder

${ }^{32} \mathrm{P}-\mathrm{dCTP}$

Agarose

BM Purple

Borsäure

Cryoblock Einbettmedium

Deoxyribonukleotidtriphosphate (dNTP)

Dig RNA Labeling Mix, 10x conc.

Ethylendiamintetraacetat (EDTA)

Glycergel Montagemedium

I-Block (Blockierung bei Antikörperfärbungen)

Immuno Mount

Ketanest S $(25 \mathrm{mg} / \mathrm{ml})$

Kolophonium

Lachsspermien-DNA (10 mg/ml)

Mayers Hämalaunlösung

Montagemedium (Vectrashield Mounting Medium with DAPI)

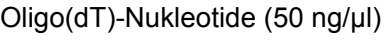

Paraformaldehyd

Pertex Montagemedium

Rapid-hyb Buffer

Ringer-Lactat (nach Hartman)

RNase-freies destilliertes Wasser

Rompun (2\%)

Sephadexg-50 fine

TriFast

Tween-20

Wasser für Injektionszwecke (Ampuwa)
Invitrogen $\mathrm{GmbH}$, Karlsruhe

Amersham Biosciences Europe $\mathrm{GmbH}$, Freiburg

Invitrogen $\mathrm{GmbH}$, Karlsruhe

Roche Diagnostics $\mathrm{GmbH}$, Mannheim

ICN Biomedicals Inc., Aurora, USA

Medite Medizintechnik GmbH, Burgdorf

Roche Diagnostics GmbH, Mannheim

Roche Diagnostics $\mathrm{GmbH}$, Mannheim

ICN Biochemicals Inc., Aurora, USA

Dako $\mathrm{GmbH}$, Hamburg

Tropix, Bedford, USA

Shandon Thermo Electron Corporation, Waltham, USA

Pfizer Pharma GmbH, Karlsruhe

Fluka Chemie $\mathrm{GmbH}$, Buchs

Stratagene, Amsterdam Zuidoost, Niederlande

Merck KgaA, Darmstadt

Vector Laboratories, Inc., Burlingame, USA

Roche Diagnostics $\mathrm{GmbH}$, Mannheim

Fluka Chemie $\mathrm{GmbH}$, Buchs

Medite Medizintechnik GmbH, Burgdorf

Amersham Biosciences Europe $\mathrm{GmbH}$, Freiburg

B. Braun Melsungen AG, Melsungen

Invitrogen $\mathrm{GmbH}$, Karlsruhe

Bayer AG, Leverkusen

Amersham Biosciences Europe $\mathrm{GmbH}$, Freiburg

Peqlab Biotechnologie $\mathrm{GmbH}$, Erlangen

Scharlau Chemie S.A., Barcelona, Spain

Fresenius Kabi Deutschland GmbH, Bad Homburg 


\subsection{Gebrauchsfertige Reaktionssysteme}

\author{
Affymetrix 430A Mouse Gene Chips \\ BigDye Terminator v1.1 Cycle Sequencing Kit \\ Cell Proliferation ELISA, BrdU \\ HiPure Plasmid DNA Purification Kit \\ MicroSpin G.50 Columns \\ One-Cycle Target Labeling and Control Reagents \\ Perfectprep Gel Cleanup \\ pGEM-Teasy TA-cloning Kit \\ Prime-It RmT Random Primer Labeling Kit \\ QuantiTect PCR Probe Kit \\ QuantiTect SYBR Green PCR \\ RNA 6000 Nano Assay Kit \\ RNeasy Fibrous Tissue Kit \\ TaqMan Ribosomal RNA Control Reagent, VIC Probe
}

\author{
Affymetrix, High Wycombe, UK \\ Applied Biosystems, Darmstadt \\ Roche Diagnostics $\mathrm{GmbH}$, Mannheim \\ Invitrogen $\mathrm{GmbH}$, Karlsruhe \\ Amersham Biosciences Europe $\mathrm{GmbH}$, Freiburg \\ Affymetrix, High Wycombe, UK \\ Eppendorf, Hamburg \\ Promega $\mathrm{GmbH}$, Mannheim \\ Stratagene, Amsterdam Zuidoost, Niederlande \\ Qiagen $\mathrm{GmbH}$, Hilden \\ Qiagen $\mathrm{GmbH}$, Hilden \\ Agilent Technologies, Waldbronn \\ Qiagen $\mathrm{GmbH}$, Hilden \\ Applied Biosystems, Darmstadt
}

Bei der Verwendung von gebrauchsfertigen Reaktionssystemen wurde nach den Angaben des jeweiligen Herstellers gearbeitet, soweit nicht anders im Text erwähnt.

\subsection{Stammlösungen}

Soweit im Text nicht anders erwähnt, wurde für alle Stammlösungen in der MilliQ-Anlage (MembraPure GmbH, Bodenheim) aufbereitetes doppelt-destilliertes Wasser verwendet.

\begin{tabular}{llll}
\hline Borsäure pH 5,1 & $0,2 \mathrm{M}$ & Borsäure & $\mathrm{pH} \mathrm{5,1}$ \\
\hline Chloroform/Isoamylalkohol (24:1) & $96 \%(\mathrm{v} / \mathrm{v})$ & Chloroform \\
$4 \%(\mathrm{v} / \mathrm{v})$ & Isoamylalkohol & $\mathrm{pH} \mathrm{3,0}$ \\
\hline Citratpuffer pH 3,0 & $10 \mathrm{mM}$ & Natriumcitrat & $\mathrm{pH} 6,0$ \\
\hline Citratpuffer pH 6,0 & $10 \mathrm{mM}$ & Natriumcitrat & Cresol \\
\hline Cresol & $0,1 \%(\mathrm{w} / \mathrm{v})$ & gesättigte Sukrose-Lösung \\
\hline Denaturierungspuffer & & NaCl \\
\hline Deoxyribonukleotidtriphosphate (dNTP-Mix) & $1,5 \mathrm{M}$ & NaOH \\
& $0,5 \mathrm{M}$ & dATP \\
& $10 \mathrm{mM}$ & dTTP \\
& $10 \mathrm{mM}$ & dGTP \\
\hline Eosin, 1\% & $10 \mathrm{mM}$ & dCTP \\
\hline Glutaraldehyd/1xPBS & $10 \mathrm{mM}$ & Eosin y (wasserlöslich) \\
\hline Hoch-stringenter Puffer & $1 \%(\mathrm{w} / \mathrm{V})$ & $80 \%(\mathrm{v} / \mathrm{v})$ & Ethanol \\
\hline
\end{tabular}




\begin{tabular}{|c|c|c|c|}
\hline \multirow[t]{4}{*}{ Hybridisierungspuffer } & $40 \%(v / v)$ & Formamid & \multirow{4}{*}{$\mathrm{pH} 6,4$} \\
\hline & $10 \%(w / v)$ & Dextransulfat & \\
\hline & & $4 \times$ SSC & \\
\hline & & 1x Denhards & \\
\hline \multirow[t]{7}{*}{ LacZ-Färbepuffer } & $5 \mathrm{mM}$ & $\mathrm{K}_{3} \mathrm{Fe}(\mathrm{CN})_{6}$ & \\
\hline & $5 \mathrm{mM}$ & $\mathrm{K}_{4} \mathrm{Fe}(\mathrm{CN})_{6}$ & \\
\hline & $2 \mathrm{mM}$ & $\mathrm{MgCl}_{2}$ & \\
\hline & $0,02 \%(v / v)$ & NP-40 & \\
\hline & $0,01 \%(w / v)$ & Natrium Deoxycholat & \\
\hline & $500 \mu \mathrm{g} / \mathrm{mlX}-\mathrm{Gal}$ & & \\
\hline & & $1 \times$ PBS & \\
\hline \multirow[t]{4}{*}{ LacZ-Puffer } & $2 \mathrm{mM}$ & $\mathrm{MgCl}_{2}$ & \\
\hline & $0,02 \%(v / v)$ & NP-40 & \\
\hline & $0,01 \%(w / v)$ & Natrium Deoxycholat & \\
\hline & & $1 \times$ PBS & \\
\hline \multirow[t]{5}{*}{ Ladepuffer } & $50 \%(v / v)$ & Glyzerol & \\
\hline & $0,02 \%(w / v)$ & Xylencyanol & \\
\hline & $0,02 \%(w / v)$ & Bromphenolblau & \\
\hline & $0,02 \%(w / v)$ & SDS & \\
\hline & $100 \mathrm{mM}$ & EDTA & \\
\hline \multirow[t]{2}{*}{ Lysepuffer für Plasmid-DNA Isolierungen } & $200 \mathrm{mM}$ & $\mathrm{NaOH}$ & \\
\hline & $1 \%(w / v)$ & SDS & \\
\hline \multirow[t]{4}{*}{ MBSTL-Puffer pH 7,5 } & $0,15 \mathrm{M}$ & $\mathrm{NaCl}$ & \\
\hline & $0,1 \mathrm{M}$ & Maleinsäure & \\
\hline & $2 \mathrm{mM}$ & Levamisol & \\
\hline & $0,1 \%$ & Tween-20 & \\
\hline \multirow[t]{7}{*}{ Neu-Fuchsin Chromogen } & $0,6 \%(v / v)$ & N,N-Dimethylformamid & \\
\hline & $0,05 \%(w / v)$ & Levamisol & \\
\hline & $0,03 \%(w / v)$ & Naphtol As-Bi Phosphat & \\
\hline & $0,02 \%(w / v)$ & $\mathrm{NaN}_{3}$ & \\
\hline & $0,01 \%(w / v)$ & Neu-Fuchsin & \\
\hline & & $1 \times$ TBS & $\mathrm{pH} 8,8$ \\
\hline & & \multicolumn{2}{|c|}{ (Tris-gepufferte Natriumchlorid-Lösung) } \\
\hline Neutralisierungspuffer & $2,55 \mathrm{M}$ & Kaliumacetat & $\mathrm{pH} 5,5$ \\
\hline \multirow[t]{2}{*}{ Niedrig-stringenter Puffer } & $0,1 \%$ & SDS & \\
\hline & & $2 \times \operatorname{SSC}$ & $\mathrm{pH} 7,0$ \\
\hline \multirow[t]{2}{*}{ NT-Puffer } & $0,15 \mathrm{M}$ & $\mathrm{NaCl}$ & \\
\hline & $0,1 \mathrm{M}$ & Tris/HCl & $\mathrm{pH} 7,5$ \\
\hline \multirow[t]{3}{*}{ NTM-Puffer } & $0,1 \mathrm{M}$ & $\mathrm{NaCl}$ & \\
\hline & $0,1 \mathrm{M}$ & Tris/HCl & $\mathrm{pH} 9,5$ \\
\hline & $50 \mathrm{mM}$ & $\mathrm{MgCl}_{2}$ & \\
\hline \multirow[t]{5}{*}{ NTMLT-Puffer } & $0,1 \mathrm{M}$ & $\mathrm{NaCl}$ & \\
\hline & $0,1 \mathrm{M}$ & Tris/HCl & $\mathrm{pH} 9,5$ \\
\hline & $50 \mathrm{mM}$ & $\mathrm{MgCl}_{2}$ & \\
\hline & $2 \mathrm{mM}$ & Levamisol & \\
\hline & $0,1 \%$ & Tween-20 & \\
\hline
\end{tabular}




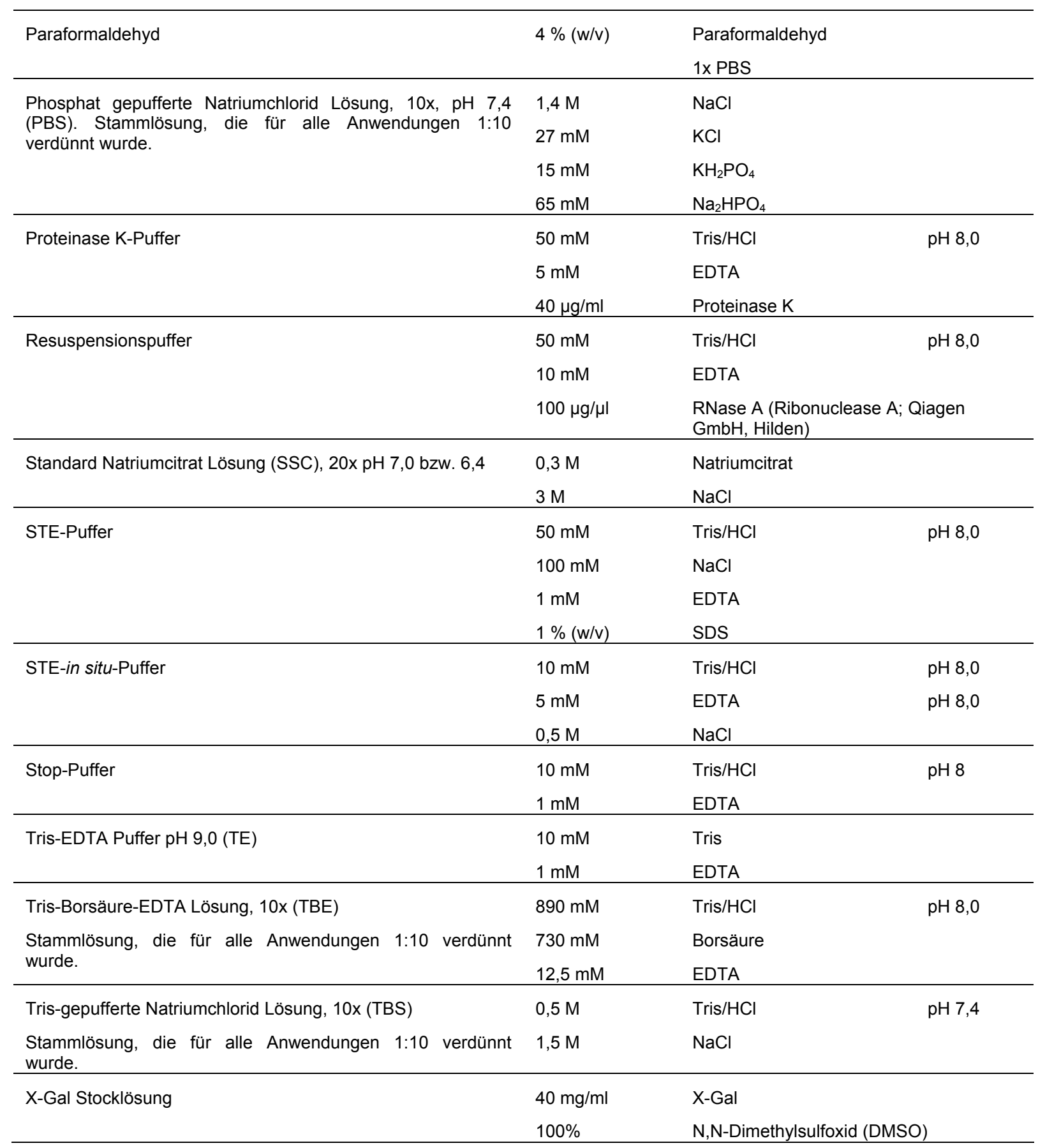

\subsection{Medien}

\subsubsection{Medien für die Bakterienkultur}

Bakterienkulturen (E. coli) wurden mit „lysogeny broth“-Medium (LB-Medium) $(1 \%$ (w/v) Bacto-Trypton, 0,5 \% (w/v) Hefeextrakt, $1 \%$ (w/v) $\mathrm{NaCl}, \mathrm{pH} 7,0)$ kultiviert. Das LB-Medium wurde mit doppelt-destilliertem Wasser angesetzt, autoklaviert und bei $4{ }^{\circ} \mathrm{C}$ gelagert. Durch Zugabe von $50 \mu \mathrm{g} / \mathrm{ml}$ Ampicillin (Stammkonzentration: $50 \mathrm{mg} / \mathrm{ml}$; Carl Roth $\mathrm{GmbH}$, Karlsruhe) bzw. $25 \mu \mathrm{g} / \mathrm{ml}$ Kanamycin (Stammkonzentration: $50 \mathrm{mg} / \mathrm{ml}$, Carl 
Roth $\mathrm{GmbH}$, Karlsruhe) unmittelbar vor Verwendung des Mediums erfolgte die Selektion auf jeweilige Resistenz-vermittelnde Gene.

\subsubsection{Agarplatten}

Zur Herstellung von LB-Agarplatten wurde dem LB-Medium 1,5 \% (w/v) Agar zugegeben, der Ansatz autoklaviert und auf $55{ }^{\circ} \mathrm{C}$ abgekühlt. Nach Zugabe entsprechender Antibiotika wurde der warme LB-Agar in $10 \mathrm{~cm}$ Petrischalen gegossen. Die Platten wurden nach dem Erstarren des Agars in sterilen Plastiktüten bei $4{ }^{\circ} \mathrm{C}$ gelagert.

\subsubsection{Medien für die Kultur eukaryontischer Zellen}

Eukaryontische Zellen wurden in Dulbeccos Modified Eagle Medium (DMEM) mit $10 \%$ fötalem Kälberserum (FCS, fetal calf serum) und Antibiotika kultiviert. Die für die verschiedenen Zelllinien verwendeten Antibiotika und die eingesetzten Konzentrationen sind unter 2.10.2 angegeben. Abweichende Serumkonzentrationen in einzelnen Experimenten sind in der jeweiligen Beschreibung genannt.

Dulbeccos Modified Eagle Medium (DMEM)

Fötales Kälberserum (fetal calf serum, FCS)

Geneticinsulfat (G418, $100 \mathrm{mg} / \mathrm{ml}$ )

Penicillin (10000 U/ml)/Streptomycin $(10 \mathrm{mg} / \mathrm{ml})$

Trypsin/EDTA

\author{
PAN Biotech $\mathrm{GmbH}$, Aidenbach \\ Gibco, Invitrogen $\mathrm{GmbH}$, Karlsruhe \\ Carl Roth $\mathrm{GmbH}$, Karlsruhe \\ PAN Biotech $\mathrm{GmbH}$, Aidenbach \\ PAN Biotech $\mathrm{GmbH}$, Aidenbach
}

\subsection{Biologisches Material}

\subsubsection{Bakterienstämme}

Zur Transformation und Amplifikation von Plasmid-DNA wurde der chemisch-kompetente Wirtsstamm E. coli DH5 $\alpha$ (Invitrogen $\mathrm{GmbH}$, Karlsruhe) verwendet.

\subsubsection{Eukaryontische Zelllinien}

Die in Tabelle 1 angegebenen eukaryontischen Zelllinien wurden in DMEM mit $10 \%$ FCS und den unter 2.9.3 beschriebenen Antibiotika in speziellen Zellkulturschalen bei $37{ }^{\circ} \mathrm{C}$ in einer konstanten $\mathrm{CO}_{2}$-haltigen Atmosphäre $\left(5 \% \mathrm{CO}_{2}\right)$ mit $95 \%$ Luftfeuchtigkeit kultiviert. 
Tabelle 1: Auflistung der verwendeten eukaryontischen Zelllinien. Spalte 1: Bezeichnung der Zelllinie; 2: Ursprungsspezies und Zelltyp; Spalte 3: Verwendete Antibiotika und Konzentrationen; Spalte 4: Hersteller und Klonnummer/Literaturreferenz; Abkürzungen: PS Penicillin/Streptomycin; G418, Geneticinsulfat.

\begin{tabular}{|c|c|c|c|}
\hline 1 & 2 & 3 & 4 \\
\hline Hek293 & embryonale humane Nierenzellen & $1 \%$ PS & $\begin{array}{l}\text { ATCC LGC Promochem, Wesel; } \\
\text { CRL-1573 }\end{array}$ \\
\hline \multirow[t]{2}{*}{ Hek293 Shh } & \multirow{2}{*}{$\begin{array}{l}\text { embryonale humane Nierenzellen } \\
\text { stabil transfiziert mit Shh-Np }\end{array}$} & $1 \%$ PS & \multirow[t]{2}{*}{ (JK Chen et al., 2002) } \\
\hline & & $0,4 \mathrm{mg} / \mathrm{ml} \mathrm{G} 418$ & \\
\hline$P t c h^{\text {floxfflox }}$ & adulte murine Fibroblasten & $1 \% \mathrm{PS}$ & diese Arbeit \\
\hline $\operatorname{Ptch}^{\text {flox/flox }} E R T 2^{+/-} \mathrm{B} 9$ & adulte murine Fibroblasten & $1 \%$ PS & diese Arbeit \\
\hline $\operatorname{Ptch}^{\text {flox/flox }} \mathrm{ERT2} 2^{+/-} \mathrm{C} 6$ & adulte murine Fibroblasten & $1 \% \mathrm{PS}$ & diese Arbeit \\
\hline $\operatorname{Ptch}^{\text {flox/flox }} E R T 2^{+/-} \mathrm{D} 2$ & adulte murine Fibroblasten & $1 \%$ PS & diese Arbeit \\
\hline $\operatorname{Ptch}^{\text {flox/flox }} E R T 2^{+/-} \mathrm{F} 4$ & adulte murine Fibroblasten & $1 \%$ PS & diese Arbeit \\
\hline $\operatorname{Ptch}^{\text {flox/flox }} E R T 2^{+/-} \mathrm{G} 2$ & adulte murine Fibroblasten & $1 \%$ PS & diese Arbeit \\
\hline tPtch $^{-/}$ & adulte murine Fibroblasten & $1 \% \mathrm{PS}$ & diese Arbeit \\
\hline
\end{tabular}

\subsubsection{Mauslinien}

Es wurden die Inzuchtlinien B6 (Charles River Laboratories, Sulzfeld), BALB/c (BALB), (Charles River Laboratories, L'Arbresle, Frankreich), DBA2J, 129Sv, FVB/N (Zucht des Tierstalls des Institutes für Humangenetik, Universität Göttingen) und die Auszuchtlinie CD1 (Zucht des Tierstalls des Institutes für Humangenetik, Universität Göttingen) verwendet. Die verwendeten genetisch manipulierten Mauslinien sind in Tabelle 2 aufgelistet, Zucht und Haltung der Tiere sowie tierexperimentelle Methoden unter 2.15.4 beschrieben.

Tabelle 2: Auflistung der verwendeten Mauslinien. Spalte 1: Bezeichnung der Mauslinie; Spalte 2: Genetischer Hintergrund; Spalte 3: Art der genetischen Veränderung; Spalte 4: Literaturreferenz.

\begin{tabular}{|c|c|c|c|}
\hline 1 & 2 & 3 & 4 \\
\hline Ptch $^{\text {neo67 }}$ & B6 / BALB / CD1 & Gendeletion (knockout) & (H Hahn et al., 1998) \\
\hline Ptch $^{\text {flox }}$ & 129Sv / B6 & konditionelle induzierbare Gendeletion & (A Uhmann et al., 2007) \\
\hline ROSA26CreERT2 & 129Sv & $\begin{array}{l}\text { CreERT2-Gen Integration in den } \\
\text { ROSA26-Lokus }\end{array}$ & (D Hameyer et al., 2007) \\
\hline ROSA26-R & B6 & $\begin{array}{l}\text { Integration des } ß \text {-Galaktosidase-Gens in } \\
\text { den ROSA26-Lokus }\end{array}$ & (P Soriano, 1999) \\
\hline $\operatorname{Tg}($ Ella-Cre $)$ & B6 & $\begin{array}{l}\text { Transgen zur Expression einer konstitutiv } \\
\text { aktiven Cre-Rekombinase unter Kontrolle } \\
\text { des Ella-Promotors }\end{array}$ & (M Lakso et al., 1996) \\
\hline
\end{tabular}




\subsection{Synthetische DNA-Oligonukleotide}

Synthetische DNA-Oligonukleotide wurden von der Firma Qiagen GmbH, Hilden, bezogen. Die Stammkonzentration von $100 \mu \mathrm{M}$ wurde mit Ampuwa eingestellt. Für die PCR wurde eine Arbeitslösung mit einer Konzentration von $10 \mu \mathrm{M}$ verwendet.

\subsubsection{DNA-Oligonukleotide zur Genotypisierung von Mäusen}

Die Genotypisierung von Mäusen ist unter 2.15.4.1.2 beschrieben. Hierzu wurde mit den in Tabelle 3 aufgelisteten DNA-Oligonukleotiden gearbeitet.

Tabelle 3: Auflistung der verwendeten DNA-Oligonukleotide für Genotypisierungen von Mauslinien. Spalte 1: Bezeichnung der getesteten Genotypen; Spalte 2: Verwendete Anlagerungstemperatur bei der PCR; Spalte 3: Amplifizierte Fragmentgröße; Spalte 4: Bezeichnung des DNA-Oligonukleotids; Spalte 5: DNA-Oligonukleotidsequenz $\left(5^{\prime} \rightarrow 3^{\prime}\right)$; Spalte 6: Literaturreferenz; Abkürzungen: ${ }^{\text {wt }}$ Wildtyp-Allel; ${ }^{\text {flox }}$ Allel mit integrierten loxP-Sequenzen; ${ }^{\text {del }}$ Allel nach erfolgter Deletion durch Cre-Rekombinase vermittelte Rekombination; ${ }^{\mathrm{Kl}}$ knockin-Allel; ${ }^{\mathrm{T}}$ transgenes Allel.

\begin{tabular}{|c|c|c|c|c|c|}
\hline 1 & 2 & 3 & 4 & 5 & 6 \\
\hline $\operatorname{Ptch}^{+/+}$ & \multirow[t]{3}{*}{$60{ }^{\circ} \mathrm{C}$} & $400 \mathrm{bp}^{\mathrm{mut}}$ & $n e o-L$ & AGTGCCAGCGGGGCTGCTAAA & \multirow{3}{*}{$\begin{array}{l}\text { (H Hahn et al., } \\
\text { 1998) }\end{array}$} \\
\hline \multirow[t]{2}{*}{$\operatorname{Ptch}^{\text {neo67/+ }}$} & & $635 \mathrm{bp} \mathrm{wt}^{\mathrm{wt}}$ & mPTC11R3 & CTGCCTGTTATGTGGTTCAAACCG & \\
\hline & & & Pst4KF & GGGAGGGGATTTCAGCAGAATGTT & \\
\hline $\operatorname{Ptch}^{+/+}$ & \multirow[t]{3}{*}{$60^{\circ} \mathrm{C}$} & \multirow[t]{3}{*}{$1401 \mathrm{bp}^{\mathrm{wt}}$} & p910F.4 & AGCACCCTGGACGACATCCTAAA & \multirow{3}{*}{$\begin{array}{l}\text { (A Uhmann et } \\
\text { al., 2007) }\end{array}$} \\
\hline $\operatorname{Ptch}^{f l o x /+}$ & & & p1011R.2 & TCTGTCCTGTTTCACTGAATGCATGG & \\
\hline $\operatorname{Ptch}^{\text {del/t+}}$ & & & & & \\
\hline $\operatorname{Ptch}^{f l o x /+}$ & \multirow[t]{2}{*}{$60^{\circ} \mathrm{C}$} & \multirow[t]{2}{*}{$843 b p^{\text {flox }}$} & P910F.4 & AGCACCCTGGACGACATCCTAAA & \multirow{2}{*}{$\begin{array}{l}\text { (A Uhmann et } \\
\text { al., 2007) }\end{array}$} \\
\hline $\operatorname{Ptch}^{\text {floxfflox }}$ & & & Neo- $R$ & GCATCAGAGCAGCCGATTGTCTG & \\
\hline $\operatorname{Ptch}^{+/+}$ & \multirow[t]{3}{*}{$60{ }^{\circ} \mathrm{C}$} & $445 b p^{w t}$ & mPTCNx_f & TGGTAATTCTGGGCTCCCGT & \multirow{3}{*}{$\begin{array}{l}\text { Assay von A. } \\
\text { Zibat, AG Hahn }\end{array}$} \\
\hline$P t c h{ }^{f l o x /+}$ & & $150 \mathrm{bp}^{\text {flox }}$ & mPTCNx_r & CCGGTAGAATTAGCTTGAAGTTCCT & \\
\hline $\operatorname{Ptch}^{\text {floxfllox }}$ & & & mPTCwt_r & TCAAGGAGCAGAGGCCCAA & \\
\hline $\operatorname{Ptch}^{\text {del/+ }}$ & \multirow[t]{2}{*}{$60^{\circ} \mathrm{C}$} & \multirow[t]{2}{*}{$950 \mathrm{bp}^{\mathrm{del}}$} & Exon7-F & AGGAAGTATATGCATTGGCAGGAG & \multirow{2}{*}{$\begin{array}{l}\text { (A Uhmann et } \\
\text { al., 2007) }\end{array}$} \\
\hline Ptch ${ }^{\text {del/del }}$ & & & Neo- $R$ & GCATCAGAGCAGCCGATTGTCTG & \\
\hline$R O S A 26-R^{+/+}$ & \multirow[t]{3}{*}{$56{ }^{\circ} \mathrm{C}$} & $250 \mathrm{bp} \mathrm{p}^{\mathrm{KI}}$ & Rosa1 & AAAGTCGCTCTGAGTTGTTAT & \multirow{3}{*}{$\begin{array}{l}(\mathrm{P} \\
1999)\end{array}$} \\
\hline \multirow[t]{2}{*}{ ROSA26- $R^{+/-}$} & & $500 \mathrm{bp}^{\mathrm{wt}}$ & Rosa2 & GCGAAGAGTTTGTCCTCAACC & \\
\hline & & & Rosa3 & GGAGCGGGAGAAATGGATATG & \\
\hline ROSA26CreERT2 $2^{-/-}$ & \multirow[t]{2}{*}{$56^{\circ} \mathrm{C}$} & \multirow[t]{2}{*}{$269 \mathrm{bp}^{\top}$} & RosCre ER-F & ACCAGCCAGCTATCAACTC & \multirow{2}{*}{$\begin{array}{l}\text { persönliche } \\
\text { Mitteilung A. } \\
\text { Berns, } \\
\text { Niederlande }\end{array}$} \\
\hline ROSA26CreERT2 ${ }^{T /-}$ & & & RosCre ER-R & $\begin{array}{l}\text { TATACGCGTGCTAGCGAAGATCTCCAC } \\
\text { TTCCAGCAG }\end{array}$ & \\
\hline
\end{tabular}

\subsubsection{DNA-Oligonukleotide für DNA-Sequenzanalysen}

Für die Sequenzierung von PCR-Produkten, die in das Plasmid $p G E M-T e a s y$ kloniert wurden, dienten die Oligonukleotide T7new (5'-TTA GGT GAC ACT ATA GAA TAC TCA A-3') und SP6new (5'-AAT ACG ACT CAC TAT AGG GCG AAT T-3'). Die für DNA- 
Sequenzanalysen von aufgereinigten PCR-Produkten verwendeten DNA-Oligonukleotide sind in Tabelle 4 aufgelistet.

Tabelle 4: Auflistung der verwendeten DNA-Oligonukleotide für DNA-Sequenzanalysen. Spalte 1: Bezeichnung des sequenzierten Gens; Spalte 2: Bezeichnung des DNA-Oligonukleotids; Spalte 3: DNA-Oligonukleotidsequenz $\left(5^{\prime} \rightarrow 3^{\prime}\right)$.

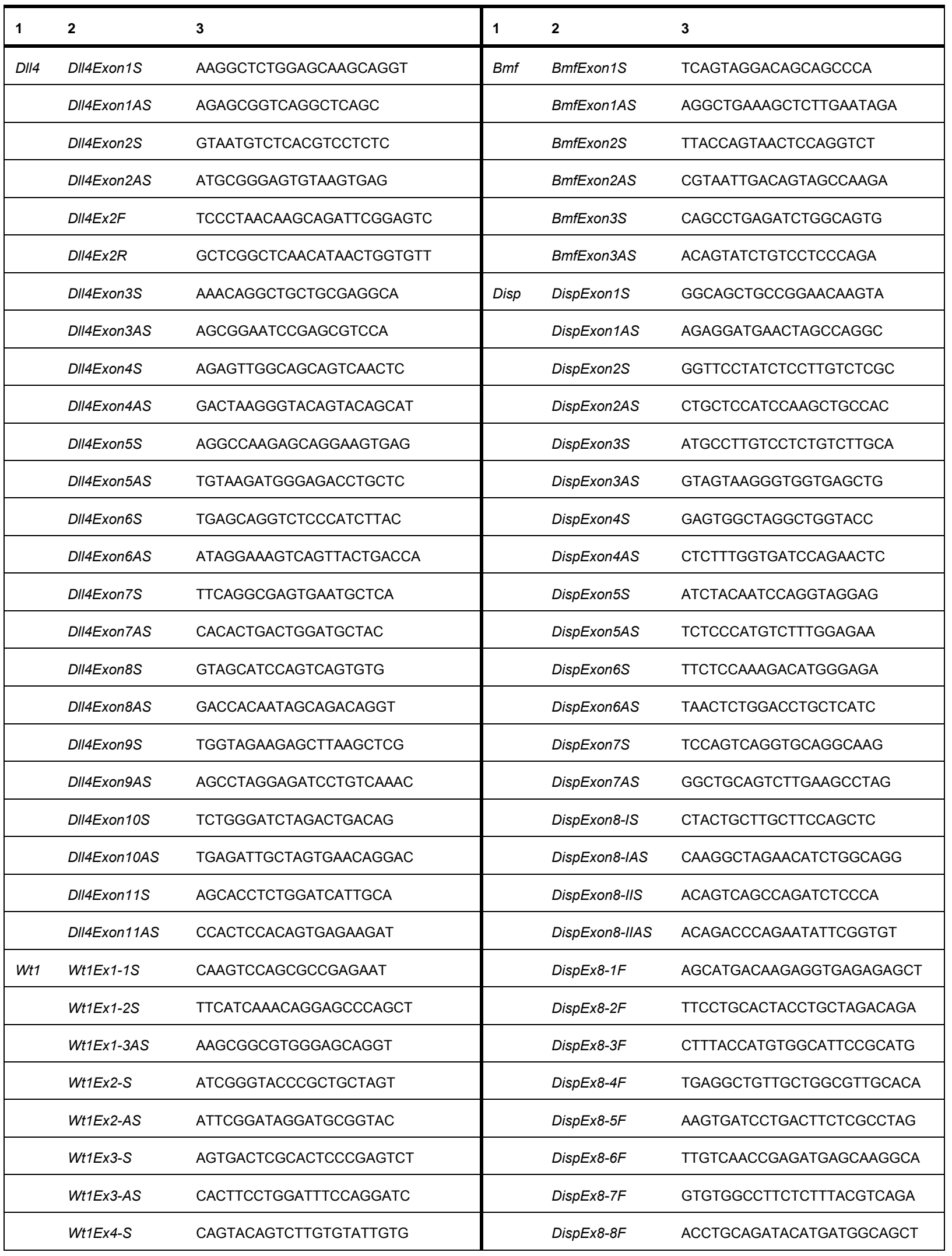




\begin{tabular}{|c|c|c|c|c|}
\hline Wt1Ex4-AS & TAGGCCTGTTCTCCCTTCAGAA & & DispEx8-9F & GTTCAGTGACGCTAAGGTACTCCA \\
\hline Wt1Ex5-S & GAACTTCCTACTGGATTCTGG & & DispEx8-10F & TCGAAAGTTACTCCACAGTGGCCT \\
\hline Wt1Ex5-AS & ATGTCAGGCCTAACTCCTGCGTT & & DispEx8-11F & AGGATGTGCCTCTTTCATGGCTGA \\
\hline Wt1Ex6-S & TGTTCCAGAGTGAGCCCATGGAGT & & DispEx8-12F & AGGCATTAGTGGGTCAGGGTTACT \\
\hline Wt1Ex6-AS & AGAAGGTCCTTCAGCTGAG & & DispEx8-13F & AGGACAAGTGGAGCAGAAACTCAG \\
\hline Wt1Ex7-S & GTTCACATATGGCACAAGGTC & Ptch & mPtc11 & AAAGCCGAAGTTGGCCATGGGTAC \\
\hline Wt1Ex7-AS & GTGTCAGAGTCCAGAATGAA & & mPtc4 & GGCCCTTGTTTTGAATGGTGGAT \\
\hline Wt1Ex8-S & TCATCTGCAGCTAGGGTTTC & & mPtc6R & AATGCCAATCAAGGAGCAGAGG \\
\hline Wt1Ex8-AS & GACAGTCACAACATCAGCTC & & $m P t c 7 R$ & TGTCCTGTTTCACTGAATGC \\
\hline Wt1Ex9-S & AGCTGCCAGAAAGCCGGCCTTATG & & \multirow[t]{4}{*}{$W 18 R 2$} & \multirow[t]{4}{*}{ TTCCAGTTAATGACTCCCA } \\
\hline Wt1Ex9-AS & CAGTTTCATTCAACAGTAGCT & & & \\
\hline Wt1Ex10-S & TGATAGTTGAACCTGTGCCCAG & & & \\
\hline Wt1Ex10-AS & GAAAGGTGAGTGGGAGGAAT & & & \\
\hline
\end{tabular}

\subsubsection{DNA-Oligonukleotide für die Kopplungsanalyse}

In Tabelle 5 sind die analysierten Mikrosatellitenmarker aufgelistet. Die Sequenzen der verwendeten Oligonukleotide sind unter http://www.informatics.jax.org/ angegeben.

Tabelle 5: Auflistung der analysierten Mikrosatellitenmarker für die gesamt-genomische Kopplungsanalyse. Abkürzung: Chr. Chromosom.

\begin{tabular}{|c|c|c|c|c|c|c|c|c|c|}
\hline Chr. 1 & Chr. 2 & Chr. 3 & Chr. 4 & Chr. 5 & Chr. 6 & Chr. 7 & Chr. 8 & Chr. 9 & Chr. 10 \\
\hline D1Mit294 & D2Mit37 & D3Mit164 & D4Mit235 & D5Mit386 & D6Mit138 & D7Mit306 & D8Mit4 & D9Mit328 & D10Mit213 \\
\hline D1Mit411 & D2Mit249 & D3Mit6 & D4Mit286 & D5Mit79 & D6Mit274 & D7Mit310 & D8Mit190 & D9Mit336 & D10Mit274 \\
\hline D1Mit22 & D2Mit398 & D3Mit49 & D4Mit15 & D5Mit197 & D6Mit230 & D7Mit96 & D8Mit231 & D9Mit35 & D10Mit95 \\
\hline D1Mit132 & D2Mit452 & D3Mit318 & D4Mit203 & D5Mit239 & D6Mit36 & D7Mit68 & D8Mit242 & D9Mit12 & D10Mit233 \\
\hline D1Mit399 & D2Mit148 & D3Mit17 & D4Mit170 & D5Mit406 & D6Mit59 & D7Mit101 & D8Mit49 & D9Mit125 & \\
\hline \multirow[t]{2}{*}{ D1Mit223 } & & D3Mit116 & & D5Mit95 & D6Mit373 & D7Mit259 & & & \\
\hline & & D3Mit19 & & & & & & & \\
\hline Chr. 11 & Chr. 12 & Chr. 13 & Chr. 14 & Chr. 15 & Chr. 16 & Chr. 17 & Chr. 18 & Chr. 19 & \\
\hline D11Mit231 & D12Mit182 & D13Mit57 & D14Mit109 & D15Mit100 & D16Mit182 & D17Mit133 & D18Mit110 & D19Mit68 & \\
\hline D11Mit333 & D12Mit124 & D13Mit250 & D14Mit60 & D15Mit209 & D16Mit211 & D17Mit49 & D18Mit177 & D19Mit19 & \\
\hline \multirow[t]{4}{*}{ D11Mit203 } & D12Mit34 & D13Mit13 & D14Mit113 & D15Mit159 & D16Mit139 & D17Mit152 & D18Mit186 & D19Mit34 & \\
\hline & D12Mit99 & D13Mit262 & D14Mit265 & & & D17Mit39 & & D19Mit71 & \\
\hline & D12Nds2 & D13Mit78 & D14Mit165 & & & & & & \\
\hline & & D13Mit151 & & & & & & & \\
\hline
\end{tabular}

\subsubsection{DNA-Oligonukleotide für RT-PCR}

Der spezifische Nachweis von Transkripten erfolgte mittels RT-PCR an cDNA und der in Tabelle 6 aufgelisteten DNA-Oligonukleotide. 
Tabelle 6: Auflistung der verwendeten DNA-Oligonukleotide für RT-PCR. Spalte 1: Bezeichnung der Gentranskripte; Spalte 2: Verwendete Anlagerungstemperatur bei der PCR; Spalte 3: Amplifizierte Fragmentgröße; Spalte 4: Bezeichnung des DNA-Oligonukleotids; Spalte 5: DNAOligonukleotidsequenz ( ${ }^{\prime} \rightarrow 3$ '); Spalte 6: Literaturreferenz; Abkürzungen: wt Wildtyp-Transkript; del Transkript nach erfolgter Deletion durch Cre-Rekombinase vermittelte Rekombination.

\begin{tabular}{|c|c|c|c|c|c|}
\hline 1 & 2 & 3 & 4 & 5 & 6 \\
\hline \multirow[t]{2}{*}{ Gapd } & \multirow[t]{2}{*}{$58^{\circ} \mathrm{C}$} & \multirow[t]{2}{*}{576 bp } & Gapd-F & АTCTTCTTGTGCAGTGCCAG & \multirow{2}{*}{$\begin{array}{l}\text { (A Uhmann et } \\
\text { al., 2005) }\end{array}$} \\
\hline & & & Gapd-R & ATGACCACAGTCCATGCCAT & \\
\hline \multirow[t]{2}{*}{ Gli1 } & \multirow[t]{2}{*}{$60^{\circ} \mathrm{C}$} & \multirow[t]{2}{*}{$419 \mathrm{bp}$} & mGliF8 & TGCACCAAGCGCTACACAGATCCCA & \multirow{2}{*}{$\begin{array}{l}\text { Regine } \\
\text { AG Hahn }\end{array}$} \\
\hline & & & mGliR9 & AGCTGATGCAGCTGATCCAGCCTA & \\
\hline \multirow[t]{2}{*}{$\operatorname{lgf2}$} & \multirow[t]{2}{*}{$55^{\circ} \mathrm{C}$} & \multirow[t]{2}{*}{$454 \mathrm{bp}$} & Igf2 TaqManF & TGTGCTGCATCGCTGCTTAC & \multirow{2}{*}{$\begin{array}{l}\text { Regine } \\
\text { AG Hahn }\end{array}$} \\
\hline & & & Igf2 Exon6R & TTGCTGGACATCTCCGAAGAG & \\
\hline wt Ptch & \multirow[t]{2}{*}{$55^{\circ} \mathrm{C}$} & $731 \mathrm{bp}^{\mathrm{wt}}$ & $m P t c 11$ & AAAGCCGAAGTTGGCCATGGGTAC & \multirow{2}{*}{$\begin{array}{l}\text { (A Uhmann et } \\
\text { al., 2005) }\end{array}$} \\
\hline $\operatorname{Ptch}^{d e l}$ & & $451 b p^{\text {del }}$ & mPtc7R & TGTCCTGTTTCACTGAATGC & \\
\hline
\end{tabular}

\subsubsection{DNA-Oligonukleotide für die quantitative real time PCR}

\subsubsection{DNA-Oligonukleotide für die quantitative real time PCR an CDNA}

DNA-Oligonukleotide für die quantitative real time PCR (qRT-PCR) mit SYBR Green (QuantiTect SYBR Green) zur Messung von Genexpressionsniveaus sind in Tabelle 7 aufgelistet.

Tabelle 7: Auflistung der für die qRT-PCR verwendeten DNA-Oligonukleotide. Spalte 1: Bezeichnung der quantifizierten Gentranskripte; Spalte 2: Verwendete Anlagerungstemperatur bei der qRT-PCR; Spalte 3: Bezeichnung des DNA-Oligonukleotids; Spalte 4: DNA-Oligonukleotidsequenz $\left(5^{\prime} \rightarrow 3^{\prime}\right)$; Spalte 5: Verwendete Endkonzentration der DNA-Oligonukleotide; Spalte 6: Referenz; Abkürzungen: ${ }^{\text {wt }}$ Wildtyp-Transkript; ${ }^{\text {del }}$ Transkript nach erfolgter Deletion durch Cre-Rekombinase vermittelte Rekombination.

\begin{tabular}{|c|c|c|c|c|c|}
\hline 1 & 2 & 3 & 4 & 5 & 6 \\
\hline \multirow{2}{*}{$\begin{array}{l}18 S \\
\text { rRNA }\end{array}$} & \multirow[t]{2}{*}{$60^{\circ} \mathrm{C}$} & $18 S$ forw & CGCAAATTACCCACTCCCG & $400 \mathrm{nM}$ & \multirow{2}{*}{$\begin{array}{l}\text { diese } \\
\text { Arbeit }\end{array}$} \\
\hline & & 18S rew2 & TTCCAATTACAGGGCCTCGAA & $400 \mathrm{nM}$ & \\
\hline \multirow[t]{2}{*}{ Bcl-2 } & \multirow[t]{2}{*}{$60^{\circ} \mathrm{C}$} & $B c / 2-F 1$ & GGACAACATCGCCCTGTGGATG & $400 \mathrm{nM}$ & \multirow{2}{*}{$\begin{array}{l}\text { diese } \\
\text { Arbeit }\end{array}$} \\
\hline & & $B c / 2-R 1$ & AACAGAGGTCGCATGCTGGG & $400 \mathrm{nM}$ & \\
\hline \multirow[t]{2}{*}{ Gli1 } & \multirow[t]{2}{*}{$58^{\circ} \mathrm{C}$} & $m$ Gli1-tq- $f$ & TACATGCTGGTGGTGCACATG & $400 \mathrm{nM}$ & \multirow{2}{*}{$\begin{array}{l}\text { diese } \\
\text { Arbeit }\end{array}$} \\
\hline & & $m$ Gli1-tq-r & ACCGAAGGTGCGTCTTGAGG & $400 \mathrm{nM}$ & \\
\hline \multirow[t]{2}{*}{ Gli2 } & \multirow[t]{2}{*}{$60{ }^{\circ} \mathrm{C}$} & mGli2 RT-PCR-F & GGTCATCTACGAGACCAACTGC & $400 \mathrm{nM}$ & \multirow{2}{*}{$\begin{array}{l}\text { diese } \\
\text { Arbeit }\end{array}$} \\
\hline & & mGli2 RT-PCR-R & GTGTCTTCAGGTTCTCCAGGC & $400 \mathrm{nM}$ & \\
\hline \multirow[t]{2}{*}{ Gli3 } & \multirow[t]{2}{*}{$60{ }^{\circ} \mathrm{C}$} & $m G l i 3 F 2$ & GAAGGAACAACCCTAGTCAAGGAGGA & $400 \mathrm{nM}$ & \multirow{2}{*}{$\begin{array}{l}\text { diese } \\
\text { Arbeit }\end{array}$} \\
\hline & & mGli3-SybrgreenR & CCAGCGGCACACGAACTCCTTCT & $400 \mathrm{nM}$ & \\
\hline \multirow[t]{2}{*}{ K1 } & \multirow[t]{2}{*}{$60^{\circ} \mathrm{C}$} & $m K 1-F$ & TCAACGTTGAGGTTGACCCTC & $400 \mathrm{nM}$ & \multirow{2}{*}{$\begin{array}{l}\text { diese } \\
\text { Arbeit }\end{array}$} \\
\hline & & $m K 1-R$ & АССTTCCTTCTGAGGATGCTG & $400 \mathrm{nM}$ & \\
\hline \multirow[t]{2}{*}{ K10 } & \multirow[t]{2}{*}{$60^{\circ} \mathrm{C}$} & $m K 10-F$ & GGATGCTGAAGAGTGGTTCAA & $400 \mathrm{nM}$ & \multirow{2}{*}{$\begin{array}{l}\text { diese } \\
\text { Arbeit }\end{array}$} \\
\hline & & $m K 10-R$ & TCTGTTTCTGCCAAGGAGGCT & $400 \mathrm{nM}$ & \\
\hline
\end{tabular}




\begin{tabular}{|c|c|c|c|c|c|}
\hline \multirow[t]{2}{*}{ Ptch } & \multirow[t]{2}{*}{$58{ }^{\circ} \mathrm{C}$} & mPtc10 & TACAGTCCGGGACAGCATACC & $400 \mathrm{nM}$ & \multirow{2}{*}{$\begin{array}{l}\text { diese } \\
\text { Arbeit }\end{array}$} \\
\hline & & mPtc11R & GTACCCATGGCCAACTTCGGCTTT & $400 \mathrm{nM}$ & \\
\hline \multirow[t]{2}{*}{$P_{t c h}{ }^{w t}$} & \multirow[t]{2}{*}{$60{ }^{\circ} \mathrm{C}$} & $m P t c-t q-E x 7 F$ & GTGGATGTCAAGGTTTATCCAG & $400 \mathrm{nM}$ & \multirow{2}{*}{$\begin{array}{l}\text { diese } \\
\text { Arbeit }\end{array}$} \\
\hline & & mPtc-tq Ex8R & TGCTTGGGAGTCATTAACTGGA & $400 \mathrm{nM}$ & \\
\hline \multirow[t]{2}{*}{$\operatorname{Ptch}^{\text {wt }}$} & \multirow[t]{2}{*}{$60{ }^{\circ} \mathrm{C}$} & $m P t c 11$ & AAAGCCGAAGTTGGCCATGGGTAC & $400 \mathrm{nM}$ & \multirow{2}{*}{$\begin{array}{l}\text { diese } \\
\text { Arbeit }\end{array}$} \\
\hline & & mPtc-tq Ex8R & TGCTTGGGAGTCATTAACTGGA & $400 \mathrm{nM}$ & \\
\hline \multirow[t]{2}{*}{$\operatorname{Ptch}^{d e l}$} & \multirow[t]{2}{*}{$60{ }^{\circ} \mathrm{C}$} & $m P t c-t q-E x 7 F$ & GTGGATGTCAAGGTTTATCCAG & $400 \mathrm{nM}$ & \multirow{2}{*}{$\begin{array}{l}\text { diese } \\
\text { Arbeit }\end{array}$} \\
\hline & & mPtc-tqEx7/10R & GCATAGGCAAGCTGACAAGTTT & $400 \mathrm{nM}$ & \\
\hline \multirow[t]{2}{*}{ Ptch $^{d e l}$} & \multirow[t]{2}{*}{$60^{\circ} \mathrm{C}$} & mPtc11 & AAAGCCGAAGTTGGCCATGGGTAC & $400 \mathrm{nM}$ & \multirow{2}{*}{$\begin{array}{l}\text { diese } \\
\text { Arbeit }\end{array}$} \\
\hline & & mPtc-tq Ex7/10R2 & TTAAACAGGCATAGGCAAGCTGAC & $400 \mathrm{nM}$ & \\
\hline
\end{tabular}

\subsubsection{DNA-Oligonukleotide für TaqMan-Analysen an gDNA}

DNA-Oligonukleotide und fluoreszenzmarkierte Sonden für TaqMan-Analysen an genomischer DNA (gDNA) sind in Tabelle 8 aufgelistet.

Tabelle 8: Auflistung der für die qRT-PCR verwendeten DNA-Oligonukleotide. Spalte 1: Bezeichnung des analysierten Genlokus; Spalte 2: Verwendete Anlagerungstemperatur bei der TaqMan-Analyse; Spalte 3: Bezeichnung des DNA-Oligonukleotids oder der Hybridisierungssonde; Spalte 4: DNA-Oligonukleotidsequenz $\left(5^{\prime} \rightarrow 3^{\prime}\right)$; Spalte 5: Verwendete Endkonzentration der DNAOligonukleotide und der Sonden-DNA; Spalte 6: Literaturreferenz; Abkürzungen: flox Allel mit integrierten loxP-Sequenzen; ${ }^{\text {del }}$ Allel nach erfolgter Deletion durch Cre-Rekombinase vermittelte Rekombination; 6-FAM, 6-Carboxyfluoreszein; YYE, Yakima Yellow.

\begin{tabular}{|c|c|c|c|c|c|}
\hline 1 & 2 & 3 & 4 & 5 & 6 \\
\hline \multirow{3}{*}{$\operatorname{Ptch}^{\text {flox }}$} & \multirow{3}{*}{$60^{\circ} \mathrm{C}$} & mPTCNx_f & TGGTAATTCTGGGCTCCCGT & $400 \mathrm{nM}$ & \multirow{3}{*}{$\begin{array}{l}\text { A. Zibat, } \\
\text { AG Hahn }\end{array}$} \\
\hline & & mPTCNx_r & CCGGTAGAATTAGCTTGAAGTTCCT & $400 \mathrm{nM}$ & \\
\hline & & mPTCNx_S2 & YYE-TTGGTTTGTAATTTTACTTTGACGGTACCTCGA & $200 \mathrm{nM}$ & \\
\hline \multirow{3}{*}{$\operatorname{Ptch}^{\text {del }}$} & \multirow{3}{*}{$60{ }^{\circ} \mathrm{C}$} & mPTCdelNx_f & TTCATTGAACCTTGGGGAACATT & $400 \mathrm{nM}$ & \multirow{3}{*}{$\begin{array}{l}\text { A. Zibat, } \\
\text { AG Hahn }\end{array}$} \\
\hline & & mPTCNx_r & CCGGTAGAATTAGCTTGAAGTTCCT & $400 \mathrm{nM}$ & \\
\hline & & mPTCdelNx_S1 & 6-Fam-CACACCAGACCAGCTTGCAAAGAGATC & $200 \mathrm{nM}$ & \\
\hline \multirow{3}{*}{ Pelota } & \multirow{3}{*}{$60^{\circ} \mathrm{C}$} & Pelo-F1 & CGGTCTGAGTGCTGGTAGGGAA & $400 \mathrm{nM}$ & \multirow{3}{*}{$\begin{array}{l}\text { A. Zibat, } \\
\text { AG Hahn }\end{array}$} \\
\hline & & Pelo-R & TCTGCACCTTAGCGTGAAGCC & $400 \mathrm{nM}$ & \\
\hline & & Pelo-Sonde2 & 6-Fam-GAGCGAGCAAAGCCAGGCAGAGTT & $200 \mathrm{nM}$ & \\
\hline
\end{tabular}

\subsubsection{Sonden}

Die im Rahmen dieser Arbeit für Southern Blot-Analysen und in situ-Hybridisierungen benutzten Sonden sind in Tabelle 9 angegeben. 
Tabelle 9: Auflistung der verwendeten Sonden. Spalte 1: Bezeichnung der detektierten Gentranskripte; Spalte 2: Bezeichnung der verwendeten Plasmide; Spalte 3: Verwendete Restriktionsendonukleasen zur Linearisierung des Plasmids; Spalte 4: Größe der Sonde; Spalte 5: Verwendung; Spalte 6: Literaturreferenz; Abkürzungen: ${ }^{\text {flox }}$ Allel mit integrierten loxP-Sequenzen; ${ }^{\text {del }}$ Allel nach erfolgter Deletion durch Cre-Rekombinase vermittelte Rekombination.

\begin{tabular}{|c|c|c|c|c|c|}
\hline 1 & 2 & 3 & 4 & 5 & 6 \\
\hline $\begin{array}{l}\text { wt Ptch } \\
\text { Ptch }^{\text {flox }}\end{array}$ & pGEM-T KO\#13 & EcoRI & $1,2 \mathrm{~kb}$ & Southern Blot-Analyse & $\begin{array}{l}\text { (A Uhmann et al., } \\
\text { 2007) }\end{array}$ \\
\hline Ptch $^{\text {del }}$ & & & & & \\
\hline Gli2 & pmGli2 & $\begin{array}{l}\text { HindIII (antisense) } \\
\text { BamHI (sense) }\end{array}$ & $1,2 \mathrm{~kb}$ & in situ-Hybridisierung & $\begin{array}{l}\text { zur Verfügung } \\
\text { gestellt von M. } \\
\text { Wijgerde, } \\
\text { Rotterdam, } \\
\text { Niederlande }\end{array}$ \\
\hline
\end{tabular}

\subsection{Gebrauchsfertige TaqMan Assays für Genexpressionsanalysen}

Ein gebrauchsfertiger 20x Mix zur Expressionsanalyse der in Tabelle 10 aufgelisteten Gene, der spezifische Oligonukleotide sowie eine FAM-markierte TaqMan Sonde enthielt, wurde von Applied Biosystems (Darmstadt) bezogen.

Tabelle 10: Auflistung der verwendeten TaqMan Assays für Genexpressionsanalysen. Spalte 1: Bezeichnung der quantifizierten Gentranskripte; Spalte 2: Bezeichnung des Assays.

\begin{tabular}{ll}
\hline $\mathbf{1}$ & 2 \\
\hline Apoptosis inhibitor 5 & Mm00500189_m1 \\
Catenin src & Mm00483042_m1 \\
Ets homologous factor & Mm00468193_m1 \\
Midkine & Mm00440279_m1 \\
Protein tyrosine phosphatase, receptor type, J & Mm00501277_m1 \\
Tnf receptor-associated factor 6 & Mm00493836_m1 \\
Wilms tumor homolog & Mm00460570_m1 \\
ADP-ribosylation factor GTPase activating protein 2 & Mm00651052_mH \\
\hline
\end{tabular}




\subsection{Enzyme}

Tabelle 11: Auflistung der verwendeten Enzyme. Spalte 1: Bezeichnung des Enzyms; Spalte 2: Anwendung des Enzyms; Spalte 3: Hersteller; Abkürzungen: IHC, Immunhistochemie; Taq, Thermus aquaticus.

\begin{tabular}{|c|c|c|}
\hline 1 & 2 & 3 \\
\hline \multirow[t]{2}{*}{ Restriktionsendonukleasen } & Restriktionshydrolyse & Invitrogen $\mathrm{GmbH}$, Karlsruhe \\
\hline & & New England Biolabs GmbH, Frankfurt a. M. \\
\hline Taq-DNA Polymerase & PCR und RT-PCR & Molzym GmbH \& Co.KG, Bremen \\
\hline T3 RNA Polymerase & $\begin{array}{l}\text { Herstellung von Sonden für } \\
\text { in situ-Hybridisierung }\end{array}$ & Promega $\mathrm{GmbH}$, Mannheim \\
\hline T7 RNA Polymerase & $\begin{array}{l}\text { Herstellung von Sonden für } \\
\text { in situ-Hybridisierung }\end{array}$ & Promega $\mathrm{GmbH}$, Mannheim \\
\hline RNase A & in situ-Hybridisierung & Carl Roth, Karlsruhe \\
\hline Collagenase $\mathrm{H}$ (Clostridiopepdidase $\mathrm{A}$ ) & $\begin{array}{l}\text { primäre Kultivierung von } \\
\text { Fibroblasten }\end{array}$ & Roche Diagnostics $\mathrm{GmbH}$, Mannheim \\
\hline \multirow[t]{3}{*}{ Proteinase $\mathrm{K}$} & DNA-Isolierung & Carl Roth, Karlsruhe \\
\hline & in situ-Hybridisierung & \\
\hline & Antigendemaskierung für $\mathrm{IHC}$ & \\
\hline $\begin{array}{l}\text { Alkaline Protease (Proteinase, bacterial, } \\
\text { Type XXIV) }\end{array}$ & Antigendemaskierung für $\mathrm{IHC}$ & Sigma-Aldrich Chemie GmbH, Steinheim \\
\hline Reverse Transkriptase SuperScript II & cDNA-Synthese & Invitrogen $\mathrm{GmbH}$, Karlsruhe \\
\hline
\end{tabular}

\subsection{Antikörper}

\subsubsection{Primäre Antikörper}

Die für Immunhistochemische Methoden verwendeten primären Antikörper sind in Tabelle 12 aufgelistet. Die jeweiligen Verdünnungsmedien der Antikörper sind der Beschreibung der jeweiligen Methode zu entnehmen.

Tabelle 12: Auflistung der verwendeten primären Antikörper. Spalte 1: Bezeichnung des primären Antikörpers; Spalte 2: Bezeichnung des Antigens und dessen Ursprungsspezies; Spalte 3: Ursprungsspezies des Antikörpers; Spalte 4: Eingesetzte Antikörperverdünnung; Spalte 5: Hersteller.

\begin{tabular}{|c|c|c|c|c|}
\hline 1 & 2 & 3 & 4 & 5 \\
\hline anti- $\beta$-Catenin & murines $\beta$-Catenin & Kaninchen, polyklonal & $1: 1000$ & $\begin{array}{l}\text { zur Verfügung gestellt von F. Brembeck, } \\
\text { Berlin }\end{array}$ \\
\hline anti-B220 & murines B220 & Ratte; monoklonal & $1: 200$ & BD Biosciences Pharmingen, San Diego \\
\hline anti-Bcl-2 & murines Bcl-2 & Kaninchen; polyklonal & $1: 250$ & BD Biosciences Pharmingen, San Diego \\
\hline anti-Caspase 3 & humane Caspase 3 & Kaninchen; polyklonal & $1: 500$ & $\begin{array}{l}\text { R\&D Systems GmbH, Wiesbaden- } \\
\text { Nordenstadt }\end{array}$ \\
\hline anti-CD3 & humanes CD3 & Ratte; monoklonal & $1: 50$ & AbD Serotec $\mathrm{GmbH}$, Düsseldorf \\
\hline anti-F4/80 & murines $\mathrm{F} 4 / 80$ & Ratte; monoklonal & $1: 100$ & AbD Serotec $\mathrm{GmbH}$, Düsseldorf \\
\hline anti-Gli1 & murines Gli1 & Kaninchen; polyklonal & $1: 150$ & Abcam, Cambridge, UK \\
\hline anti-K1 & murines $\mathrm{K} 1$ & Kaninchen; polyklonal & $1: 1000$ & $\begin{array}{l}\text { Covance Inc., HISS Diagnostics GmbH, } \\
\text { Freiburg i. Br. }\end{array}$ \\
\hline
\end{tabular}




\begin{tabular}{lllll}
\hline anti-K10 & murines K10 & Kaninchen; polyklonal & $1: 500$ & $\begin{array}{l}\text { Covance Inc., HISS Diagnostics GmbH, } \\
\text { Freiburg i. Br. }\end{array}$ \\
\hline anti-K17 & murines K17 & Kaninchen; polyklonal & $1: 4000$ & $\begin{array}{l}\text { zur Verfügung gestellt von P. Coulombe, } \\
\text { Baltimore, USA }\end{array}$ \\
\hline anti-Ki-67 & humanes Ki-67 & Maus; monoklonal & $1: 50$ & BD Biosciences Pharmingen, San Diego \\
\hline anti-p53 & murines p53 & Kaninchen; polyklonal & $1: 500$ & Novocastra, Newcastle upon Tyne, UK \\
\hline anti-p63 & humanes p63 & Maus, monoklonal & $1: 100$ & Santa Cruz Biotechnology, Inc, Heidelberg \\
\hline
\end{tabular}

\subsubsection{Sekundäre Antikörper und Alkalische Phosphatase-gekoppelte Streptavidin Reagenzien}

Die für immunhistochemische Methoden verwendeten sekundären Antikörper sind in Tabelle 13 aufgelistet. Für die Detektion des biotinylierten anti-Ratte Immunglobulins wurde StreptABComplex/AP (Dako GmbH, Hamburg) verwendet.

Tabelle 13: Auflistung der verwendeten sekundären Antikörper. Spalte 1: Bezeichnung des sekundären Antikörpers; Spalte 2: Antigen; Spalte 3: Ursprungsspezies des Antikörpers; Spalte 4: Eingesetzte Antikörperverdünnung und Verdünnungsmedium; Spalte 5: Hersteller; Abkürzungen: AP, Alkalische Phosphatase; Db, Dot blot; Fab, antigenbindendes Fragment; Ig, Immunglobulin; ISH, in situ-Hybridisierung; IHC, Immunhistochemie; HRP, horseradish peroxidase (Meerrettich Peroxidase).

\begin{tabular}{|c|c|c|c|c|}
\hline 1 & 2 & 3 & 4 & 5 \\
\hline anti-Maus Ig AP-konjugiert & Maus IgG & Ziege & $\begin{array}{l}\text { IHC: } 1: 500 \text { in } 0,2 \% \text { I-Block in } \\
\text { TBS }\end{array}$ & Dako GmbH, Hamburg \\
\hline $\begin{array}{l}\text { anti-Kaninchen Ig AP- } \\
\text { konjugiert }\end{array}$ & Kaninchen IgG & Ziege & $\begin{array}{l}\text { IHC: } 1: 50 \text { in } 0,02 \% \text { I-Block in } \\
\text { TBS }\end{array}$ & Dako GmbH, Hamburg \\
\hline anti-Ratte Ig biotinyliert ${ }^{\star}$ & Ratte lgG & Kaninchen & $\begin{array}{l}\text { IHC: } 1: 50 \text { in } 0,02 \% \text { I-Block in } \\
\text { TBS }\end{array}$ & Dako GmbH, Hamburg \\
\hline $\begin{array}{l}\text { anti-Maus Ig HRP- } \\
\text { konjugiert }^{\star *}\end{array}$ & Maus & Ziege & IHC: lag als Arbeitslösung vor & Dako $\mathrm{GmbH}$, Hamburg \\
\hline $\begin{array}{l}\text { Anti-Digoxigenin Fab AP- } \\
\text { konjugiert }\end{array}$ & Digoxigenin & Schaf & $\begin{array}{l}\text { Db: 1:5000 in NT-Puffer } \\
\text { ISH: } 1: 500 \text { in } 0,02 \% \text { I-Block in } \\
\text { MBSTL }\end{array}$ & $\begin{array}{l}\text { Roche Diagnostics } \\
\text { GmbH, Mannheim }\end{array}$ \\
\hline
\end{tabular}

\subsection{Molekularbiologische Methoden}

\subsubsection{Präparative und analytische Arbeiten mit Nukleinsäuren}

\subsubsection{Isolierung von Plasmid-DNA}

\subsection{Transformation von Bakterienzellen}

Zur Transformation von Bakterienzellen wurden $50 \mu \mathrm{l}$ kompetenten Zellen (E. coli DH5a, Invitrogen $\mathrm{GmbH}$, Karlsruhe) $100 \mathrm{ng}$ reine Plasmid-DNA oder 5 bis $10 \mu$ eines Ligationsansatzes zugegeben und für 20 min auf Eis inkubiert. Die Transformation der DNA in die Bakterienzellen erfolgte durch einen Hitzeschock des Ansatzes bei $42{ }^{\circ} \mathrm{C}$ für 
45 sek. Anschließend wurde der Ansatz für 2 min auf Eis gelagert und mit $500 \mu \mathrm{S}$. O.C.-Medium aufgefüllt. Nach einer Inkubation von $1 \mathrm{~h}$ bei $37{ }^{\circ} \mathrm{C}$ unter leichtem Schwenken wurden $50 \mu \mathrm{l}$ transformierte Zellen auf Agarplatten mit entsprechendem Antibiotikum ausplattiert und die Platten über Nacht im Brutschrank bei $37^{\circ} \mathrm{C}$ inkubiert.

\subsection{Plasmidpräparation geringer DNA-Mengen}

Um geringe Mengen Plasmid-DNA zu isolieren, wurde eine 4 ml-Übernachtkultur transformierter Bakterien bei 5000xg für 2 min abzentrifugiert. Die pelletierten Bakterien wurden in $200 \mu \mathrm{l}$ Resuspensionspuffer aufgenommen und durch die Zugabe von $200 \mu \mathrm{l}$ Lysepuffer lysiert. Anschließend wurden zelluläre Proteine und genomische DNA mit $200 \mu \mathrm{l}$ Neutralisierungspuffer gefällt und bei 16000xg für $10 \mathrm{~min}$ abzentrifugiert. Zur Präzipitation der Plasmid-DNA wurde der klare Überstand in 0,7 Vol.-\% 99,5\% Isopropanol überführt und bei 16000xg für 20 min pelletiert. Das DNA-Pellet wurde in $70 \%$ Ethanol gewaschen, getrocknet und in 20-50 $\mu$ Ampuwa aufgenommen. Anschließend wurde die DNA-Konzentration mit einem Photometer bestimmt und 100 bis 200 ng DNA wurden mit Hilfe einer oder mehrerer Restriktionshydrolysen (siehe 2.15.1.1.4) analysiert.

\subsection{Plasmidpräparation großer DNA-Mengen}

Für die Isolierung großer Mengen von Plasmid-DNA wurde eine 100 ml Übernachtkultur transformierter Bakterien für $10 \mathrm{~min}$ bei 10000xg abzentrifugiert. Die Isolierung von Plasmid-DNA aus dem Bakterien-Pellet erfolgte mit Hilfe des HiPure Plasmid DNA Purification Kit (Invitrogen $\mathrm{GmbH}$, Karlsruhe) nach Angaben des Herstellers. Anschließend erfolgten die Messung der DNA-Konzentration und eine oder mehrere Restriktionshydrolysen (siehe 2.15.1.1.4) von 100 bis 200 ng aufgereinigter PlasmidDNA.

\subsection{Restriktionshydrolyse}

Die Restriktionshydrolyse von DNA wurde in einem Volumen von 10 bis $50 \mu \mathrm{l}$ durchgeführt. Pro $\mu$ g DNA erfolgte die Zugabe von 2 bis $3 U$ des jeweiligen Enzyms. Bei der simultanen Hydrolyse mit zwei unterschiedlichen Restriktionsendonukleasen wurde ein für beide Enzyme optimaler Puffer verwendet. Der Reaktionsansatz wurde für $1 \mathrm{~h}$ oder über Nacht bei einer für das Enzym optimalen Temperatur inkubiert. Anschließend 
folgten die Zugabe von 0,2 Vol.-\% Ladepuffer (siehe 2.8) und die Auftrennung der Fragmente auf einem Agarosegel.

\subsubsection{Phenol/Chloroform-Aufreinigung von Nukleinsäuren}

Die Phenol/Chloroform-Aufreinigung ermöglicht die Trennung der hydrophilen Nukleinsäuren von hydrophoben Protein- und Membranbestandteilen. Dazu wurden die Proben mit gleichem Volumen gepufferten Phenol/Chloroform (1:1) versetzt und kräftig geschüttelt. Durch Zentrifugation für $10 \mathrm{~min}$ bei 16000xg erfolgte eine Phasentrennung, wodurch die Nukleinsäuren in der oberen wässrigen Phase verblieben. Die obere Phase wurde in 1 Vol.-\% Chloroform/lsoamylalkohol (24:1) überführt und kräftig geschüttelt. Nach einer weiteren Zentrifugation für 10 min bei $16000 x g$ wurde die obere wässrige Phase in 3 Vol.-\% 96 \% Ethanol überführt und abzentrifugiert. Das DNA-Pellet wurde mit $70 \%$ Ethanol gewaschen, getrocknet und in Ampuwa aufgenommen.

\subsubsection{Isolierung von genomischer DNA}

\subsection{Isolierung von genomischer DNA aus eukaryontischen Zellen}

Die Zellen wurden mit PBS gewaschen und pro Loch einer 6-Loch-Platte in $1 \mathrm{ml}$ STEPuffer mit $50 \mu \mathrm{l}$ Proteinase K (10 mg/ml) aufgenommen. Die abgelösten Zellen wurden in ein $2 \mathrm{ml}$ Reaktionsgefäß überführt und über Nacht bei $37^{\circ} \mathrm{C}$ inkubiert. Zur Präzipitation der DNA wurde $1 \mathrm{ml}$ 99,5 \% Isopropanol zugefügt und die DNA durch Zentrifugation bei 16000xg für 30 min pelletiert. Das DNA-Pellet wurde mit $70 \%$ Ethanol gewaschen, getrocknet und in Ampuwa aufgenommen. Mit einem Photometer erfolgte die Bestimmung der DNA-Konzentration. Für die PCR wurden 10 bis 100 ng DNA als Matrize eingesetzt.

\subsection{Isolierung von genomischer DNA aus Gewebe für Genotypisierungen} Gewebeproben wurden über Nacht bei $55^{\circ} \mathrm{C}$ in $250 \mu \mathrm{l}$ STE-Puffer mit $12,5 \mu \mathrm{l}$ Proteinase K $(10 \mathrm{mg} / \mathrm{ml})$ inkubiert. Feste Bestandteile wurden abzentrifugiert und der klare Überstand in 3 Vol.-\% 99 \% Ethanol überführt. Zur Präzipitation der DNA wurden die Reaktionsgefäße kräftig geschüttelt und für 10 min bei $16000 x g$ zentrifugiert. Das DNA-Pellet wurde mit $70 \%$ Ethanol gewaschen, getrocknet und in Ampuwa aufgenommen. Die Bestimmung der DNA-Konzentration erfolgte am Photometer. 


\subsection{Isolierung von genomischer DNA aus Gewebe für Southern Blot- Analysen}

Gewebeproben wurden über Nacht bei $55^{\circ} \mathrm{C}$ in $500 \mu \mathrm{l}$ STE-Puffer mit $25 \mu$ l Proteinase K (10 $\mathrm{mg} / \mathrm{ml}$ ) inkubiert. Zur Isolierung hochreiner genomischer DNA folgte eine Phenol/Chloroform-Aufreinigung.

\subsubsection{Isolierung von Gesamt-RNA}

\subsection{Isolierung von Gesamt-RNA aus eukaryontischer Zellkultur}

Für die Isolierung von Gesamt-RNA aus Zellen wurden die Zellen mit PBS gewaschen und anschließend durch die Zugabe von $1 \mathrm{ml}$ TriFast Reagent lysiert. Das Lysat wurden in ein steriles $2 \mathrm{ml}$ Reaktionsgefäß überführt und 60 sek homogenisiert (Vortexer). Nach einer Inkubation von 5 min bei Raumtemperatur wurden $200 \mu$ l Chloroform zugegeben, der Ansatz kräftig gemischt (Vortexer) und nochmals für 3 min bei Raumtemperatur inkubiert. Die Phasentrennung erfolgte bei $4000 x g$ für 40 min bei $4{ }^{\circ} \mathrm{C}$. Die obere wässrige Phase wurde in ein neues Gefäß mit $1 \mathrm{ml}$ 99,5 \% Isopropanol überführt und die RNA durch eine Inkubation des Ansatzes bei $-20{ }^{\circ} \mathrm{C}$ für $10 \mathrm{~min}$ bis über Nacht präzipitiert. Danach wurde die RNA bei 16000xg für 35 min abzentrifugiert und das RNAPellet mit $70 \%$ Ethanol gewaschen, getrocknet und in $20 \mu \mathrm{l}$ RNase-freiem destilliertem Wasser aufgenommen. Die RNA-Konzentration wurde am Photometer bestimmt.

\subsection{Isolierung von Gesamt-RNA aus Gewebe}

Für die Isolierung von Gesamt-RNA aus Gewebe mit TriFast (Peqlab, Erlangen) wurde die Gewebeprobe mit einem Skalpell zerkleinert und in TriFast überführt. Anschließend wurde das Gewebe für 60 sek auf Eis mit einem Homogenisator homogenisiert, für 5 min bei Raumtemperatur inkubiert und mit $400 \mu$ l Chloroform versetzt. Die folgenden Schritte sind unter 2.15.1.4.1 beschrieben. Für die Isolierung von RNA für Mikroarray-Analysen wurde anschließend eine zusätzliche Aufreinigung mit dem Rneasy Kit (Qiagen, Hilden) nach Herstellerangeben durchgeführt.

RNA aus Hautproben zur Durchführung von qRT-PCR wurde mit Hilfe des RNeasy Fibrous Tissue Kit (Qiagen, Hilden) nach Herstellerangaben isoliert. Anschließend folgte eine zusätzliche Behandlung mit der in diesem Kit enthaltenen DNase I und dem zugehörigen Puffer (RDD-Puffer). Dazu wurden $20 \mu \mathrm{l}$ Eluat mit $10 \%$ (v/v) RDD-Puffer und 2,7 U DNase I versetzt, für $1 \mathrm{~h}$ bei $37^{\circ} \mathrm{C}$ und danach für $15 \mathrm{~min}$ bei $75^{\circ} \mathrm{C}$ inkubiert. 
Die RNA wurde mit $99 \%$ Ethanol über Nacht bei $-20{ }^{\circ} \mathrm{C}$ gefällt, bei $16000 x g$ für 35 min abzentrifugiert und mit $70 \%$ Ethanol gewaschen. Das Pellet wurde in $20 \mu \mathrm{l}$ RNasefreiem destilliertem Wasser aufgenommen und die RNA-Konzentration am Photometer bestimmt.

\subsubsection{Konzentrationsbestimmung von Nukleinsäuren}

Die Konzentrationbestimmung von Nukleinsäuren erfolgte durch Messung der optischen Dichte (OD) bei $260 \mathrm{~nm}$ mit Hilfe eines Spektralphotometers. Anhand der folgenden Formel wurde die Konzentration berechnet.

$$
c=O D_{260} \cdot f \cdot C
$$

Formel zur Berechnung von Nukleinsäure-Konzentrationen. Abkürzungen: $c$ gemessene Konzentration in $\mu \mathrm{g} / \mu \mathrm{l} ; f$, Verdünnungsfaktor; $C$, nukleinsäurespezifischer Koeffizient $(0,05 \mu \mathrm{g} / \mu \mathrm{l}$ für DNA; $0,04 \mu \mathrm{g} / \mu \mathrm{l}$ für RNA).

Zur Bestimmung der Reinheit von Nukleinsäurelösungen wurden außerdem die OD bei $230 \mathrm{~nm}$ und $280 \mathrm{~nm}$ gemessen. Protein- und Salzkontaminationen können durch die Bildung der Quotienten von $\mathrm{OD}_{260 / 280}$ und $\mathrm{OD}_{260 / 230}$ ermittelt werden. Im Folgenden sind diese Quotienten für reine Nukleinsäurelösungen angegeben:

$$
\begin{aligned}
& \mathrm{OD}_{260 / 280}(\mathrm{DNA})>1,8 \\
& \mathrm{OD}_{260 / 230}(\mathrm{DNA})=2 \\
& \mathrm{OD}_{260 / 280}(\mathrm{RNA})>2 \\
& \mathrm{OD}_{260 / 230}(\mathrm{RNA})=2
\end{aligned}
$$

\subsubsection{Polymerase-Kettenreaktion (PCR)}

Die Amplifikation von DNA in Reaktionsvolumina von $10 \mu \mathrm{l}$ bis $20 \mu \mathrm{l}$ pro Ansatz wurde mit folgenden Reagenzien und Endkonzentrationen durchgeführt:

$\begin{array}{ll}10-100 \mathrm{ng} & \text { Matrizen-DNA } \\ 0,5 \mu \mathrm{M} & \text { sequenzspezifisches Vorwärts-DNA-Oligonukleotid } \\ 0,5 \mu \mathrm{M} & \text { sequenzspezifisches Rückwärts-DNA-Oligonukleotid } \\ 0,2 \mathrm{mM} & \text { dNTP-Mix } \\ 1 \%(\mathrm{v} / \mathrm{v}) & \text { N.N.-Dimethylsulfoxid (DMSO) } \\ 10 \%(\mathrm{v} / \mathrm{v}) & \text { Cresol } \\ 1 \mathrm{x} & \text { Polymerase-Puffer } \\ 0,1 \mathrm{U} & \text { Polymerase }\end{array}$

Die PCR-Bedingungen variierten abhängig von den verwendeten DNA-Oligonukleotiden. Dem ersten Denaturierungsschritt für 5 bis 10 min bei $95{ }^{\circ} \mathrm{C}$ folgten 25 bis 35 Zyklen 
bestehend aus je einem Denaturierungsschritt ( $95^{\circ} \mathrm{C}$ für 30 bis 60 sek), je einem DNAOligonukleotid-Anlagerungsschritt bei 55 bis $68{ }^{\circ} \mathrm{C}$ (30 sek bis 2 min) und je einem Elongationsschritt bei 68 oder $72{ }^{\circ} \mathrm{C}$ (1 bis $2 \mathrm{~min}$ ). Zu Programmende erfolgte ein Elongationsschritt für $10 \mathrm{~min}$ bei $72{ }^{\circ} \mathrm{C}$. Mittels Agarosegelelektrophorese wurde der gesamte Ansatz analysiert.

\subsection{Polymerase-Kettenreaktion an cDNA}

\subsection{Reverse Transkription}

Die reverse Transkription von RNA in cDNA erfolgte in einem Endvolumen von $20 \mu \mathrm{l}$. Zwischen 1 und $4 \mu \mathrm{g}$ RNA wurden mit $250 \mathrm{ng}$ Hexameren versetzt und für $10 \mathrm{~min}$ bei $70{ }^{\circ} \mathrm{C}$ inkubiert. Nach Zugabe von 5x First Strand Buffer Mix (Endkonzentration 1x), 100 mM DTT (Endkonzentration $10 \mathrm{mM}$ ) und dNTPs (Endkonzentration 0,5 mM) erfolgten 10 min Inkubation bei $25{ }^{\circ} \mathrm{C}$ und $2 \mathrm{~min}$ bei $42{ }^{\circ} \mathrm{C}$. Den cDNA-Proben wurde jeweils $1 \mu \mathrm{l}$ reverse Transkriptase SuperScript II zugefügt $(200 \mathrm{U} / \mu \mathrm{l})$, die reverse Transkription erfolgte für $60 \mathrm{~min}$ bei $42^{\circ} \mathrm{C}$. Anschließend wurde die Reaktion durch eine Inkubation bei $70{ }^{\circ} \mathrm{C}$ für 10 min abgestoppt. Zur ungefähren Kalkulation der cDNA-Konzentration wurde angenommen, dass die Effizienz der reversen Transkription von RNA bei ca. 50 \% liegt.

\subsubsection{2 qRT-PCR}

Um Expressionsniveaus eines Gens an cDNA oder die Effizienz nach Cre-Rekombinasevermittelter Rekombination von gDNA in unterschiedlichen Proben vergleichen zu können, erfolgte eine relative Quantifizierung mittels quantitativer real-time PCR. Sowohl TaqMan-Analysen mit fluoreszenzmarkierten, sequenzspezifischen Sonden als auch die qRT-PCR mit SYBR Green wurden durchgeführt. Da die ermittelten Daten anhand der Standardkurvenmethode errechnet wurden, musste für jede Messung eine entsprechende Standardkurve mit cDNA oder gDNA als Matrize erstellt werden. Für die Erstellung sämtlicher Standardkurven wurde jeweils eine serielle 1:5 Verdünnungsreihe hergestellt und die einzelnen Verdünnungsstufen (S1-S6) amplifiziert. Zur Normalisierung wurde ein geeignetes endogenes Kontrollgen vermessen. Für sämtliche im Folgenden beschrieben qRT-PCR-Analysen wurde das ABI Prism 7900HT Sequence Detection System verwendet. 


\subsection{Durchführung und Aufbau der TaqMan-Analyse zur Quantifizie- rung der Rekombinationseffizienz nach Aktivierung der Cre-Re- kombinase}

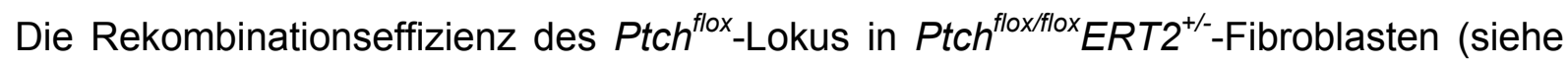
2.10.2) nach Aktivierung der Cre-Rekombinase durch Tamoxifen wurde anhand einer TaqMan-Analyse bestimmt. Dazu wurde jede gDNA-Probe in drei Replikaten je Lauf in einem Reaktionsvolumen von $10 \mu \mathrm{l}$ in PCR-384-Loch-Platten (TaqMan-Platten, Applied Biosystems, Darmstadt) vermessen.

Für die Assays zur Quantifizierung und zum Nachweis der Ptch flox - und Ptch ${ }^{\text {del-Allele und }}$ des Gens Pelota (zur Erstellung der Standardkurve) wurden dieselben PCR-Konditionen eingesetzt. Nach der Aktivierung der DNA-Polymerase für $10 \mathrm{~min}$ bei $95{ }^{\circ} \mathrm{C}$ folgten 40 Zyklen, jeweils bestehend aus einer Denaturierung bei $95^{\circ} \mathrm{C}$ für 15 sek und einem 60 sek langen Anlagerungs-/Elongationsschritt bei $60^{\circ} \mathrm{C}$.

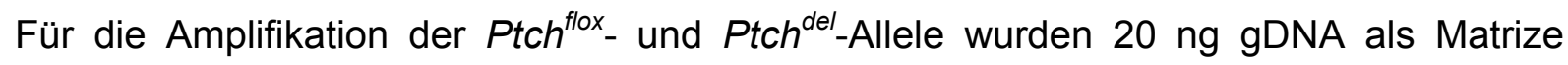
eingesetzt. Dazu wurde das QuantiTect PCR Probe Kit nach Herstellerangaben und die unter 2.11.5.2 angegebenen Oligonukleotide und fluoreszenzmarkierten Sonden verwendet.

Zur Normalisierung wurde für jede gDNA-Probe das Haushaltsgen Pelota in drei Replikaten pro Lauf vermessen. Als Matrize diente für jede Probe 20 ng gDNA. Für die Erstellung einer Standardkurve bei der Analyse von Pelota erfolgte die Amplifikation der Verdünnungsstufen S1-S6, wobei als S1 200 ng gDNA einer Schwanzbiopsie eingesetzt wurden. Dabei wurde das QuantiTect PCR Probe Kit (Qiagen, Hilden) nach Herstellerangaben und die unter 2.11.5.2 angegebenen Oligonukleotide und Sonden verwendet.

\subsection{Durchführung und Aufbau der gebrauchsfertigen TaqMan Assays}

Anhand von TaqMan-Analysen wurde das Expressionsniveau mehrerer Zielgene (siehe 2.12) an cDNA aus dem Skelettmuskel von B6- oder BALB-Mäusen bestimmt. Die Bestimmung des Expressionsniveaus jedes Gens erfolgte für jede cDNA-Probe in einem Reaktionsvolumen von $20 \mu \mathrm{l}$ in PCR-96-Loch-Platten (TaqMan-Platten, Applied Biosystems, Darmstadt) in zwei Replikaten je Lauf. Für die Amplifikation des Zielgens wurden je nach dem Expressionsniveau des Gens in Skelettmuskel 20 bis 200 ng cDNA als Matrize eingesetzt. Die in Tabelle 10 genannten Gen-Expressions Assays und das Reaktionssystem QuantiTect PCR Probe Kit wurden nach Herstellerangaben verwendet. Für die Erstellung einer Standardkurve bei der Messung jedes Gens wurden die im Folgenden genannten Verdünnungsstufen S1 und Matrizen verwendet. 


\begin{tabular}{llc}
\multicolumn{1}{c}{ analysiertes Gentranskript } & Matrize für S1 Verdünnungsstufe & eingesetzte Menge für S1 \\
\hline Apoptosis inhibitor 5 & Nieren-cDNA (murin) & $100 \mathrm{ng}$ \\
Catenin src & Nieren-cDNA (murin) & $100 \mathrm{ng}$ \\
Ets homologous factor & Nieren-cDNA (murin) & $20 \mathrm{ng}$ \\
Midkine & E9,5-cDNA (murin) & $200 \mathrm{ng}$ \\
Protein tyrosine phosphatase, receptor type, J & Nieren-cDNA (murin) & $100 \mathrm{ng}$ \\
Tnf receptor-associated factor 6 & Nieren-cDNA (murin) & $100 \mathrm{ng}$ \\
Wilms tumor homolog & Nieren-cDNA (murin) & $100 \mathrm{ng}$ \\
ADP-ribosylation factor GTPase activating protein 2 & Nieren-cDNA (murin) & $100 \mathrm{ng}$ \\
\hline
\end{tabular}

Die PCR-Konditionen sind unter 2.15.1.6.2.1 angegeben. Zur Normalisierung wurde für jede cDNA-Probe das Haushaltsgen $18 S$ rRNA in zwei Replikaten pro Lauf vermessen, dabei dienten jeweils 3,2 pg als Matrize. Als Standard wurde murine Nieren-cDNA in S1-S6 Verdünnungsstufen amplifiziert, wobei für die $S 1$ Verdünnungsstufe $32 \mathrm{pg}$ verwendet wurden. Das gebrauchsfertige Reaktionssystem TaqMan Ribosomal RNA Control Reagent, VIC Probe (Applied Biosytsems, Darmstadt) wurde nach Herstellerangaben verwendet, die PCR-Konditionen sind unter 2.15.1.6.2.1 genannt.

\subsection{Durchführung und Aufbau der qRT-PCR mit SYBR Green}

Die qRT-PCR mit SYBR Green diente der Bestimmung des Expressionsniveaus verschiedener Gene in Experimenten mit Fibroblasten oder in Gewebeproben von Mäusen. Dazu erfolgte die Messung des jeweiligen Gens in einem Reaktionsvolumen von $10 \mu \mathrm{l}$ in PCR-384-Loch-Platten (TaqMan-Platten, Applied Biosystems, Darmstadt) in drei Replikaten für jede cDNA-Probe. Als Matrize wurden für die Amplifikation des Zielgens bei Zellkulturexperimenten $5 \mathrm{ng}$ cDNA und bei Gewebeproben $50 \mathrm{ng}$ cDNA eingesetzt. In Tabelle 7 sind die jeweils verwendeten Oligonukleotide und Temperaturen für den Anlagerungsschritt angegeben.

Für die Erstellung einer Standardkurve für jede Analyse wurden die folgenden Verdünnungsstufen und Matrizen verwendet: 


\begin{tabular}{lll}
$\begin{array}{l}\text { analysiertes } \\
\text { Gentranskript }\end{array}$ & Matrize für S1 Verdünnungsstufe & $\begin{array}{l}\text { eingesetzte Menge } \\
\text { für S1 }\end{array}$ \\
\hline Gli1 & murine embryonale cDNA 12,5 Tage nach der Befruchtung & $40 \mathrm{ng}$ \\
Gli2 & murine embryonale cDNA 12,5 Tage nach der Befruchtung & $40 \mathrm{ng}$ \\
Gli3 & murine embryonale cDNA 12,5 Tage nach der Befruchtung & $40 \mathrm{ng}$ \\
K10 & murine Basalzellkarzinom-cDNA & $10 \mathrm{ng}$ \\
Ptch & murine embryonale cDNA 12,5 Tage nach der Befruchtung & $40 \mathrm{ng}$ \\
wt Ptch & murine embryonale cDNA 12,5 Tage nach der Befruchtung & $40 \mathrm{ng}$ \\
Ptch ${ }^{\text {del }}$ & RMS einer Ptch ${ }^{\text {del/ }}$ Maus & $40 \mathrm{ng}$ \\
\hline
\end{tabular}

Das Reaktionssystem QuantiTect SYBR Green PCR wurde nach Herstellerangaben verwendet. Zunächst wurde die DNA-Polymerase für $15 \mathrm{~min}$ bei $95{ }^{\circ} \mathrm{C}$ aktiviert, anschließend folgten 40 Zyklen bestehend aus einer 15 sek langen Denaturierung, einem Anlagerungsschritt bei $58^{\circ} \mathrm{C}$ oder $60{ }^{\circ} \mathrm{C}$ für 30 sek und einem Elongationsschritt bei $72{ }^{\circ} \mathrm{C}$ für 30 sek.

Für die Normalisierung des Expressionsniveaus von Genen wurde die Expression von $18 S$ rRNA jeder untersuchten cDNA-Probe in drei Replikaten pro Lauf gemessen. Dabei wurden jeweils 3,3 bis 6,3 pg cDNA (je nach Assay) als Matrize eingesetzt. Als Standard diente murine embryonale cDNA 12,5 Tage nach der Befruchtung mit 250 pg als Verdünnungsstufe S1. Dazu wurden die in Tabelle 7 genannten sequenzspezifischen DNA-Oligonukleotide und das Reaktionssystem QuantiTect SYBR Green PCR (Qiagen, Hilden) nach Herstellerangaben benutzt. Die PCR-Konditionen sind unter 2.15.1.6.2.3 genannt, wobei der Anlagerungsschritt bei $60{ }^{\circ} \mathrm{C}$ erfolgte.

\subsection{Auswertung nach der Standardkurvenmethode}

Die Auswertung der qRT-PCR erfolgte mit den Pogrammen SDS2.1 (Applied Biosystems, Darmstadt) und Microsoft EXCEL (Microsoft Co., Redmond, USA). Die Standardkurve wurde durch eine serielle 1:5 Verdünnung hergestellt. Durch die 5-fache Verdünnung wird der Schwellenwert, bei dem sich das Fluoreszenzsignal vom Reaktionshintergrund abhebt, jeweils 2,3 Zyklen später erreicht. Eine Standardkurve wurde anhand der Auftragung des Logarithmus der jeweils eingesetzten cDNA-Mengen gegen den Schnittpunkt der Amplifikationskurve mit dem Schwellenwert (Ct-Wert) erstellt. Der Schnittpunkt mit der Amplifikationskurve musste in der exponentiellen Phase des Reaktionsverlaufes liegen. Dabei folgte die resultierende Standardkurve der Gleichung $y=m x+b$. Anhand dieser Gleichung wurde die Produktmenge jeder Probe ermittelt. Für eine relative Quantifizierung der Proben untereinander wurden die Proben auf die endogene Kontrolle normalisiert, d. h. auf das Gen Pelota oder die Expression von $18 S$ rRNA. So wurden unterschiedliche Ausgangsmengen der Matrize zwischen 
verschiedenen Proben ausgeglichen. Für jede Probe erfolgte die Normalisierung durch die Bildung des Quotienten der Produktmengen Zielgen/endogene Kontrolle. Danach wurde die Probe mit dem niedrigsten Quotienten als sogenannter Kalibrator definiert und gleich 1 gesetzt.

\subsubsection{Agarosegelelektrophorese}

Die Agarosegelelektrophorese diente der Auftrennung von DNA-Fragmenten. Abhängig von der Größe der DNA-Fragmente wurden Gele von 0,7 bis $4 \%(\mathrm{w} / \mathrm{v})$ Agaroseanteil in TBE mit $0,2 \mu \mathrm{g} / \mathrm{ml}$ Ethidiumbromid verwendet. Falls die Proben keine Cresollösung (siehe 2.8) enthielten, wurde innen vor dem Beladen des Gels 0,2 Vol.-\% Ladepuffer zugefügt. Die Auftrennung der Fragmente in einer mit TBE gefülten Gelelektrophoresekammer erfolgte bei einer konstanten Spannung von 30 bis $100 \mathrm{~V}$. Ein UV-Transilluminator (Intas, Göttingen) wurde für die Dokumentation verwendet. Durch das gleichzeitige Mitführen eines DNA Längenstandards konnten die Größen und durch vergleichendes Abschätzen mit dem Standard die Konzentration der DNA-Fragmente ermittelt werden.

\subsubsection{Southern Blot-Analyse zur Detektion der homologen Rekombination des Vektors pPtch flox}

$10 \mu \mathrm{g}$ genomische DNA wurden bei $37^{\circ} \mathrm{C}$ mit einer entsprechenden Restriktionsendonuklease über Nacht inkubiert. Nach Zugabe von 0,2 Vol.-\% Ladepuffer wurden die DNA-Fragmente über Nacht bei $60-80 \mathrm{~V}$ in einem 1 bis $1,5 \%$ Agarosegel aufgetrennt. Nach Dokumentation des Gels neben einem Lineal unter UV-Licht wurde das Gel für 30 min in einer 0,25 N HCl-Lösung geschwenkt. Anschließend wurde es kurz mit MilliQ Wasser gespült, für 30 min in Denaturierungspuffer inkubiert und erneut in MilliQ Wasser geschwenkt. Danach wurde das Gel für 15 min in 20x SSC $(\mathrm{pH} 7,0)$ inkubiert. Eine auf Gelgröße zurechtgeschnittene Nitrozellulosemembran wurde in 20x SSC (pH 7,0) äquilibriert, luftblasenfrei auf das Gel gelegt und nach Herstellerangaben in ein Blotsystem (Whatman Inc., New Jersey, USA) eingebaut. Der Transfer der DNA auf die Membran erfolgte über Nacht bei Raumtemperatur. Am nächsten Tag wurde die Membran getrocknet und die DNA bei $100 \mathrm{~mJ} / \mathrm{cm}^{2} \mathrm{im} \mathrm{UV-}$ Crosslinker kovalent auf der Membran gebunden. Zusätzlich wurde die Membran bei $80^{\circ} \mathrm{C}$ für $2 \mathrm{~h}$ im Hybridisierungsofen gebacken. Die Vorhybridisierung erfolgte in einer Hybridisierungsröhre bei $65^{\circ} \mathrm{C}$ im Hybridisierungsofen für $2 \mathrm{~h}$ mit $5 \mathrm{ml}$ Rapid-Hyb Puffer 
und $200 \mu \mathrm{g} / \mathrm{ml}$ denaturierter Lachsspermien-DNA (Stratagene, Amsterdam Zuidoost, Niederlande).

Der Hybridisierungslokus der verwendeten Sonde ist in Abbildung 10 dargestellt. Die $1,2 \mathrm{~kb}$ Sonde wurde durch Restriktionshydrolyse des Plasmids pGEM-TKO\#13 mit EcoRI hergestellt. Das 1,2 kb DNA-Fragment wurde durch zweifache Agarosegelelution aufgereinigt und durch Agarosegelelektrophorese quantifiziert. 25 bis $50 \mathrm{ng}$ der Hybridisierungssonde wurde mit dem Prime-It RmT Random Primer Labeling Kit durch den Einbau von alpha ${ }^{32} \mathrm{P}$-dCTP nach Herstellerangaben radioaktiv markiert. Danach wurde die radioaktiv markierte Sonde nach Herstellerangaben mit MicroSpin G-50 Säulchen aufgereinigt. Die aufgereinigte Sonden-DNA wurde 5 min bei $99^{\circ} \mathrm{C}$ denaturiert und bis zur Verwendung auf Eis gelagert.

Nach dem Abgießen der Vorhybridsierungslösung aus der Hybridisierungsröhre wurden erneut $5 \mathrm{ml}$ Rapid-Hyb Buffer mit $200 \mu \mathrm{g} / \mathrm{ml}$ denaturierter Lachsspermien-DNA zugegeben. Die radioaktiv-markierte, denaturierte Sonden-DNA wurde in die Hybridisierungslösung pipettiert und die Membran über Nacht bei $65^{\circ} \mathrm{C}$ hybridisiert. Am nächsten Tag wurde die Hybridisierungslösung abgekippt und die Membran bei $65^{\circ} \mathrm{C}$ zunächst mit hoch- und anschließend ggfs. mehrmals mit niedrig-stringentem Waschpuffer für 20 min gewaschen, bis die Restaktivität der Membran $5 \mathrm{~Bq} / \mathrm{cm}^{2}$ nicht überstieg. Danach wurde die Membran in MilliQ Wasser geschwenkt, auf Filterpapier getrocknet, in Klarsichtfolie eingeschweißt und in eine Filmkassette überführt. Ein Autoradiographie-Film wurde bei $-80{ }^{\circ} \mathrm{C}$ für 2-3 Tage auf der Membran inkubiert und anschließend entwickelt.

\subsubsection{DNA-Sequenzanalyse}

DNA-Sequenzanalysen wurden sowohl mit aufgereinigten PCR-Produkten als auch mit PCR-Produkten durchgeführt, die in das Plasmid pGEM-Teasy kloniert wurden (siehe 2.15.1.9.2). Die Sequenzierung von DNA-Proben erfolgte mit dem BigDye Terminator v1.1 Cycle Sequencing Kit nach Herstellerangaben. Anschließend wurden die Proben mit Sephadexg50 in einer MAHV N45-Platte aufgereinigt. Zur Durchführung der Sequenzalanysen wurden der ABI 3100 Genetic Analyser und das zugehörige Programm (ABI 3100 Genetic Analyser Data Collection 1.0, Applied Biosystems, Darmstadt) benutzt. Die Auswertung erfolgte mit dem Programm Sequencher (Applied Biosystems, Darmstadt). 


\subsection{Isolierung und Aufreinigung von DNA-Fragmenten aus Agarosegelen}

Aufzureinigende DNA-Fragmente wurden mit einem Skalpell unter UV-Licht aus dem Agarosegel geschnitten. Für die Aufreinigung wurde das Reaktionssystem Perfectprep Gel Cleanup (Eppendorf, Hamburg) nach Herstellerangaben verwendet.

\subsection{Klonierung von PCR-Produkten}

Die Klonierung von PCR-Produkten erfolgte mit Hilfe des pGEM-Teasy TA-Cloning Kits (Promega, Mannheim) nach Angaben des Herstellers. Die Inkubation der Ligationsansätze erfolgte bei $4{ }^{\circ} \mathrm{C}$ über Nacht.

\subsubsection{Mikroarray-Analyse}

Mikroarray-Analysen wurden zur Untersuchung des Expressionsprofils von murinen Tumoren (RMS) eingesetzt. RNA wurde wie unter 2.15.1.4.2 beschrieben isoliert. Für die Markierungsreaktion zur Herstellung von Biotin-markierter cRNA wurde das Reaktionssystem One-Cycle Target Labeling and Control Reagents (Affymetrix, High Wycombe, UK) nach Herstellerangaben verwendet. Mit Hilfe des Agilent 2100 Bioanalyzers (Agilent Technologies, Waldbronn) wurden die RNA-Extrakte auf Integrität überprüft und quantifiziert. Dazu wurde das RNA 6000 Nano Assay Kit (Agilent Technologies, Waldbronn) wie vom Hersteller beschrieben benutzt. Die Durchführung der Mikroarray-Analyse mit Affymetrix 430A Mouse Gene Chips (Affymetrix, High Wycombe, UK) erfolgte durch das Deutsche Ressourcenzentrum für Genomforschung (RZPD GmbH, Berlin).

\subsubsection{Histologische Techniken}

\subsubsection{Einbettung von Geweben}

Für die Anfertigung von Kryoschnitten wurde das Gewebematerial in Cryoblock Einbettmedium auf Trockeneis eingebettet. Am Kryostat wurden Gewebeschnitte von 5 bis $10 \mu \mathrm{m}$ Dicke angefertigt, auf Objektträger aufgezogen und bei Raumtemperatur getrocknet.

Für die Herstellung von Paraffinschnitten wurden die zu analysierende Gewebe routinemäßig für zwei Wochen bei $4{ }^{\circ} \mathrm{C}$ in Paraformaldehyd fixiert. Vor der Paraffineinbettung wurden die Gewebe und Organe mit Hilfe eines Gewebeeinbett- und 
-entwässerungsautomaten entwässert und anschließend manuell in Paraffin eingegossen (Paraffinspender und Ausgießstation Tissue Block Dispenser PAG 12). Paraffinschnitte von ca. $3 \mu \mathrm{m}$ Dicke wurden am Schlittenmikrotom angefertigt und auf Superfrost Objektträger aufgezogen. Für HE-Färbungen wurden die Paraffinschnitte für 20 min bei $80{ }^{\circ} \mathrm{C}$ inkubiert, für immunhistologische Antikörperfärbungen und in situ-Hybridisierungen über Nacht bei $37^{\circ} \mathrm{C}$ getrocknet.

\subsubsection{Hämatoxylin/Eosin-Färbung}

Vor einer Hämatoxylin/Eosin (HE)-Färbung wurden Paraffinschnitte 2x 10 min in Xylol entparaffiniert und anschließend in einer absteigenden Ethanol-Reihe rehydriert. Getrocknete Kryoschnitte konnten ohne zusätzliche Vorbehandlung verwendet werden. Die Objektträger wurden 8 min in Hämatoxylin-Lösung inkubiert und 5 min in warmem Leitungswasser gebläut. Danach wurden die Schnitte $5 \mathrm{~min}$ in Eosin-Lösung inkubiert und in einer aufsteigenden Ethanol-Reihe dehydriert. Anschließend wurden die Präparate in Xylol überführt und mit Pertex Montagemedium eingedeckt.

\subsubsection{X-Gal-Färbung an Kryoschnitten}

Die Gewebeschnitte wurden zunächst in 0,2 \% Glutaraldehyd /PBS für 10 min auf Eis gelagert und anschließend 3x 10 min in LacZ-Puffer inkubiert. Die Farbreaktion erfolgte in LacZ-Färbepuffer über Nacht bei $30^{\circ} \mathrm{C}$. Danach wurden die Präparate mit einem DAPI-haltigen (4'6-Diamino-2-phenylindiol) Montagemedium (Vector Laboratories, Inc., Burlingame, USA) oder Immuno Mount (Shandon Thermo Electron Corporation, Waltham, USA) eingedeckt.

\subsubsection{Immunhistologische Antikörperfärbungen}

Zur Entparaffinierung wurden die Gewebeschnitte für 2x $10 \mathrm{~min}$ in Xylol gestellt und anschließend in einer absteigenden Alkoholreihe rehydriert. Die Demaskierung der Antigene erfolgte durch unterschiedliche Vorbehandlungen, jeweils abhängig vom verwendeten Primärantikörper, siehe Tabelle 14. Danach wurden die Gewebeschnitte in TBS oder TBS/0,1 \% Triton X-100 gespült und unspezifische Bindungsstellen mit 0,2\% I-Block/PBS für 15 min blockiert. Der Primärantikörper wurde für 90 min auf die Gewebeschnitte gegeben, das jeweilige Verdünnungsmedium ist Tabelle $14 \mathrm{zu}$ entnehmen. Anschließend wurden die Schnitte mit TBS oder TBS/0,1 \% Triton X-100 gut gespült und der Sekundär-Antikörper für $60 \mathrm{~min}$ auf den Schnitten inkubiert. Alle 
sekundären Antikörper waren AP-konjugiert und wurden mit Neu-Fuchsin Chromogen nachgewiesen. Nur für die Detektion des Ki-67-Primärantikörpers wurden Reagenzien des En Vision+ System-HRP (DAB) Reaktionssystems (Dako GmbH, Hamburg) verwendet.

Um Kreuzreaktionen des sekundären Antikörpers beim Gebrauch von Primärantikörpern aus der Ratte auszuschließen, wurde der Sekundärantikörper vor der Verwendung für $2 \mathrm{~h}$ mit Mausserum (siehe 2.15.4.1.3) in einer Verdünnung von $1: 100$ bei $4{ }^{\circ} \mathrm{C}$ präabsorbiert.

Nach gründlichem Spülen der Schnitte in TBS oder TBS/0,1\% Triton X-100 erfolgte die Farbreaktion für 10 bis $30 \mathrm{~min}$ in Neu-Fuchsin Chromogen. Anschließend wurden die Gewebeschnitte in $\mathrm{H}_{2} \mathrm{O}$ überführt, kurz mit Hämalaun gegengefärbt und mit Immuno Mount eingedeckt.

Tabelle 14: Auflistung der Vorbehandlung der Gewebsschnitte und verwendete Puffer für Primärantikörper. Spalte 1: Bezeichnung des Antigens; Spalte 2: Antigendemaskierung; Spalte 3: Puffer für den Primärantikörper

\begin{tabular}{|c|c|c|c|c|}
\hline 1 & 2 & & & 3 \\
\hline$\beta$-Catenin & TE-Puffer & $\mathrm{pH} 9,0$ & $16 \min 100^{\circ} \mathrm{C}$ & $0,02 \%$ I-Block in TBS \\
\hline B220 & Citratpuffer & $\mathrm{pH} 6,0$ & $16 \min 100^{\circ} \mathrm{C}$ & TBS \\
\hline $\mathrm{Bcl}-2$ & $0,2 \mathrm{M}$ Borsäure & $\mathrm{pH} 5,1$ & $30 \min 58^{\circ} \mathrm{C}$ & $0,02 \%$ I-Block in TBS \\
\hline Caspase 3 & Citratpuffer & $\mathrm{pH} 6,0$ & $16 \min 100^{\circ} \mathrm{C}$ & $0,02 \%$ I-Block in TBS \\
\hline CD3 & Citratpuffer & $\mathrm{pH} 6,0$ & $16 \min 100^{\circ} \mathrm{C}$ & TBS \\
\hline $\mathrm{F} 4 / 80$ & entfällt & & & $0,02 \%$ I-Block in TBS \\
\hline Gli1 & 0,2 M Borsäure & $\mathrm{pH} 5,1$ & $30 \min 58^{\circ} \mathrm{C}$ & $0,02 \%$ I-Block in TBS \\
\hline $\mathrm{K} 1$ & $0,2 \mathrm{M}$ Borsäure & $\mathrm{pH} 5,1$ & $30 \min 58^{\circ} \mathrm{C}$ & $0,02 \%$ I-Block in TBS \\
\hline $\mathrm{K} 10$ & 4,9 U/ml Alkaline Protease & & $10 \min 37^{\circ} \mathrm{C}$ & $0,2 \%$ I-Block in TBS \\
\hline K17 & Citratpuffer & $\mathrm{pH} 3,0$ & $30 \min 37^{\circ} \mathrm{C}$ & $0,1 \%$ I-Block in TBS \\
\hline Ki-67 & Citratpuffer & $\mathrm{pH} 6,0$ & $16 \min 100^{\circ} \mathrm{C}$ & TBS \\
\hline p53 & TE-Puffer & $\mathrm{pH} 9,0$ & $16 \min 100^{\circ} \mathrm{C}$ & PBS \\
\hline p63 & Citratpuffer & $\mathrm{pH} 6,0$ & $16 \min 100^{\circ} \mathrm{C}$ & $0,02 \%$ I-Block in TBS \\
\hline
\end{tabular}

\subsubsection{In situ-Hybridisierung}

Zum Nachweis von mRNA-Transkripten in Gewebeschnitten wurde die Methode der in situ Hybrididsierung durchgeführt. Mit Ausnahme von 0,1 M Triethanolamin pH 8,0, STE-in situ-Puffer, MBSTL-Puffer und NTMTL-Puffer wurden sämtliche für die Herstellung der Sonden (siehe 2.8) und die Durchführung benötigten Lösungen und Puffer vor der Verwendung mit Diethylpyrocarbonat (DEPC) behandelt, um eine RNADegradation zu verhindern. Dazu wurden die Lösungen/Puffer mit 0,03 \% DEPC 
versetzt, über Nacht bei Raumtemperatur inkubiert und danach zur DEPC-Inaktivierung autoklaviert.

\subsection{Herstellung Digoxigenin-markierter Sonden für in situ-Hybridisierung}

Zur Herstellung von Digoxigenin-markierten RNA-Sonden zur Detektion von Gli2 mRNA wurden $10 \mu \mathrm{g}$ des Plasmids pmGli2 linearisiert. Als Restriktionsenzyme wurden für die antisense-Sonde Hindll und für die sense-Sonde BamHI verwendet. Dazu wurde der Reaktionsansatz für $2 \mathrm{~h}$ bei $37^{\circ} \mathrm{C}$ inkubiert und anschließend die DNA mit $99 \%$ Ethanol gefällt. Die Fällung erfolgte für mindestens 30 min bei $-20^{\circ} \mathrm{C}$, danach wurde die DNA bei $16000 x g$ für 30 min abzentrifugiert und mit $70 \%$ Ethanol gewaschen. Das getrocknete Pellet wurde in $20 \mu \mathrm{l}$ RNase-freiem $\mathrm{H}_{2} \mathrm{O}$ aufgenommen. Zur Quantifizierung der DNAMenge wurden $2 \mu$ mittels Agarosegelelektrophorese aufgetrennt und durch vergleichendes Abschätzen mit dem Größenstandard die Konzentration ermittelt.

Für die Markierungsreaktion wurden folgende Reagenzien eingesetzt:

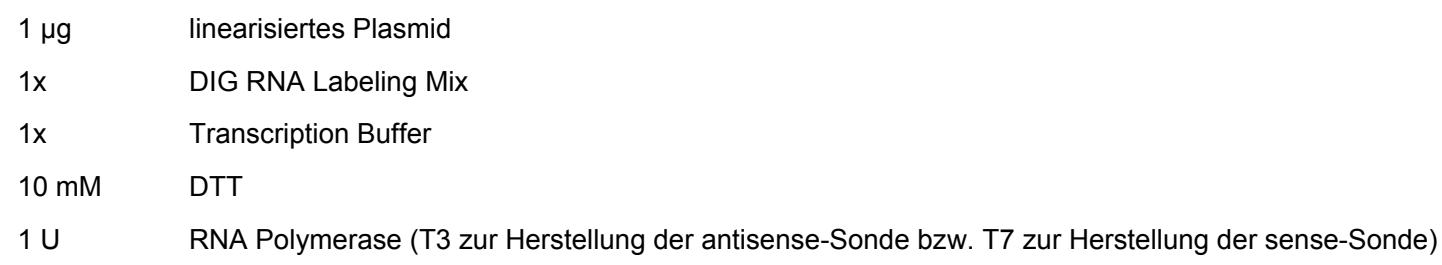

Der Reaktionsansatz wurde für $2 \mathrm{~h}$ bei $37^{\circ} \mathrm{C}$ inkubiert. Danach wurde die Reaktion mit

$\begin{array}{ll}\text { 1x } & \text { DIG RNA Labeling Mix } \\ 1 \mathrm{x} & \text { Transcription Buffer } \\ 10 \mathrm{mM} & \text { DTT } \\ 1 \mathrm{U} & \text { RNA Polymerase (T3 oder T7) }\end{array}$

für $1 \mathrm{~h}$ wiederholt.

Dann wurde die Sonde mit $99 \%$ Ethanol, $5 \mathrm{mM}$ EDTA, $130 \mathrm{mM} \mathrm{LiCl}$ bei $-20{ }^{\circ} \mathrm{C}$ für mindestens 30 min präzipitiert, bei $16000 x g$ für 30 min abzentrifugiert und mit $70 \%$ Ethanol gewaschen. Das Pellet wurde in $110 \mu \mathrm{l}$ Rase-freiem $\mathrm{H}_{2} \mathrm{O}$ aufgenommen und mit 99 \% Ethanol, $130 \mathrm{mM} \mathrm{LiCl}$, präzipitiert. Die Sonde wurde bei 16000xg für 30 min abzentrifugiert, mit $70 \%$ Ethanol gewaschen und das Pellet in $25 \mu \mathrm{RNase-freiem} \mathrm{H}_{2} \mathrm{O}$ gelöst.

Zur Überprüfung der Qualität der hergestellten Sonde wurden $1 \mu \mathrm{l}$ der Sondenlösung sowie ein $1 \mu$ Aliquot, das mit RNaseA verdaut wurde, auf ein Agarosegel aufgetragen. Nach der Gelelektrophorese darf nur bei der unbehandelten Sonde eine Bande im Gel sichtbar sein. 
Des Weiteren wurde ein so genannter Dot Blot durchgeführt. Dafür wurde eine 1:10 Verdünnungsreihe der Sonde in $6 x \operatorname{SSC}(\mathrm{pH} 6,4)$ hergestellt. $1 \mu \mathrm{l}$ der 1:10 Verdünnung und jeweils $1 \mu \mathrm{l}$ der fünf weiteren Verdünnungsstufen wurden auf eine Nitrocellulosemembran pipettiert und mittels Cross-Linker bei $125 \mathrm{~mJ}$ auf der Membran fixiert. Anschließend wurden überschüssige Bindungsstellen der Membran für 5 min mit $55{ }^{\circ} \mathrm{C}$ warmen $4 \%$ BSA in NT-Puffer blockiert. Die Membran wurde kurz in NT-Puffer gewaschen und für $7 \mathrm{~min}$ in die Antikörperlösung (1:5000 anti-Digoxigenin Fab Fragments/AP in NT-Puffer) gelegt. Danach wurde die Membran dreimal kurz in NTPuffer gewaschen und 3 min mit NTM-Puffer auf einen pH-Wert von 9,5 umgepuffert. Zur Färbung wurde BM-Purple (Roche) auf die Membran gegeben und für 10-20 min im Dunkeln inkubiert. Abschließend wurde die Membran kräftig mit MilliQ Wasser gespült.

\subsection{Durchführung der in situ-Hybridisierung}

Für diese Methode wurden auf Superfrost Objektträger aufgezogene Paraffinschnitte verwendet, die nach Anfertigung über Nacht bei $37^{\circ} \mathrm{C}$ getrocknet wurden (siehe 2.15.2.1). Nach einer Inkubation der Objektträger bei $65^{\circ} \mathrm{C}$ für 30 min wurden die Paraffinschnitte in Xylol entparaffiniert und in einer absteigenden Ethanolreihe rehydriert. Es folgten 5 min Inkubation in PBS und 0,83 \% $\mathrm{NaCl}$ und eine Fixierung in 4 \% PFA/PBS für 20 min auf Eis. Nach erneutem Waschen in PBS wurden die Gewebeschnitte mit Proteinase K-Puffer für 7,5 min permeabilisiert. Die Schnitte wurden kurz in PBS geschwenkt, erneut in 4 \% PFA/PBS für 5 min auf Eis fixiert und in 0,1 M Triethanolamin, $\mathrm{pH} 8,0$, überführt. Nach Zugabe von 0,25 \% (v/v) Essigsäureanhydrid wurden die Schnitte für 10 min inkubiert, mit PBS und 0,83\% $\mathrm{NaCl}$ gewaschen und schließlich mit einer aufsteigenden Ethanolreihe dehydriert. Die Schnitte wurden an der Luft getrocknet und am selben Tag für die Hybridisierung verwendet. Die sense- und antisense-Sonden wurden 1:1000 in Hybridisierungspuffer verdünnt, für 2 min bei $80^{\circ} \mathrm{C}$ denaturiert und auf Eis gestellt. $\mathrm{Zu} 1 \mathrm{ml}$ Hybridisierungspuffer wurden $50 \mu \mathrm{g}$ denaturierte LachsspermienDNA zugegeben und gut vermischt. Der Hybridisierungspuffer wurde auf das Gewebe pipettiert und luftblasenfrei mit einem sauberen Deckgläschen abgedeckt. Für die Hybridisierung wurden die Gewebeschnitte in eine feuchte Kammer mit 50 \% Formamid, 5x SSC überführt und über Nacht bei $59{ }^{\circ} \mathrm{C}$ inkubiert. Am nächsten Tag wurden die Objektträger in eine Küvette mit 5x SSC gestellt, um die Deckgläschen zu entfernen. Anschließend wurden die Gewebeschnitte für $30 \mathrm{~min}$ in $5 \mathrm{x}$ SSC $(\mathrm{pH} 6,4)$ bei $55^{\circ} \mathrm{C}$ inkubiert und für 30 min in $50 \%$ Formamid, 2x SSC $(\mathrm{pH} 6,4)$ bei $63{ }^{\circ} \mathrm{C}$ gewaschen. Es folgten ein Waschschritt bei Raumtemperatur und 3 Waschschritte bei $37^{\circ} \mathrm{C}$ in STE- 
in situ-Puffer für jeweils $10 \mathrm{~min}$. Nach einer Inkubation mit $8 \mathrm{ng} / \mathrm{ml}$ RNase A in STEin situ-Puffer für 30 min bei $37^{\circ} \mathrm{C}$ und 15 min Spülen mit STE-in situ-Puffer bei $37^{\circ} \mathrm{C}$ erfolgte eine erneute Inkubation für $30 \mathrm{~min}$ in $50 \%$ Formamid, $2 x \mathrm{SSC}(\mathrm{pH} \mathrm{6,4)}$ bei $63^{\circ} \mathrm{C}$. Dann wurden die Objektträger für $15 \mathrm{~min}$ bei RT in $2 x \operatorname{SSC}(\mathrm{pH} \mathrm{6,4)}$ und anschließend für 10 min bei RT in NT-Puffer überführt. Die Gewebeschnitte wurden mit einem Fettstift eingekreist und 3x 5 min mit MBSTL-Puffer gespült. Danach wurde 0,2 \% I-Block/PBS zur Blockade unspezifischer Bindungsstellen auf die Gewebeproben gegeben und die Objektträger für $1 \mathrm{~h}$ in einer feuchten Kammer bei Raumtemperatur inkubiert. Anti-Digoxigenin Fab fragments/AP wurden 1:500 in 0,02 \% I-Block in MBSTLPuffer verdünnt und auf die Gewebeschnitte pipettiert. Die Inkubation erfolgte über Nacht bei $4{ }^{\circ} \mathrm{C}$ in einer feuchten Kammer. Am folgenden Tag wurden die Objektträger $6 \mathrm{x}$ für 20 min bei Raumtemperatur in MBSTL und 3x 5 min in NTMLT-Puffer gewaschen. Anschließend wurden sie in eine feuchte Kammer überführt und mit BM-Purple (Roche Diagnostics $\mathrm{GmbH}$, Mannheim) bedeckt. Die Objektträger wurden dann bei Raumtemperatur solange im Dunkeln gelagert, bis eine ausreichende Signalintensität erreicht wurde (meist für mehrere Tage). Dabei wurde täglich frisches BM-Purple auf die Gewebeschnitte gegeben. Zum Abstoppen der Färbereaktion wurden die Objektträger in Stop-Puffer und danach in PBS überführt. Zuletzt wurden sie für $1 \mathrm{~h}$ in $4 \% \mathrm{PFA} / 0,2 \%$ Glutaraldehyd in PBS inkubiert, mit PBS gewaschen und mit Glycergel (Dako GmbH, Hamburg) eingedeckt.

\subsubsection{Zellbiologische Methoden}

\subsubsection{Zellkultur eukaryontischer Zellen}

Eukaryontische Zellen wurden in Zellkulturschalen im Begasungsbrutschrank in einer wasserdampfgesättigten Atmosphäre mit $16 \% \mathrm{O}_{2}, 5 \% \mathrm{CO}_{2}$ und $79 \% \mathrm{~N}_{2}$ bei $37{ }^{\circ} \mathrm{C}$ kultiviert. Die verwendeten Medien sind unter 2.10.2 angegeben. Abweichende Serumkonzentrationen bzw. Antibiotika bei einzelnen Experimenten sind unter 2.15.3 und bei der Beschreibung der Experimente angegeben.

Die verwendeten eukaryontischen Zelllinien und die Kulturbedingungen sind in Tabelle 1 aufgeführt. Kommerziell erhältliche Zelllinien wurden maximal 20x, selbst hergestellte maximal $30 x$ passagiert. 


\subsubsection{Kryokonservierung eukaryontischer Zellen}

Zur Kryokonservierung wurden die Zellen mit PBS gewaschen und mit $5 \mathrm{ml}$ Trypsin/EDTA von einer $10 \mathrm{~cm}$ Zellkulturschale abgelöst. Nach der Zugabe von $3 \mathrm{ml}$ Medium wurde durch vorsichtiges Auf- und Abpipettieren eine Einzellsuspension hergestellt. Die Zellen wurden bei $300 x g$ pelletiert, der Überstand vorsichtig abgenommen und in $10 \mathrm{ml}$ Medium mit $10 \%$ DMSO aufgenommen. Die durch vorsichtiges Auf- und Abpipettieren hergestellte Einzellsuspension wurde zu je $1 \mathrm{ml}$ in Kryokonservierungsröhrchen aliquotiert. Das Einfrieren der Zelllinien erfolgte zunächst für 1 bis $2 \mathrm{~h}$ bei $-20{ }^{\circ} \mathrm{C}$ und anschließend für $24 \mathrm{~h}$ bei $-80{ }^{\circ} \mathrm{C}$, bevor sie zur Dauerlagerung in flüssigen Stickstoff überführt wurden.

Zur Revitalisierung von Zelllinien wurde ein Zellaliquot bei $37^{\circ} \mathrm{C}$ aufgetaut und die Zellen in eine Zellkulturschale mit Medium überführt.

\subsubsection{Isolierung und Kultivierung adulter muriner Fibroblasten}

Zur Gewinnung von Ptch ${ }^{\text {floxflox }} E R T 2^{+/}$- und Ptch floxfllox - Fibroblasten (siehe Tabelle 1) wurden zwei 5 Monate alte Mäuse mit den Genotypen $\operatorname{Ptch}^{\text {floxflox}} E R T 2^{+/-}$bzw.

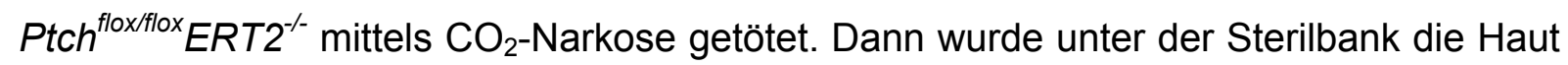
vorsichtig vom Rumpf abgetrennt. Mit der behaarten Seite nach unten wurde das Hautstück fixiert, um das Abschaben von Zellen der Dermis mit einer Skalpellklinge zu ermöglichen. Das so gewonnene Gewebe wurde in sterilfiltriertes DMEM mit 3 \% PS und $0,25 \%$ Collagenase überführt und für 2 bis $3 \mathrm{~h}$ bei $30{ }^{\circ} \mathrm{C}$ leicht geschüttelt. Anschließend wurden die Zellen bei $300 x g$ für 6 min abzentrifugiert und das Pellet in $2 \mathrm{ml}$ $\mathrm{DMEM} / 10 \% \mathrm{FCS} / 3 \% \mathrm{PS}$ auf einer kleinen Petrischale ausplattiert. Die weitere Kultivierung nach der ersten Passage erfolgte mit DMEM/10 \% FCS/1 \% PS.

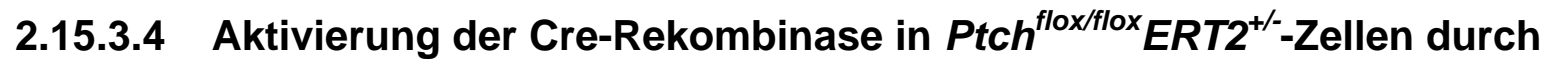 Tamoxifen}

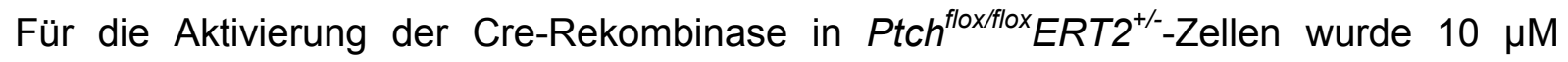
Tamoxifen (Stammlösung $100 \mathrm{mM}$ in DMSO) ins Kulturmedium gegeben. Als Lösungsmittelkontrolle diente 0,01 \% (v/v) DMSO in Medium. Genauere Angaben zur Stimulationsdauer sind in der Beschreibung der jeweiligen Experimente angegeben. 


\subsubsection{Herstellung von Shh-konditioniertem Medium}

Hek293 Shh-Zellen wurden in DMEM/10 \% FCS/1 \% PS/0,4 mg/ml G418 kultiviert. Bei $70 \%$ Konfluenz wurden die Zellen mit PBS gewaschen und anschließend $\mathrm{DMEM} / 2 \% \mathrm{FCS} / 1$ \% PS ohne G418 zugegeben. Nach $24 \mathrm{~h}$ wurde das Medium abgezogen, sterilfiltriert und bis zur weiteren Verwendung bei $4{ }^{\circ} \mathrm{C}$ gelagert. Zur Herstellung von Kontrollmedium ohne Shh dienten Hek293-Zellen, die entsprechend behandelt wurden, allerdings erfolgte bei diesen Zellen die Kultivierung stets ohne den Zusatz von G418.

\subsubsection{Stimulation des Hh/Ptch-Signalweges durch konditioniertes Shh Medium}

Für die Stimulation des Hh/Ptch-Signalweges wurde durch Hek293 Shh-Zellen konditioniertes Medium verwendet. Dazu wurde das konditionierte Medium 1:1 mit $\mathrm{DMEM} / 0,5$ \% FCS/1 \% PS verdünnt und auf die Zellen gegeben. Als Kontrollmedium wurde konditioniertes Medium von Hek293-Zellen benutzt. Genauere Angaben zur Stimulationsdauer der Zielzellen durch die konditionierten Medien erfolgen in der Beschreibung der jeweiligen Experimente.

\subsubsection{Blockade des Hh/Ptch-Signalweges durch Cyclopamin}

Für eine spezifische Blockade des Hh/Ptch-Signalweges wurde das Alkaloid Cyclopamin verwendet. Cyclopamin bzw. das inaktive Strukturanalogon Tomatidin wurden dem Medium zugefügt. Dabei betrug die maximal eingesetzte Konzentration $5 \mu \mathrm{M}$. Um Lösungsmitteleffekte auszuschließen, wurden Zellen mit 0,5 \% (v/v) Ethanol in Medium behandelt. Wenn nicht anders angegeben, betrug die Stimulationsdauer $72 \mathrm{~h}$, wobei die Zellen nach 24 und $48 \mathrm{~h}$ mit PBS gewaschen und erneut Cyclopamin, Tomatidin oder Ethanol zum Medium zugegeben wurden.

\subsubsection{Bestimmung der Zellproliferationsrate mittels Inkorporation von 5- Bromo-2-Deoxyuridin}

Zur Bestimmung der Proliferationsrate wurden 7000 Zellen pro Loch einer 96-Loch-Platte ausgesät. Nach $24 \mathrm{~h}$ wurde den Zellen $10 \mu \mathrm{M}$ Bromo-2-Deoxyuridin (BrdU) zugegeben. Nach maximal weiteren $22 \mathrm{~h}$ erfolgte die Fixierung der Zellen mit anschließender Antikörperfärbung mit Peroxidase-konjugierten anti-BrdU Fab-Fragmenten. Dabei wurde das Reaktionssystem Cell Proliferation ELISA, BrdU (Roche Diagnostics GmbH, Mannheim) nach Herstellerangaben verwendet. Die Messung des BrdU Einbaus erfolgte 
nach Zugabe des Peroxidase-Substrates am Luminometer (Berthold Detection Systems $\mathrm{GmbH}$, Pforzheim).

\subsubsection{Tierexperimentelle Methoden}

\subsubsection{Zucht und Haltung von Mus musculus}

Die verwendeten Mausstämme wurden im institutseigenen Tierstall (Gentechnischer Arbeitsbereich S1; Institut für Humangenetik, Universität Göttingen) gezüchtet. Die Tierhaltung erfolgte in Makrolonkäfigen Typ II und III, bei einem zwölfstündigen HellDunkel-Rhythmus (Hell-Periode: 6.00-18.00 Uhr), einer Temperatur von $20 \pm 2{ }^{\circ} \mathrm{C}$ und einer relativen Luftfeuchtigkeit von $50 \pm 10 \%$. Pelletierte Zuchtdiät (Alleinfutter für MäuseZucht, Ssniff Spezialdiäten $\mathrm{GmbH}$, Soest) und Wasser (Leitungswasser) standen den Tieren ständig zur Verfügung.

Für sämtliche im Rahmen dieser Arbeit durchgeführten tierexperimentellen Analysen lagen die entsprechenden genehmigten Tierversuchsanträge vor.

\subsection{Schwanzbiopsie und Ohrlochmarkierung}

Schwanzbiopsien (ca. 0,2 cm der Schwanzspitze) und gleichzeitige Ohrlochmarkierungen zur Kennzeichnung von vier Wochen alten Mäusen wurden vom Tierstallpersonal im institutseigenen Tierstall vorgenommen.

\subsection{Genotypisierung von Mäusen}

Standardmäßig erfolgte die Genotypisierung von Mäusen durch PCR an gDNA aus Schwanzbiopsien. Die verwendeten DNA-Oligonukleotide und Konditionen sind unter 2.11.1 und 2.15.1.3.2 genannt. Zusätzlich wurden einzelne Genotypisierungen mittels Southern Blot-Analyse (siehe 2.15.1.8) bestätigt.

\subsection{Isolierung von Mausserum}

Zur Vermeidung von Kreuzreaktionen beim Gebrauch von Primärantikörpern aus der Ratte bei immunhistologischen Analysen wurde eine Präabsorption des sekundären Antikörpers mit Mausserum durchgeführt (siehe 2.15.2.4). Zur Herstellung des Mausserums wurden einer Maus nach schmerzfreier Tötung durch $\mathrm{CO}_{2}$-Narkose und zervikaler Dislokation mittels Herzpunktion ca. $300 \mu$ Blut entnommen und in ein Reaktionsgefäß überführt. Eine Inkubation für $2 \mathrm{~h}$ bei $4{ }^{\circ} \mathrm{C}$ führte zur Koagulation des 
Blutes. Anschließend wurde das Blut bei $1500 x g$ für 30 min bei $4{ }^{\circ} \mathrm{C}$ zentrifugiert. Der Serum-Überstand wurde vorsichtig abgezogen, in ein Reaktionsgefäß überführt und bei $-20{ }^{\circ} \mathrm{C}$ gelagert.

\subsection{Bestimmung des Kopulationszeitpunktes und der Trächtigkeit sowie Isolierung von Mausembryonen}

Um Embryonen eines definierten Stadiums der Embryonalentwicklung zu isolieren, wurden jeden Morgen Weibchen aus Verpaarungen auf eine erfolgte Kopulation untersucht. Das Koagulat des Ejakulats bildet bis zu 24 h nach Ejakulation einen sichtbaren Vaginalplug. Der Zeitpunkt der Vaginalplugsichtung wurde als Tag 0,5 nach erfolgter Kopulation definiert (engl.: days post coitum; $d p c$ - Tage nach der Befruchtung). Die tatsächliche Trächtigkeit der vaginalplug-positiven Weibchen konnte visuell erst frühestens nach 9,5 Tagen bestätigt werden. Für die Isolierung bestimmter Embryonalstadien wurden vaginalplug-positive Weibchen am entsprechenden Tag präpariert und die Embryonen isoliert. Die tragenden Weibchen wurden schmerzfrei mittels $\mathrm{CO}_{2}$-Narkose und zervikaler Dislokation getötet und der Uterus mit den Embryonen isoliert. Die Embryonen wurden in PBS auf Eis aus dem Uterusgewebe präpariert. Für die Isolierung von embryonaler RNA wurden die Embryonen direkt in TriFast Reagent aufgenommen.

\subsection{Narkotisierung von Mäusen}

Zur Narkotisierung wurde den Mäusen intraperitoneal $64 \mu \mathrm{g}$ Ketanest S und $12 \mu \mathrm{g}$ Rompun pro $1 \mathrm{~g}$ Körpergewicht injiziert. Während der Narkose wurden die Augen mit 0,9 \%iger $\mathrm{NaCl}$ Lösung bedeckt, um eine Austrocknung zu vermeiden.

\subsection{Epilation}

Für die Epilation einer dorsalen, ca. $2 \mathrm{~cm}^{2}$ großen Fläche wurden die Tiere zunächst wie unter 2.15.4.1.5 beschrieben anästhesiert. Anschließend wurden die narkotisierten Tiere vorsichtig auf einer Unterlage fixiert. Die zu enthaarende Region wurde mit einer Schablone mit einer $2 \mathrm{~cm}^{2}$-großen Aussparung markiert. Das Fell in der Aussparung wurde mit einer Mullbinde abgedeckt. Dann wurde eine 1:1 Mischung von heißem Bienenwachs (Sigma-Aldrich, Chemie $\mathrm{GmbH}$, Steinheim) und Kolophonium (Fluka Chemie $\mathrm{GmbH}$, Buchs) auf die Mullbinde aufgetragen. Nach Erkaltung wurde das mittlerweile feste Bienenwachs/Kolophonium mit der Mullbinde vorsichtig abgezogen und 
dabei die am Bienenwachs/Kolophonium festgeklebten Haare mitsamt den Haarwurzeln entfernt. Anschließend wurden die Tiere in Papierhandtücher eingewickelt in den Käfig gelegt, um eine Auskühlung der Tiere zu vermeiden.

\subsection{Lokale Applikation von Tamoxifen auf die epilierte Haut}

Vor der lokalen Applikation von Tamoxifen wurden die Mäuse wie unter 2.15.4.1.5 beschrieben narkotisiert. Die narkotisierten Tiere wurden vorsichtig auf einer Unterlage fixiert. Auf beide zuvor enthaarte Regionen (siehe 2.15.4.1.6) wurde für 10 min $500 \mu \mathrm{g}$ Tamoxifen in $20 \mu \mathrm{l}$ DMSO aufgetragen. Danach wurde den Mäusen vorsichtig mit warmem Wasser und Seife auf der Haut verbliebenes Tamoxifen abgespült. Anschließend wurden die Tiere in Papierhandtücher eingewickelt in den Käfig gelegt. Die Behandlung wurde am selben Tag wie oben beschrieben wiederholt.

\subsection{Intraperitoneale und intramuskuläre Injektion von Tamoxifen}

Um die Cre-ERT2 der verschiedenen Mauskreuzungen (siehe 2.10.3) zu aktivieren, wurde Mäusen intraperitoneal (i.p.) oder intramuskulär (i.m.) Tamoxifen (Sigma-Aldrich, Chemie $\mathrm{GmbH}$, Steinheim) injiziert. Eine Lösung von $100 \mathrm{mg}$ Tamoxifen pro $\mathrm{ml} 96 \%$ Ethanol wurde mit sterilem Sonnenblumenöl (Sigma-Aldrich, Chemie GmbH, Steinheim) 1:10 verdünnt, so dass die Endkonzentration $10 \mathrm{mg} / \mathrm{ml}$ betrug. Die Lagerung erfolgte bei $-20{ }^{\circ} \mathrm{C}$. Für die Verabreichung wurden die Mäuse im Genick fixiert und $100 \mu \mathrm{l}$ der Tamoxifenemulsion (Dosis $1 \mathrm{mg}$ Tamoxifen) i.p. oder $10 \mu \mathrm{l}$ (Dosis $100 \mu \mathrm{g}$ Tamoxifen) i.m. in den musculus soleus injiziert. Den Tieren wurde entweder durch i.p. Injektionen an fünf aufeinander folgenden Tagen eine kumulative Dosis von $5 \mathrm{mg}$ Tamoxifen oder durch eine einmalige i.m. Injektion $100 \mu \mathrm{g}$ Tamoxifen verabreicht. Für die Injektion von Kontrolltieren wurde eine entsprechende Öl-Ethanol-Emulsion ohne Tamoxifen verwendet.

\subsection{Perfusion von Mäusen mit Paraformaldehyd}

Die Betäubung der Mäuse erfolgte mit einer letalen Dosis Ketanest $S$ (4 mg) und Rompun (0,9 mg). Zur Freilegung des Herzens wurde der Brustraum geöffnet. Das rechte Atrium wurde zur Eröffnung des Blutkreislaufs punktiert, der linke Ventrikel wurde punktiert, um die Blutgefäße zunächst 10 min mit Ringer-Lactat und danach 10 min mit $4 \%$ Paraformaldehyd zu spülen. Die fixierte Maus wurde bis zur Analyse bei $4{ }^{\circ} \mathrm{C}$ in Paraformaldehyd gelagert. 


\subsection{Sichtung und Präparation von Tumoren}

Mäuse mit einer erhöhten Tumorprädisposition wurden engmaschig auf die Entstehung von Tumoren überwacht. Zur Erfassung von Weichteiltumoren wurde der Rumpf zweibis dreimal wöchentlich abgetastet. Weiterhin wurden die Tiere auf typische Symptome von Medulloblastomen hin untersucht. Hierzu gehören Ataxie, Abmagerung, Lethargie oder Entwicklung eines Hydrozephalus. Beim Verdacht auf ein Medulloblastom wurden die Tiere umgehend schmerzfrei mittels $\mathrm{CO}_{2}$-Narkose getötet.

Beim Vorliegen von Weichteiltumoren wurde das Datum vermerkt und das Tier spätestens nach Erreichen einer Tumorgröße von $1 \mathrm{~cm}$ Durchmesser getötet. Hier erfolgte die Tötung der Mäuse schmerzfrei durch $\mathrm{CO}_{2}$-Narkose und zervikaler Dislokation.

Nach der Tötung wurde die Maus auf dem Präparationstisch fixiert und mit 70 \% Ethanol desinfiziert. Dann wurde routinemässig bei jeder Maus das Abdomen entlang der Mittellinie eröffnet, die Bauchaorta freigelegt und durchtrennt, um das Tier auszubluten. Für die Entnahme des Kleinhirns wurde die Kopfhaut mit $70 \%$ Ethanol desinfiziert, entfernt, die Schädelkalotte vom Foramen magnum ausgehend geöffnet und das Kleinhirn entnommen. Bei Weichteiltumoren wurde der Tumor freipräpariert und auch normales Referenzgewebe (meist Skelettmuskel) isoliert.

Die histologische Abklärung aller Tumoren erfolgte anhand von HE-gefärbten Gewebeschnitten durch einen erfahrenen Pathologen (W. Schulz-Schaeffer). 


\section{Ergebnisse}

\subsection{Abhängigkeit der Tumorinzidenz vom genetischen Hinter- grund bei Ptch $^{\text {neo67/+ }}$-Mäusen}

Die Inzidenz von RMS und MB bei $\mathrm{Ptch}^{\text {neo67/+ }}$-Mäusen ist vom genetischen Hintergrund abhängig. Während Ptch-heterozygote Mäuse auf dem genetischen Hintergrund B6 innerhalb der ersten 200 Tage keine RMS entwickeln, liegt die RMS-Inzidenz beim Hintergrund CD1 bei ca. 15 \% (J Calzada-Wack et al., 2002). Dagegen entstehen MB bei $72 \%$ der B6Ptch ${ }^{\text {neo67/+ }}$-Mäuse und nur bei $8 \%$ der CD1Ptch ${ }^{\text {neo67/+ }}$-Mäuse (S Pazzaglia et al., 2002; H Hahn et al., 2004). Somit variiert die Inzidenz von MB und RMS in heterozygoten $\mathrm{Ptch}^{\text {neo67/+}}$-Mäusen je nach dem genetischen Hintergrund der Tiere und eine Identifikation der hierfür verantwortlichen Lozi musste möglich sein.

Da es sich bei der CD1-Mauslinie, die für RMS prädisponiert ist, um einen Auszuchtstamm handelt, sind viele genomische Regionen heterozygot und polymorph. Dieser Stamm eignet sich deshalb nicht für Kartierungsexperimente. Daher wurden zunächst B6Ptch ${ }^{\text {neo67/+}}$-Mäuse, die ausschließlich MB, jedoch keine RMS entwickeln (siehe Abbildung 3), auf den Inzuchtstamm BALB zurückgekreuzt. In der resultierenden F1-Generation ist die Frequenz von RMS bei bestehender Ptch-Heterozygotie stark erhöht, wohingegen MB kaum noch auftreten (siehe Abbildung 3). Insgesamt 62 Ptch $^{\text {neo67/+ }}$-Tiere der (BALBxB6)F1-Generation wurden über 420 Tage auf die Entwicklung von Tumoren hin beobachtet. In diesem Zeitraum erkrankten fünf Tiere (8\%) an MB und 41 Tiere (66 \%) entwickelten Weichteiltumoren, von denen 39 (63\%) histologisch abgesicherte RMS waren. Zwei Tiere (3\%) entwickelten beide Tumorentitäten (H Hahn et al., 2004) (siehe auch 3.1.1, Tabelle 15). Daran ist folgendes erkennbar:

a) BALB besitzt einen oder mehrere dominante Suszeptibilitätslozi für RMS

b) B6 besitzt einen oder mehrere rezessive Suszeptibilitätslozi für MB 


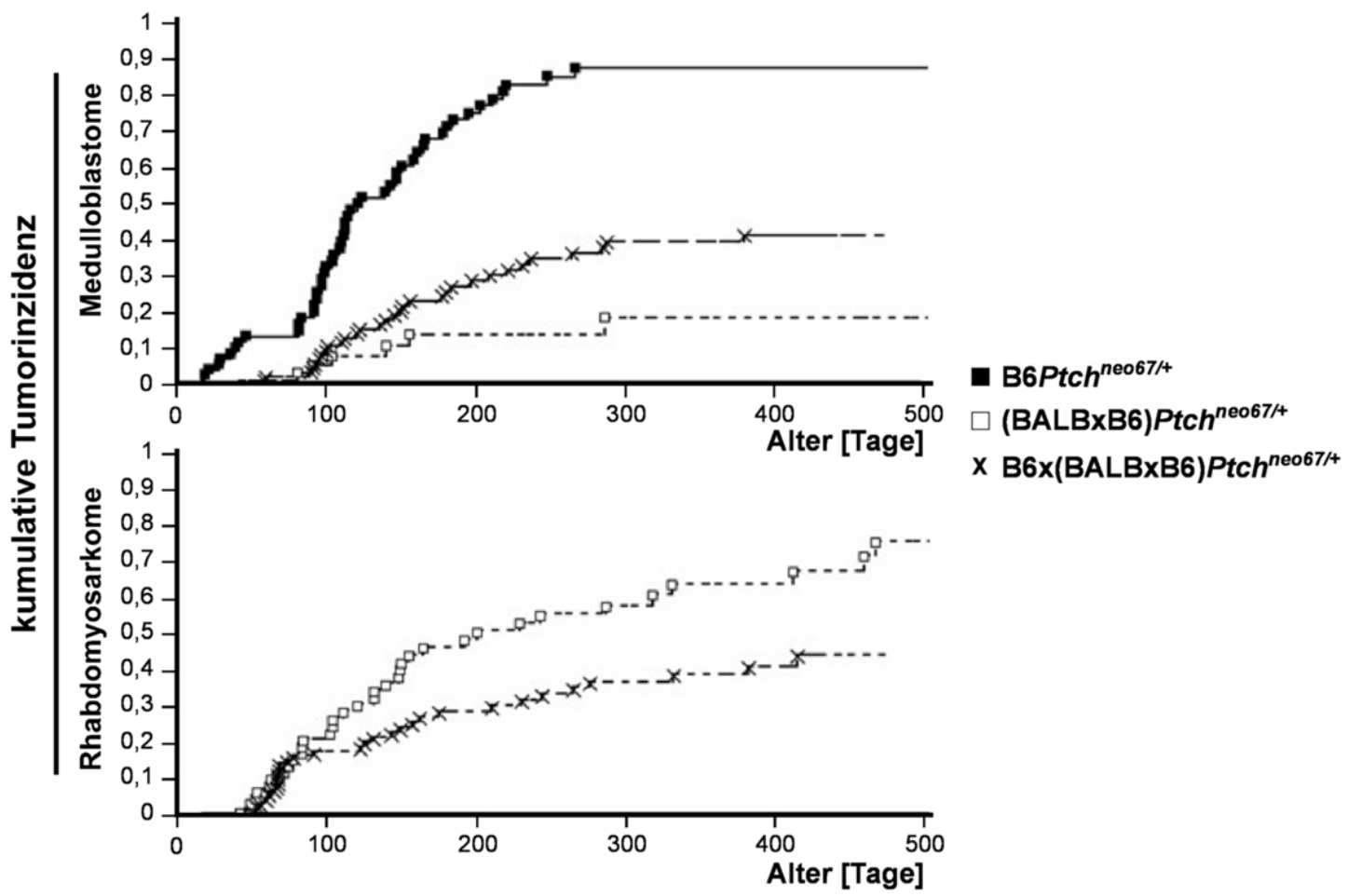

Abbildung 3: Inzidenzen von Medulloblastomen und Rhabdomyosarkomen bei Ptch ${ }^{\text {neo67/+ }}$ Mäusen mit unterschiedlichem genetischen Hintergrund. Dargestellt sind die kumulativen Tumorinzidenzen von Medulloblastomen und Rhabdomyosarkomen bei B6Ptch ${ }^{\text {neo67/+ }}$ - (घ), $\left(\right.$ BALBxB6)Ptch ${ }^{\text {neo67/+ }}$ - (口) und B6x(BALBxB6)Ptch ${ }^{\text {neo67/+ }}$ - (x) Mäusen.

Für die Kartierung von Lozi, die Suszeptibilität für die Entwicklung von Tumoren vermitteln, können keine F1-Hybride aus zwei unterschiedlichen Mausstämmen verwendet werden. Diese Tiere sind an jedem genetischen Lokus heterozygot für die entsprechenden Allele und unterscheiden sich somit genetisch nicht. Daher wurden männliche (BALBXB6)Ptch ${ }^{\text {neo67/t }}$-Hybride mit weiblichen B6-Mäusen gekreuzt. Die Tumorinzidenzen bei der resultierenden B6x(BALBxB6)Ptch ${ }^{\text {neo67/+ }}$ N2-Generation sind ebenfalls in Abbildung 3 gezeigt (siehe auch 3.1.1, Tabelle 15).

Jedes Tier der B6x(BALBxB6)Ptch ${ }^{\text {ne067/+ }}$ N2-Generation verfügt in jedem Chromosomenpaar über maternale B6 Geschwisterchromatiden, während die paternalen Chromatiden entweder aus BALB- oder aus B6-Sequenzen bestehen können. Das Kreuzungsschema für die Generierung der B6x(BALBxB6)Ptch ${ }^{\text {neo67/+ }}$ N2-Mäuse und eine vereinfachte Darstellung der möglichen Zusammensetzungen der Chromosomen sind zum besseren Verständnis in Abbildung 4 dargestellt.

Da die männlichen (BALBxB6)Ptch ${ }^{\text {neo67/t }}$-Hybride ein paternales B6- und ein maternales BALB-Chromosom haben, kann eine Rekombination („Crossing-over“) während der Meiose eine Variabilität der paternalen Chromatiden in den resultierenden B6x(BALBxB6)Ptch ${ }^{\text {neo67/+ }}$ N2-Mäusen bewirken. Bei der Meiose der B6-Weibchen ist die 
Rekombination irrelevant, da bei dieser Inzuchtlinie ohnehin homologe Chromatiden vorliegen.

B6x(BALBxB6)Ptch ${ }^{\text {neo67/+ }}$ N2-Tiere, die im Folgenden mit „N2“ bezeichnet werden, können für Kartierungsexperimente verwendet werden, da die Nachkommen aufgrund des Kreuzungsschemas unterschiedliche Genotypen aufweisen und somit die Ausprägung der zu analysierenden Phänotypen variieren sollte. Alle N2-Tiere verfügen an jedem Lokus über ein B6-Allel maternaler Herkunft und zusätzlich über ein B6- oder ein BALB-Allel, das paternal vererbt wurde. Grundlegend für die Kartierung von Genen ist die Bestimmung dieser Allele für mehrere Lozi im gesamten Genom. Dies kann z. B. mit Hilfe von Mikrosatellitenmarkern erfolgen, die eine Unterscheidung zwischen B6- und BALB-Allelen ermöglichen. Anhand dieser Daten kann nach Abschluss der Beobachtung - in diesem Fall der Entstehung von RMS oder MB - eine Korrelation zwischen den Genotypen und Phänotypen gesucht werden. Alle Tiere, die z. B. ein RMS entwickelt haben, sollten an den hierfür verantworlichen Lozi denselben Genotyp besitzen. Genau nach diesen Lozi wird bei einer Kopplungsanalyse gesucht. Unter der Annahme, dass sich im Genom des Mausstammes BALB ein dominanter Suszeptibilitätslokus für RMS befindet, sollten daher Tiere, die an diesem Lokus den Genotyp B6/BALB aufweisen, eine deutlich höhere RMS-Inzidenz zeigen als Tiere mit dem Genotyp B6/B6 (siehe Abbildung 4).

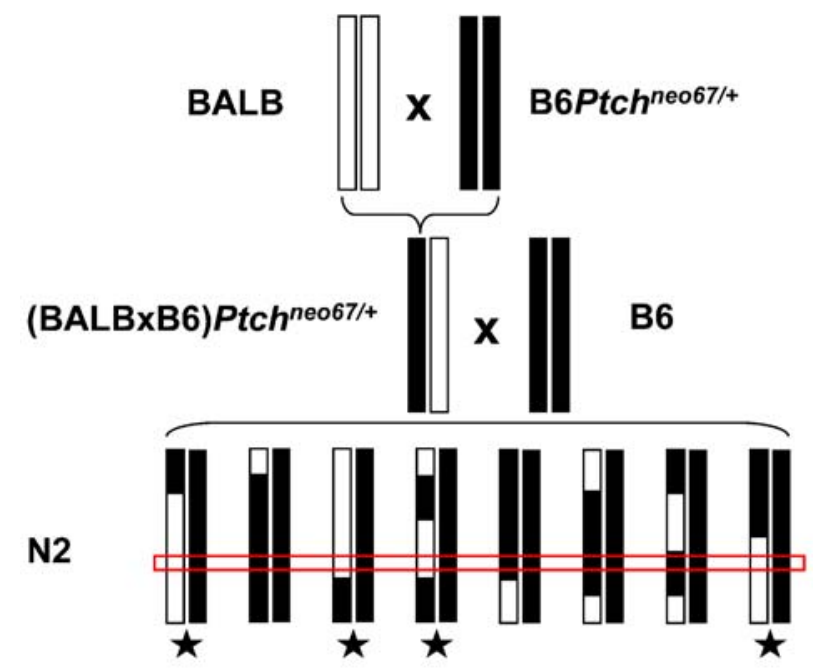

Abbildung 4: Generierung der N2-Mäuse zur Kartierung von Tumor-Suszeptibilitätslozi. Gezeigt ist das Kreuzungsschema für die Etablierung der N2-Mäuse. Weiß dargestellt sind Chromosomenabschnitte mit BALB-Hintergrund und schwarz diejenigen mit B6-Hintergrund. Wenn sich im Genom vom Mausstamm BALB ein dominanter Suszeptibilitätslokus für RMS befindet, müssen Tiere, die an diesem Lokus den Genotyp B6/BALB aufweisen, eine deutlich höhere RMSInzidenz zeigen als Tiere mit dem Genotyp B6/B6. Der rote Rahmen markiert einen möglichen dominanten BALB RMS-Suszeptibilitätslokus. Die Sterne kennzeichnen Tiere, die für den Lokus heterozygot sind und RMS entwickeln. Abkürzung: N2, B6x(BALBxB6)Ptch ${ }^{\text {neo67/+ }}$ N2-Tiere 


\subsubsection{Detektion des RMS-Suszeptibilitätslokus Parms1 auf Chro- mosom 2}

Für die Kopplungsanalyse dienten 89 N2-Mäuse, die über einen Zeitraum von 420 Tagen regelmäßig auf das Auftreten von Tumoren untersucht wurden. Beim Auftreten eines MB oder beim Überschreiten eines Durchmessers von $1 \mathrm{~cm}$ von Weichteiltumoren wurden die Tiere vor Ablauf des Zeitraumes getötet und präpariert. Bei 32 Tieren wurden histologisch bestätigte RMS diagnostiziert, 28 entwickelten ein MB, bei sechs dieser Mäuse wurden bei der Präparation zusätzliche RMS gefunden. In Tabelle 15 ist ein Überblick dieser Tumorinzidenzen im Vergleich zu Ptch $^{\text {neo67/t+ }}$-Mäusen auf einem BALBxB6- und B6-Hintergrund und zu Wildtyp BALB- und B6-Mäusen gezeigt.

Tabelle 15: Tumoren bei (BALBXB6)Ptch ${ }^{\text {neo67/+ }}$-, N2-, B6Ptch $h^{\text {neo67/+ }}$ - und Wildtyp BALB- und B6Mäusen. Dargestellt ist die Inzidenz von Medulloblastomen (MB), Rhabdomyosarkomen (RMS) und andere Tumoren. Die Daten für B6 wurden der Datenbank $\mathrm{MGI}$ entnommen (http://www.informatics.jax.org/external/festing/mouse/docs/C57BL.shtml).

\begin{tabular}{|c|c|c|c|c|c|}
\hline Phänotyp & $\begin{array}{l}\text { (BALBxB6)Ptch } \\
62 \text { Mäuse }\end{array}$ & $\begin{array}{l}\text { N2 } \\
89 \text { Mäuse }\end{array}$ & $\begin{array}{l}\text { B6Ptch }^{\text {neo67/+ }} \\
69 \text { Mäuse }\end{array}$ & $\begin{array}{l}\text { BALB } \\
40 \text { Mäuse }\end{array}$ & B6 \\
\hline MB & $8 \%$ (5 Tiere) & $25 \%$ (22 Tiere) & $72 \%$ (50 Tiere) & $0 \%$ & $0 \%$ \\
\hline RMS & $63 \%$ (39 Tiere) & $29 \%$ (26 Tiere) & $0 \%$ & $0 \%$ & $0 \%$ \\
\hline MB + RMS & $3 \%$ (2 Tiere) & $7 \%$ (6 Tiere) & $0 \%$ & $0 \%$ & $0 \%$ \\
\hline $\begin{array}{l}\text { andere } \\
\text { Tumoren }\end{array}$ & $8 \%$ (5 Tiere) & $10 \%$ (9 Tiere) & $0 \%$ & $5 \%$ (2 Tiere) & $\sim 10 \%$ \\
\hline tumorfrei & $18 \%$ (11 Tiere) & $29 \%$ (26 Tiere) & $28 \%$ (19 Tiere) & $95 \%$ (38 Tiere) & $\sim 90 \%$ \\
\hline
\end{tabular}

Für die Durchführung einer genomweiten Kopplungsanalyse wurden mittels PCR 97 polymorphe Mikrosatellitenmarker in den N2-Mäusen analysiert. Die verwendeten Marker sind informativ für die Unterscheidung von B6- und BALB-Genotypen und liegen in einem Abstand von 10 bis 20 centiMorgan (cM). Die möglichen Genotypen für jeden Lokus waren B6/B6 oder B6/BALB (siehe auch Abbildung 4).

Eine Kopplungsanalyse (durchgeführt von Michael Rosemann, GSF, Neuherberg) erfolgte durch den Vergleich des Genotyps B6/B6 oder B6/BALB mit dem Phänotyp, d. h. der Entstehung eines RMS, MB oder dem tumorfreien Überleben für jeden Lokus. Anhand des berechneten LOD-Scores (engl.: „logarithm of the odds“ - Logarithmus der Wahrscheinlichkeit) konnte die Wahrscheinlichkeit für die Kopplung der Suszeptibilität für RMS, MB oder tumorfreies Überleben mit einem genomischen Lokus bzw. Marker 
angegeben werden. Die LOD-Scores und jeweiligen $\mathrm{p}$-Werte wurden durch den Chi ${ }^{2}$-Test berechnet.

Für die Suszeptibilität von MB wurden mehrere signifikante Lozi identifiziert, an denen BALB-Allele mit einer Resistenz gegenüber MB assoziiert waren (siehe Tabelle 16). Mit Ausnahme des Markers D13Mit151 waren die LOD-Scores jedoch recht niedrig. Der zunächst widersprüchlich erscheinende, mit dem Genotyp B6/B6 und geringer Inzidenz von MB assoziierte hohe LOD-Score am Marker D13Mit151 lässt sich durch die Nähe zum Ptch-Lokus erklären.

Tabelle 16: Mögliche MB-Suszeptibilitätslozi in B6x(BALBxB6)Ptch ${ }^{\text {neo67/+ }}$ N2-Mäusen: Gezeigt sind die Mikrosatellitenmarker, an denen Kopplung eines Markers mit der Suszeptibilität für MB gefunden wurde. Die Anzahl der Tiere mit oder ohne MB ist nach Genotyp B6/B6 und B6/BALB geordnet. In den Spalten $\mathrm{Chi}^{2}$, LOD-Score und $\mathrm{p}$-Wert sind die Ergebnisse der Kopplungsanalyse angegeben.

\begin{tabular}{|c|c|c|c|c|c|c|c|c|}
\hline \multirow[t]{2}{*}{ Marker } & \multirow{2}{*}{$\begin{array}{l}\text { Pos. } \\
\text { [cM] }\end{array}$} & \multicolumn{2}{|c|}{ Tiere mit MB } & \multicolumn{2}{|c|}{ Tiere ohne MB } & \multirow[t]{2}{*}{$\mathrm{Chi}^{2}$} & \multirow{2}{*}{$\begin{array}{l}\text { LOD- } \\
\text { Score }\end{array}$} & \multirow[t]{2}{*}{ p-Wert } \\
\hline & & B6/B6 & B6/BALB & B6/B6 & B6/BALB & & & \\
\hline D4Mit235 & 1,9 & 19 & 9 & 25 & 36 & 5,54 & 1,21 & 0,019 \\
\hline D6Mit138 & 0,68 & 20 & 8 & 25 & 36 & 7,12 & 1,55 & 0,008 \\
\hline D7Mit259 & 72 & 18 & 10 & 24 & 37 & 4,79 & 1,04 & 0,03 \\
\hline D9Mit35 & 52 & 10 & 18 & 38 & 23 & 5,46 & 1,19 & 0,02 \\
\hline D13Mit151 & 71 & 13 & 15 & 49 & 12 & 10,44 & 2,27 & 0,0012 \\
\hline
\end{tabular}

Anhand der Kopplungsanalyse für RMS-Suszeptibilität wurde hingegen ein signifikanter Lokus auf dem 2. Chromosom identifiziert. So ließ sich die Suszeptibilität für histologisch abgesicherte RMS, die durch das BALB-Allel vermittelt wird, zu einem einzigen genomischen Lokus kartieren und zeigte eine Kopplung mit dem Marker D2Mit42 mit einem LOD-Score von 2,44 (p-Wert: 0,0048).

Am Lokus D2Mit42 waren von den 32 Tieren mit RMS 18 B6/BALB heterozygot und 14 B6/B6 homozygot, während von den 32 Tieren, die lange tumorfrei gelebt hatten, nur sieben B6/BALB heterozygot, aber 25 B6/B6 homozygot waren. Der Vergleich der tumorfreien Überlebenszeit zwischen Tieren mit dem Genotyp B6/BALB oder B6/B6 am Lokus D2Mit42 ist in Abbildung 5 anhand einer Kaplan-Meier-Kurve dargestellt. Der Genotyp B6/B6 zeigt einen weniger steilen Kurvenverlauf als B6/BALB und bestätigt somit das verlängerte tumorfreie Überleben dieser Tiere. 


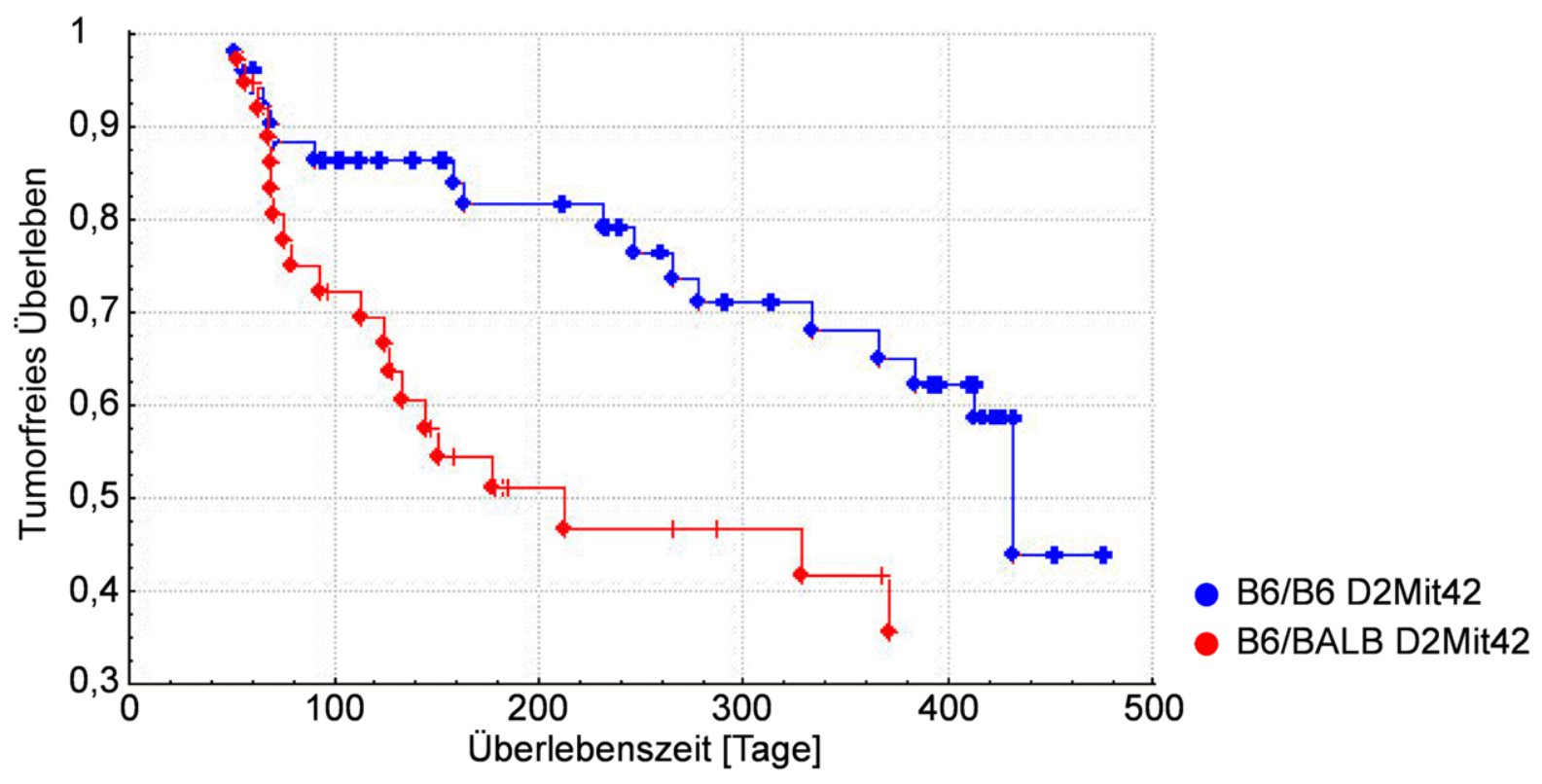

Abbildung 5: RMS-freie Überlebenszeit von B6x(BALBxB6)Ptch ${ }^{\text {neo67/+ }}$ N2-Mäusen. Dargestellt ist die tumorfreie Überlebenszeit von B6x(BALBxB6)Ptch ${ }^{\text {neo67/+ }}$ N2-Mäusen, die homozygot B6/B6 (blau) oder heterozygot B6/BALB (rot) am Marker D2Mit42 waren. Das Auftreten eines RMS ist mit einem Kreis gekennzeichnet. Tiere, die wegen eines Medulloblastoms oder aus anderen Gründen präpariert werden mussten, wurden als zensierte Beobachtungen in die Überlebenskurve einbezogen und sind mit Strichen eingezeichnet.

Für eine bessere Auflösung wurde im Rahmen dieser Arbeit in der Region um den Marker D2Mit42 eine weitere Analyse mit elf zusätzlichen Mikrosatellitenmarkern durchgeführt. Anhand dieser Marker konnte die Region für RMS-Suszeptibilität zwischen D2Mit37 und D2Mit102 eingegrenzt werden. Weiterhin zeigen die Daten, dass mehrere Mäuse im Intervall zwischen den an den Marker D2Mit42 angrenzenden Markern D2Mit37 und D2Mit102 (die für die Kopplungsanalyse verwendet wurden) ein Crossingover aufwiesen (siehe Tabelle 17). Diese Tiere konnten für eine weitere Einengung des Lokus verwendet werden (siehe 3.1).

Tabelle 17: Mäuse mit Crossing-over zwischen den Markern D2Mit37 und D2Mit102. Gezeigt ist die Anzahl der Tiere mit Crossing over zwischen den Markern D2Mit37 und D2Mit42 bzw. D2Mit42 und D2Mit102. Die Positionen der Marker wurden der Datenbank Ensembl entnommen. Abkürzungen: $\mathrm{cM}$, centiMorgan; Mb, Megabasen.

Intervall

$\mathrm{cM}$

$\mathrm{Mb}$

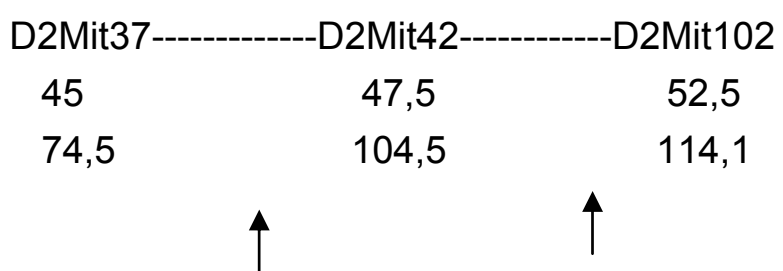

8

$30 \mathrm{Mb}$
5

$9.6 \mathrm{Mb}$ 
Mit den erhobenen Daten wurde ein Permutationstest durchgeführt. Bei diesem Test wird die Wahrscheinlichkeit der gefundenen Kopplung unter der Hypothese, dass der Zusammenhang zufällig ist, berechnet und mit dem LRS-Score (engl.: „likelihood ratio statistic“) angegeben. Mit einem LRS-Score von >10 war die Kopplung zum Marker D2Mit42 signifikant, da die Signifikanzschwelle bei 6,92 lag.

Anhand der erhobenen Daten konnte gezeigt werden, dass ein dominantes BALB-Allel in der Nähe des Markers D2Mit42 im Intervall zwischen D2Mit37 und D2Mit102 die Entstehung von RMS begünstigt. Der Lokus wurde mit Parms1 (Patched-Associated RMS 1) bezeichnet und erstreckt sich über $7,5 \mathrm{cM}$ bzw. 40 Megabasen (Mb). In Abbildung 6 ist das Ergebnis des Permutationstests dargestellt.

Aufgrund der Größe des Lokus Parms1 konnte die Möglichkeit, dass sich in diesem Bereich mehrere modifizierende Gene befinden, nicht ausgeschlossen werden. In der Region Parms1 sind derzeit 571 Gene bekannt, davon sind 55 bisher noch nicht beschrieben und 256 kodieren olfaktorische Rezeptoren. Diese Daten wurden 2004 in der Zeitschrift Genomics publiziert (H Hahn et al., 2004).

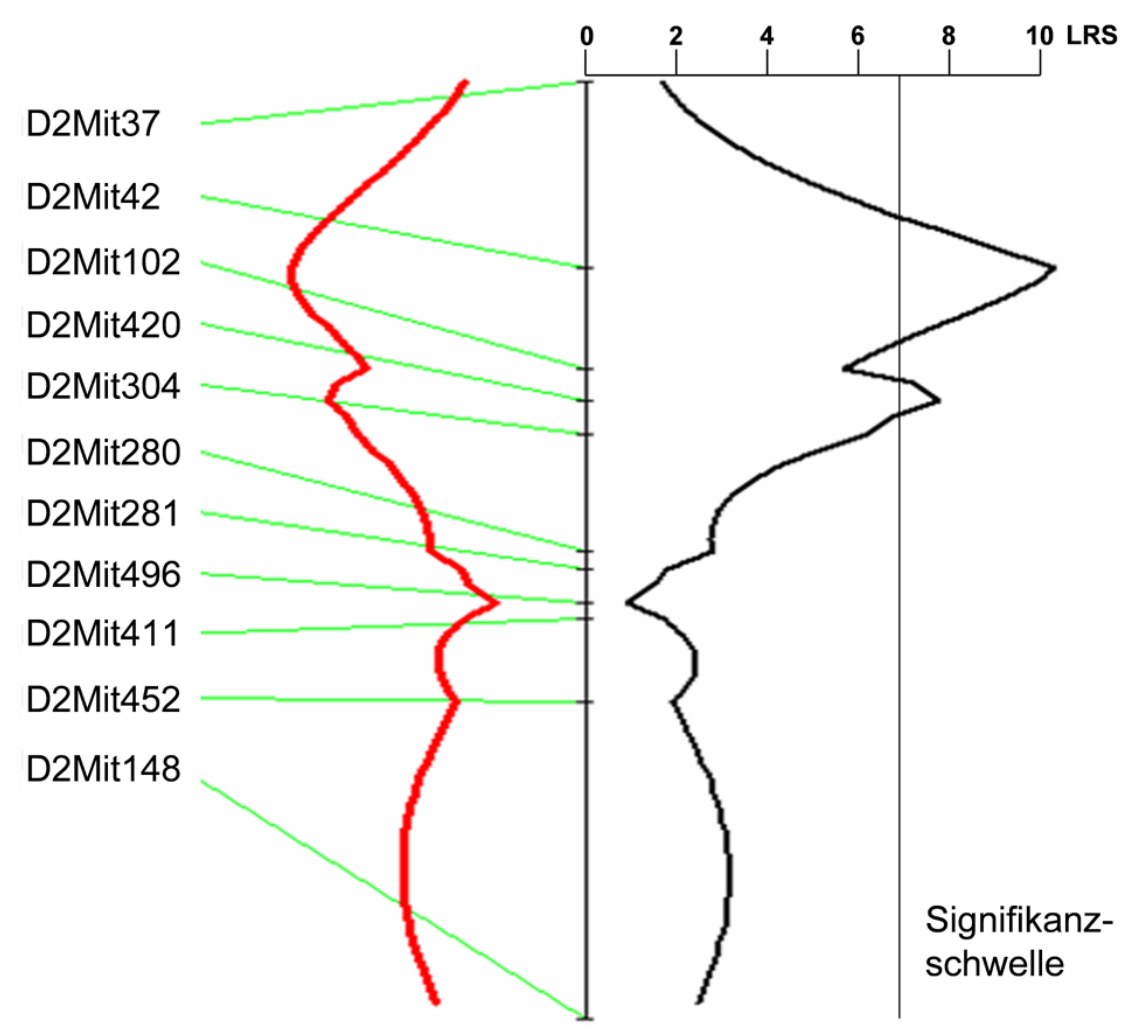

Abbildung 6: Position des RMS-Suszeptibilitätslokus Parms1. Anhand eines Permutationstests wurde der 7,5 cM umfassende Lokus Parms1 zwischen D2Mit37 und D2Mit102 identifiziert. In diesem Bereich lag der LRS-Score (schwarze Linie) oberhalb der Signifikanzschwelle. Die rote Linie zeigt den relativen Effekt eines mutmaßlichen RMS-Suszeptibilitäts-Allels auf die Entstehung von RMS. Abkürzung: LRS, likelihood ratio statistic. 


\subsubsection{Analyse von Kandidatengenen}

Im Rahmen dieser Arbeit wurden potentielle Kandidatengene untersucht, die die Suszeptibilität von RMS beeinflussen könnten. Da zum Zeitpunkt dieser Analysen die unter 3.1.1 beschriebenen Auswertungen noch nicht abgeschlossen waren, wurden auch Gene in der Region zwischen D2Mit102 und D2Mit304 als Kandidaten in Erwägung gezogen. Für eine Analyse wurden elf Kandidatengene ausgewählt. Von diesen lagen acht zwischen den Markern D2Mit37 und D2Mit102 und drei zwischen den Markern D2Mit102 und D2Mit304 in der Nähe des Markers D2Mit420. Sie wurden entweder mittels SNP-Analysen (engl.: „Single Nucleotide Polymorphism“ - Einzelpunktmutation) oder anhand von Expressionsanalysen an cDNA analysiert.

\subsection{SNP-Analysen}

Vier Gene wurden einer SNP-Analyse unterzogen. Während das Gen Wilms tumor homolog (Wt1) in Parms1 beim Marker D2Mit42 liegt, befinden sich Bcl-2 modifying factor (Bmf), Dispatched homolog 2 (Disp2) und Delta-like 4 (DIl4) in der Nähe des Markers D2Mit420.

Unter der Annahme, dass Polymorphismen zwischen B6 und BALB in den untersuchten Kandidatengenen zu den unterschiedlichen RMS-Inzidenzen bei Ptch $^{\text {neo67/+ }}{ }_{\text {-Mäusen }}$ abhängig vom genetischen Hintergrund führen können, wurden Abschnitte dieser Gene sequenziert. Es wurde ausschließlich genomische DNA des Mausstamms BALB sequenziert, da die Gensequenzen der Mauslinie B6 aus der Datenbank Ensembl bekannt waren.

Die Sequenzierungsanalysen beschränkten sich hierbei auf die kodierenden translatierten Regionen der Gene. Dazu wurden die Oligonukleotide so ausgewählt, dass die Anlagerungsstelle im Intron ca. 50 bis 80 Basenpaare vor dem Beginn oder Ende des zu sequenzierenden Exons lag. Für die Amplifikation und Sequenzierung der Fragmente wurden dieselben Oligonukleotide verwendet, daher konnte durch den Abstand zwischen Anlagerungsstelle und Exon die gesamte Sequenz des Exons erfasst werden. Bei großen Exonen wurden zusätzliche, im Exon lokalisierte Oligonukleotide für die Sequenzierung benutzt. Die verwendeten Oligonukleotide sind Tabelle 4 zu entnehmen.

Sämtliche im Rahmen dieser Arbeit ermittelten Polymorphismen von Einzelbasen (engl.: single nucleotide polymorphism - SNP) in kodierenden Regionen der Gene (sogenannte coding SNP oder cSNP) sind inzwischen auch in der Mouse Phenome Database (MPD) 
und anderen Datenbanken zu finden. Darüber hinaus wurden weitere cSNP für den Mausstamm BALB in dieser Arbeit detektiert.

Die bekannten sowie die in dieser Arbeit ermittelten cSNP werden im Folgenden beschrieben und sind zusammengefasst in Tabelle 18 dargestellt.

\subsection{Detektion von cSNP in Bmf}

Aufgrund der Interaktion von Bmf mit antiapoptotischen B-cell leukemia- (Bcl-2) Proteinen und eines möglichen Zusammenhangs mit dem Gli1-Zielgen Bcl-2 wurde eine Sequenzanalyse von Bmf durchgeführt. Zum Zeitpunkt der Analyse lautete die Bezeichnung Bmf-pending, und es waren nur drei Exone bekannt. Heute weiß man jedoch, dass das Gen Bmf aus fünf Exonen besteht. Die in der vorliegenden Arbeit sequenzierten Regionen entsprechen dabei den heutigen Exonen 3 und 4 sowie den ersten $130 \mathrm{bp}$ des Exons 5. Anhand der Analyse konnten zwei cSNP in den Exonen 3 und 5 gefunden werden (siehe Tabelle 18). Da es sich um synonyme SNP handelt, bewirken sie jedoch keine Veränderung der Aminosäuresequenz.

\subsection{Detektion von cSNP in Disp2}

Bei Disp1, das in den zellulären Export von modifiziertem Hh involviert ist, und auch bei dem bisher weniger genau charakterisierten Disp2 handelt es sich um Ptch-Homologe (M Evangelista et al., 2006). Disp2 ist in der Nähe der Region Parms1 beim Marker D2Mit420 lokalisiert, somit war es aufgrund einer möglichen Funktion in der Modulation der Hh/Ptch-Signalkaskade ein interessantes Kandidatengen. Zum Zeitpunkt der Sequenzierung war lediglich ein aus acht Exonen bestehendes Transkript bekannt. Das entsprechende Transkript, das in dieser Arbeit sequenziert wurde, kann in der Ensembl Datenbank unter der Nummer ENSMUST00000037547 abgerufen werden.

Insgesamt wurden 13 cSNP in den Exonen 2 und 8 gefunden (siehe Tabelle 18). Davon waren zwölf synonyme SNP, während eine T-C Transition an der mRNA-Position 3697 in Exon 8 einen Serin-Prolin Austausch in BALB bewirkt.

\subsection{Detektion von cSNP in Wt1}

Da die Expression von Wt1 in RMS beschrieben wurde, war die Analyse dieses Tumorsuppressorgens von Interesse (DF Carpentieri et al., 2002; T Mentzel und C Kuhnen, 2006). Das Wt1-Gen, das im Lokus Parms1 liegt, verfügt über zehn Exone, die 
alle sequenziert wurden. Dabei wurde ein synonymer cSNP in Exon 6 gefunden (siehe Tabelle 18).

\subsection{Detektion von CSNP in DII4}

Als weiteres Kandidatengen galt DII4, da es den Notch-Signalweg aktiviert, dessen Fehlregulation in verschiedenen Tumoren auftritt. Sämtliche elf Exone von DII4 wurden sequenziert, dabei wurden in den Exonen 8 und 9 insgesamt fünf cSNP identifiziert (siehe Tabelle 18), von denen vier SNP synonym waren. Ein SNP an mRNA-Position 1879 war nicht-synonym, da eine G-A Transition zu einem Glycin-Serin Austausch in BALB führt.

Tabelle 18: Zusammenstellung der gefundenen cSNP in Bmf, Disp2, Wt1 und DII4. Die SNP sind nach den mRNA-Positionen in den jeweiligen Genen sortiert. Für die Nummerierung der Exone wurde die heute bekannte Exon-Intron Struktur der Gene aus der Datenbank Mouse Phenome Database (MPD) verwendet. In der Spalte „SNP \#“ findet sich die Bezeichnung des SNP. Die SNP für B6 und BALB aus der MPD sind in der Spalte MPD angegeben, daneben die im Rahmen dieser Arbeit gefundenen SNP in BALB (in weißer Schrift). Bei weißen Feldern fehlt eine Angabe in der Datenbank MPD. Die letzte Spalte bezeichnet die Art des SNP, dabei steht Cs für einen synonymen und Cn für einen nicht-synonymen SNP.

\begin{tabular}{|c|c|c|c|c|c|c|c|}
\hline \multirow[t]{2}{*}{ Gen } & \multicolumn{2}{|c|}{ Position } & \multirow[t]{2}{*}{ SNP \# } & \multicolumn{2}{|c|}{ MPD } & \multirow[b]{2}{*}{ 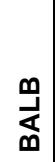 } & \multirow{2}{*}{$\begin{array}{l}\text { Art des } \\
\text { SNNP }\end{array}$} \\
\hline & mRNA & & & $\ddot{\infty}$ & $\underset{⿱ 亠}{\vec{\Phi}}$ & & \\
\hline \multirow[t]{2}{*}{$B m f$} & 437 & Exon 3 & rs3149883 & $T$ & & c & Cs \\
\hline & 773 & Exon 5 & rs3144666 & $\mathbf{T}$ & & c & Cs \\
\hline \multirow[t]{13}{*}{ Disp2 } & 51 & \multirow[t]{3}{*}{ Exon 2} & rs3144427 & $\mathbf{T}$ & c & c & Cs \\
\hline & 87 & & rs3149637 & c & 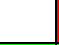 & A & Cs \\
\hline & 228 & & rs3149638 & A & $\mathbf{G}$ & G & Cs \\
\hline & 1212 & \multirow[t]{10}{*}{ Exon 8} & rs3149649 & $T$ & c & c & Cs \\
\hline & 1566 & & rs3149651 & $\mathbf{T}$ & c & c & Cs \\
\hline & 1632 & & rs3149652 & C & $\mathbf{T}$ & $\mathrm{T}$ & Cs \\
\hline & 1812 & & rs3144436 & C & $\mathbf{T}$ & $T$ & Cs \\
\hline & 1995 & & rs3149653 & C & A & A & Cs \\
\hline & 2428 & & rs3144437 & $T$ & c & c & Cs \\
\hline & 2451 & & rs3149655 & $T$ & c & c & Cs \\
\hline & 2874 & & rs3149656 & $T$ & & c & Cs \\
\hline & 3697 & & rs3149657 & $T$ & C & c & $\mathrm{Cn}$ \\
\hline & 4032 & & rs3144438 & $T$ & c & c & Cs \\
\hline Wt1 & 1284 & Exon 6 & rs27444886 & $T$ & & c & Cs \\
\hline \multirow[t]{5}{*}{ DII4 } & 1101 & Exon 8 & rs 27423758 & C & $\mathbf{T}$ & $\mathbf{T}$ & Cs \\
\hline & 1256 & \multirow[t]{4}{*}{ Exon 9} & rs 27423750 & A & $\mathbf{T}$ & $\mathbf{T}$ & Cs \\
\hline & 1419 & & rs27423749 & A & c & C & Cs \\
\hline & 1635 & & rs27423748 & C & $\mathbf{G}$ & G & Cs \\
\hline & 1879 & & rs 27423747 & G & $\mathrm{A}$ & A & $\mathrm{Cn}$ \\
\hline
\end{tabular}




\subsection{Expressionsanalysen}

Neben SNP-Analysen wurden Expressionsanalysen von Kandiatengenen der Region Parms1 durchgeführt. Dies erfolgte an cDNA aus dem Skelettmuskel (SM) von BALBund B6-Mäusen anhand von gebrauchsfertigen TaqMan-Assays. Für die Normalisierung der Expressionen der untersuchten Gene wurde ein 18s rRNA-spezifischer Assay der Firma Applied Biosystems verwendet.

Wie Abbildung 7 zeigt, wurden einige der untersuchten Gene unterschiedlich im SM von BALB und B6 exprimiert. Für Tnf receptor-associated factor 6 (Traf6), Catenin src (Catns) und ADP-ribosylation factor GTPase activating protein 2 (Zfp289) wurde eine ca. 2-fach höhere Expression in SM von B6 gefunden. Hingegen wiesen Midkine (Mdk), Apoptosis inhibitor 5 (Api5), Protein tyrosine phosphatase, receptor type, $J$ (Ptprj) und Ets homologous factor (Ehf) gleiche Expressionsniveaus in SM von BALB und B6 auf, während die Wilms tumor homolog (Wt1)-Expression im SM zu gering für eine zuverlässige Messung war (nicht gezeigt).

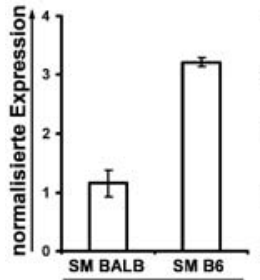

Traf6

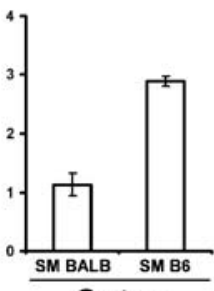

Catns

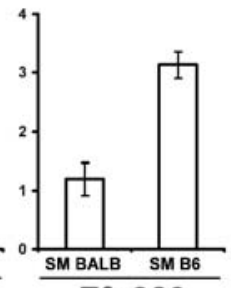

Zfp289

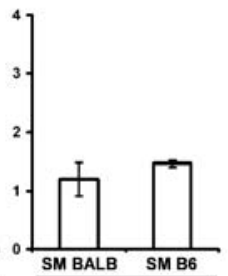

Mdk

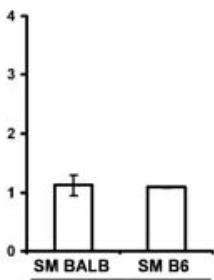

Api5

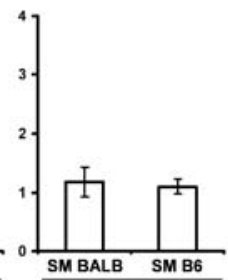

Ptprj

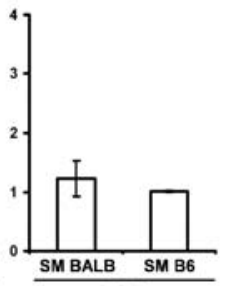

Ehf

Abbildung 7: Expressionsanalyse von Kandidatengenen in SM von BALB und B6. Die Expression wurde mittels TaqMan-Analysen an cDNA bestimmt und auf die Expression der 18S rRNA normalisiert.

\subsubsection{Etablierung einer neuen N2-Mauskolonie zur Eingrenzung von Parms1}

Da bekannt ist, dass die Auflösung einer genomweit durchgeführten Kartierung von QTL (engl.: quantitative trait locus) nicht besonders gut ist und sich meistens im Bereich von 10 bis 20 cM befindet (KW Hunter und RW Williams, 2002), musste eine zweite N2Rückkreuzung aufgebaut werden. Von dieser Rückkreuzung sollten dann solche Mäuse für weitere Feinkartierungsuntersuchungen eingesetzt werden, die in der Region zwischen den Markern D2Mit37 bis D2Mit102 (oder nach der zusätzlichen Kartierung eventuell noch enger zusammen liegender Marker) eine Rekombination zeigen. Anhand solcher Tiere wird eine weitere Engrenzung auf eine oder mehrere Kanidatenregionen innerhalb des Parms1-Lokus ermöglicht. Dazu benötigt man Mäuse, die in 
übereinstimmenden Bereichen von Parms1 eine Rekombination und gleichzeitig eine veränderte Suszeptibilität für RMS im Vergleich zu Mäusen ohne diese Rekombination aufweisen. Da D2Mit37 und D2Mit102 ca. 40 Mb auseinander liegen, wurde erwartet, dass ca. $25 \%$ aller Nachkommen eine Rekombination in diesem Intervall aufweisen (Mäuse zeigen ca. alle 1,7 cM ein Crossing-over).

Aus der neuen Rückkreuzung gingen 218 N2-Mäuse hervor. Mit Hilfe dieser Tiere sollte zunächst der Parms1-Lokus bestätigt, und weiterhin sollten diejenigen Mäuse für weiterführende Analysen einsetzt werden, welche eine Rekombination zwischen D2Mit37 und D2Mit102 zeigten.

Um die Anzahl der Tiere zu erhöhen, die zur Einengung des Lokus verwendet werden können, wurden auch zusätzlich Ptch $^{+/+}$-Wildtyp-Tiere, die rekombinant an diesem Lokus waren, mit B6Ptch ${ }^{\text {neo67/+}}$-Mäusen zurückgekreuzt.

\subsubsection{Detektion einer genetischen Kontamination im Mausstamm B6}

\subsection{Nachweis von auffälligen Genotypen in N2-Mäusen}

Zur Bestätigung des Parms1-Lokus wurde an der neu aufgebauten N2-Mauskolonie eine zweite genomweite Kopplungsanalyse mit 97 polymorphen Mikrosatellitenmarkern durchgeführt. Das Vorgehen ist bereits unter 3.1.1 beschrieben.

Im Verlauf der Datenerhebung wurden vermehrt Genotypen an mehreren Markern nachgewiesen, die scheinbar homozygot für BALB waren. Diese „BALB/BALB“Genotypen waren zunächst unerklärlich, da sämtliche Tiere Nachkommen einer Rückkreuzung von (BALBxB6)Ptch ${ }^{\text {neo67/+ }}$-Hybriden auf die Mauslinie B6 waren und somit an keinem Lokus das Vorliegen eines „BALB/BALB“-Genotyps bzw. das Fehlen eines B6-Allels möglich schien.

Nach der Genotypisierung von 85 Markern in 57 Mäusen bei 32 verschiedenen Mikrosatellitenmarkern wurden 134 dieser „BALB/BALB“-Genotypen gefunden. Alle analysierten Marker und die Anzahl der Tiere mit diesen Genotypen für den jeweiligen Marker sind in Tabelle 19 angegeben. Diese Ergebnisse wurden durch mehrfache Wiederholungen bestätigt.

Um die Ursache für die „BALB/BALB“-Genotypen in N2-Mäusen zu finden, wurden die Elterngenerationen (BALBxB6)Ptch ${ }^{\text {neo67/+ }}$ und B6 überprüft. (BALBxB6)Ptch ${ }^{\text {neo67/+ }}$-Mäuse wurden aus weiblichen BALB-Mäusen, die von Charles River Laboratories (L'Arbresle, Frankreich) erworben wurden, und männlichen B6Ptch ${ }^{\text {neo67/+ }}$-Tieren aus der Hauszucht generiert. Sämtliche für die Zucht von N2-Mäusen verwendeten Wildtyp B6-Weibchen 
hingegen stammten von Charles River Laboratories (Sulzfeld). Es wurden 17 Mikrosatellitenmarker bei 15 (BALBxB6) $P_{t c h}{ }^{\text {neo67/+}}$-Männchen genotypisiert. Alle Tiere zeigten den zu erwartenden heterozygoten Genotyp B6/BALB (siehe Tabelle 19). Dagegen wurde bei acht von zwölf weiblichen Wildtyp B6-Mäusen von Charles River Laboratories mit 18 verschiedenen Mikrosatellitenmarkern tatsächlich eine Heterozygotie festgestellt. Da diese Tiere zur Inzuchtlinie B6 gehörten, waren aber ausschließlich B6/B6-Genotypen zu erwarten. Somit wurde eine genetische Kontamination von B6Mäusen von Charles River Laboratories festgestellt.

\subsection{Zeitverlauf der Kontamination von B6-Mäusen}

Um die Kontamination zu bestätigen, erfolgten weitere Analysen von B6-Mäusen von Charles River Laboratories. Die zuerst genotypisierten weiblichen Wildtyp B6-Mäuse (siehe oben) waren im Herbst 2003 zugekauft worden. Ebenfalls genotypisiert wurden sieben B6-Mäuse, die im Frühjahr 2004, und zwölf B6-Mäuse, die im Mai 2005 von Charles River Laboratories bezogen wurden. Dabei konnten bei fünf der sieben Mäuse vom Frühjahr 2003 heterozygote Genotypen an sieben verschiedenen Markern nachgewiesen werden. Von den zwölf Tieren vom Mai 2005 zeigten sieben Tiere mit fünf unterschiedlichen Markern Heterozygotie. Wie auf Nachfrage von Charles River Laboratories mitgeteilt wurde, stammten sämtliche im Zeitraum zwischen Herbst 2003 und Mai 2005 erworbenen B6-Mäuse aus demselben Zuchtraum (A).

Zusätzlich wurde eine Analyse von 26 weiteren B6-Mäusen aus einem anderen Zuchtraum (B) desselben Anbieters durchgeführt. Diese Tiere waren im Januar 2005 zugekauft und für ein anderes Kartierungsprojekt verwendet worden. Unter diesen Tieren fanden sich nur zwei Mäuse, die für jeweils einen Marker heterozygot waren. Sämtliche Ergebnisse sind in Tabelle 19 aufgelistet. 
Tabelle 19: Analysierte Marker bei N2-, (BALBxB6)Ptch ${ }^{\text {neo67/+ }}$ - und B6-Mäusen. Eine Genotypisierung mit 85 Mikrosatellitenmarkern erfolgte von N2-, (BALBxB6)Ptch ${ }^{\text {neo67/+ }}$ - und zusätzlich von B6-Mäusen, die zu vier verschiedenen Zeitpunkten aus zwei verschiedenen Zuchträumen (Räume A und B) von Charles River Laboratories erworben wurden. B6-Tiere vom Herbst 2003, Frühjahr 2004 und Mai 2005 stammten aus Raum A, die Tiere vom Januar 2005 aus Raum B. Sämtliche 85 Marker wurden bei N2-Mäusen analysiert. Die bei (BALBXB6)Ptch ${ }^{\text {neo67/+ }}$ und B6 untersuchten Marker sind mit „+“ markiert. In den Spalten „Tiere mit abweichendem Genotyp“ ist die Anzahl der Mäuse mit fehlendem B6-Allel am jeweiligen Marker angegeben. Die prozentualen Anteile betroffener Marker bzw. Mäuse in den verschiedenen Gruppen finden sich am Tabellenende.

\begin{tabular}{|c|c|c|c|c|c|c|c|c|c|c|c|c|c|}
\hline \multirow[b]{2}{*}{ 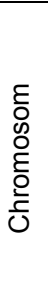 } & \multirow[b]{2}{*}{ 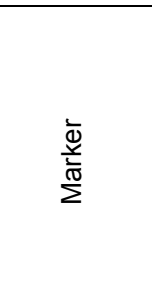 } & \multicolumn{2}{|l|}{$\mathrm{N} 2$} & \multicolumn{2}{|c|}{$\begin{array}{l}\text { (BALBXB6) } \\
P_{t c h^{\text {noo67//+ }}}\end{array}$} & \multicolumn{2}{|c|}{$\begin{array}{l}\text { B6 } \\
\text { Herbst } 2003\end{array}$} & \multicolumn{2}{|c|}{$\begin{array}{l}\text { B6 } \\
\text { Frühjahr } 2004\end{array}$} & \multicolumn{2}{|c|}{$\begin{array}{l}\text { B6 } \\
\text { Mai } 2005\end{array}$} & \multicolumn{2}{|c|}{$\begin{array}{l}\text { B6 } \\
\text { Januar } 2005\end{array}$} \\
\hline & & $\frac{\frac{t}{d}}{\frac{\pi}{\omega}}$ & 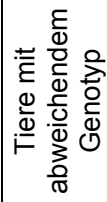 & 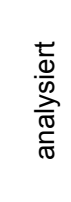 & 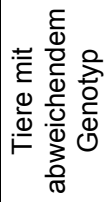 & $\frac{\frac{\pi}{\omega}}{\frac{\pi}{\omega}}$ & 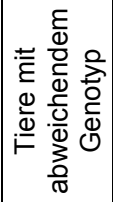 & 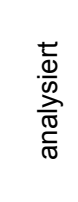 & 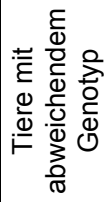 & 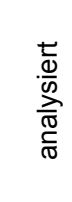 & 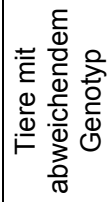 & 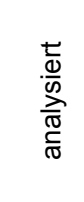 & 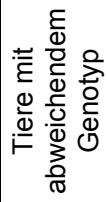 \\
\hline \multirow[t]{6}{*}{1} & D1Mit411 & + & & & & & & & & & & & \\
\hline & D1Mit22 & + & 4 & + & & + & 2 & + & & + & & + & \\
\hline & D1Mit132 & + & & & & & & & & & & & \\
\hline & D1Mit187 & + & 2 & + & & + & 2 & + & 3 & & & & \\
\hline & D1Mit399 & + & & & & & & & & & & & \\
\hline & D1Mit223 & + & & & & & & & & & & & \\
\hline \multirow[t]{4}{*}{2} & D2Mit37 & + & & & & & & + & & + & & + & \\
\hline & D2Mit249 & + & & & & & & & & & & & \\
\hline & D2Mit452 & + & & & & & & & & & & & \\
\hline & D2Mit148 & + & & & & & & + & & + & & + & \\
\hline \multirow[t]{6}{*}{3} & D3Mit164 & + & 1 & + & & + & 2 & + & & + & & + & \\
\hline & D3Mit6 & + & 1 & & & + & 2 & + & & + & 1 & + & \\
\hline & D3Mit49 & + & & & & & & & & & & & \\
\hline & D3Mit318 & + & & & & & & & & & & & \\
\hline & D3Mit116 & + & & & & & & & & & & & \\
\hline & D3Mit19 & + & 4 & & & + & 4 & + & & & & & \\
\hline \multirow[t]{5}{*}{4} & D4Mit235 & + & 6 & + & & & & + & & + & & + & \\
\hline & D4Mit286 & + & & & & & & & & & & & \\
\hline & D4Mit15 & + & & & & & & & & & & & \\
\hline & D4Mit203 & + & & & & & & & & & & & \\
\hline & D4Mit170 & + & & & & & & & & & & & \\
\hline \multirow[t]{6}{*}{5} & D5Mit386 & + & & & & & & & & & & & \\
\hline & D5Mit79 & + & 5 & + & & + & 2 & + & & + & & + & \\
\hline & D5Mit197 & + & & & & & & & & & & & \\
\hline & D5Mit239 & + & & & & & & & & & & & \\
\hline & D5Mit406 & + & & & & & & & & & & & \\
\hline & D5Mit95 & + & & & & & & & & & & & \\
\hline \multirow[t]{6}{*}{6} & D6Mit138 & + & & & & & & & & & & & \\
\hline & D6Mit274 & + & 1 & + & & + & & + & & + & & + & \\
\hline & D6Mit230 & + & & + & & + & & + & 1 & + & & + & \\
\hline & D6Mit36 & + & & & & & & & & & & & \\
\hline & D6Mit59 & + & 3 & + & & + & & + & & + & & + & 1 \\
\hline & D6Mit373 & + & & & & & & & & & & & \\
\hline \multirow[t]{5}{*}{7} & D7Mit306 & + & & & & & & & & & & & \\
\hline & D7Mit310 & + & & & & & & & & & & & \\
\hline & D7Mit96 & + & & & & & & & & & & & \\
\hline & D7Mit68 & + & & & & & & & & & & & \\
\hline & D7Mit101 & + & & & & & & & & & & & \\
\hline \multirow[t]{2}{*}{8} & D8Mit231 & + & & & & & & & & & & & \\
\hline & D8Mit49 & + & & & & & & & & & & & \\
\hline \multirow[t]{5}{*}{9} & D9Mit328 & + & 6 & + & & + & & + & & + & 2 & + & \\
\hline & D9Mit336 & + & & & & & & & & & & & \\
\hline & D9Mit35 & + & & & & & & & & & & & \\
\hline & D9Mit12 & + & 9 & + & & + & 2 & + & & + & & + & \\
\hline & D9Mit125 & + & & & & & & & & & & & \\
\hline 10 & D10Mit213 & + & & & & & & & & & & & \\
\hline & D10Mit274 & + & & & & & & & & & & & \\
\hline & D10Mit95 & + & 1 & + & & + & & + & & + & & + & 1 \\
\hline
\end{tabular}




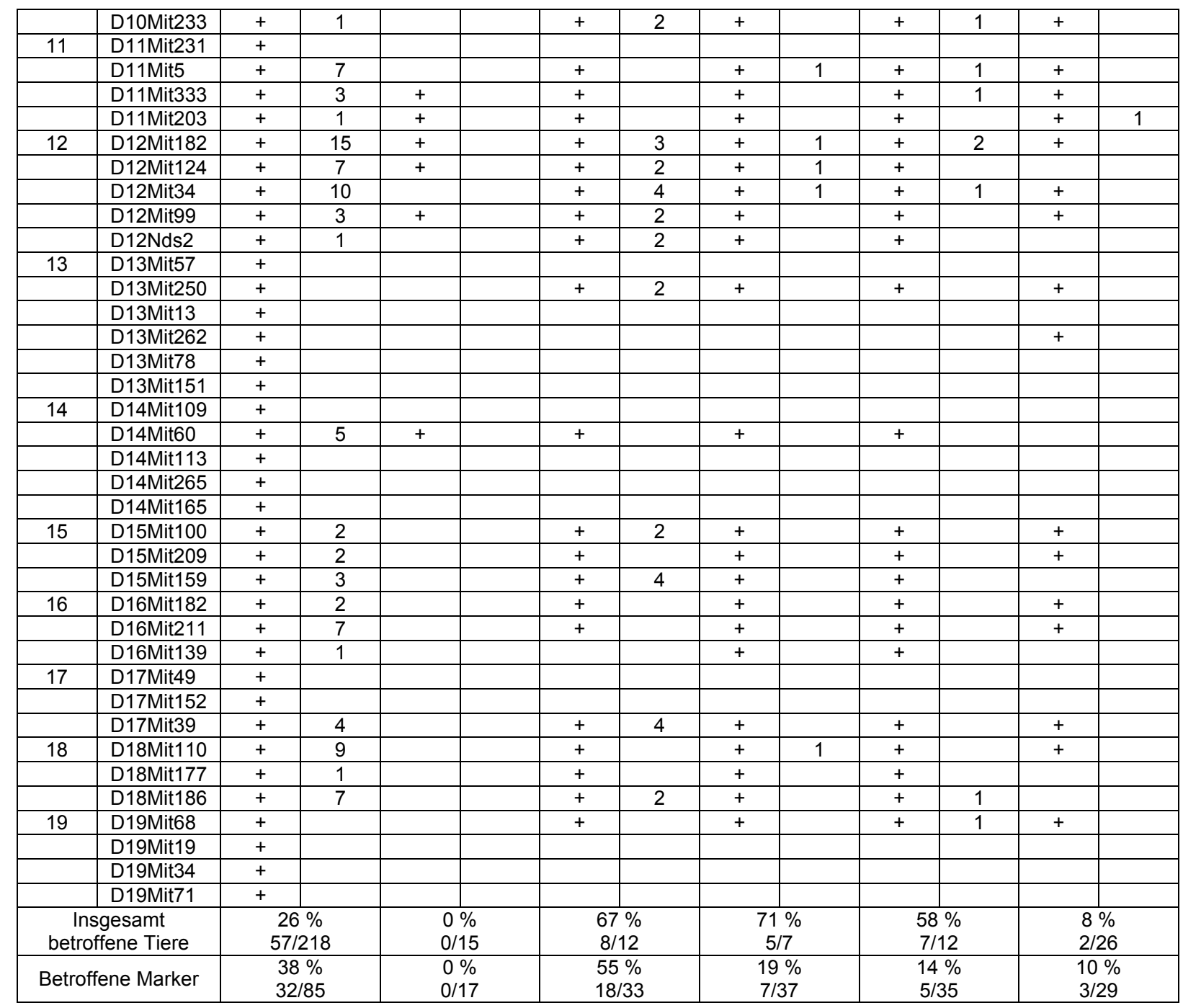

Zusammengefasst zeigen diese Ergebnisse, dass sich unter allen zu den verschiedenen Zeitpunkten aus zwei verschiedenen Zuchträumen (A und B) erworbenen Tieren B6Mäuse mit einer genetischen Kontamination befanden. Dabei waren die beiden Zuchträume offensichtlich unterschiedlich stark betroffen. Die für die Generierung der N2-Mäuse verwendeten Tiere stammten aus dem stärker betroffenen Raum A. Innerhalb der Zeit vom Herbst 2003 bis Frühjahr 2005 scheint sich das Ausmaß der Kontamination etwas verringert zu haben, zumindest in den analysierten Tieren.

\subsection{Identifikation der kontaminierenden Mauslinie}

Eine Kontamination mit dem BALB-Mausstamm wäre zunächst denkbar, da die „Kontaminante“ in der PCR stets Fragmente ergab, die auch für die entsprechenden Mikrosatelliten des Mausstamms BALB erwartet wurden. Allerdings ist eine genaue Bestimmung der Mikrosatellitengröße über die PCR-Analyse nicht möglich. Da es weitere, mit BALB verwandte Mauslinien gibt, die mit den verwendeten Markern dieselbe Fragmentgröße wie BALB in der PCR zeigen, wurde eine Analyse von 100 SNP durch 
das Jackson Laboratory (Bar Harbor, USA) durchgeführt. Anhand dieser SNP, die jedes Autosom und das X-Chromosom abdecken, wird eine Unterscheidung zwischen verschiedenen Inzuchtlinien ermöglicht (PM Petkov et al., 2004).

Zwei B6-Mäuse vom Herbst 2003, eine vom Frühling 2004 und sieben vom Mai 2005 wurden mit der SNP-Auswahl des Jackson Laboratories analysiert. Insgesamt 79 der untersuchten SNP zeigten einen homozygoten B6-Genotyp, wohingegen 21 SNP bei jeweils bis zu drei Mäusen heterozygot waren (Tabelle 20). B6-Tiere aus allen untersuchten Zeiträumen zwischen 2003 und 2005 waren betroffen. Alle heterozygoten Genotypen wiesen ein B6-Allel und ein davon abweichendes Allel auf. Um die Herkunft dieser Allele festzustellen, wurden sie mit den Allelen von 103 verschiedenen Inzuchtlinien verglichen (PM Petkov et al., 2004). Dabei stellte sich heraus, dass 20 der 21 von B6 abweichenden Allele in drei von vier DBA-Inzuchtlinien des Jackson Laboratories vorkommen (siehe Tabelle 21). Somit war eine Kontamination der B6Mäuse mit einer DBA-Inzuchtlinie am wahrscheinlichsten.

Tabelle 20: Wildtyp B6-Mäuse von Charles River Laboratories zeigen für 21 SNP einer Auswahl von 100 SNP eine Heterozygotie, die die Unterscheidung von verschiedenen Inzuchtlinien ermöglicht. Von zehn Mäusen (M1 bis M10), die im Zeitraum von 2003 bis 2005 bei Charles River Laboratories zugekauft worden sind, waren jeweils bis zu drei Mäuse für 21 von 100 analysierten SNP heterozygot. Die Bezeichnung der SNP ist unter „SNP \#“ angegeben, daneben mit „Allel I" benannt der Genotyp von B6. Unter „Allel II“ sind die von Allel I, d. h. von B6 abweichenden Allele, in den analysierten Mäusen aufgelistet.

\begin{tabular}{|c|c|c|c|c|c|c|c|c|c|c|c|}
\hline \multirow{3}{*}{ SNP \# } & \multirow{3}{*}{ Allel I } & \multicolumn{10}{|c|}{ Allel II (wenn abweichend von Allel I) } \\
\hline & & \multicolumn{2}{|c|}{ 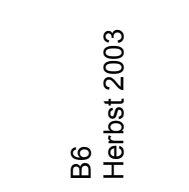 } & \multirow{2}{*}{ 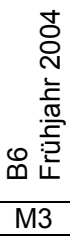 } & \multicolumn{7}{|c|}{ œ } \\
\hline & & M1 & M2 & & M4 & M5 & M6 & M7 & M8 & M9 & M10 \\
\hline 01-191804699-M & A & & & $\mathrm{T}$ & $\mathrm{T}$ & & & & & & \\
\hline 02-146910375-M & $\mathrm{G}$ & & & & & A & & & & & \\
\hline 04-068252469-M & $\mathrm{C}$ & $\mathrm{T}$ & $\mathrm{T}$ & & & & & & & & \\
\hline 04-151168886-M & $\mathrm{G}$ & $\mathrm{T}$ & $\mathrm{T}$ & & & & & & & & \\
\hline $07-135345950-\mathrm{N}$ & A & & & & & & $\mathrm{G}$ & & & & \\
\hline $09-013396060-\mathrm{N}$ & A & & & & & & & & & G & \\
\hline $09-066767939-\mathrm{N}$ & $\mathrm{G}$ & & & & & & & & & A & \\
\hline 11-041505703-M & $\mathrm{T}$ & & & & & G & & & & & $\mathrm{G}$ \\
\hline $11-066278669-\mathrm{N}$ & A & & & $\mathrm{T}$ & & $\mathrm{T}$ & & & & & \\
\hline 12-037298090-M & A & & & $\mathrm{C}$ & $\mathrm{C}$ & & & & & & \\
\hline $12-064212930-\mathrm{N}$ & $A$ & & & $\mathrm{G}$ & $\mathrm{G}$ & & & & & & $\mathrm{T}$ \\
\hline 12-112276179-M & A & $\mathrm{T}$ & $\mathrm{T}$ & & & & & & & & \\
\hline 14-016156211-M & $\mathrm{G}$ & & & & & $\mathrm{A}$ & & & & & \\
\hline 15-026132801-M & A & $\mathrm{G}$ & $\mathrm{G}$ & & & & & & & & \\
\hline 15-052940678-M & A & $\mathrm{T}$ & $\mathrm{T}$ & & & & & & & & \\
\hline 15-088202966-M & A & $\mathrm{G}$ & $\mathrm{G}$ & & & & & & & & \\
\hline 17-089136255-M & $\mathrm{T}$ & $\mathrm{C}$ & $\mathrm{C}$ & & & & & & & & \\
\hline 17-093441700-M & $\mathrm{T}$ & $\mathrm{C}$ & $\mathrm{C}$ & & & & & & & & \\
\hline 18-086980249-M & $\mathrm{G}$ & & & & & & A & & & & \\
\hline $19-005218596-\mathrm{N}$ & $\mathrm{T}$ & & & & & $\mathrm{C}$ & & & & & \\
\hline X-143466659-M & $\mathrm{A}$ & & & & & $\mathrm{C}$ & & & & & \\
\hline
\end{tabular}


Tabelle 21: 20 der 21 „nicht-B6“-Allele (siehe Tabelle 20) stammen aus dem Mausstamm DBA. Für 103 Inzuchtlinien sind die Allele der 21 SNP aufgelistet, die heterozygot bei B6 waren (siehe Tabelle 20). In den Spalten unter der Bezeichnung der SNP ist der Genotyp in den verschiedenen Mauslinien angegeben. Die Inzuchtlinien samt Bezeichnung vom Jackson Laboratory (,JAX Stock \#“) sind nach sinkender Wahrscheinlichkeit für die Herkunft der Kontamination von B6 aus diesen Linien sortiert. In der letzten Spalte sind die Unterschiede der Inzuchtlinien zu B6 dargestellt, dabei entspricht 1 der maximalen Diskrepanz zu B6. Lila markiert sind von B6 unterschiedliche, schwarz markiert nicht bestimmte Allele.

\begin{tabular}{|c|c|c|c|c|c|c|c|c|c|c|c|c|c|c|c|c|c|c|c|c|c|c|c|}
\hline Mauslinie & 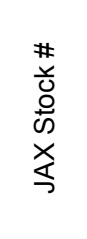 & $\begin{array}{l}\Sigma \\
1 \\
\delta \\
0 \\
0 \\
0 \\
\infty \\
\sigma \\
\frac{\sigma}{1} \\
\vdots \\
0\end{array}$ & 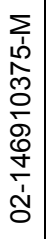 & 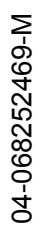 & 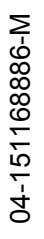 & 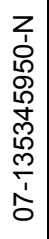 & 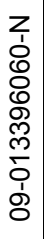 & 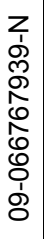 & $\begin{array}{l}\sum_{1} \\
0 \\
0 \\
0 \\
10 \\
0 \\
10 \\
\dot{1} \\
0 \\
1 \\
\frac{1}{\sigma}\end{array}$ & 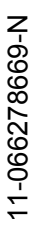 & 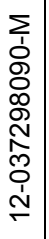 & 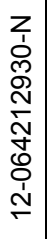 & 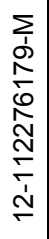 & 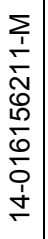 & 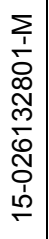 & 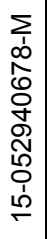 & 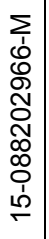 & 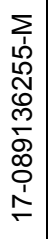 & 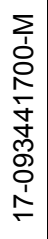 & 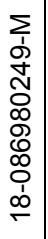 & 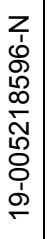 & 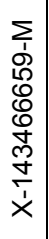 & 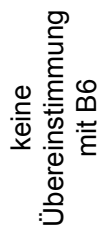 \\
\hline DBA/1J & 670 & $\mathrm{~T}$ & $\mathrm{G}$ & $\mathrm{T}$ & $\mathrm{T}$ & $\mathrm{G}$ & $\mathrm{G}$ & $\mathrm{A}$ & $\mathrm{G}$ & $\mathrm{T}$ & $\mathrm{C}$ & $\mathrm{G}$ & $\mathrm{T}$ & $\mathrm{A}$ & $\mathrm{G}$ & $\mathrm{T}$ & $\mathrm{G}$ & $\mathrm{C}$ & $\mathrm{C}$ & $\mathrm{A}$ & $\mathrm{C}$ & $\mathrm{C}$ & 0,95 \\
\hline DBA/1LacJ & 1140 & $\mathrm{~T}$ & $\mathrm{G}$ & $\mathrm{T}$ & $\mathrm{T}$ & $\mathrm{G}$ & $\mathrm{G}$ & $\mathrm{A}$ & $\mathrm{G}$ & $\mathrm{T}$ & $\mathrm{C}$ & $\mathrm{G}$ & $\mathrm{T}$ & $\mathrm{A}$ & $\mathrm{G}$ & $\mathrm{T}$ & $\mathrm{G}$ & $\mathrm{C}$ & $\mathrm{C}$ & $\mathrm{A}$ & $\mathrm{C}$ & $\mathrm{C}$ & 0,95 \\
\hline DBA/2HaSmnJ & 973 & $\mathrm{~T}$ & $\mathrm{~A}$ & $\mathrm{~T}$ & $\mathrm{~T}$ & $\mathrm{G}$ & $\mathrm{G}$ & $\mathrm{A}$ & $\mathrm{T}$ & $\mathrm{T}$ & $\mathrm{C}$ & $\mathrm{G}$ & $\mathrm{T}$ & $\mathrm{A}$ & $\mathrm{G}$ & $\mathrm{T}$ & $\mathrm{G}$ & $\mathrm{C}$ & $\mathrm{C}$ & $A$ & $\mathrm{C}$ & $\mathrm{C}$ & 0,95 \\
\hline $\mathrm{DBA} / 2 \mathrm{~J}$ & 671 & $\mathrm{~T}$ & $\mathrm{G}$ & $\mathrm{T}$ & $\mathrm{T}$ & $\mathrm{G}$ & $\mathrm{G}$ & $\mathrm{A}$ & $\mathrm{T}$ & $\mathrm{T}$ & $\mathrm{C}$ & $\mathrm{G}$ & $\mathrm{T}$ & $\mathrm{A}$ & $\mathrm{G}$ & $\mathrm{T}$ & $\mathrm{G}$ & $\mathrm{C}$ & $\mathrm{C}$ & $A$ & $\mathrm{C}$ & $\mathrm{C}$ & 0,90 \\
\hline SENCARA/PtJ & 2746 & $\mathrm{~T}$ & $\mathrm{~A}$ & $\mathrm{~T}$ & $\mathrm{~T}$ & $\mathrm{G}$ & $\mathrm{A}$ & $\mathrm{A}$ & $\mathrm{G}$ & $\mathrm{A}$ & $\mathrm{C}$ & $\mathrm{G}$ & $\mathrm{T}$ & $\mathrm{A}$ & $\mathrm{G}$ & $\mathrm{T}$ & $\mathrm{G}$ & $\mathrm{C}$ & $\mathrm{C}$ & $\mathrm{A}$ & $\mathrm{C}$ & $\mathrm{C}$ & 0,90 \\
\hline SENCARB/PtJ & 2747 & $\mathrm{~T}$ & $\mathrm{~A}$ & $\mathrm{~T}$ & $\mathrm{~T}$ & $\mathrm{G}$ & $\mathrm{A}$ & $\mathrm{A}$ & $\mathrm{G}$ & $\mathrm{A}$ & $\mathrm{C}$ & $\mathrm{G}$ & $\mathrm{T}$ & $\mathrm{A}$ & $\mathrm{G}$ & $\mathrm{T}$ & $\mathrm{G}$ & $\mathrm{C}$ & $\mathrm{C}$ & $\mathrm{A}$ & $\mathrm{C}$ & $\mathrm{C}$ & 0,90 \\
\hline ST/bJ & 688 & $\mathrm{~T}$ & $\mathrm{~A}$ & $\mathrm{~T}$ & $\mathrm{~T}$ & $\mathrm{G}$ & $\mathrm{G}$ & $\mathrm{A}$ & $\mathrm{T}$ & $\mathrm{T}$ & $\mathrm{C}$ & $\mathrm{G}$ & $\mathrm{A}$ & $\mathrm{A}$ & $\mathrm{G}$ & $\mathrm{T}$ & $\mathrm{G}$ & $\mathrm{C}$ & $\mathrm{C}$ & $\mathrm{A}$ & $\mathrm{C}$ & $\mathrm{C}$ & 0,90 \\
\hline BALB/cByJ & 1026 & $\mathrm{~T}$ & $\mathrm{~A}$ & $\mathrm{~T}$ & $\mathrm{~T}$ & $\mathrm{G}$ & $\mathrm{G}$ & $\mathrm{A}$ & $\mathrm{G}$ & $\mathrm{T}$ & $\mathrm{C}$ & $\mathrm{G}$ & $\mathrm{T}$ & $\mathrm{A}$ & $\mathrm{A}$ & $\mathrm{A}$ & $\mathrm{G}$ & $\mathrm{C}$ & $\mathrm{T}$ & $\mathrm{A}$ & $\mathrm{C}$ & $\mathrm{C}$ & 0,86 \\
\hline $\mathrm{BALB} / \mathrm{cJ}$ & 651 & $\mathrm{~T}$ & $\mathrm{~A}$ & $\mathrm{~T}$ & $\mathrm{~T}$ & $\mathrm{G}$ & $\mathrm{G}$ & $\mathrm{A}$ & $\mathrm{G}$ & $\mathrm{T}$ & $\mathrm{C}$ & $\mathrm{G}$ & $\mathrm{T}$ & $\mathrm{A}$ & $\mathrm{A}$ & $\mathrm{A}$ & $\mathrm{G}$ & $\mathrm{C}$ & $\mathrm{T}$ & $\mathrm{A}$ & $\mathrm{C}$ & $\mathrm{C}$ & 0,86 \\
\hline BUB/BnJ & 653 & $\mathrm{~T}$ & $\mathrm{~A}$ & $\mathrm{~T}$ & $\mathrm{~T}$ & $\mathrm{G}$ & $\mathrm{G}$ & $\mathrm{A}$ & $\mathrm{G}$ & $\mathrm{A}$ & $\mathrm{C}$ & $\mathrm{G}$ & $\mathrm{T}$ & $\mathrm{G}$ & $\mathrm{A}$ & $\mathrm{T}$ & $\mathrm{G}$ & $\mathrm{C}$ & $\mathrm{C}$ & $A$ & $\mathrm{C}$ & $\mathrm{C}$ & 0,86 \\
\hline CBA/CaJ & 654 & $\mathrm{~T}$ & $\mathrm{~A}$ & $\mathrm{~T}$ & $\mathrm{~T}$ & $\mathrm{G}$ & $\mathrm{G}$ & $\mathrm{G}$ & $\mathrm{G}$ & A & $\mathrm{C}$ & $\mathrm{G}$ & $\mathrm{T}$ & $\mathrm{A}$ & $\mathrm{G}$ & $\mathrm{T}$ & $\mathrm{A}$ & $\mathrm{C}$ & $\mathrm{C}$ & $\mathrm{A}$ & $\mathrm{C}$ & $\mathrm{C}$ & 0,86 \\
\hline SENCARC/PtJ & 2748 & $\mathrm{~T}$ & $\mathrm{~A}$ & $\mathrm{~T}$ & $\mathrm{~T}$ & $\mathrm{G}$ & $\mathrm{A}$ & $\mathrm{A}$ & $\mathrm{T}$ & $\mathrm{A}$ & $\mathrm{C}$ & $\mathrm{G}$ & $\mathrm{T}$ & $\mathrm{A}$ & $\mathrm{G}$ & $\mathrm{T}$ & $\mathrm{G}$ & $\mathrm{C}$ & $\mathrm{C}$ & $\mathrm{A}$ & $\mathrm{C}$ & $\mathrm{C}$ & 0,86 \\
\hline SEC/1ReJ & 685 & $\mathrm{~T}$ & $\mathrm{~A}$ & $\mathrm{~T}$ & $\mathrm{~T}$ & $\mathrm{G}$ & $\mathrm{G}$ & $A$ & $\mathrm{G}$ & $A$ & $\mathrm{C}$ & $\mathrm{G}$ & & $A$ & $A$ & & $\mathrm{G}$ & $\mathrm{C}$ & $\mathrm{T}$ & $A$ & $\mathrm{C}$ & $\mathrm{C}$ & 0,84 \\
\hline $\mathrm{C} 3 \mathrm{H} / \mathrm{HeJ}$ & 659 & $\mathrm{~T}$ & A & $\mathrm{T}$ & $\mathrm{T}$ & $\mathrm{G}$ & $\mathrm{G}$ & A & $\mathrm{G}$ & A & $\mathrm{C}$ & $\mathrm{G}$ & $\mathrm{T}$ & G & $\mathrm{A}$ & $\mathrm{T}$ & $\mathrm{A}$ & $\mathrm{C}$ & C & A & $\mathrm{C}$ & $\mathrm{C}$ & 0,81 \\
\hline $\mathrm{C} 3 \mathrm{H} / \mathrm{HeN}$ & & $\mathrm{T}$ & $\mathrm{A}$ & $\mathrm{T}$ & $\mathrm{T}$ & $\mathrm{G}$ & $\mathrm{G}$ & $\mathrm{A}$ & $\mathrm{G}$ & $\mathrm{A}$ & $\mathrm{C}$ & $\mathrm{G}$ & $\mathrm{T}$ & $\mathrm{G}$ & $\mathrm{A}$ & $\mathrm{T}$ & $\mathrm{A}$ & $\mathrm{C}$ & C & $\mathrm{A}$ & $\mathrm{C}$ & $\mathrm{C}$ & 0,81 \\
\hline $\mathrm{C} 3 \mathrm{H} / \mathrm{HeOuJ}$ & 635 & $\mathrm{~T}$ & $\mathrm{~A}$ & $\mathrm{~T}$ & $\mathrm{~T}$ & $\mathrm{G}$ & $\mathrm{G}$ & $\mathrm{A}$ & $\mathrm{G}$ & $\mathrm{A}$ & $\mathrm{C}$ & $\mathrm{G}$ & $\mathrm{T}$ & $\mathrm{G}$ & $\mathrm{A}$ & $\mathrm{T}$ & $\mathrm{A}$ & $\mathrm{C}$ & $\mathrm{C}$ & $\mathrm{A}$ & $\mathrm{C}$ & $\mathrm{C}$ & 0,81 \\
\hline $\mathrm{C} 3 \mathrm{H} / \mathrm{HeSnJ}$ & 661 & $\mathrm{~T}$ & $\mathrm{~A}$ & $\mathrm{~T}$ & $\mathrm{~T}$ & $\mathrm{G}$ & $\mathrm{G}$ & $\mathrm{A}$ & $\mathrm{G}$ & $A$ & $\mathrm{C}$ & $\mathrm{G}$ & $\mathrm{T}$ & $\mathrm{G}$ & $\mathrm{A}$ & $\mathrm{T}$ & $\mathrm{A}$ & $\mathrm{C}$ & $\mathrm{C}$ & $\mathrm{A}$ & $\mathrm{C}$ & $\mathrm{C}$ & 0,81 \\
\hline I/LnJ & 674 & $\mathrm{~A}$ & $\mathrm{~A}$ & $\mathrm{~T}$ & $\mathrm{G}$ & $\mathrm{G}$ & $\mathrm{A}$ & $\mathrm{A}$ & $\mathrm{T}$ & $\mathrm{T}$ & $\mathrm{C}$ & $\mathrm{G}$ & $\mathrm{T}$ & $\mathrm{A}$ & $\mathrm{G}$ & $\mathrm{T}$ & $\mathrm{G}$ & $\mathrm{C}$ & $\mathrm{C}$ & $\mathrm{A}$ & $\mathrm{C}$ & $\mathrm{C}$ & 0,81 \\
\hline NONcNZO5 & & $\mathrm{T}$ & $\mathrm{A}$ & $\mathrm{T}$ & $\mathrm{T}$ & $\mathrm{G}$ & $\mathrm{A}$ & $\mathrm{A}$ & $\mathrm{G}$ & $\mathrm{A}$ & $\mathrm{A}$ & $\mathrm{G}$ & $\mathrm{T}$ & $\mathrm{G}$ & $\mathrm{G}$ & $\mathrm{T}$ & $\mathrm{G}$ & $\mathrm{C}$ & $\mathrm{C}$ & $\mathrm{A}$ & $\mathrm{C}$ & $\mathrm{C}$ & 0,81 \\
\hline RIIIS/J & 683 & $\mathrm{~T}$ & $A$ & $\mathrm{~T}$ & $\mathrm{~T}$ & $\mathrm{G}$ & $\mathrm{A}$ & $\mathrm{A}$ & $\mathrm{T}$ & $\mathrm{T}$ & $\mathrm{C}$ & $\mathrm{G}$ & $\mathrm{T}$ & $A$ & $\mathrm{G}$ & $\mathrm{T}$ & $\mathrm{G}$ & $\mathrm{C}$ & $\mathrm{C}$ & $\mathrm{G}$ & $\mathrm{C}$ & $\mathrm{A}$ & 0,81 \\
\hline SJL/Bm & & $\mathrm{T}$ & $\mathrm{A}$ & $\mathrm{T}$ & $\mathrm{T}$ & $\mathrm{G}$ & $\mathrm{G}$ & $\mathrm{G}$ & $\mathrm{T}$ & $\mathrm{T}$ & $\mathrm{C}$ & $\mathrm{G}$ & $\mathrm{T}$ & $\mathrm{A}$ & $\mathrm{G}$ & $\mathrm{T}$ & $\mathrm{A}$ & $\mathrm{C}$ & $\mathrm{T}$ & $\mathrm{A}$ & $\mathrm{C}$ & $\mathrm{C}$ & 0,81 \\
\hline C3HeB/FeJ & 658 & $\mathrm{~T}$ & $\mathrm{~A}$ & $\mathrm{~T}$ & $\mathrm{~T}$ & $\mathrm{G}$ & $\mathrm{G}$ & $\mathrm{A}$ & $\mathrm{G}$ & $A$ & $\mathrm{C}$ & $\mathrm{G}$ & $\mathrm{T}$ & $\mathrm{G}$ & $A$ & $\mathrm{~T}$ & $\mathrm{~A}$ & $\mathrm{C}$ & & $A$ & $\mathrm{C}$ & $\mathrm{C}$ & 0,80 \\
\hline EL/SuzSeyFrkJ & 1956 & $\mathrm{~T}$ & $A$ & $\mathrm{~T}$ & G & $\mathrm{G}$ & $\mathrm{G}$ & $\mathrm{A}$ & $\mathrm{T}$ & $\mathrm{T}$ & $\mathrm{A}$ & $\mathrm{G}$ & $A$ & $\mathrm{~A}$ & $\mathrm{G}$ & & $\mathrm{G}$ & $\mathrm{C}$ & C & $A$ & $\mathrm{C}$ & $\mathrm{C}$ & 0,80 \\
\hline NON/LtJ & 2423 & $\mathrm{~T}$ & $\mathrm{~A}$ & $\mathrm{~T}$ & $\mathrm{~T}$ & $\mathrm{G}$ & $\mathrm{A}$ & A & $\mathrm{G}$ & A & $\mathrm{A}$ & $\mathrm{G}$ & $\mathrm{T}$ & $\mathrm{G}$ & $\mathrm{G}$ & $\mathrm{T}$ & $\mathrm{G}$ & $\mathrm{C}$ & C & & $\mathrm{C}$ & $\mathrm{C}$ & 0,80 \\
\hline SJL/J & 686 & $\mathrm{~T}$ & $\mathrm{~A}$ & $\mathrm{~T}$ & $\mathrm{~T}$ & $\mathrm{G}$ & $\mathrm{G}$ & $\mathrm{G}$ & $\mathrm{T}$ & $\mathrm{T}$ & $\mathrm{C}$ & $\mathrm{G}$ & & $\mathrm{A}$ & $\mathrm{G}$ & $\mathrm{T}$ & $\mathrm{A}$ & $\mathrm{C}$ & $\mathrm{T}$ & $\mathrm{A}$ & $\mathrm{C}$ & $\mathrm{C}$ & 0,80 \\
\hline $\mathrm{A} / \mathrm{HeJ}$ & 645 & $\mathrm{~T}$ & $A$ & $\mathrm{~T}$ & $\mathrm{~T}$ & $\mathrm{G}$ & $\mathrm{G}$ & $\mathrm{A}$ & $\mathrm{G}$ & $\mathrm{A}$ & $\mathrm{C}$ & $\mathrm{G}$ & $\mathrm{T}$ & $\mathrm{G}$ & $\mathrm{G}$ & $\mathrm{A}$ & $A$ & $\mathrm{C}$ & $\mathrm{T}$ & $A$ & $\mathrm{C}$ & $\mathrm{C}$ & 0,76 \\
\hline $\mathrm{A} / \mathrm{J}$ & 646 & $\mathrm{~T}$ & $\mathrm{~A}$ & $T$ & $\mathrm{~T}$ & $\mathrm{G}$ & $\mathrm{G}$ & $\mathrm{A}$ & $\mathrm{G}$ & $\mathrm{A}$ & $\mathrm{C}$ & $\mathrm{G}$ & $\mathrm{T}$ & $\mathrm{G}$ & $\mathrm{G}$ & $\mathrm{A}$ & $\mathrm{A}$ & C & $\mathrm{T}$ & A & C & C & 0,76 \\
\hline A/WySnJ & 647 & $\mathrm{~T}$ & $\mathrm{~A}$ & $\mathrm{~T}$ & $\mathrm{~T}$ & $\mathrm{G}$ & $\mathrm{G}$ & $\mathrm{A}$ & $\mathrm{G}$ & $A$ & $\mathrm{C}$ & $\mathrm{G}$ & $\mathrm{T}$ & $\mathrm{G}$ & $\mathrm{G}$ & $\mathrm{A}$ & $A$ & $\mathrm{C}$ & $\mathrm{T}$ & $A$ & $\mathrm{C}$ & $\mathrm{C}$ & 0,76 \\
\hline ALR/LtJ & 3070 & $\mathrm{~T}$ & $\mathrm{~A}$ & $\mathrm{~T}$ & $\mathrm{~T}$ & $\mathrm{G}$ & $\mathrm{G}$ & $\mathrm{A}$ & $\mathrm{G}$ & $A$ & $\mathrm{C}$ & $\mathrm{G}$ & $\mathrm{T}$ & $\mathrm{G}$ & $\mathrm{G}$ & $\mathrm{A}$ & $\mathrm{A}$ & C & $\mathrm{T}$ & $A$ & $\mathrm{C}$ & $\mathrm{C}$ & 0,76 \\
\hline CBA/J & 656 & $\mathrm{~T}$ & $\mathrm{~A}$ & $\mathrm{~T}$ & $\mathrm{~T}$ & $\mathrm{G}$ & $\mathrm{A}$ & $\mathrm{G}$ & $\mathrm{G}$ & $\mathrm{T}$ & $\mathrm{C}$ & $\mathrm{G}$ & $\mathrm{T}$ & $\mathrm{A}$ & $\mathrm{G}$ & $\mathrm{T}$ & $\mathrm{A}$ & $\mathrm{C}$ & $\mathrm{T}$ & $\mathrm{A}$ & $\mathrm{C}$ & $\mathrm{C}$ & 0,76 \\
\hline $\mathrm{KK} / \mathrm{HIJ}$ & 2106 & $\mathrm{~T}$ & $\mathrm{G}$ & $\mathrm{T}$ & $\mathrm{G}$ & $\mathrm{G}$ & $\mathrm{A}$ & $\mathrm{A}$ & $\mathrm{T}$ & $\mathrm{A}$ & $\mathrm{C}$ & $\mathrm{G}$ & $\mathrm{T}$ & $\mathrm{A}$ & $\mathrm{G}$ & $\mathrm{T}$ & $\mathrm{G}$ & $\mathrm{C}$ & $\mathrm{C}$ & $\mathrm{A}$ & $\mathrm{C}$ & $\mathrm{C}$ & 0,76 \\
\hline NOD.NON-H2<nb1>/LtJ & 1626 & $\mathrm{~T}$ & $\mathrm{~A}$ & $\mathrm{~T}$ & $\mathrm{~T}$ & $\mathrm{G}$ & $\mathrm{G}$ & A & $\mathrm{T}$ & $\mathrm{A}$ & $\mathrm{C}$ & $\mathrm{G}$ & $\mathrm{T}$ & $A$ & $\mathrm{~A}$ & $\mathrm{~A}$ & $\mathrm{G}$ & $\mathrm{C}$ & $\mathrm{T}$ & $A$ & $\mathrm{C}$ & $\mathrm{C}$ & 0,76 \\
\hline NOD/LtJ & 1976 & $\mathrm{~T}$ & A & $\mathrm{T}$ & $\mathrm{T}$ & $\mathrm{G}$ & $\mathrm{G}$ & A & $\mathrm{T}$ & A & $\mathrm{C}$ & $\mathrm{G}$ & $\mathrm{T}$ & A & $\mathrm{A}$ & $\mathrm{A}$ & G & $\mathrm{C}$ & $\mathrm{T}$ & $A$ & $\mathrm{C}$ & $\mathrm{C}$ & 0,76 \\
\hline $\mathrm{PL} / \mathrm{J}$ & 680 & $\mathrm{~T}$ & $\mathrm{G}$ & $\mathrm{T}$ & $\mathrm{T}$ & $\mathrm{G}$ & $\mathrm{G}$ & $\mathrm{A}$ & $\mathrm{G}$ & A & $\mathrm{C}$ & $\mathrm{G}$ & $\mathrm{T}$ & $\mathrm{G}$ & $\mathrm{G}$ & $\mathrm{A}$ & $\mathrm{A}$ & $\mathrm{C}$ & $\mathrm{C}$ & A & $\mathrm{C}$ & $\mathrm{C}$ & 0,76 \\
\hline $\mathrm{RF} / \mathrm{J}$ & 682 & $\mathrm{~T}$ & $\mathrm{~A}$ & $\mathrm{~T}$ & $\mathrm{~T}$ & $\mathrm{G}$ & $\mathrm{G}$ & $\mathrm{A}$ & $\mathrm{T}$ & $A$ & $\mathrm{C}$ & $\mathrm{G}$ & $\mathrm{T}$ & $\mathrm{G}$ & $\mathrm{A}$ & $\mathrm{T}$ & $\mathrm{G}$ & $\mathrm{C}$ & $\mathrm{T}$ & $A$ & $\mathrm{C}$ & $\mathrm{C}$ & 0,76 \\
\hline YBR/EiJ & 933 & $A$ & $\mathrm{~A}$ & $T$ & G & $\mathrm{G}$ & $\mathrm{A}$ & $\mathrm{A}$ & $\mathrm{T}$ & $A$ & $\mathrm{C}$ & $\mathrm{G}$ & $\mathrm{T}$ & $\mathrm{A}$ & $\mathrm{G}$ & $\mathrm{T}$ & $\mathrm{G}$ & $\mathrm{C}$ & $\mathrm{C}$ & $A$ & C & $\mathrm{C}$ & 0,76 \\
\hline MRL/MpJ & 486 & $\mathrm{~T}$ & $\mathrm{~A}$ & $\mathrm{~T}$ & $\mathrm{~T}$ & $\mathrm{G}$ & $\mathrm{G}$ & $\mathrm{A}$ & $\mathrm{G}$ & $\mathrm{A}$ & C & & $\mathrm{T}$ & $\mathrm{G}$ & $\mathrm{A}$ & $\mathrm{A}$ & $\mathrm{A}$ & $\mathrm{C}$ & C & $\mathrm{A}$ & $\mathrm{C}$ & $\mathrm{C}$ & 0,75 \\
\hline AKR/J & 648 & $\mathrm{~T}$ & $\mathrm{G}$ & $\mathrm{T}$ & $\mathrm{T}$ & $\mathrm{G}$ & $\mathrm{G}$ & $\mathrm{A}$ & $\mathrm{G}$ & $\mathrm{A}$ & $\mathrm{C}$ & $\mathrm{G}$ & $\mathrm{T}$ & $\mathrm{G}$ & $\mathrm{A}$ & $\mathrm{A}$ & $\mathrm{G}$ & $\mathrm{C}$ & C & $\mathrm{A}$ & $\mathrm{C}$ & $\mathrm{C}$ & 0,71 \\
\hline $\mathrm{BPH} / 2 \mathrm{~J}$ & 3005 & $\mathrm{~T}$ & $\mathrm{G}$ & $\mathrm{T}$ & $\mathrm{T}$ & $\mathrm{G}$ & $\mathrm{G}$ & $\mathrm{A}$ & $\mathrm{G}$ & $\mathrm{A}$ & $\mathrm{C}$ & $\mathrm{G}$ & $\mathrm{T}$ & $\mathrm{G}$ & $\mathrm{G}$ & $\mathrm{T}$ & $\mathrm{A}$ & $\mathrm{C}$ & $\mathrm{T}$ & $A$ & $\mathrm{C}$ & $\mathrm{A}$ & 0,71 \\
\hline DDY/JclSidSeyFrkJ & 2243 & $\mathrm{~T}$ & $\mathrm{~A}$ & $\mathrm{~T}$ & $\mathrm{G}$ & $\mathrm{G}$ & $\mathrm{A}$ & $\mathrm{A}$ & $\mathrm{T}$ & $\mathrm{T}$ & $\mathrm{A}$ & $\mathrm{G}$ & $\mathrm{A}$ & $\mathrm{A}$ & $\mathrm{G}$ & $\mathrm{A}$ & $\mathrm{G}$ & $\mathrm{C}$ & $\mathrm{C}$ & $\mathrm{A}$ & $\mathrm{C}$ & $\mathrm{C}$ & 0,71 \\
\hline FVB/NJ & 1800 & $\mathrm{~T}$ & $\mathrm{~A}$ & $\mathrm{~T}$ & $\mathrm{~T}$ & $\mathrm{G}$ & $\mathrm{A}$ & $\mathrm{G}$ & $\mathrm{T}$ & $\mathrm{T}$ & $\mathrm{C}$ & $\mathrm{G}$ & $\mathrm{A}$ & $\mathrm{A}$ & $\mathrm{G}$ & $\mathrm{T}$ & $\mathrm{G}$ & $\mathrm{T}$ & $\mathrm{T}$ & $\mathrm{A}$ & $\mathrm{C}$ & $\mathrm{C}$ & 0,71 \\
\hline $\mathrm{LG} / \mathrm{J}$ & 675 & $\mathrm{~T}$ & $\mathrm{~A}$ & $\mathrm{~T}$ & $\mathrm{~T}$ & $\mathrm{G}$ & $\mathrm{G}$ & $\mathrm{A}$ & $\mathrm{T}$ & $\mathrm{T}$ & $\mathrm{C}$ & $\mathrm{A}$ & $\mathrm{T}$ & $\mathrm{G}$ & $\mathrm{A}$ & $\mathrm{A}$ & $\mathrm{A}$ & $\mathrm{C}$ & $\mathrm{C}$ & $\mathrm{A}$ & $\mathrm{C}$ & $\mathrm{C}$ & 0,71 \\
\hline MA/MyJ & 677 & & $A$ & $\mathrm{~T}$ & $\mathrm{G}$ & $A$ & $\mathrm{G}$ & $\mathrm{A}$ & $\mathrm{T}$ & $\mathrm{T}$ & $\mathrm{A}$ & $\mathrm{G}$ & $\mathrm{T}$ & $\mathrm{A}$ & $\mathrm{A}$ & $\mathrm{T}$ & $\mathrm{G}$ & $\mathrm{C}$ & $\mathrm{C}$ & $\mathrm{A}$ & $\mathrm{T}$ & $\mathrm{C}$ & 0,70 \\
\hline SB/LeJ & 269 & $A$ & & $\mathrm{~T}$ & $\mathrm{~T}$ & $\mathrm{G}$ & $\mathrm{G}$ & $\mathrm{A}$ & $\mathrm{G}$ & $\mathrm{A}$ & $\mathrm{A}$ & $\mathrm{G}$ & $\mathrm{A}$ & $\mathrm{A}$ & $\mathrm{G}$ & $\mathrm{T}$ & $\mathrm{A}$ & $\mathrm{C}$ & $\mathrm{C}$ & $\mathrm{A}$ & $\mathrm{C}$ & $\mathrm{A}$ & 0,70 \\
\hline WSB/EiJ & 1145 & & $\mathrm{~A}$ & $\mathrm{~T}$ & $\mathrm{~T}$ & $\mathrm{G}$ & $\mathrm{A}$ & $\mathrm{G}$ & $\mathrm{G}$ & $\mathrm{T}$ & $\mathrm{C}$ & $\mathrm{A}$ & $\mathrm{T}$ & $\mathrm{A}$ & $\mathrm{G}$ & $\mathrm{T}$ & $\mathrm{G}$ & $\mathrm{C}$ & $\mathrm{T}$ & $\mathrm{G}$ & $\mathrm{C}$ & $\mathrm{A}$ & 0,70 \\
\hline ALS/LtJ & 3072 & $\mathrm{~A}$ & $\mathrm{~A}$ & $\mathrm{~T}$ & $\mathrm{~T}$ & $\mathrm{G}$ & $\mathrm{G}$ & $\mathrm{A}$ & $\mathrm{T}$ & A & $\mathrm{C}$ & $\mathrm{G}$ & $\mathrm{T}$ & $\mathrm{G}$ & $\mathrm{A}$ & $\mathrm{T}$ & $\mathrm{G}$ & $\mathrm{C}$ & $\mathrm{T}$ & $\mathrm{A}$ & $\mathrm{C}$ & $\mathrm{C}$ & 0,67 \\
\hline IS/CamRkJ & 573 & $\mathrm{~T}$ & $\mathrm{~A}$ & $\mathrm{~T}$ & $\mathrm{G}$ & $\mathrm{G}$ & $\mathrm{A}$ & $\mathrm{G}$ & $\mathrm{G}$ & $\mathrm{T}$ & $\mathrm{C}$ & $\mathrm{G}$ & $\mathrm{T}$ & $\mathrm{A}$ & $\mathrm{G}$ & $\mathrm{T}$ & $\mathrm{G}$ & $\mathrm{T}$ & $\mathrm{T}$ & $\mathrm{G}$ & $\mathrm{C}$ & $\mathrm{A}$ & 0,67 \\
\hline NONcNZO10 & & $\mathrm{T}$ & $\mathrm{A}$ & $\mathrm{T}$ & $\mathrm{T}$ & $\mathrm{G}$ & $\mathrm{A}$ & $\mathrm{A}$ & $\mathrm{T}$ & $\mathrm{T}$ & $\mathrm{A}$ & $\mathrm{G}$ & $\mathrm{A}$ & $\mathrm{G}$ & $\mathrm{G}$ & $\mathrm{T}$ & $\mathrm{A}$ & $\mathrm{C}$ & $\mathrm{C}$ & $\mathrm{G}$ & $\mathrm{C}$ & $\mathrm{C}$ & 0,67 \\
\hline NOR/LtJ & 2050 & $\mathrm{~T}$ & $\mathrm{G}$ & $\mathrm{T}$ & $\mathrm{T}$ & $\mathrm{G}$ & $\mathrm{G}$ & $\mathrm{A}$ & $\mathrm{T}$ & $\mathrm{T}$ & $\mathrm{C}$ & $\mathrm{G}$ & $\mathrm{T}$ & $\mathrm{A}$ & $\mathrm{A}$ & $\mathrm{A}$ & $\mathrm{G}$ & $\mathrm{C}$ & $\mathrm{T}$ & $\mathrm{G}$ & $\mathrm{C}$ & $\mathrm{C}$ & 0,67 \\
\hline SWXL4/TyJ & 74 & $\mathrm{~A}$ & $\mathrm{~A}$ & $\mathrm{~T}$ & $\mathrm{~T}$ & $\mathrm{G}$ & $\mathrm{A}$ & $\mathrm{A}$ & $\mathrm{T}$ & $\mathrm{A}$ & $\mathrm{C}$ & $\mathrm{G}$ & $\mathrm{T}$ & $\mathrm{G}$ & $\mathrm{G}$ & $\mathrm{A}$ & $\mathrm{A}$ & $\mathrm{C}$ & $\mathrm{C}$ & $\mathrm{A}$ & $\mathrm{C}$ & $\mathrm{C}$ & 0,67 \\
\hline BPL/1J & 3006 & $\mathrm{~T}$ & & $\mathrm{~T}$ & G & $\mathrm{G}$ & $\mathrm{G}$ & $\mathrm{G}$ & $\mathrm{G}$ & $\mathrm{T}$ & $\mathrm{C}$ & $\mathrm{A}$ & $\mathrm{T}$ & $\mathrm{A}$ & $\mathrm{G}$ & $\mathrm{A}$ & $\mathrm{A}$ & $\mathrm{C}$ & $\mathrm{T}$ & $\mathrm{G}$ & $\mathrm{C}$ & $\mathrm{C}$ & 0,65 \\
\hline LEWES/EiJ & 2798 & $\mathrm{~T}$ & $\mathrm{G}$ & $\mathrm{T}$ & G & & $\mathrm{G}$ & $\mathrm{G}$ & $\mathrm{G}$ & $\mathrm{T}$ & $\mathrm{C}$ & $\mathrm{A}$ & $\mathrm{T}$ & $\mathrm{A}$ & $\mathrm{A}$ & $\mathrm{T}$ & $\mathrm{G}$ & $\mathrm{C}$ & $\mathrm{T}$ & $\mathrm{A}$ & $\mathrm{C}$ & $\mathrm{A}$ & 0,65 \\
\hline PERC/EiJ & 1307 & $\mathrm{~T}$ & $\mathrm{~A}$ & $\mathrm{~T}$ & $\mathrm{G}$ & $\mathrm{G}$ & $\mathrm{A}$ & $\mathrm{G}$ & $\mathrm{G}$ & $\mathrm{T}$ & $\mathrm{C}$ & $\mathrm{G}$ & $\mathrm{T}$ & $A$ & & $\mathrm{~A}$ & $\mathrm{G}$ & $\mathrm{C}$ & $\mathrm{T}$ & $\mathrm{G}$ & $\mathrm{C}$ & $\mathrm{A}$ & 0,65 \\
\hline
\end{tabular}




\begin{tabular}{|c|c|c|c|c|c|c|c|c|c|c|c|c|c|c|c|c|c|c|c|c|c|c|c|}
\hline PWK/PhJ & 3715 & $\mathrm{~T}$ & $\mathrm{G}$ & $\mathrm{T}$ & $\mathrm{G}$ & $\mathrm{G}$ & & $\mathrm{G}$ & $T$ & $\mathrm{~T}$ & C & $\mathrm{G}$ & $T$ & $\mathrm{G}$ & $\mathrm{G}$ & $\mathrm{T}$ & G & C & $\mathrm{T}$ & $\mathrm{G}$ & $\mathrm{C}$ & C & 0,65 \\
\hline RBF/DnJ & 726 & $\mathrm{~T}$ & A & $T$ & $\mathrm{~T}$ & G & A & G & $T$ & $\mathrm{~T}$ & C & & $T$ & A & $\mathrm{G}$ & $\mathrm{T}$ & G & $T$ & $\mathrm{~T}$ & $\mathrm{G}$ & C & $\mathrm{A}$ & 0,65 \\
\hline CE/J & 657 & $\mathrm{~T}$ & $\mathrm{G}$ & $T$ & $\mathrm{G}$ & $\mathrm{G}$ & A & A & $T$ & $\mathrm{~T}$ & C & G & $T$ & G & A & $\begin{array}{llll}T & \end{array}$ & G & C & & $\mathrm{G}$ & C & C & 0,63 \\
\hline 129S1/SvImJ & 2448 & $\mathrm{~T}$ & $\mathrm{G}$ & $\mathrm{T}$ & $\mathrm{T}$ & $\mathrm{G}$ & $\mathrm{A}$ & A & $\mathrm{G}$ & $\mathrm{A}$ & $\mathrm{A}$ & A & $T$ & A & $\mathrm{G}$ & $T$ & G & $\mathrm{C}$ & $\mathrm{T}$ & $\mathrm{G}$ & $\mathrm{T}$ & $\mathrm{C}$ & 0,62 \\
\hline 129T2/SvEmsJ & 2065 & $\mathrm{~T}$ & $\mathrm{G}$ & $\mathrm{T}$ & $\mathrm{T}$ & $\mathrm{G}$ & $\mathrm{A}$ & $\mathrm{A}$ & $\mathrm{G}$ & $\mathrm{A}$ & $\mathrm{A}$ & A & $T$ & $\mathrm{~A}$ & $\mathrm{G}$ & $\begin{array}{c}T \\
T\end{array}$ & $G$ & $\mathrm{C}$ & $T$ & $\mathrm{G}$ & $T$ & $\mathrm{C}$ & 0,62 \\
\hline $\mathrm{BDP} / \mathrm{J}$ & 652 & $\mathrm{~A}$ & $\mathrm{G}$ & $\mathrm{T}$ & $\mathrm{G}$ & $\mathrm{A}$ & A & A & $T$ & $\mathrm{~T}$ & C & G & $T$ & A & A & $\begin{array}{ll}T \\
\end{array}$ & G & C & $T$ & A & C & C & 0,62 \\
\hline BPN/3J & 3004 & $\mathrm{~T}$ & $\mathrm{G}$ & $\mathrm{C}$ & $\mathrm{G}$ & $\mathrm{G}$ & G & A & $\mathrm{G}$ & $\mathrm{T}$ & $\mathrm{C}$ & $\mathrm{G}$ & $T$ & A & $\mathrm{G}$ & $\begin{array}{cc}T \\
\end{array}$ & A & $\mathrm{C}$ & $\mathrm{T}$ & $\mathrm{G}$ & $\mathrm{T}$ & $\mathrm{C}$ & 0,62 \\
\hline LP/J & 676 & $\mathrm{~T}$ & $\mathrm{G}$ & $T$ & $\mathrm{G}$ & $\mathrm{G}$ & $\mathrm{A}$ & $\mathrm{A}$ & $\mathrm{G}$ & $\mathrm{A}$ & $\mathrm{A}$ & $\mathrm{G}$ & $A$ & $\mathrm{~A}$ & $\mathrm{G}$ & $\begin{array}{c}T \\
T\end{array}$ & G & $\mathrm{C}$ & C & $\mathrm{G}$ & $\mathrm{T}$ & $\mathrm{C}$ & 0,62 \\
\hline $\mathrm{P} / \mathrm{J}$ & 679 & $\mathrm{~A}$ & $\mathrm{G}$ & $\mathrm{T}$ & $\mathrm{G}$ & $\mathrm{A}$ & A & A & $T$ & $\mathrm{~T}$ & C & G & $T$ & A & A & $\begin{array}{lll}T \\
T\end{array}$ & G & C & $\mathrm{T}$ & $A$ & $\mathrm{C}$ & $\mathrm{C}$ & 0,62 \\
\hline SEA/GnJ & 644 & $\mathrm{~A}$ & A & $\mathrm{T}$ & $\mathrm{G}$ & $\mathrm{G}$ & $\mathrm{A}$ & A & $T$ & $\mathrm{~T}$ & $\mathrm{C}$ & G & $T$ & $\mathrm{~A}$ & $\mathrm{~A}$ & A & G & $\mathrm{C}$ & $T$ & $\mathrm{~A}$ & $\mathrm{C}$ & $\mathrm{C}$ & 0,62 \\
\hline SF/CamEiJ & 280 & $\mathrm{~T}$ & A & $\mathrm{T}$ & $\mathrm{G}$ & $\mathrm{G}$ & $A$ & G & $T$ & $\mathrm{~T}$ & C & A & $\mathrm{T}$ & G & $\mathrm{G}$ & A & G & C & C & $\mathrm{G}$ & $\mathrm{C}$ & $\mathrm{C}$ & 0,62 \\
\hline SWR/J & 689 & $\mathrm{~A}$ & A & $\mathrm{T}$ & $\mathrm{T}$ & $\mathrm{G}$ & A & A & $T$ & $\mathrm{~A}$ & C & G & A & A & $\mathrm{G}$ & $\mathrm{A}$ & G & $\mathrm{T}$ & $\mathrm{T}$ & $\mathrm{A}$ & C & C & 0,62 \\
\hline 129P2/OlaHsd & & $\mathrm{T}$ & $\mathrm{G}$ & $T$ & $\begin{array}{cc}T \\
\end{array}$ & $\mathrm{G}$ & $\mathrm{A}$ & $\mathrm{A}$ & G & $\mathrm{A}$ & $\mathrm{A}$ & A & $T$ & $\mathrm{~A}$ & & $\begin{array}{c}T \\
T\end{array}$ & $G$ & & $T$ & & $\mathrm{~T}$ & $\mathrm{C}$ & 0,61 \\
\hline CZECHI/EiJ & 2799 & $\mathrm{~A}$ & $\mathrm{G}$ & $\mathrm{T}$ & $\mathrm{G}$ & $\mathrm{G}$ & & $\mathrm{G}$ & $\mathrm{T}$ & $\mathrm{T}$ & C & $\mathrm{G}$ & $T$ & $\mathrm{G}$ & $\mathrm{G}$ & $\begin{array}{cc}T \\
\end{array}$ & G & $\mathrm{C}$ & $\mathrm{T}$ & $\mathrm{G}$ & $\mathrm{C}$ & C & 0,60 \\
\hline CZECHII/EiJ & 1144 & $\mathrm{~A}$ & $\mathrm{G}$ & $\mathrm{T}$ & $\mathrm{G}$ & G & & G & $\mathrm{T}$ & $\mathrm{T}$ & C & G & $T$ & G & $\mathrm{G}$ & $T$ & G & $\mathrm{C}$ & $T$ & $\mathrm{G}$ & C & C & 0,60 \\
\hline NZW/LacJ & 1058 & $\mathrm{~T}$ & $\mathrm{G}$ & $\mathrm{T}$ & $\mathrm{G}$ & $\mathrm{G}$ & A & G & $\mathrm{T}$ & $\mathrm{T}$ & $\mathrm{A}$ & $\mathrm{G}$ & $A$ & $\mathrm{~A}$ & $\mathrm{~A}$ & $\begin{array}{cc}T \\
T\end{array}$ & G & $\mathrm{C}$ & & $\mathrm{A}$ & $\mathrm{C}$ & $\mathrm{C}$ & 0,60 \\
\hline SKIVE/EiJ & 1393 & $\mathrm{~A}$ & $\mathrm{G}$ & $\mathrm{T}$ & $\mathrm{G}$ & $\mathrm{G}$ & & G & $\mathrm{T}$ & $\mathrm{T}$ & $\mathrm{C}$ & G & $T$ & $\mathrm{G}$ & $\mathrm{G}$ & $\mathrm{T}$ & G & $\mathrm{C}$ & $\mathrm{T}$ & $\mathrm{G}$ & $\mathrm{C}$ & $\mathrm{C}$ & 0,60 \\
\hline Pohn1(F?9) & & & $\mathrm{G}$ & $\mathrm{T}$ & $\mathrm{G}$ & G & & $\mathrm{G}$ & & $\mathrm{T}$ & C & G & $\mathrm{T}$ & $\mathrm{G}$ & & A & G & $\mathrm{T}$ & $\mathrm{T}$ & $\mathrm{G}$ & C & $\mathrm{C}$ & 0,59 \\
\hline BTBR T<+>tf/J & 2282 & $\mathrm{~T}$ & $\mathrm{G}$ & $\mathrm{T}$ & $\mathrm{G}$ & $\mathrm{G}$ & A & $\mathrm{A}$ & $\mathrm{T}$ & $\mathrm{A}$ & C & G & $A$ & $\mathrm{~A}$ & $\mathrm{G}$ & $\mathrm{A}$ & $\mathrm{A}$ & $\mathrm{C}$ & $\mathrm{C}$ & $\mathrm{G}$ & $\begin{array}{c}\mathrm{T} \\
\mathrm{T}\end{array}$ & C & 0,57 \\
\hline NZB/BINJ & 684 & $\mathrm{~T}$ & $\mathrm{G}$ & $\mathrm{T}$ & $\mathrm{G}$ & $\mathrm{G}$ & $\mathrm{A}$ & $\mathrm{A}$ & $\mathrm{T}$ & $\mathrm{T}$ & $\mathrm{C}$ & A & $T$ & $\mathrm{~A}$ & $\mathrm{~A}$ & $T$ & G & $\mathrm{C}$ & $\mathrm{T}$ & $\mathrm{G}$ & $T$ & $\mathrm{C}$ & 0,57 \\
\hline $\mathrm{SM} / \mathrm{J}$ & 687 & $\mathrm{~A}$ & $\mathrm{G}$ & $\mathrm{T}$ & $\mathrm{G}$ & A & A & A & $\mathrm{T}$ & $\mathrm{T}$ & $\mathrm{C}$ & $\mathrm{G}$ & A & A & A & $\mathrm{A}$ & G & C & C & A & $\mathrm{C}$ & C & 0,57 \\
\hline WMP/PasDnJ & 1746 & $\mathrm{~A}$ & $\mathrm{G}$ & $\mathrm{T}$ & $\mathrm{G}$ & $\mathrm{G}$ & $\mathrm{A}$ & $\mathrm{G}$ & $\mathrm{G}$ & $\mathrm{T}$ & $\mathrm{C}$ & G & $T$ & A & $\mathrm{G}$ & $\mathrm{A}$ & G & $\mathrm{T}$ & $\mathrm{T}$ & A & C & $\mathrm{A}$ & 0,57 \\
\hline SPRET/EiJ & 1146 & $\mathrm{~A}$ & $\mathrm{G}$ & $\mathrm{T}$ & $\mathrm{G}$ & $\mathrm{G}$ & & $\mathrm{A}$ & & & $\mathrm{C}$ & $G$ & $T$ & $\mathrm{G}$ & $\mathrm{G}$ & $A$ & G & $\mathrm{C}$ & $\mathrm{T}$ & $\mathrm{G}$ & $\mathrm{C}$ & $\mathrm{A}$ & 0,56 \\
\hline JF1/Ms & 3720 & $\mathrm{~A}$ & $\mathrm{G}$ & $\mathrm{T}$ & $\mathrm{G}$ & $A$ & & $\mathrm{G}$ & $\mathrm{T}$ & $\mathrm{T}$ & C & G & $T$ & $\mathrm{G}$ & $\mathrm{G}$ & $T$ & G & $\mathrm{C}$ & $\mathrm{T}$ & $\mathrm{G}$ & $\mathrm{C}$ & $\mathrm{C}$ & 0,55 \\
\hline MOLF/EiJ & 550 & $\mathrm{~A}$ & $\mathrm{G}$ & $\mathrm{T}$ & $\mathrm{G}$ & $\mathrm{A}$ & & G & $\mathrm{T}$ & $\mathrm{T}$ & $\mathrm{C}$ & G & $T$ & $\mathrm{G}$ & $\mathrm{G}$ & $T$ & G & $\mathrm{C}$ & $\mathrm{T}$ & $\mathrm{G}$ & $\mathrm{C}$ & C & 0,55 \\
\hline MSM/Ms & 3719 & $A$ & $\mathrm{G}$ & $\mathrm{T}$ & $\mathrm{G}$ & $\mathrm{A}$ & & $\mathrm{G}$ & $\mathrm{T}$ & $\mathrm{T}$ & C & G & $T$ & $\mathrm{G}$ & $\mathrm{G}$ & $\mathrm{T}$ & G & C & $\mathrm{T}$ & $\mathrm{G}$ & $\mathrm{C}$ & $\mathrm{C}$ & 0,55 \\
\hline PERA/EiJ & 930 & $T$ & $\mathrm{G}$ & $\mathrm{T}$ & $\mathrm{G}$ & $\mathrm{G}$ & A & $\mathrm{G}$ & $\mathrm{T}$ & $\mathrm{A}$ & $\mathrm{C}$ & $G$ & & $A$ & $\mathrm{G}$ & $T$ & G & $\mathrm{T}$ & $\mathrm{T}$ & $\mathrm{A}$ & $\mathrm{C}$ & $A$ & 0,55 \\
\hline CAST/EiJ & 928 & A & $\mathrm{G}$ & $\mathrm{T}$ & $\mathrm{G}$ & $\mathrm{G}$ & $\mathrm{G}$ & G & $\mathrm{T}$ & $\mathrm{T}$ & C & $\mathrm{G}$ & $\mathrm{T}$ & G & $\mathrm{G}$ & $\mathrm{A}$ & G & C & $\mathrm{T}$ & $\mathrm{G}$ & C & C & 0,52 \\
\hline CASA/RkJ & 735 & $A$ & $\mathrm{G}$ & $\mathrm{T}$ & $\mathrm{G}$ & $\mathrm{G}$ & & $\mathrm{G}$ & $\mathrm{T}$ & $\mathrm{T}$ & C & $\mathrm{G}$ & $T$ & G & $\mathrm{A}$ & $\mathrm{A}$ & G & $\mathrm{C}$ & $\mathrm{T}$ & $\mathrm{G}$ & $\mathrm{C}$ & $\mathrm{C}$ & 0,50 \\
\hline LT/SvEi male & 3588 & $T$ & $\mathrm{G}$ & $\mathrm{T}$ & $\mathrm{T}$ & $\mathrm{A}$ & A & $\mathrm{A}$ & $\mathrm{T}$ & $\mathrm{T}$ & $\mathrm{A}$ & $\mathrm{A}$ & $T$ & & & $\mathrm{~A}$ & A & & $\mathrm{T}$ & $\mathrm{A}$ & $\mathrm{C}$ & & 0,50 \\
\hline MOLC/RkJ & 731 & A & $\mathrm{G}$ & $\mathrm{T}$ & $\mathrm{G}$ & A & & G & $\mathrm{T}$ & $\mathrm{T}$ & C & $\mathrm{A}$ & $\mathrm{T}$ & $G$ & $\mathrm{G}$ & $\mathrm{T}$ & G & C & $\mathrm{T}$ & $\mathrm{G}$ & $\mathrm{C}$ & $\mathrm{C}$ & 0,50 \\
\hline MOLD/RkJ & 734 & A & $\mathrm{G}$ & $\mathrm{T}$ & $\mathrm{G}$ & $\mathrm{A}$ & & G & $\mathrm{T}$ & $\mathrm{T}$ & C & $\mathrm{A}$ & $\mathrm{T}$ & G & $\mathrm{G}$ & 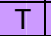 & G & $\mathrm{C}$ & $\mathrm{T}$ & $\mathrm{G}$ & $\mathrm{C}$ & $\mathrm{C}$ & 0,50 \\
\hline PANCEVO/EiJ & 1384 & A & $\mathrm{G}$ & $\mathrm{T}$ & $\mathrm{G}$ & $\mathrm{G}$ & & $\mathrm{G}$ & & $\mathrm{T}$ & $\mathrm{C}$ & $\mathrm{G}$ & & $\mathrm{G}$ & $\mathrm{G}$ & $\mathrm{A}$ & G & $\mathrm{C}$ & $\mathrm{T}$ & $\mathrm{G}$ & $\mathrm{C}$ & $\mathrm{A}$ & 0,50 \\
\hline Pohn2(F?9) & & A & $\mathrm{G}$ & $\mathrm{T}$ & $\mathrm{G}$ & $\mathrm{G}$ & A & $\mathrm{G}$ & & $\mathrm{T}$ & C & $\mathrm{G}$ & $\mathrm{T}$ & G & $\mathrm{G}$ & $\mathrm{A}$ & G & $\mathrm{T}$ & $\mathrm{T}$ & $\mathrm{G}$ & C & C & 0,50 \\
\hline TIRANO/EiJ & 929 & A & A & $\mathrm{T}$ & $\mathrm{G}$ & $\mathrm{G}$ & A & G & $\mathrm{T}$ & $\mathrm{T}$ & C & $\mathrm{G}$ & $\mathrm{T}$ & $\mathrm{A}$ & $\mathrm{A}$ & A & G & $\mathrm{T}$ & $\mathrm{T}$ & $\mathrm{G}$ & C & $\mathrm{A}$ & 0,48 \\
\hline NZO/HILtJ & 2105 & $T$ & $\mathrm{G}$ & $\mathrm{T}$ & $\mathrm{T}$ & $\mathrm{G}$ & $\mathrm{G}$ & $\mathrm{A}$ & $\mathrm{T}$ & $\mathrm{T}$ & $\mathrm{A}$ & $\mathrm{A}$ & $A$ & $\mathrm{~A}$ & $\mathrm{~A}$ & & $\mathrm{~A}$ & $\mathrm{C}$ & $\mathrm{T}$ & $\mathrm{G}$ & $\mathrm{T}$ & & 0,47 \\
\hline 129X1/SvJ & 691 & $T$ & $\mathrm{G}$ & $\mathrm{T}$ & $\mathrm{T}$ & & A & A & $\mathrm{G}$ & $\mathrm{A}$ & $\mathrm{A}$ & $\mathrm{A}$ & $T$ & $\mathrm{G}$ & & $T$ & & & $\mathrm{~T}$ & $\mathrm{G}$ & $T$ & $\mathrm{C}$ & 0,47 \\
\hline BXSB/MpJ & 740 & A & $\mathrm{G}$ & $\mathrm{T}$ & G & G & $\mathrm{G}$ & $\mathrm{G}$ & $\mathrm{G}$ & $\mathrm{A}$ & $\mathrm{A}$ & $\mathrm{A}$ & A & G & $\mathrm{A}$ & $\mathrm{T}$ & A & C & C & A & C & $\mathrm{A}$ & 0,43 \\
\hline C57BR/cdJ & 667 & $T$ & $\mathrm{G}$ & $\mathrm{T}$ & G & $\mathrm{A}$ & $\mathrm{A}$ & A & $\mathrm{T}$ & $\mathrm{T}$ & $\mathrm{A}$ & $\mathrm{A}$ & $T$ & $\mathrm{G}$ & $\mathrm{G}$ & $\mathrm{A}$ & G & $T$ & $\mathrm{C}$ & $\mathrm{G}$ & $\mathrm{C}$ & $\mathrm{A}$ & 0,43 \\
\hline ZALENDE/EiJ & & A & $\mathrm{G}$ & $\mathrm{T}$ & G & $\mathrm{G}$ & $\mathrm{A}$ & G & $\mathrm{T}$ & $\mathrm{T}$ & $\mathrm{C}$ & $\mathrm{G}$ & $T$ & A & $\mathrm{A}$ & $\mathrm{A}$ & G & $T$ & $\mathrm{~T}$ & $\mathrm{G}$ & C & $\mathrm{A}$ & 0,43 \\
\hline C57BLKS/J & 662 & $A$ & $\mathrm{G}$ & $\mathrm{C}$ & $\mathrm{G}$ & $\mathrm{G}$ & $\mathrm{A}$ & A & $\mathrm{T}$ & $\mathrm{T}$ & $\mathrm{C}$ & $\mathrm{G}$ & A & A & $\mathrm{A}$ & $\mathrm{A}$ & G & $T$ & $\mathrm{~T}$ & $\mathrm{G}$ & $\mathrm{T}$ & $\mathrm{C}$ & 0,38 \\
\hline C57L/J & 668 & A & $\mathrm{G}$ & $T$ & $\mathrm{G}$ & $\mathrm{A}$ & $\mathrm{A}$ & $\mathrm{A}$ & $\mathrm{T}$ & $\mathrm{T}$ & $\mathrm{A}$ & $\mathrm{A}$ & $T$ & $\mathrm{G}$ & $\mathrm{G}$ & $\mathrm{A}$ & $\mathrm{A}$ & $\mathrm{C}$ & $\mathrm{C}$ & $\mathrm{G}$ & $\mathrm{C}$ & $\mathrm{A}$ & 0,38 \\
\hline CALB/RkJ & 1489 & A & $\mathrm{G}$ & $\mathrm{T}$ & G & $\mathrm{G}$ & $\mathrm{A}$ & G & $\mathrm{T}$ & $\mathrm{A}$ & $\mathrm{C}$ & $\mathrm{G}$ & $T$ & G & $\mathrm{G}$ & $\mathrm{A}$ & G & $T$ & $\mathrm{~T}$ & $\mathrm{G}$ & C & A & 0,38 \\
\hline $\mathrm{C} 58 / \mathrm{J}$ & 669 & $T$ & $\mathrm{G}$ & $\mathrm{T}$ & G & $\mathrm{A}$ & $\mathrm{A}$ & G & $\mathrm{T}$ & $\mathrm{A}$ & $\mathrm{A}$ & $\mathrm{A}$ & $T$ & G & $\mathrm{A}$ & $\mathrm{A}$ & $\mathrm{A}$ & $\mathrm{T}$ & $\mathrm{T}$ & A & $\mathrm{C}$ & $\mathrm{C}$ & 0,29 \\
\hline C57BL/10J & 665 & A & $\mathrm{G}$ & $\mathrm{T}$ & G & A & A & A & $\mathrm{T}$ & $\mathrm{A}$ & $A$ & $\mathrm{~A}$ & A & G & $\mathrm{A}$ & $\mathrm{A}$ & A & $\mathrm{T}$ & $\mathrm{T}$ & $\mathrm{G}$ & $\mathrm{T}$ & $\mathrm{A}$ & 0,10 \\
\hline C57BL/10SnJ & 666 & A & $\mathrm{G}$ & $\mathrm{T}$ & G & $\mathrm{A}$ & $\mathrm{A}$ & A & $\mathrm{T}$ & $\mathrm{A}$ & $\mathrm{A}$ & $\mathrm{A}$ & $A$ & G & $\mathrm{A}$ & $\mathrm{A}$ & A & $\mathrm{T}$ & $\mathrm{T}$ & $\mathrm{G}$ & $\mathrm{T}$ & $\mathrm{A}$ & 0,10 \\
\hline C57BL/6ByJ & 1139 & $\mathrm{~A}$ & $\mathrm{G}$ & $\mathrm{C}$ & $G$ & $\mathrm{~A}$ & $\mathrm{~A}$ & $\mathrm{G}$ & $\mathrm{T}$ & $\mathrm{A}$ & $\mathrm{A}$ & $\mathrm{A}$ & A & $\mathrm{G}$ & $\mathrm{A}$ & $\mathrm{A}$ & $\mathrm{A}$ & $\mathrm{T}$ & $\mathrm{T}$ & & $\mathrm{T}$ & $\mathrm{A}$ & 0,00 \\
\hline C57BL/6J & 664 & $A$ & $\mathrm{G}$ & $\mathrm{C}$ & $\mathrm{G}$ & $\mathrm{A}$ & $\mathrm{A}$ & G & $\mathrm{T}$ & $\mathrm{A}$ & $A$ & A & A & G & $\mathrm{A}$ & $\mathrm{A}$ & A & $\mathrm{T}$ & $\mathrm{T}$ & $\mathrm{G}$ & $\mathrm{T}$ & $\mathrm{A}$ & 0,00 \\
\hline C57BL/6N & & A & $\mathrm{G}$ & $\mathrm{C}$ & G & A & A & G & $T$ & $\mathrm{~A}$ & A & A & A & G & $\mathrm{A}$ & $\mathrm{A}$ & $\mathrm{A}$ & $\mathrm{T}$ & $\mathrm{T}$ & $\mathrm{G}$ & $\mathrm{T}$ & $\mathrm{A}$ & 0,00 \\
\hline MOR/RkJ & 1297 & A & $\mathrm{G}$ & $\mathrm{C}$ & G & $\mathrm{A}$ & $\mathrm{A}$ & G & $\mathrm{T}$ & & & & & $\mathrm{G}$ & $\mathrm{A}$ & $\mathrm{A}$ & & & $\mathrm{T}$ & $\mathrm{G}$ & & $\mathrm{A}$ & 0,00 \\
\hline
\end{tabular}

Zusammenfassend konnte in kommerziell erhältlichen B6-Mäusen eine genetische Kontamination gezeigt werden, die im Rahmen einer genomweiten Kopplungsanalyse aufgefallen war. Diese Kontamination konnte in vier verschiedenen Mauslieferungen, die zu unterschiedlichen Zeitpunkten zugekauft wurden, nachgewiesen werden. Dabei waren insgesamt zwischen 8 und $71 \%$ der Tiere sowie 10 bis $55 \%$ (siehe Tabelle 19) der analysierten Mikrosatellitenmarker betroffen. Die analysierten Tiere aus drei Lieferungen stammten aus einem einzigen Zuchtraum und wurden im Zeitraum von 2003 bis 2005 erworben. An diesen Tieren war ein leichter Rückgang der Kontamination im Verlauf der Zeit erkennbar. Des Weiteren zeigten auch Mäuse aus einem weiteren Zuchtraum, die im Januar 2005 zugekauft wurden, eine Kontamination. Diese war jedoch etwas geringer als bei Tieren des anderen Raumes. 
Diese Daten wurden 2007 in der Zeitschrift Laboratory Animals veröffentlicht (F Nitzki et al., 2007).

\subsubsection{Entwicklung von RMS in Ptch ${ }^{\text {neo67/+ }}$-Mäusen mit 50 \% DBA2J-, 129Sv- und FVB/N-Hintergrund}

Die meisten Inzuchtstämme von Labormäusen stammen von einer kleinen, begrenzten Population von Mäusen aus wenigen Laboratorien ab. Deshalb können die gemeinsamen oder unterschiedlichen Vorfahren zwischen verschiedenen Inzuchtstämmen anhand der Varianz von SNP festgestellt werden (CM Wade et al., 2002).

Aufgrund dieser Tatsache sollte es auch möglich sein, eine Kartierung der RMSSuszeptibilität mit Hilfe weiterer Inzuchtmausstämme vorzunehmen. Dies sollte auf der Grundlage der Korrelation von der Segmentidentität, d. h. der Übereinstimmung oder Abweichung von Chromosomenabschnitten, und Phänotyp erfolgen. Wie bereits erklärt, war durch Kreuzungen von B6Ptch ${ }^{\text {neo67/+ }}$ - mit BALB-Mäusen erkennbar, dass der BALBHintergrund einen Lokus auf Chromosom 2 besitzt, der diesen Mausstamm dominant zu RMS prädisponiert (siehe 3.1.1). Zusätzlich wurden Kreuzungen von B6Ptch ${ }^{\text {neo67/+ }}$ Mäusen mit den Inzuchtstämmen 129Sv, DBA2J und FVB/N hergestellt und ebenfalls einem sorgfältigen Tumormonitoring unterzogen. Es wurde erwartet, dass sich die verschiedenen F1-Tiere bei den Tumorinzidenzen abhängig vom genetischen Hintergrund unterscheiden. Je nach Ergebnis sollte die ca. $40 \mathrm{Mb}$ große Region zwischen D2Mit37 und D2Mit102 nach weiterer Einengung (siehe 3.1.1.2) in den entsprechenden Mausstämmen sequenziert werden. Die Sequenzen sollten dann auf konservierte und weniger konservierte Regionen hin untersucht werden. Man würde erwarten, dass Mausstämme mit gleichem Phänotyp (z. B. hohe oder niedrige Tumorinzidenz) eine oder auch mehrere konservierte Regionen zwischen den Markern D2Mit37 und D2Mit102 auf Chromosom 2 aufzeigen. In diesen konservierten Regionen wären dann die Kanditatengene für die Ausprägung des Phänotyps zu suchen.

Jede Mauskolonie umfasste zwischen 18 und 28 Tiere und wurde über einen Zeitraum von mindestens 430 Tagen sorgfältig auf die Entwicklung von Tumoren überwacht. Beim Verdacht auf MB oder wenn Weichteiltumoren einen Durchmesser von $1 \mathrm{~cm}$ überschritten, wurden die Tiere getötet und die entsprechenden Gewebe präpariert. Die

Diagnose der Gewebeproben erfolgte mittels HE-Färbungen von Paraffin- oder Kryoschnitten durch einen erfahrenen Pathologen (W. Schulz-Schaeffer). In Tabelle 22 ist ein Überblick sämtlicher Befunde gezeigt. 
Tabelle 22: Tumorinzidenz bei DBA2JxB6Ptch $h^{\text {neo67/+ }}-$, 129SvxB6Ptch ${ }^{\text {neo67/+ }}$-, und FVB/NxB6Ptch ${ }^{\text {neo67/+ }}$-Mäusen. Gezeigt sind die Befunde der DBA2JxB6-Ptch ${ }^{\text {neo67/+ }}$-, 129SvxB6$P_{t c h}{ }^{\text {neo67/+ }}$ - und FVB/NxB6-Ptch ${ }^{\text {neo67/+ }}$-Mäuse. In der Spalte „Alter" ist das Alter zum Zeitpunkt der Präparation angegeben, unter „Befund“ findet sich die Diagnose für jedes Tier. Abkürzungen: LMS, Leiomyosarkom; MB, Medulloblastom; RMS, Rhabdomyosarkom.

\begin{tabular}{|l|l|}
\hline \multicolumn{2}{|l|}{ DBA2JxB6Ptch ${ }^{\text {neo67/+ }}$} \\
\hline $\begin{array}{l}\text { Alter } \\
\text { [Tage] }\end{array}$ & Befund \\
\hline 149 & MB \\
\hline 222 & Cyste \\
\hline 231 & RMS \\
\hline 268 & MB-Vorläufer, RMS \\
\hline 441 & $\begin{array}{l}\text { Beckencyste, } \\
\text { Nierenbeckenerweiterung }\end{array}$ \\
\hline 441 & RMS + 2 Cysten \\
\hline 441 & keine Auffälligkeiten \\
\hline 441 & RMS \\
\hline 441 & Urotheltumor (evtl. LMS) \\
\hline 442 & RMS \\
\hline 442 & RMS \\
\hline 442 & mesenchymaler Tumor \\
\hline 442 & RMS \\
\hline 443 & Cyste \\
\hline 443 & RMS \\
\hline 444 & keine Auffälligkeiten \\
\hline 447 & Urotheltumor (evtl. LMS) \\
\hline 450 & RMS + evtl. LMS \\
\hline $\mathbf{5 0 \%}$ (9/18) RMS innerhalb von \\
$\mathbf{4 5 0}$ Tagen \\
\hline
\end{tabular}

\begin{tabular}{|l|l|}
\hline \multicolumn{1}{|l|}{ 129Svx6Ptch ${ }^{\text {neo67/+ }}$} \\
\hline $\begin{array}{l}\text { Alter } \\
\text { [Tage] }\end{array}$ & Befund \\
\hline 100 & MB \\
\hline 125 & MB \\
\hline 147 & MB \\
\hline 198 & MB \\
\hline 198 & MB \\
\hline 353 & LMS \\
\hline 432 & $\begin{array}{l}\text { bindegewebige Abkapselung } \\
\text { einer Einblutung }\end{array}$ \\
\hline 443 & LMS \\
\hline 443 & keine Auffälligkeiten \\
\hline 443 & RMS \\
\hline 444 & Epidermoid \\
\hline 444 & keine Auffälligkeiten \\
\hline 444 & Hämangiom (?), 2 LMS (?) \\
\hline 444 & keine Auffälligkeiten \\
\hline 444 & keine Auffälligkeiten \\
\hline 444 & keine Auffälligkeiten \\
\hline 444 & keine Auffälligkeiten \\
\hline 444 & RMS \\
\hline 444 & LMS \\
\hline 449 & LMS \\
\hline 449 & LMS \\
\hline 449 & Uterusmyom \\
\hline $9 \%$ (2/22) RMS innerhalb von \\
444 Tagen \\
\hline
\end{tabular}

\begin{tabular}{|c|c|}
\hline \multicolumn{2}{|c|}{ FVB/NxB6Ptch $h^{\text {neo67/+ }}$} \\
\hline $\begin{array}{l}\text { Alter } \\
\text { [Tage] }\end{array}$ & Befund \\
\hline 37 & Wasserkopf \\
\hline 42 & $\mathrm{MB}$ \\
\hline 53 & Darmvorfall \\
\hline 86 & $\mathrm{MB}$ \\
\hline 111 & RMS \\
\hline 164 & keine Auffälligkeiten \\
\hline 198 & degenerierte Niere, RMS \\
\hline 207 & $\mathrm{MB}$ \\
\hline 214 & $\mathrm{MB}$ \\
\hline 231 & RMS \\
\hline 250 & $\mathrm{MB}$ \\
\hline 265 & RMS \\
\hline 274 & 2 RMS \\
\hline 313 & evtl. venöses LMS \\
\hline 315 & RMS \\
\hline 347 & Nierenbeckencyste, RMS \\
\hline 400 & RMS + LMS \\
\hline 409 & MB \\
\hline 441 & LMS \\
\hline 441 & LMS \\
\hline 443 & Cyste \\
\hline 443 & RMS \\
\hline 443 & keine Auffälligkeiten \\
\hline 443 & RMS oder LMS \\
\hline 443 & Tumor mit Plasmazellen \\
\hline 444 & evtl. LMS \\
\hline 444 & Cystenniere \\
\hline 446 & Aufstau des Nierenbeckens \\
\hline
\end{tabular}

Von 18 DBA2JxB6Ptch ${ }^{\text {neo67/+ }-M a ̈ u s e n ~ z e i g t e n ~ z w e i ~ T i e r e ~ k e i n e ~ A u f f a ̈ l l i g k e i t e n . ~ B e i ~ n e u n ~}$ Tieren wurden RMS gefunden, drei entwickelten Leiomyosarkome (LMS) und zwei ein MB bzw. MB-Vorläuferläsionen 


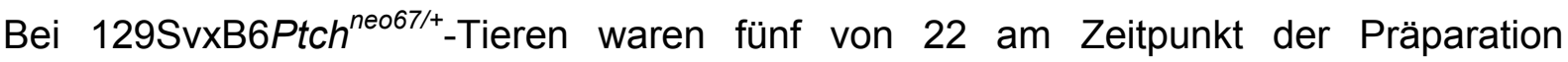
unauffällig. Von den übrigen Mäusen hatten sechs Tiere ein LMS, zwei ein RMS und fünf ein MB entwickelt.

Zwei der 28 FVB/NxB6Ptch ${ }^{\text {neo67/+ }}$-Mäuse zeigten bei der Präparation keine Besonderheiten. Bei neun Tieren wurden RMS, bei fünf Tieren LMS und bei sechs MB gefunden.

Deutliche Unterschiede in der Suszeptibilität für Tumoren zwischen den verschienen Hintergründen sind erkennbar. Mit $50 \%$ zeigten DBA2JxB6Ptch ${ }^{\text {neo67/t+}-M a ̈ u s e ~ d i e ~ h o ̈ c h s t e ~}$ Inzidenz von RMS. In der Linie FVB/NxB6Ptch ${ }^{\text {neo67/+ }}$ entwickelten $32 \%$ der Tiere RMS, die niedrigste RMS-Inzidenz von $9 \%$ wiesen 129 SvxB6Ptch ${ }^{\text {neo67/+ }}$-Tiere auf.

Die Daten zeigen, dass der Mausstamm 129Sv Allele besitzt, die weniger zu RMS prädisponieren als diejenigen des Mausstamms DBA2J oder FVB/N.

Aufgrund der genetischen Kontamination der auch für dieses Projekt zugekauften B6Mäuse wurde die Analyse jedoch frühzeitig abgebrochen, und es wurden keine weiteren SNP-Analysen der DBA2JxB6Ptch ${ }^{\text {neo67/+}}-$, $129 S v x B 6 P t c h^{\text {neo67/+_}}$ und FVB/NxB6Ptch ${ }^{\text {neo67/+ }}$-Mäuse zur Identifikation der Segmente von gemeinsamen oder unterschiedlichen Vorfahren durchgeführt.

\subsubsection{Zusammenfassung der Ergebnisse des Kartierungsprojektes}

In dieser Arbeit sollte der 7,5 cM bzw. $40 \mathrm{Mb}$ umfassende Lokus Parms1 genauer analysiert und möglichst auch weiter eingeengt werden. Dieser Lokus ist mit der Entstehung von Ptch-assoziierten RMS assoziiert. Er wurde in unserer Arbeitsgruppe anhand einer genomweiten Kopplungsanalyse in der Maus identifiziert und liegt auf dem 2. Chromosom im Intervall zwischen dem Mikrosatellitenmarker D2Mit37 und D2Mit102. BALB-Allele in dieser Region begünstigen im Gegensatz zu B6-Allelen die Entstehung von RMS (H Hahn et al., 2004). Elf Gene, die sich in diesem Lokus oder seiner unmittelbaren Umgebung befinden, wurden als Kandidatengene für eine Modifikation der Suszeptibilität für RMS in Erwägung gezogen und anhand von SNP- oder qRT-PCRAnalysen untersucht. Dabei wurde in den Genen Disp2 und D/l4 jeweils ein nicht-synonymer cSNP identifiziert. Die Gene Zfp289, Traf6 und Catns wiesen im SM von B6-Mäusen im Vergleich zu BALB-Mäusen eine erhöhte Expression auf. Weiterhin wurde zur zusätzlichen Eingrenzung von Parms1 eine neue N2-Mauskolonie aufgebaut, an der eine zweite genomweite Kopplungsanalyse mit 97 polymorphen Mikrosatellitenmarkern durchgeführt wurde. Dabei wurde eine genetische Kontamination 
bei Wildtyp B6-Mäusen festgestellt. Diese Tiere sind im Zeitraum von Herbst 2003 bis Frühjahr 2005 zur Etablierung der N2-Kolonie von der Firma Charles River Laboratories zugekauft worden. Die Kontamination betraf bis zu 18 Marker und trat bei 8 bis $71 \%$ aller untersuchten Mäuse auf. Eine genauere Analyse erwies einen Rückgang der Kontamination im Zeitraum von 2003 bis 2005. Zusätzlich konnte gezeigt werden, dass Tiere aus zwei verschiedenen Zuchträumen des Anbieters unterschiedlich stark kontaminiert waren. Die durch das Jackson Laboratory durchgeführte SNP-Analyse ließ auf eine Kontamination mit einer DBA-Inzuchtlinie schließen (F Nitzki et al., 2007).

Bevor die Kontamination bei N2- bzw. B6-Mäuse festgestellt wurde, waren Kreuzungen von B6Ptch ${ }^{\text {neo67/+ }}$-Mäusen mit den Inzuchtstämmen 129Sv, DBA2J und FVB/N hergestellt worden. Man würde erwarten, dass Mausstämme mit gleichem Phänotyp (z. B. hohe oder niedrige Tumorinzidenz) eine oder auch mehrere konservierte Regionen zwischen den Markern D2Mit37 und D2Mit102 auf Chromosom 2 aufzeigen. Auf der Basis der Korrelation von Segmentidentität und Phänotyp sollte eine weitere Einengung des RMSSuszeptibilitätskandidatenlokus vorgenommen werden. Anhand der Kreuzungen war erkennbar, dass eine hohe RMS-Suszeptibilität nicht nur durch den BALB-, sondern auch durch den DBA2J-Mausstamm vermittelt wurde, eine niedrige hingegen durch den Mausstamm 129Sv. Aufgrund der genetischen Kontamination bei den zugekauften B6Mäusen waren die Daten jedoch nicht zuverlässig und dieses Teilprojekt wurde daher nicht weiterverfolgt.

\subsubsection{Mikroarray-basierte Genexpressionsanalysen von RMS aus CD1Ptch ${ }^{\text {neo67/+ }}$ - und (BALBXB6)Ptch ${ }^{\text {neo67/+ }}$-Mäusen}

Im Rahmen von Vorarbeiten für einen Antrag bei der Deutschen Forschungsgemeinschaft wurden Mikroarray-Expressionsanalysen an RMS aus $P t c h^{\text {ne067/4 }}$-Mäusen mit unterschiedlichen genetischen Hintergründen durchgeführt. Die generierten Daten sollten als Grundlage für ein Projekt dienen, bei dem die Bedeutung der genetischen Tumor-Variabilität im Vergleich zur genetischen Wirts-Variabilität am Therapieerfolg der Behandlung von Ptch-assoziierten Tumoren untersucht werden soll. Hierzu sollte das Expressionsmuster von RMS in Abhängigkeit vom genetischen Hintergrund erstellt werden.

Für die Expressionsanalyse von RMS aus $P t c h^{\text {neo67/t+}}$-Mäusen wurden jeweils zwei Tumoren aus vier CD1Ptch ${ }^{\text {neo67/+ }}$ - und vier (BALBxB6)Ptch ${ }^{\text {neo67/+ }}$-Mäusen analysiert. Somit war ein Vergleich der Expression in RMS aus Mäusen sowohl mit unterschiedlichen (CD1 und gemischter B6xBALB-Hintergrund) und gleichen 
genetischen Hintergründen, als auch ein Vergleich zwischen zwei unabhängig voneinander entstandenen Tumoren innerhalb eines Tieres möglich.

In einer ersten Analyse sollte an den erhobenen Daten untersucht werden, ob und wie sich Tumoren einer einzigen Entität (in diesem Fall RMS), die alle durch eine einzige (Ptch-) Mutation hervorgerufen wurden, in ihrem Expressionsmuster in Abhängigkeit vom genetischen Hintergrund voneinander unterscheiden.

Vor der Hybridisierung der Proben auf Mikroarray-Chips wurde von jeder RNA-Probe Gesamt-RNA und nach ihrer Fertigstellung die Biotin-markierte cRNA mit Hilfe des RNA 6000 Nano Assay Kits auf eine mögliche Degradation hin untersucht. Anhand der Chromatogramme war erkennbar, dass sämtliche RNA-Proben sowohl vor der BiotinMarkierung als auch danach eine gute Qualität aufwiesen. Abbildung 8 zeigt die erstellten Chromatogramme für eine repräsentative Gesamt-RNA $(A)$ und entsprechende Biotin-markierte cRNA Probe (B). Die Fraktionen der 18S und 28S RNA der GesamtRNA sind klar erkennbar und somit ein Hinweis auf nicht-degradierte RNA. Qualitativ hochwertige Biotin-markierte cRNA hingegen zeigt in einem Chromatogramm die Verteilung einer Gaußkurve.
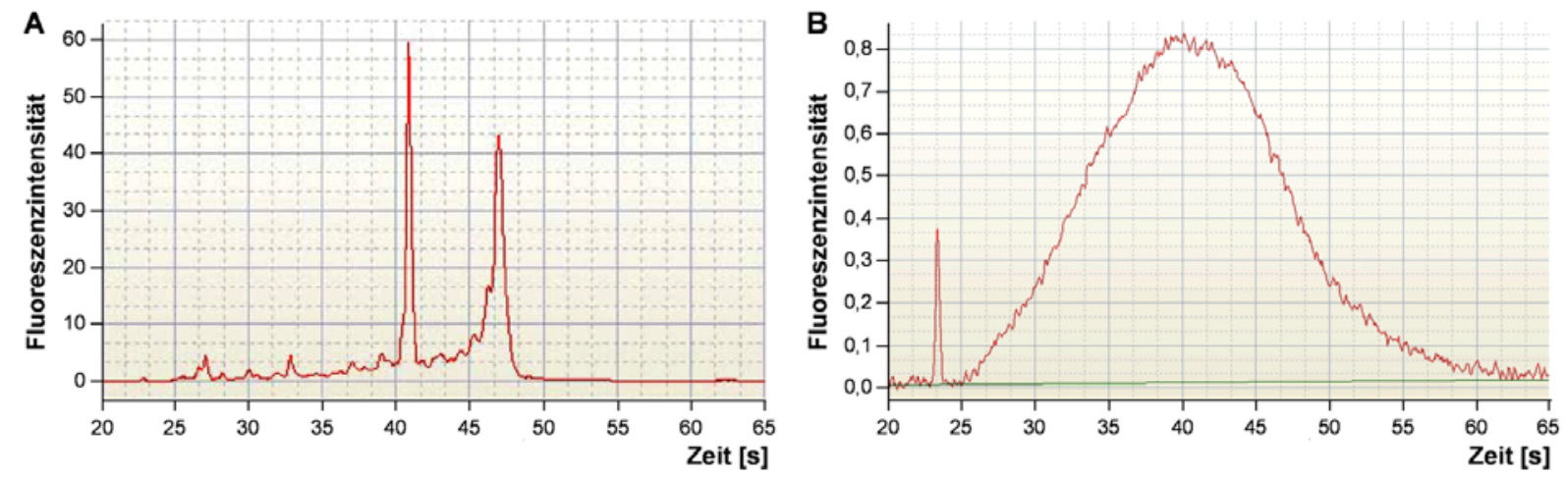

Abbildung 8: Integrität der RNA-Proben für Mikroarray-Analysen. Dargestellt sind die mit Hilfe des des RNA 6000 Nano Assay Kits hergestellten Chromatogramme von repräsentativen Gesamt-RNA (A) und Biotin-markierten cRNA Proben (B). Aufgetragen ist jeweils die Fluoreszenzintensität gegen die Laufzeit [s] der Fragmente im Gel.

Sämtliche weiteren Schritte, die vor der Hybridisierung mit Mikroarray Chips notwendig sind, sowie die Hybridisierung der Arrays wurden durch das Deutsche Ressourcenzentrum für Genomforschung in Berlin (RZPD) durchgeführt.

Die verwendeten Mikroarray-Chips (Affymetrix 430A mouse gene chips) ermöglichen die Analyse von mehr als 22.000 Transkripten. Vom RZPD wurde uns mitgeteilt, dass sowohl das Hintergrundrauschen aller Proben als auch die internen Hybridisierungskontrollen, für die dieselben RNA-Proben zweimal verarbeitet und hybridisiert worden waren, auf eine gelungene Durchführung hinwiesen. 
Anschließend wurde eine erste hierarchische Clusteranalyse der Daten von Bettina Kulle (Department of Biostatistics \& Department of Mathematics, Oslo, Norwegen) durchgeführt. Dabei wurde die Expression von 50 Transkripten verwendet, welche statistisch die größten Unterschiede zwischen den Tumorproben der beiden genetischen Hintergründe zeigten. Durch die Analyse konnten die RMS eindeutig je nach ihrem genetischen Hintergrund (CD1 und BALBxB6) getrennt werden (siehe Abbildung 9).

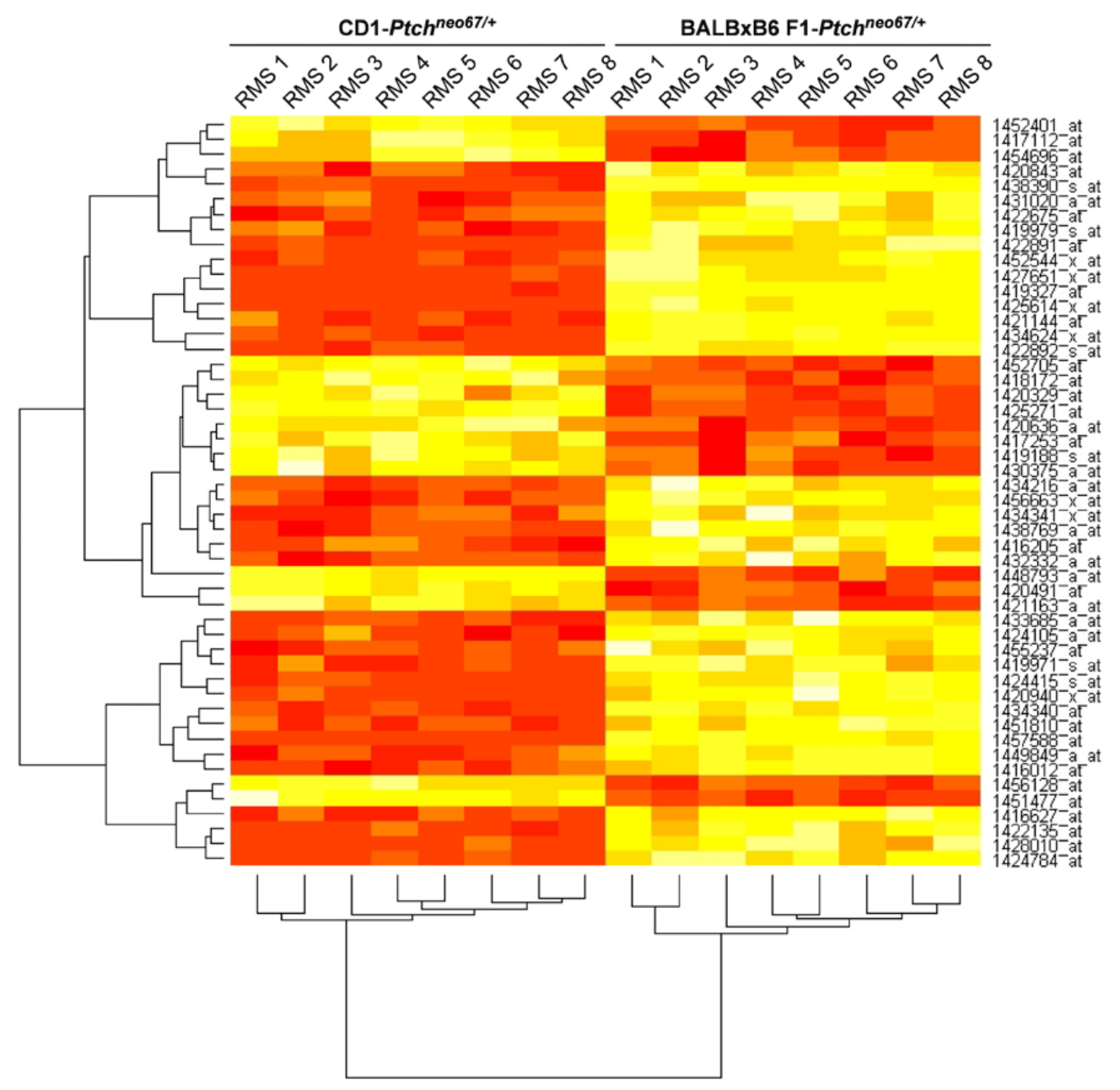

Abbildung 9: Clusteranalyse von RMS aus CD1Ptch ${ }^{\text {neo67/+ }}$ - und (BALBXB6)Ptch ${ }^{\text {neo67/+ }}-$ Mäusen. Gezeigt ist die Clusteranalyse der 50 Transkripte mit dem jeweils größten signifikanten Unterschied zwischen beiden Gruppen in je acht RMS aus CD1Ptch ${ }^{\text {neo67/+ }}$ - und (BALBxB6)Ptch ${ }^{\text {neo67/+ }}$-Mäusen. Rechts ist die Transkriptnummer von Affymetrix aufgeführt. Dunkelrote Felder repräsentieren stark exprimierte, hellgelbe Felder schwach exprimierte Transkripte. Auf der linken Seite und unterhalb sind Dendrogramme gezeigt, die eine Zuordnung in Gruppen („cluster“) nach Ähnlichkeit der Merkmalsausprägung darstellen.

Ein ebenso eindeutiges Ergebnis, das eine klare Zuordnung zum jeweiligen genetischen Hintergrund ermöglicht, zeigte eine äquivalente Analyse von 250 Transkripten (nicht gezeigt). 
Unter den in der Clusteranalyse (Abbildung 9) dargestellten Transkripten, deren Expressionsniveaus sich in RMS von CD1Ptch ${ }^{\text {neo67/+ }}$ und (BALBxB6)Ptch ${ }^{\text {neo67/+ }}$ unterschieden, finden sich $u$. a. Transkripte von Genen, die für den Histokompatibilitätskomplex kodieren, für regulatorische Transkriptionsfaktoren oder von Genen, die an Metabolismus oder Signaltransduktion beteiligt sind.

Zusammenfassend ist festzuhalten, dass diese erste Clusteranalyse eine eindeutige Einteilung der Tumoren basierend auf ihrem genetischen Hintergrund ermöglichte.

\subsection{Analyse von konditionellen Ptch $^{f l o x}$-knockout-Mäusen: Allge- meine Charakterisierung und Induktion von BCC}

In den letzten Jahren hat sich gezeigt, dass Ptch-Mutationen auch für die Entstehung des sporadischen BCC ursächlich sind. Diese Hypothese wird durch eine erhöhte Expression von Gli1 und Ptch in nahezu allen BCC gestützt, was auf eine generelle Aktivierung des Hh/Ptch-Signalweges in diesen Tumoren hinweist (M Evangelista et al., 2006). Tatsächlich haben molekulare Untersuchungen an sporadischen BCC gezeigt, dass in ca. 50 \% der Fälle somatische, d. h. erworbene heterozygote oder homozygote Ptch-Mutationen in den Tumorzellen vorliegen. BCC entwickeln sich auch in verschiedenen Tiermodellen, bei denen die Hh/Ptch-Signalkaskade in der Haut dereguliert ist. So entstehen diese Tumoren bei Ptch $^{\text {neo67/t }}$-Mäusen, dazu müssen die Tiere jedoch bestrahlt werden (M Mancuso et al., 2004; S Pazzaglia et al., 2004). Da durch die Bestrahlung viele unspezifische Veränderungen in der Haut hervorgerufen werden, ist fraglich, inwiefern dieses Modell tatsächlich nur den Effekt von PtchMutationen darstellt.

In unserem Labor wurde eine konditionelle Ptch ${ }^{\text {flox }}$-knockout-Maus generiert. Im Rahmen dieser Arbeit wurde zur Charakterisierung dieser Maus beigetragen und analysiert, ob sich in dieser Maus BCC induzieren lassen.

\subsubsection{Allgemeine Charakterisierung}

\subsubsection{Ptch-Transkription und Spleißen von Ptch-Transkripten}

In Abbildung 10 sind das wt (Wildtyp) Ptch-Allel, der für die Generierung der Mauslinie Ptch $^{\text {flox }}$ verwendete Zielvektor $\left(p P t c h^{N X}\right)$ sowie das Ptch ${ }^{\text {flox }}$ - und das Ptch ${ }^{\text {del }}$-Allel dargestellt. Im Ptch flox-Lokus befinden sich loxP-Sequenzen in Intron 7 und Intron 9. Sie ermöglichen die Deletion der Exone 8 und 9 durch eine Cre-Rekombinase-vermittelte 


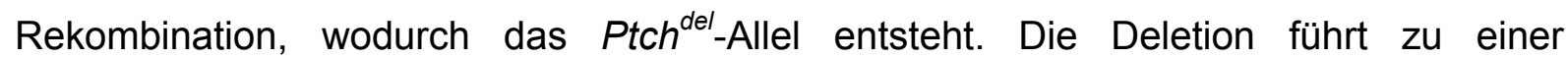
Verschiebung des Leserasters und dadurch zum vorzeitigen Abbruch der Translation. Die im Intron 9 liegende Neomycin-Resistenzkassette ist durch frt-Konsensussequenzen flankiert, die eine Deletion dieser Resistenzkassette mit Hilfe einer speziellen Rekombinase (FLPase) ermöglichen, falls sie die korrekte Transkription des Ptch ${ }^{\text {flox }}$ Allels stören sollte. Der Zielvektor $p P t c h^{N X}$ wurde in unserem Labor von Milena Koleva generiert.

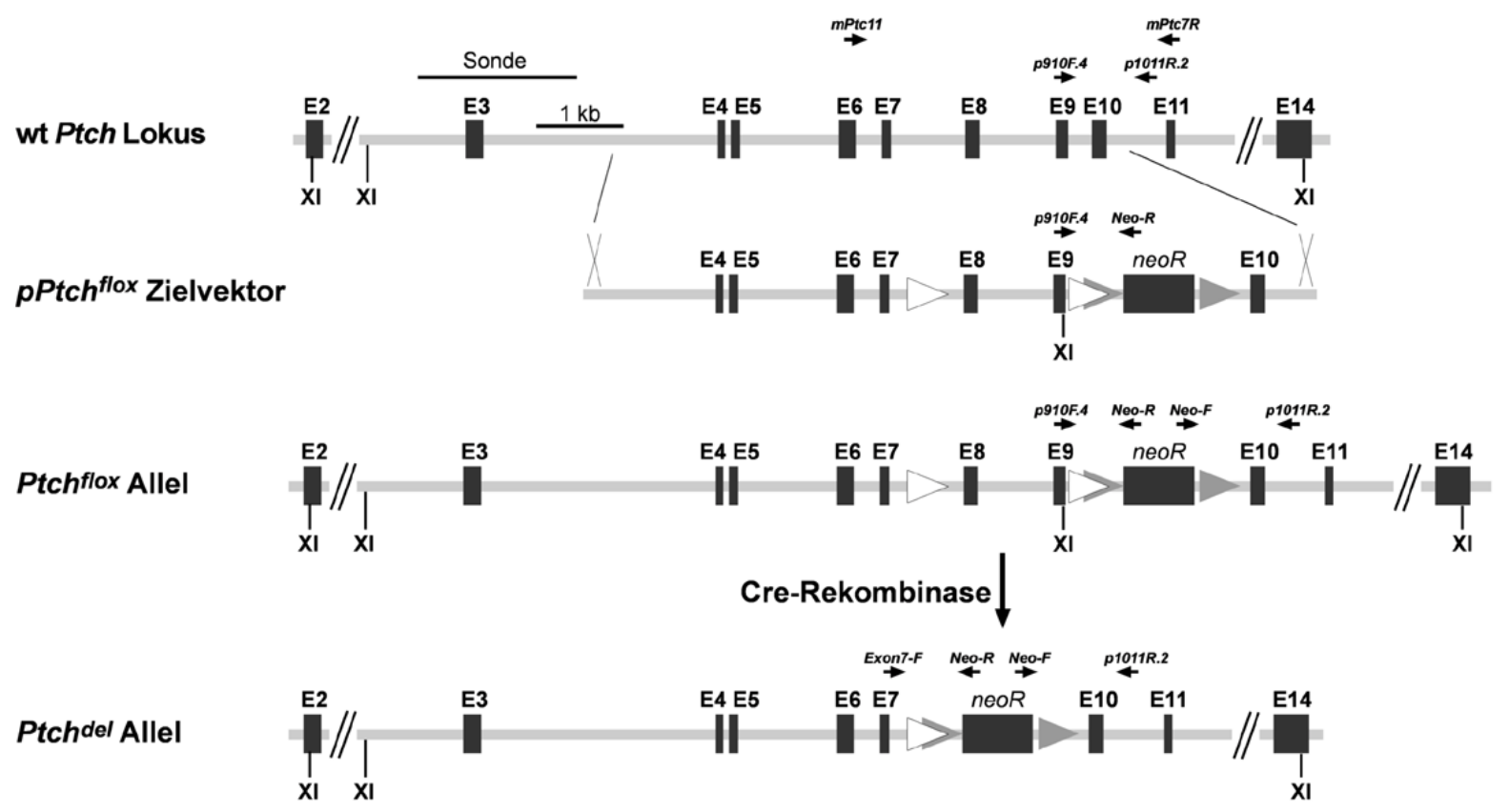

Abbildung 10: Schematische Darstellung der Strategie zur Herstellung einer konditionellen

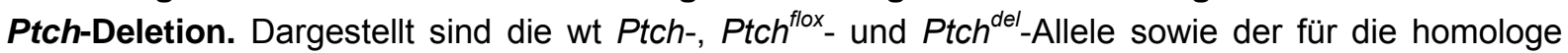
Rekombination verwendete $p P t c h^{\text {flox }}$-Zielvektor. Das $P$ tch $^{\text {flox }}$-Allel verfügt in den Introns 7 und 9 über je eine loxP-Sequenz und in Intron 9 über eine frt-Sequenz-flankierte Neomycin-Resistenzkassette $(n e o R)$. Durch die Cre-Rekombinase-vermittelte Rekombination der loxP-Sequenzen erfolgt eine

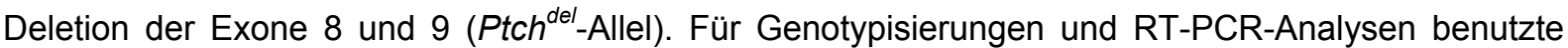
Oligonukleotide (Pfeile) und die Lokalisation der für Southern Blot-Analysen verwendeten Sonde sind eingezeichnet. Abkürzungen: E, Exon; XI, Xhol

Weiterhin sind Abbildung 10 die Positionen der im Rahmen dieser Arbeit für Genotypisierungen verwendeten Oligonukleotide und der Sonde für Southern BlotAnalysen zu entnehmen. Die Genotypisierung des Ptch ${ }^{\text {flox }}$-Lokus erfolgte mittels PCR und wurde gegebenenfalls anhand von Southern Blot-Analysen durch mich verifiziert (siehe Abbildung 11). 


\section{Ptch $^{+/+}$Ptch $^{\text {flox/+ }}$ \\ Ptchwt Allel 15948 bp \\ Ptch flox Allel 8640 bp}

Abbildung 11: Southern Blot-Analyse von $\mathrm{Ptch}^{+/+}$- und $\mathrm{Ptch}^{\text {flox/+}}$-Mäusen. Mit $\mathrm{Xhol}$ erfolgte die Restriktionshydrolyse der gDNA aus Schwanzbiopsien von $\mathrm{Ptch}^{+/+}$- und $\mathrm{Ptch}^{f l o x /+}$-Mäusen. Die Southern Blot-Analyse wurde mit der in Abbildung 10 eingezeichneten Sonde durchgeführt.

Die Expression von Ptch-Transkripten wurde in diversen Organen aus $\mathrm{Ptch}^{+/+}$- und Ptch ${ }^{\text {floxflox}}$-Tieren mittels RT-PCR-Analysen untersucht. Dazu wurden die Oligonukleotide mPtc11 und mPtch7R verwendet (siehe Tabelle 6), da sie sowohl die Detektion des $P t c h^{\text {wt }}$-Transkriptes (731 bp) als auch des Ptch $^{\text {del }}$ Trankriptes (451 bp) ermöglichen. Wie in Abbildung 12 gezeigt, wurde in allen analysierten Organen das Ptch ${ }^{\text {wt }}$-Transkript nachgewiesen. Daher konnte eine Beeinträchtigung des Spleißens durch die loxPSequenzen oder das Neomycin-Resistenzgen ausgeschlossen werden. In SM von $\mathrm{PtCh}^{+/+}$-Mäusen wurde eine bekannte Spleißvariante von Ptch gefunden, die durch das Spleißen von Exon 9 in Exon 11 entsteht $\left(\operatorname{Ptch}^{\Delta 10}\right)$ und anhand einer Sequenzanalyse bestätigt wurde.

Weder in Ptch floxflox - noch in Ptch ${ }^{f l o x /+}$-Tieren wurden in einem Zeitraum von 15 Monaten Tumoren gefunden, die Tiere waren phänotypisch unauffällig, fertil und das Ptch $^{\text {flox}}$-Allel wurde im Mendelschen Verhältnis vererbt.

Somit konnte gezeigt werden, dass Transkription und Spleißen von Ptch in Ptch floxflox_ Tieren nicht beeinträchtigt sind und die Tiere eine normale Entwicklung aufweisen. Daher war die Deletion des Neomycin-Resistenzgens mit Hilfe einer FLPaseexprimierenden Mauslinie nicht nötig. 


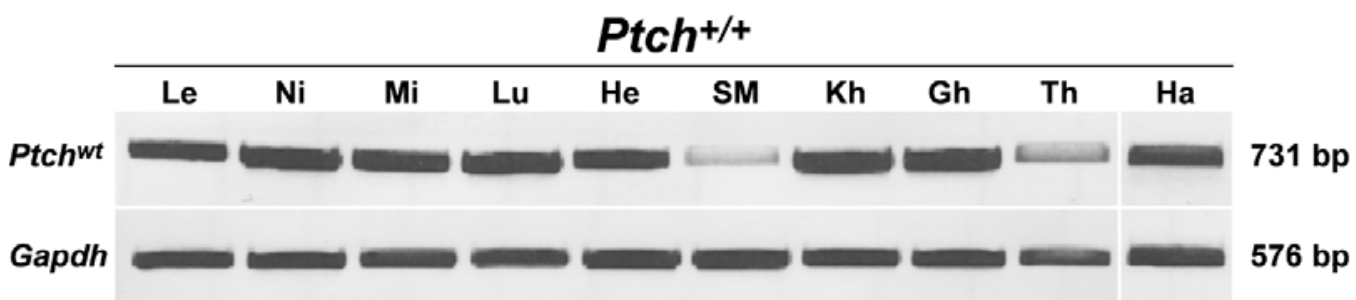

\section{Ptchflox/flox}

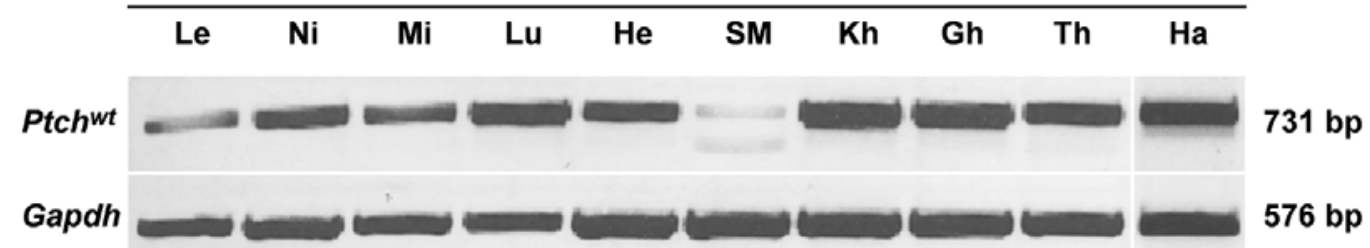

Abbildung 12: Ptch ${ }^{\text {flox/flox }}$-Mäuse exprimieren Ptch $^{\text {wt }}$-Transkripte. Zur Untersuchung der PtchExpression wurden RT-PCR-Analysen an cDNA von $\mathrm{Ptch}^{+/+}$- und $\mathrm{Ptch}^{\text {floxflox }}$-Tieren von verschiedenen Organen durchgeführt. Die verwendeten Oligonukleotide $\mathrm{mPtc} 11$ und $m P t c 7 R$ hybridisieren in Exon 6 bzw. Exon 11. Im SM der Ptch ${ }^{\text {floxflox }}$-Maus wurde eine Spleißvariante nachgewiesen, die von K. Nagao et al. beschrieben wurde (K Nagao et al., 2005a; K Nagao et al., 2005b). Als Kontrolle der cDNA diente die Amplifikation von Gapdh-Transkripten. Abkürzungen: Le, Leber; Ni, Niere; Mi, Milz; Lu, Lunge; He, Herz; SM, Skelettmuskel; Kh, Kleinhirn; Gh, Großhirn; Th, Thymus; Ha, Haut.

\subsubsection{Deletion von Ptch in der Keimbahn}

Konventionelle $P$ tch $^{\text {neo67// }}$-Mäuse sind für die Entwicklung von RMS und MB prädisponiert. Dagegen sterben homozygot mutante $P_{t c h}{ }^{\text {ne067/neo67 }}$-Embryonen aufgrund von Neuralrohr- und Herzdefekten zwischen 9,0 und 10,5 dpc in utero (LV Goodrich et al., 1997; H Hahn et al., 1998).

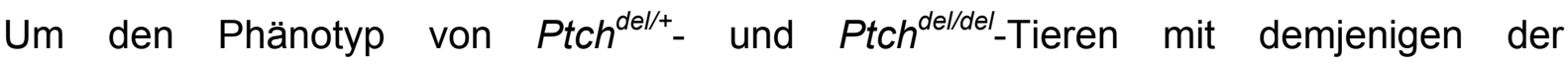
$P t c h^{\text {neo67 }}$-Nullmutation zu vergleichen, wurden männliche $P t c h^{\text {flox/t }}$-Mäuse mit weiblichen Tg(Ella-Cre)-Mäusen (M Lakso et al., 1996) verpaart. In Tg(Ella-Cre)-Mäusen wird die Cre-Rekombinase unter dem Ella-Promotor exprimiert, der ausschließlich während der ersten meiotischen Teilung der Keimbahnzellen aktiv ist. Durch eine Geschwisterverpaarung der resultierenden $\mathrm{Ptch}^{\mathrm{del/+}}$-Mäuse konnten $\mathrm{Ptch}^{+/+}{ }_{-}, \mathrm{Ptch}^{\mathrm{del/+}}{ }_{-}$ und $P t c h^{\text {del/del }}$-Embryonen generiert und analysiert werden.

Wie in der Disseration von Anja Uhmann (2005) bereits beschrieben, ist die homozygote Keimbahnmutation Ptch ${ }^{\text {del/del }}$ embryonal letal, wobei der Phänotyp (Verschlussdefekte des Neuralrohrs) und der Zeitpunkt des Todes zwischen dem Tag 9,0 und 10,5 dpc in utero mit dem von $P$ tch $^{\text {neo67/neo67 }}$-Embryonen übereinstimmen. In adulten $\mathrm{Ptch}^{\mathrm{del/}+}$-Mäusen wurde ebenso wie in $\mathrm{Ptch}^{\text {neo67/+ }}$-Tieren die Entwicklung von RMS und MB beobachtet. 
Zur Untersuchung der Expression der Hh/Ptch-Zielgene in 9,5 bis 10,5 Tage alten

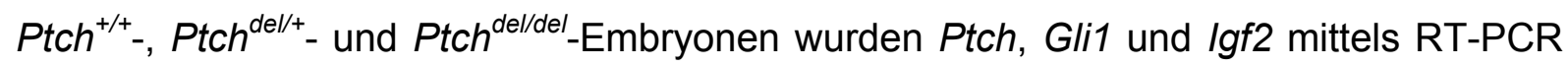
analysiert. Da für die Amplifikation von Ptch die Oligonukleotide mPtc11 und mPtc7R (Tabelle 6) verwendet wurden, konnten Ptch ${ }^{\text {wt }}$ - und $P t c h^{d e l}$-Transkripte unterschieden werden. Wie in Abbildung 13 gezeigt, konnte das Ptch ${ }^{\text {wt }}$-Transkript ausschließlich in $\mathrm{Ptch}^{+/+}$- und Ptch ${ }^{\mathrm{del} /+}$-Embryonen nachgewiesen werden, während in $P t c h^{\text {del/+ }}$ - und $P t c h^{\text {del/del }}$-Embryonen das $P t c h^{\text {del }}$-Transkript exprimiert wurde. Des Weiteren war eine leicht erhöhte Expression von Gli1 in Ptch ${ }^{\text {deldel }}$-Embryonen erkennbar, Igf2 dagegen zeigte eine normale Expression im Vergleich zu Ptch ${ }^{+/+}$- und $\mathrm{Ptch}^{\text {del/t}}$-Embryonen. Sequenzanalysen der amplifizierten Transkripte aus $P t c h^{\text {del/ }}$ - und $P t c h^{\text {del/del }}$-Embryonen belegen die Deletion der Exone 8 und 9 des $P t c h^{d e l}$-Transkriptes.

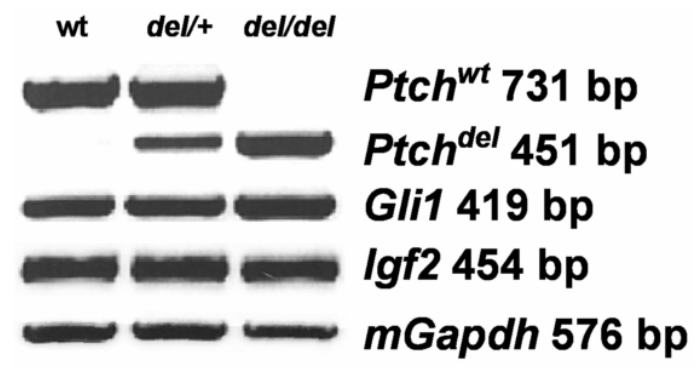

Abbildung 13: Ptch $^{\text {del/+- }}$ und Ptch ${ }^{\text {del/del }}$-Embryonen exprimieren das Ptch ${ }^{\text {del }}$-Transkript. Embryonen im Alter von 9,5 und 10,5 dpc wurden isoliert und anhand der gDNA der Dottersäcke genotypisiert. Expressionsanalysen für Ptch, Gli1 und Igf2 erfolgten mittels RT-PCR an cDNA von

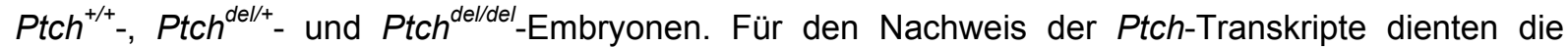
Oligonukleotide mPtc11 und mPtc7R. Für die Analyse der Expression von Gli1 und lgf2 wurden die Oligonukleotide mGliF8 und mGliR9 bzw. Igf2 TaqManF und Igf2 Exon6R (siehe Tabelle 6) verwendet. Zur Kontrolle der cDNA erfolgte die Amplifikation von Gapdh-Transkripten.

Auch in RMS aus adulten Ptch ${ }^{\text {del/+}}$-Mäusen wurde die Expression von Hh/Ptch-Zielgenen untersucht. Mittels RT-PCR erfolgte die Expressionsanalyse von Ptch, Gli1 und Igf2. In Abbildung 14 ist die erhöhte Expression aller drei Transkripte im Vergleich zu SM dieser Tieren erkennbar, wobei die Zunahme bei Igf2 sehr moderat war. Ausschließlich Ptch ${ }^{d e l}$ Transkripte waren in den untersuchten RMS detektierbar. Die Sequenz der Transkripte wurde anhand einer Sequenzanalyse bestätigt. 


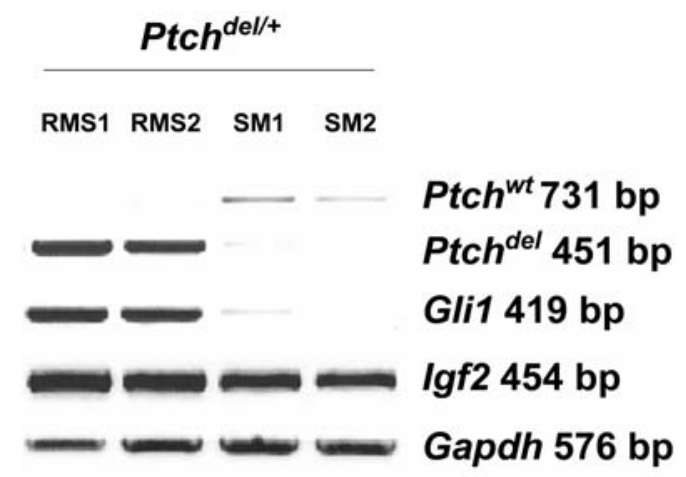

Abbildung 14: Erhöhte Aktivität der Hh/Ptch-Signalkaskade in RMS aus Ptch ${ }^{\text {del/t+}-M a ̈ u s e n . ~ R T-~}$ PCR-Analysen wurden an cDNA von RMS und SM aus Ptch ${ }^{\text {del/t+}}$-Mäusen für Ptch, Gli1 und Igf2 durchgeführt. Dabei wurden die Oligonukleotidpaare mPtc11 // mPtc7R, mGliF8 // mGliR9 bzw. Igf2 TaqManF // Igf2 Exon6R verwendet. Zur Kontrolle der cDNA wurden Gapdh-Transkripte amplifiziert.

Zusammenfassend ist festzuhalten, dass die Cre-Rekombinase eine effiziente Deletion der gefloxten Ptch-Sequenz hervorruft. Der Phänotyp von adulten $P t c h^{\text {del/+ }}$-Mäusen entspricht demjenigen von konventionellen heterozygoten knockout-Mäusen $\left(P t c h^{n e 067 /+}\right)$. Diese Analysen weisen somit darauf hin, dass Mäuse mit dem Ptch $^{\text {flox }}$-Allel ein geeignetes Modell für die Analyse einer gewebs- und/oder zeitspezifischen Deletion von Ptch sind. Daher sollte mit Hilfe dieser Maus eine konditionelle homozygote Deletion von Ptch in der Haut und somit die Induktion von BCC möglich sein.

\subsubsection{Deletion von Ptch in adulten Ptch ${ }^{\text {flox }}$-Mäusen und Induktion von BCC-Vorläuferläsionen}

Um Ptch in adulten Mäusen zu deletieren, wurden Ptch floxflox-Mäuse mit ROSA26ERT2Mäusen, die im Folgenden als ERT2 bezeichnet werden, gekreuzt. ERT2-Mäuse exprimieren eine Tamoxifen-induzierbare Cre-Rekombinase (Cre-ERT2) unter der Kontrolle des endogenen ROSA26-Promotors (D Hameyer et al., 2007). Durch systemische oder lokale Gabe von Tamoxifen kann die Cre-ERT2 im Tier aktiviert werden.

\subsection{Deletion von Ptch durch i.p. Gabe von $5 \mathrm{mg}$ Tamoxifen}

Die systemische Induktion der Cre-ERT2 erfolgte in sechs bis acht Wochen alten Ptch $^{\text {floxflox}}{ }^{2} R 2_{2}^{+/}$-Mäusen durch die Verabreichung einer Gesamtdosis von $5 \mathrm{mg}$ Tamoxifen. Dabei wurde jeweils $1 \mathrm{mg}$ des Medikaments an fünf aufeinander folgenden Tagen intraperitoneal (i.p.) injiziert. Die nach diesem Schema i.p. behandelten $P t c h^{\text {floxflox}} E R T 2^{+/-}$-Tiere werden im Folgenden als „tPtch ${ }^{-/-4}$-Mäuse bezeichnet. 
Kontrolltiere wurden entsprechend mit dem Lösungsmittel für Tamoxifen (Emulsion aus

Ethanol und Sonnenblumenöl; siehe 2.15.4.1.7) behandelt. Weiterhin wurden als

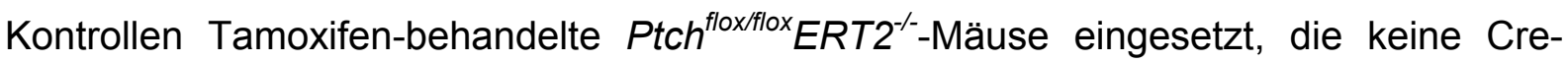
ERT2 exprimieren.

\subsection{BCC-Vorläuferläsionen und andere Anomalien in $\mathrm{tPtch}^{-/-}$-Mäusen}

Bereits zehn Tage nach der ersten Injektion zeigten $\mathrm{tPtch}^{-/}$-Mäuse phänotypische Veränderungen. Nach 19 Tagen wurde anhand von histologischen Analysen eine Hyperproliferation diverser Gewebe festgestellt. Wie in Abbildung 15 erkennbar, zeigten sich tatsächlich proliferative Veränderungen in der interfollikulären und follikulären Epidermis. Aufgrund einer rapiden Verschlechterung der körperlichen Verfassung mussten die Tiere spätestens 23 Tage nach der ersten Tamoxifen-Injektion getötet werden. Daher konnte nicht untersucht werden, ob sich BCC aus den proliferativen Veränderungen entwickelt hätten.
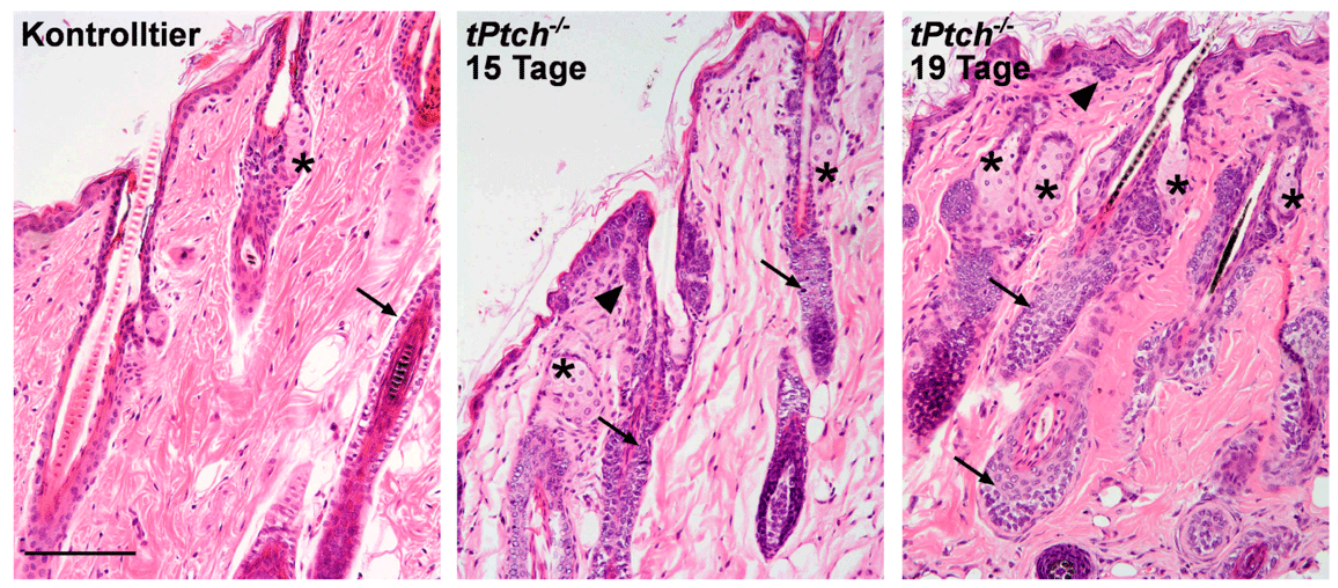

Abbildung 15: Hyperproliferation der Epidermis in $\mathrm{tPtch}^{-1}$-Mäusen. Gezeigt sind HE-gefärbte Paraffinschnitte der Haut aus tPtch $^{-/}$-Mäusen 15 Tage und 19 Tage nach der ersten TamoxifenInjektion und aus einem Lösungsmittel-behandelten $P t c h^{f l o x}{ }^{\prime f l o x} E R T 2^{+/}-$Kontrolltier. Hyperproliferative Bereiche der Epidermis sind mit Pfeilköpfen markiert, Pfeile kennzeichnen die äußere Wurzelscheide der Haarfollikel und Sterne die Talgdrüsen. Der Balken entspricht $2 \mathrm{~mm}$ im Präparat.

Dennoch wurden diverse weitere Analysen an diesen Tieren durchgeführt. So zeigten auch die Magenwand (Abbildung 16) und das Mesenterium starke hyperproliferative Veränderungen (Abbildung 17). Herz, Lunge, Leber, Niere, Pankreas und SM waren indes nicht betroffen (nicht gezeigt). 

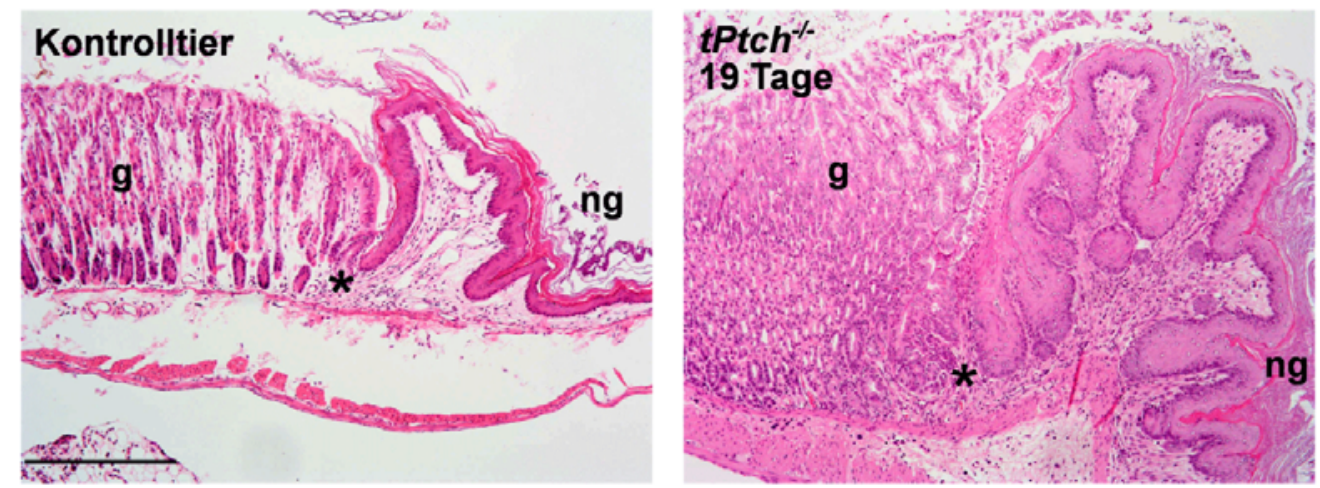

Abbildung 16: Hyperproliferative Bereiche des Magens aus $\mathrm{tPtch}{ }^{-{ }_{-}}$-Mäusen. Dargestellt sind HEgefärbte Paraffinschnitte einer $\mathrm{tPtch}^{-/}$-Maus 19 Tage nach der ersten Tamoxifen-Injektion und einer

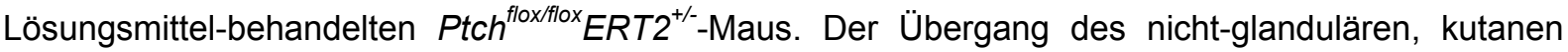
(ng) Magens zum glandulären, mukösen Magen (g) ist mit Sternen markiert. Der Balken entspricht $5 \mathrm{~mm}$ im Präparat.
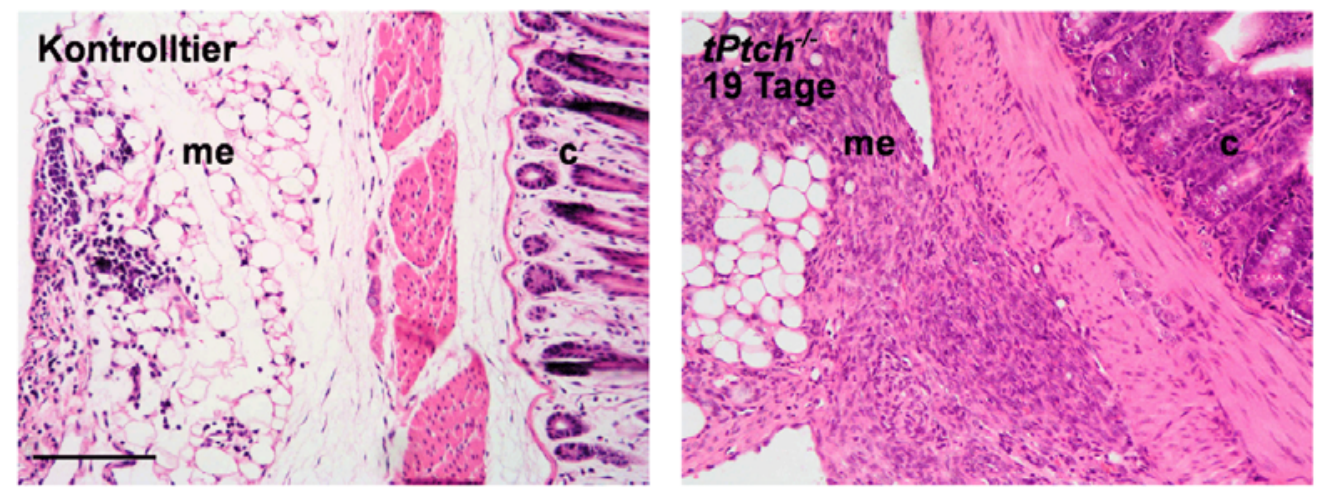

Abbildung 17: Hyperproliferative Bereiche des Mesenteriums von Ptch $^{-/}$-Mäusen. Dargestellt sind HE-gefärbte Paraffinschnitte einer $\mathrm{tPtch}^{-/}$-Maus 19 Tage nach der ersten Tamoxifen-Gabe im Vergleich zu einer Lösungsmittel-behandelten Ptch $^{\text {flox/flox }}{ }^{2} R T 2^{+/}$-Maus. Der Balken entspricht $2 \mathrm{~mm}$ im Präparat. Abkürzungen: c, Magenkorpus, me, Mesenterium.

Des Weiteren zeigten Ptch $^{-/}$-Mäuse im Gegensatz zu Kontrolltieren eine dramatische Verkleinerung des Thymus mit morphologischen Veränderungen und eine starke Verminderung der Thymozytenzahl (Dissertation Anja Uhmann, 2005). Anhand von durchflusszytometrischen Analysen wurde ein Entwicklungsdefekt der Thymozyten in einem frühen Stadium nachgewiesen. Ebenso war in der Milz eine Verringerung der B-Lymphozyten erkennbar, die auf einem Defekt in der frühen Differenzierung dieser Zellen beruht. Schließlich konnte gezeigt werden, dass die Ptch-Mutation in Ptch $^{-/-}$ Mäusen bereits einen Entwicklungsdefekt der allgemeinen lymphoiden Vorläuferzellen im Knochenmark bewirkte. Zellen der myeloischen Linie und deren Entwicklung waren im Gegensatz zu Zellen der lymphoiden Linie nicht gestört. 
Im Rahmen der Charakterisierung von tPtch $^{-/}$-Mäusen wurde in dieser Arbeit die Expression von Ptch-Transkripten und weiteren Zielgenen des Hh/Ptch-Signalweges in verschiedenen Organen analysiert. Dabei wurde die Expession in Organen einer Ptch $^{-1}$ Maus 15 Tage nach der ersten Tamoxifengabe mit der in Organen unbehandelter $P_{t c h}{ }^{\text {floxflox }} E R T 2^{+/-}$- bzw. Ptch ${ }^{\text {flox/flox }}$-Mäuse verglichen (die Daten für die Ptch ${ }^{\text {floxflox }}$-Maus

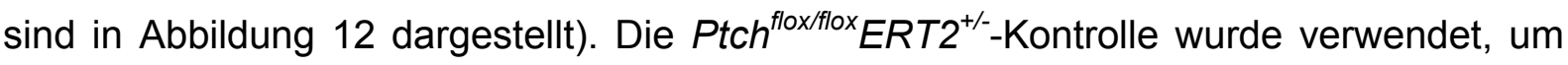
die Grundaktivität der Cre-ERT2 ohne Gabe von Tamoxifen zu charakterisieren.

Die Analysen zeigten, dass unbehandelte $P t c h^{f l o x / f l o x} E R T 2^{+/}$-Mäuse keine detektierbaren Level an Ptch $^{\text {del }}$-Transkripten exprimieren (siehe Abbildung 18). Jedoch konnten Ptch ${ }^{\text {del }}$ Transkripte in allen analysierten Organen der Ptch $^{-/}$-Maus mit Ausnahme von Klein- und Großhirn nachgewiesen werden (siehe Abbildung 18). Dabei variierte die Expression von

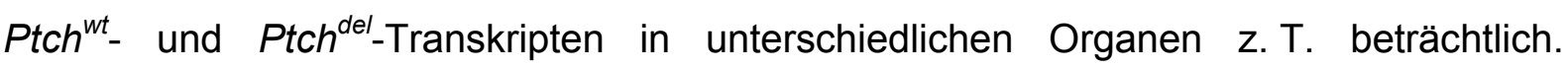
Aufgrund der geringen Aktivität des ROSA26-Promotors in Groß- und Kleinhirn (D

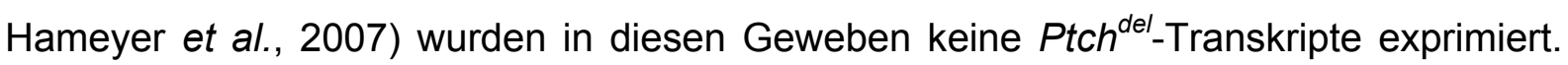
Zusätzlich zu Ptch ${ }^{\text {wt }}$ wurde im SM aller untersuchten Tiere die bereits unter 3.2 beschriebene Spleißvariante $P t c h^{\Delta 10}$ detektiert und anhand einer Sequenzanalyse bestätigt.

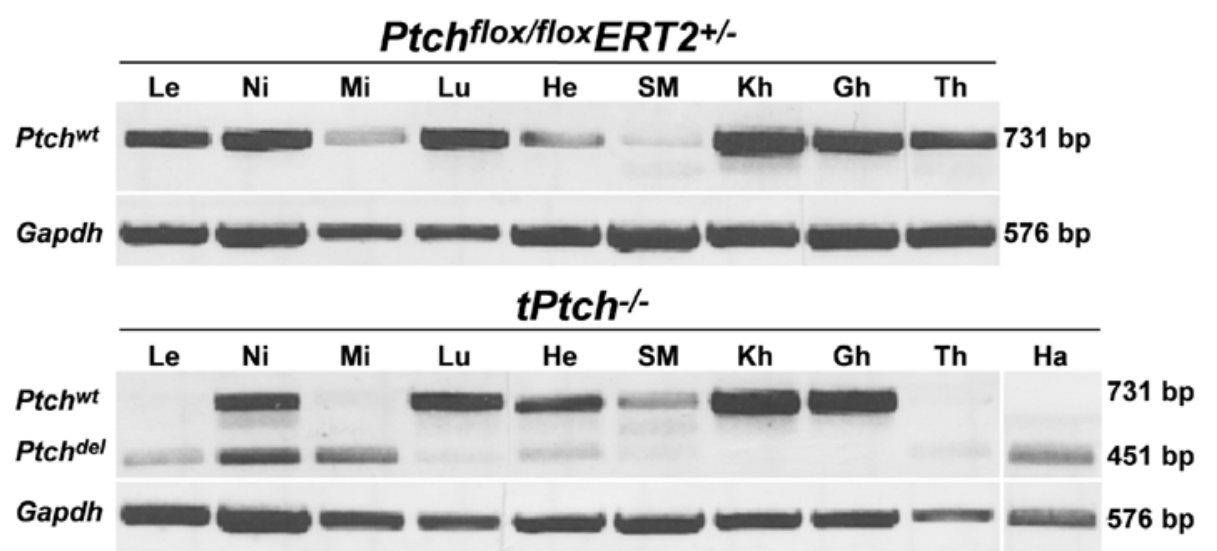

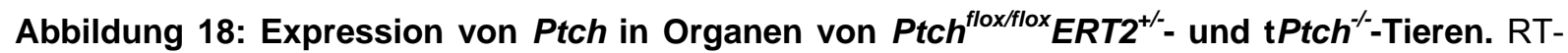
PCR-Analysen für die Expression von Ptch wurden an CDNA einer unbehandelten Ptch $^{\text {floxfllox }}$ ERT2 $^{+/}$und einer $\mathrm{tPtch}^{-/}$-Maus 15 Tage nach der ersten Tamoxifengabe aus verschiedenen Organen mit den Oligonukleotiden mPtc11 und mPtc7R durchgeführt. Im SM wurde eine von K. Nagao et al. beschriebene Spleißvariante nachgewiesen (K Nagao et al., 2005a; K Nagao et al., 2005b). Als Kontrolle der cDNA diente die Amplifikation von Gapdh-Transkripten. Abkürzungen: Le, Leber; Ni, Niere; Mi, Milz; Lu, Lunge; He, Herz; SM, Skelettmuskel; Kh, Kleinhirn; Gh, Großhirn; Th, Thymus; Ha, Haut.

Die Analyse der Expression von Gli1- und Igf2-Transkripten, deren Expressionsstärke zur Bestimmung der Aktivität des Hh/Ptch-Signalweges nach einer Ptch-Mutation herangezogen werden kann, zeigte keine Unterschiede zwischen der Tamoxifen- 
behandelten $\mathrm{Ptch}^{\text {floxflox}} E R T 2^{+/}$-Maus und den beiden untersuchten Kontrolltieren (nicht gezeigt).

Zusammengefasst zeigen diese Daten, dass die Eigenaktivität der Cre-ERT2 in vivo unter dem detektierbaren Niveau liegt und dass sich die Cre-ERT2 durch eine i.p. Injektion von $5 \mathrm{mg}$ Tamoxifen sehr gut aktivieren lässt. Durch diese Aktivierung wird Ptch

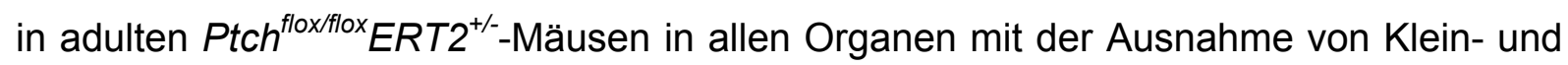
Großhirn mutiert. Obwohl keine Zunahme der Aktivität der Hh/Ptch-Signalkaskade bei RT-PCR-Analysen erkennbar war, führte die Induktion der Ptch-Mutation in adulten Mäusen zur Hyperproliferation der Epidermis, der Magenwand und des Mesenteriums sowie zu einem Entwicklungsdefekt der allgemeinen lymphoiden Vorläuferzellen. Die Tiere mussten aufgrund eines sehr schlechten Allgemeinzustandes jedoch 23 Tage nach der ersten Tamoxifen-Injektion ababgetötet werden. Diese Daten wurden in der Zeitschrift Blood publiziert (A Uhmann et al., 2007).

\subsubsection{Induktion von BCC durch i.m. Gabe von $100 \mu \mathrm{g}$ Tamoxifen}

Wie unter 3.2.1.3.2 erläutert, bewirkte die i.p. Injektion von $5 \mathrm{mg}$ Tamoxifen bei Ptch $^{\text {floxfflox }} E R$ T2 $^{+/}$-Mäusen eine Hyperproliferation der Haut. Diese Läsionen wurden als Vorläufer von BCC identifiziert. Interessanterweise entwickelten jedoch Ptch ${ }^{\text {floxflox }} E R T 2^{+/-}$ Mäuse, denen eine Dosis von $100 \mu \mathrm{g}$ Tamoxifen intramuskulär (i.m.) in den Musculus soleus injiziert wurde, BCC an der unbehaarten Haut (siehe Abbildung 19). Da diese Tiere auch im Alter keine weiteren Organveränderungen und keine Entwicklung von RMS zeigten, wurden sie über Zeiträume bis zu 350 Tage nach der Tamoxifen-Injektion beobachtet.

Schon 45 Tage nach der Injektion waren BCC-Vorläuferläsionen an der interfollikulären und follikulären Epidermis histologisch erkennbar (siehe Abbildung 20). Innerhalb von 90 Tagen hatten sich aus diesen Vorläuferläsionen voll-ausgebildete BCC entwickelt. 


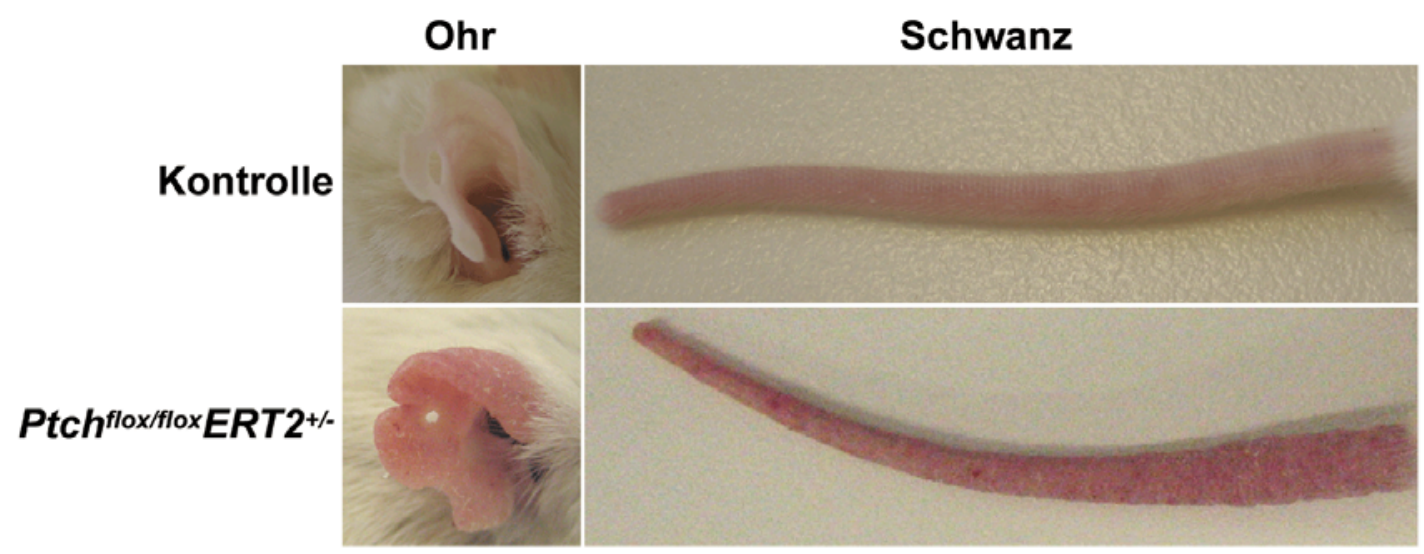

Abbildung 19: Induktion von BCC an Ohr- und Schwanzhaut in Ptch $^{\text {flox/flox }}$ ERT2 ${ }^{+/-}$-Mäusen nach i.m. Injektion von 100 $\mathbf{~ g}$ Tamoxifen. Dargestellt sind die Ohren und Schwänze einer Ptch $^{\text {floxfllox }} E R T 2^{+/}$-Maus zehn Wochen nach der i.m. Injektion von $100 \mu \mathrm{g}$ Tamoxifen und einer Lösungsmittel-behandelten Kontrollmaus.

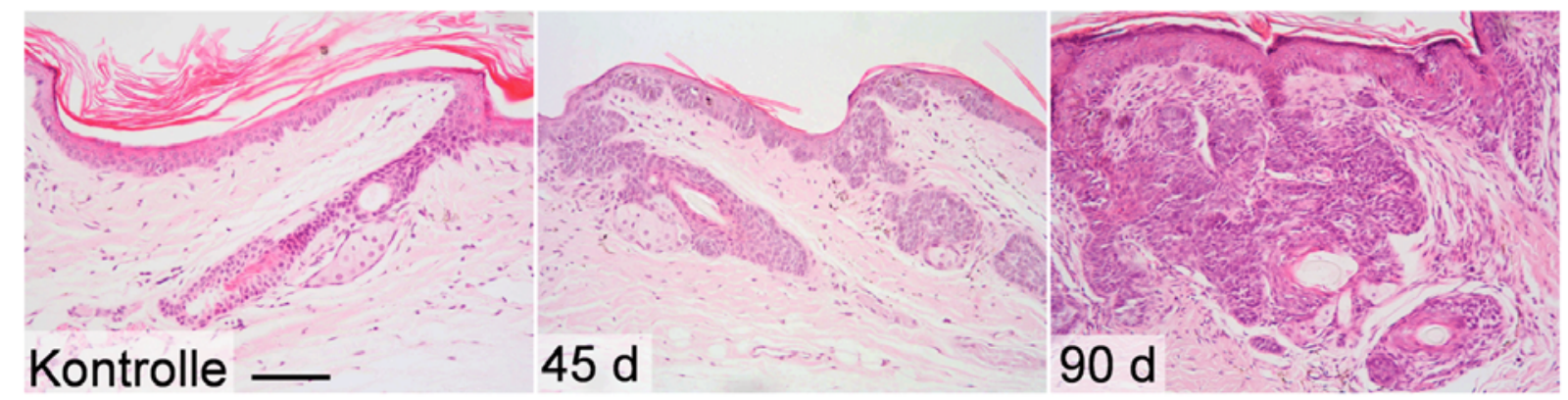

Abbildung 20: Induktion von BCC in Ptch flox/flox $E R T 2^{+/-}$-Mäusen nach i.m. Injektion von $100 \mu \mathrm{g}$

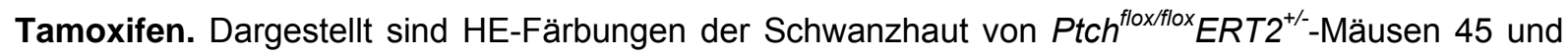
90 Tage nach der i.m. Tamoxifen-Injektion und einer Lösungsmittel-behandelten Ptch $^{\text {floxfllox}} E R T 2^{+/}$Maus (Kontrolle). Der Balken entspricht $1 \mathrm{~mm}$ im Präparat. Abkürzung: d, Tage.

An den Fußsohlen wurden ebenfalls Hauttumoren beobachtet, die als Trichoblastome identifiziert wurden (siehe Abbildung 21). Des Weiteren wurde am Schwanz einer Maus zusätzlich zu BCC ein Bindegewebstumor gefunden (Abbildung 21).

In der behaarten Haut entwickelte sich bei keinem Tier ein BCC, in Einzelfällen waren jedoch Vorläuferläsionen sichtbar. Ansonsten waren die Tiere phänotypisch unauffällig. In keiner der Lösungsmittel-behandelten Ptch floxflox ERT2 ${ }^{+/}$- oder Tamoxifen- oder

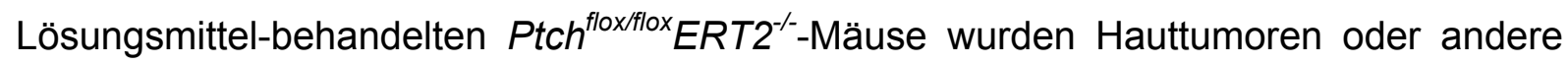
Anomalien gefunden. 


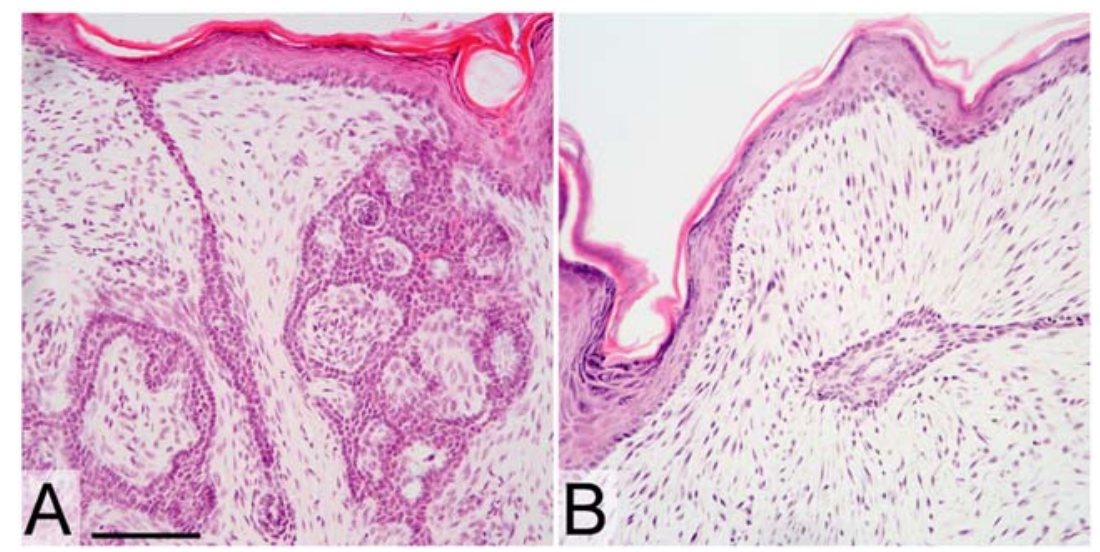

Abbildung 21: Induktion von Trichoblastomen und eines Bindegewebstumors in

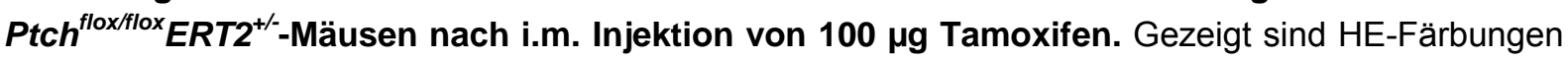

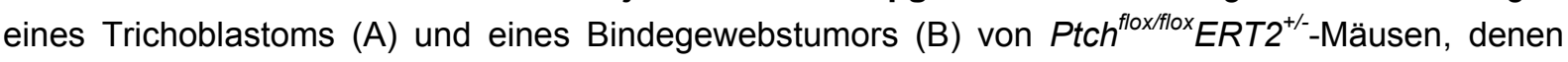
$100 \mu \mathrm{g}$ Tamoxifen i.m. appliziert wurde. Der Balken entspricht $1 \mathrm{~mm}$ im Präparat.

\subsubsection{In vivo-Analyse der Tamoxifen-induzierten Aktivität der Cre-ERT2 in ROSA26-R-Reportermäusen}

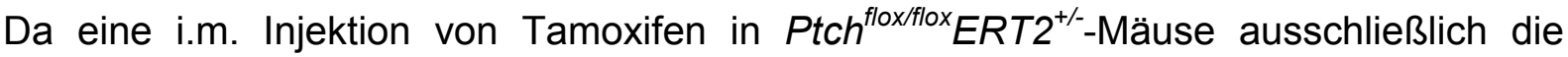
Entwicklung von Hauttumoren induzierte und keine weiteren Auffälligkeiten festgestellt wurden, erfolgte eine Analyse der Tamoxifen-induzierten Aktivität der Cre-ERT2 in ROSA26-R-Reportermäusen. Bei ROSA26-R-Reportermäusen befindet sich im endogenen ROSA26-Lokus eine loxP-Sequenz-flankierte Neomycin-Resistenzkassette mit nachgeschaltetem $\beta$-Galaktosidasegen. Durch Cre-ERT2-vermittelte Rekombination der loxP-Sequenzen wird die Neomycin-Resistenzkassette deletiert, und es kommt somit zur Expression des $\beta$-Galaktosidasegens.

Die Expression des $\beta$-Galaktosidasegens wurde in doppelt heterozygoten ROSA26ERT2 ${ }^{+/} ;$ROSA26- $R^{+/-}$-Mäusen nach der i.m. Injektion von $100 \mu \mathrm{g}$ Tamoxifen in verschiedenen Organen untersucht. Zum Vergleich wurde zusätzlich eine $R O S A 26 E R T 2^{+/} ; R O S A 26-R^{+/}$-Maus mit $5 \mathrm{mg}$ Tamoxifen (i.p.) behandelt. Fünf Tage nach der ersten Injektion wurden die Organe der Tiere zur Analyse entnommen. Anhand einer X-Gal-Färbung an Kryoschnitten der Organe konnte die Aktivität der Cre-ERT2 festgestellt werden (siehe Abbildung 22).

Dabei zeigte sich, dass eine i.m. Injektion von Tamoxifen die Aktivierung der Cre-ERT2 in der Epidermis, insbesondere in der unbehaarten Haut von Ohren und Schwanz, bewirkt. Eine fokale X-Gal-Färbung wurde in der Niere detektiert, des Weiteren fanden sich schwache Färbungen in Leber, Milz und Lunge. Keinerlei Aktivität war im Herz, Thymus, SM und in Reproduktionsorganen nachweisbar. 


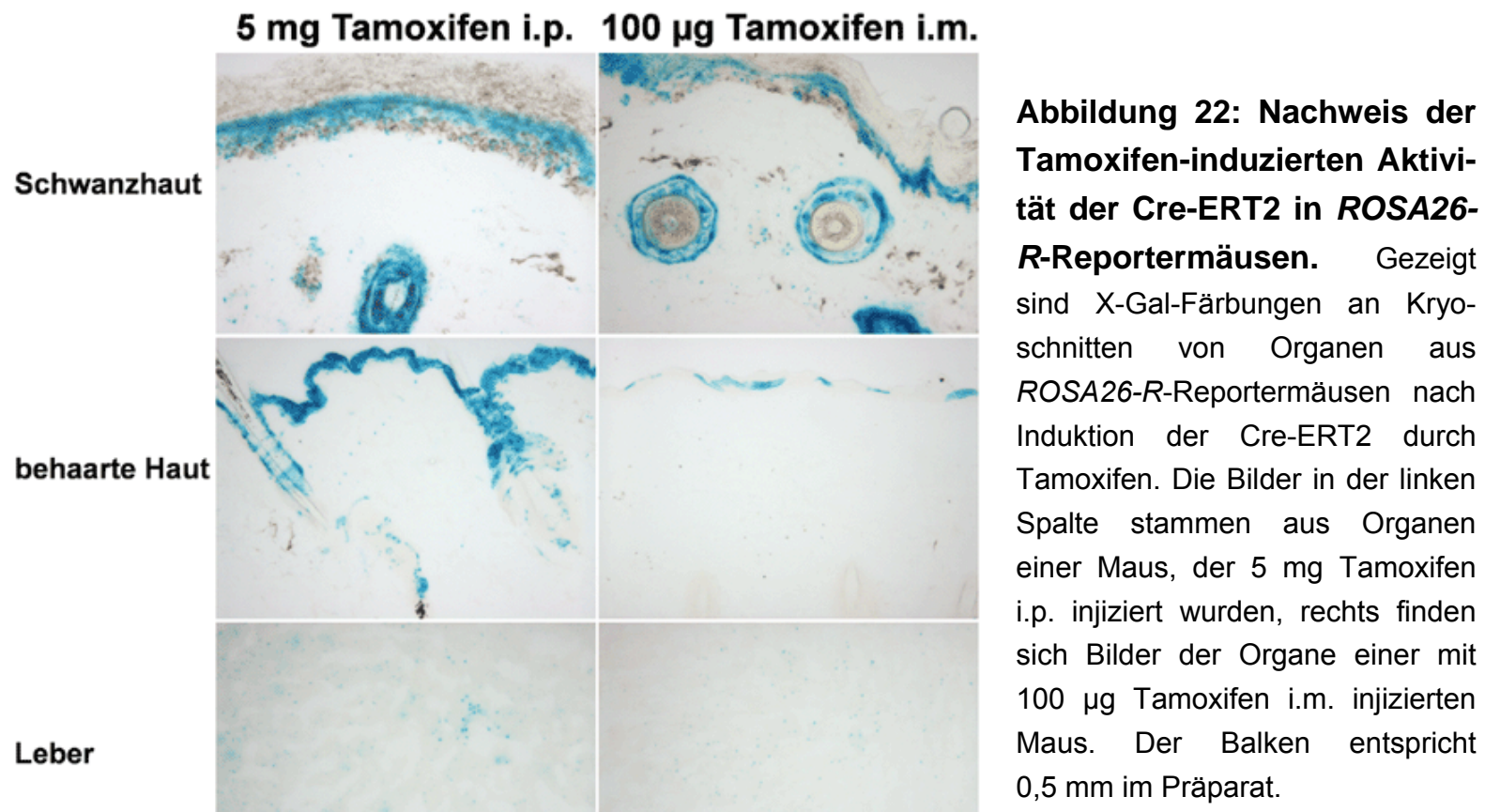

Niere

Milz

Herz

SM

Thymus

5 mg Tamoxifen i.p. $100 \mu g$ Tamoxifen i.m.

0,5 mm im Präparat. 
Die i.p. Gabe von $5 \mathrm{mg}$ Tamoxifen hingegen führte zur Aktivität der Cre-ERT2 in allen untersuchten Organen. Dabei wurde die stärkste X-Gal-Färbung in der Epidermis, die schwächste in der Lunge gefunden. Diese Daten stimmen mit der Beobachtung überein, dass nach einer i.p. Applikation von $5 \mathrm{mg}$ Tamoxifen hyperproliferative Veränderungen

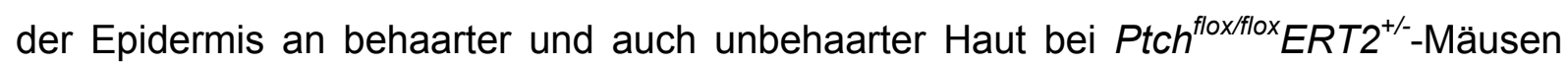
auftraten, wohingegen eine i.m. Applikation von $100 \mu \mathrm{g}$ Tamoxifen ausschließlich die Entstehung von BCC in unbehaarter Haut bewirkte. Offensichtlich ist für eine Deletion von Ptch in behaarter Haut im Gegensatz zu unbehaarter Haut eine wesentlich höhere Tamoxifen-Dosis nötig.

\subsubsection{Entstehung von BCC aus Basalzellen und der äußeren Wurzel- scheide}

Wie in Abbildung 20 erkennbar, entstehen Vorläuferläsionen 45 Tage nach der Tamoxifen-Injektion an der interfollikulären Epidermis und den Haarfollikeln. Zu Beginn

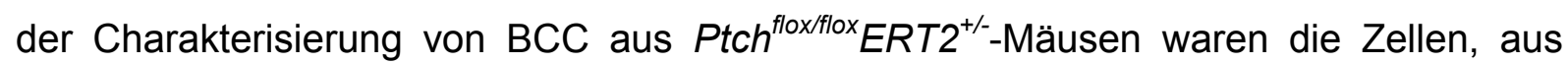
denen sich die Tumoren entwickeln, noch nicht genau bekannt. Als Ursprungszellen wurden jedoch die Basalzellen und Zellen des Haarfollikels (siehe Abbildung 23 und 1.4.4) vermutet (K Kruger et al., 1999; JP Lacour, 2002). Daher wurde im Rahmen dieser Arbeit die Expression von Proteinen, die spezifisch in verschiedenen Kompartimenten

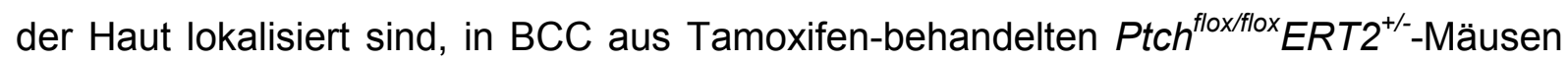
anhand von Immunfärbungen analysiert.

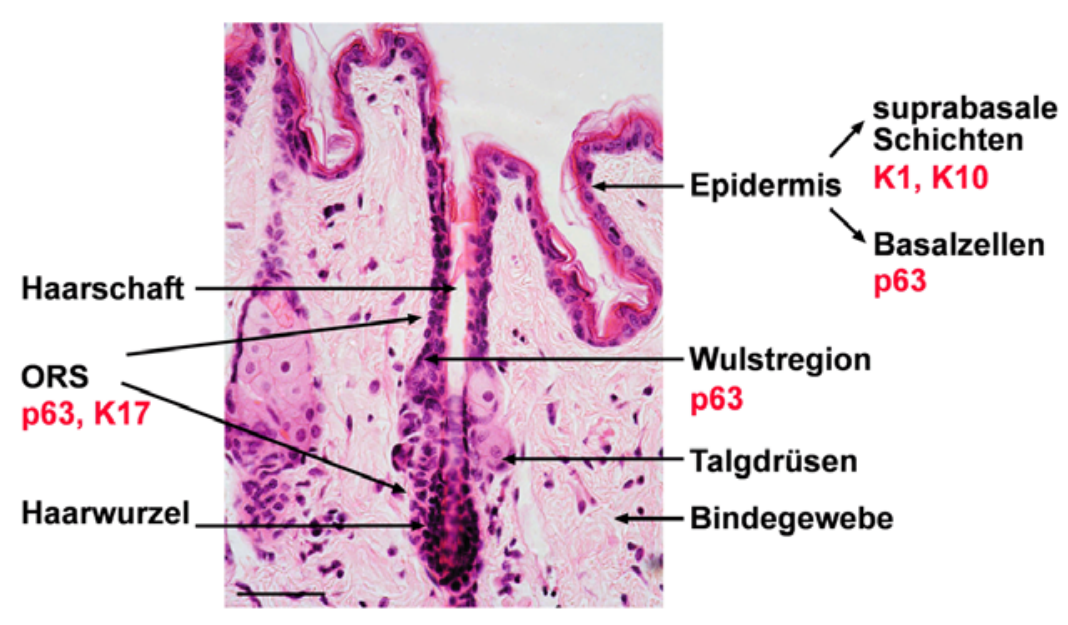

Abbildung 23: Struktur eines Haarfollikels. Gezeigt ist der Aufbau eines Haarfollikels anhand einer HE-Färbung eines Paraffinschnittes von normaler muriner Haut. In der Wulstregion sind die Stammzellen des Haarfollikels lokalisiert. Bei einigen Strukturen ist in roter Schrift ein jeweils spezifischer Marker angegeben. Der Balken entspricht $0,5 \mathrm{~mm}$ im Präparat. Abkürzungen: K1, Keratin 1; K10, Keratin 10; K17, Keratin 17; ORS, äußere Wurzelscheide. 
Als Marker für die Zellen der äußeren Wurzelscheide (engl.: „outer root sheath“ - ORS) dienten Keratin 17 (K17) und p63, wobei p63 in normaler Haut nicht nur in der ORS, sondern auch in Basalzellen exprimiert wird (A Yang et al., 1998). Spezifische Marker für die suprabasalen Schichten der Epidermis und die innere Wurzelscheide (engl.: „inner root sheath" - IRS) des Haarfollikels sind Keratin 1 (K1) und Keratin 10 (K10) (E Fuchs, 1993).

In allen analysierten BCC wurde die Expression von $\mathrm{K} 17$ nachgewiesen. Wie in Abbildung 24 erkennbar, wurde K17 sowohl in Vorläuferläsionen als auch in BCC späterer Stadien am Tag 90 und 180 nach der Induktion exprimiert. Weiterhin zeigten sowohl alle untersuchten BCC-Vorläuferläsionen als auch voll-ausgebildeten BCC die Expression von p63 (siehe Abbildung 24). Im Gegensatz zu p63 wurde K17 jedoch nicht in allen Vorläuferläsionen der interfollikulären Epidermis exprimiert (siehe Abbildung 24). Dies betraf insbesondere von Haarfollikeln entfernt liegende Tumorknötchen.

Zusammengefasst könnten diese Daten als Hinweise für die Entstehung von BCC aus Zellen der ORS sowie unabhängig davon aus Basalzellen gewertet werden.

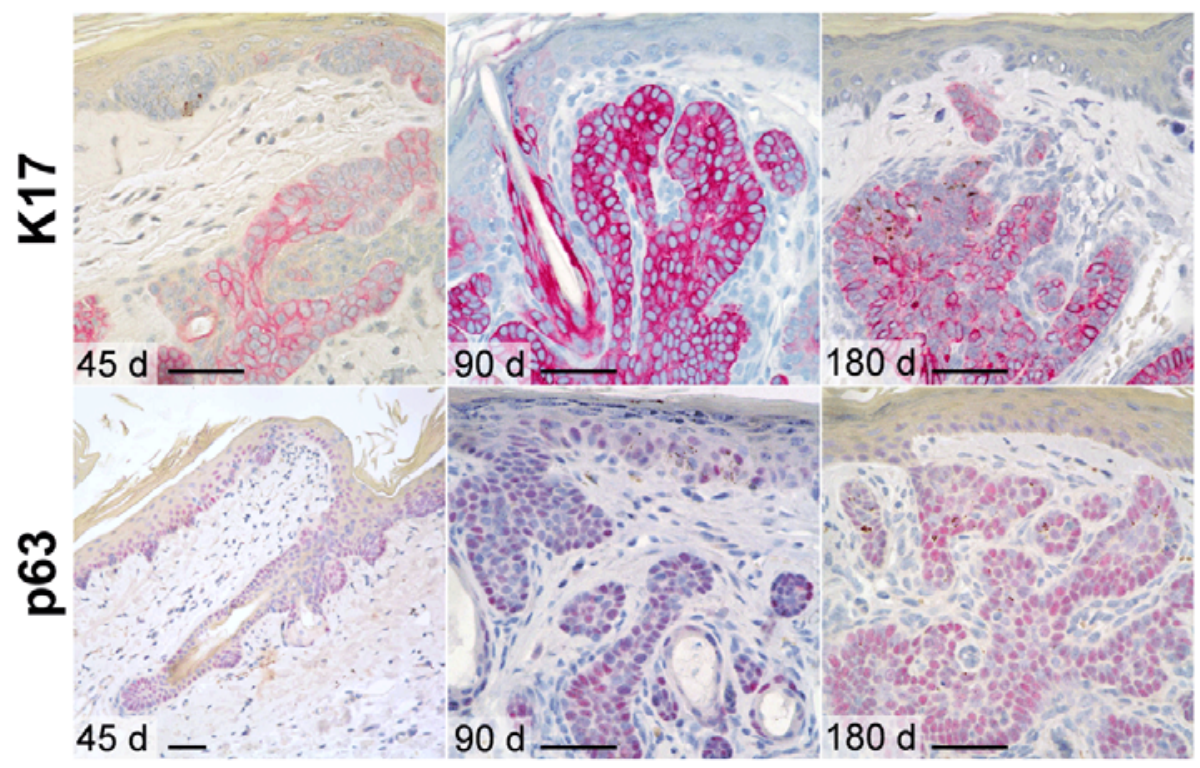

Abbildung 24: Expression von $\mathrm{K} 17$ und p63 in BCC. Gezeigt sind immunhistochemische Färbungen (Chromogen: Neufuchsin) für K17 und p63 an BCC $45 \mathrm{~d}, 90 \mathrm{~d}$ und $180 \mathrm{~d}$ nach der Tamoxifen-Injektion. Die Balken entsprechen $0,5 \mathrm{~mm}$ im Präparat. Abkürzung: $d$, Tage.

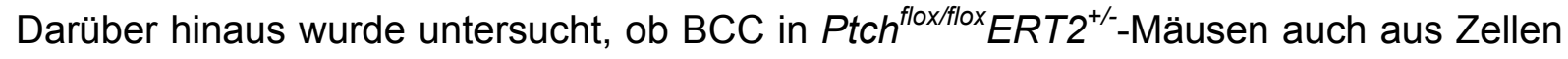
der IRS entstehen. Anhand von Immunfärbungen an Vorläuferläsionen (nicht gezeigt) und BCC 90 Tage nach Tamoxifen-Injektion wurde nachgewiesen, dass weder K1 noch K10 von den Tumoren exprimiert wurde (Abbildung 25). Daher wurden Zellen der IRS als Ursprungszellen für BCC ausgeschlossen. 


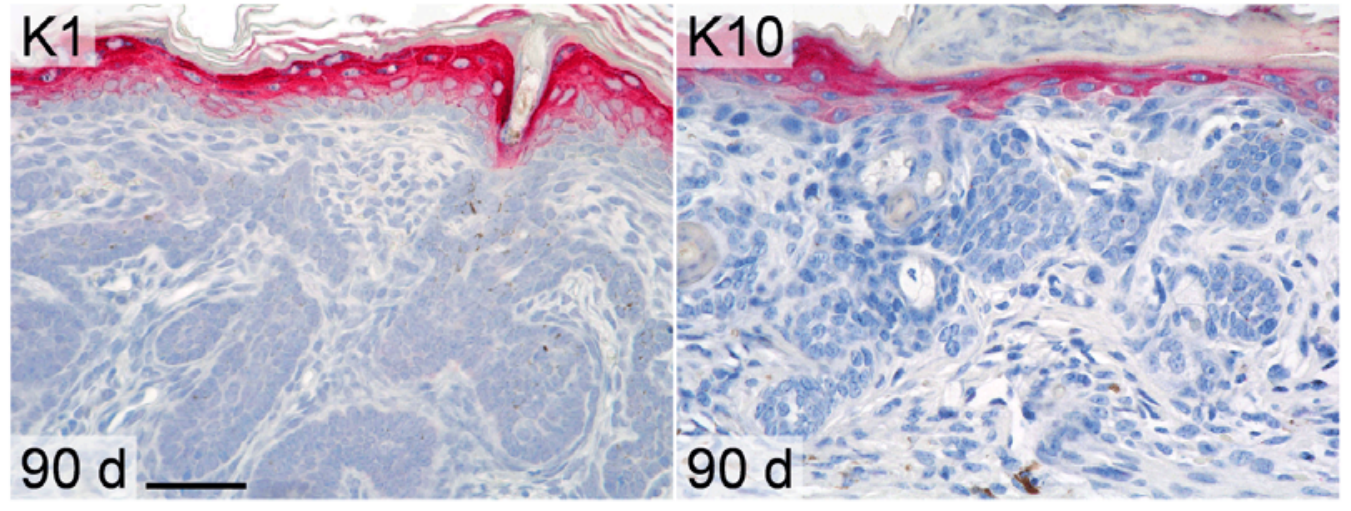

Abbildung 25: BCC entstehen nicht aus der IRS oder suprabasalen Zellen. Immunhistochemische Färbungen (Chromogen: Neufuchsin) für K1 und K10 wurden an BCC aus $\mathrm{Ptch}^{\text {floxflox }} E R T 2^{+/}$-Mäusen 90 Tage nach der Tamoxifen-Injektion durchgeführt. Der Balken entspricht $0,5 \mathrm{~mm}$ im Präparat. Abkürzung: $d$, Tage.

\subsubsection{Spontane Regression von BCC}

Einige BCC-tragende Mäuse wurden für Langzeitbeobachtungen der Tumoren über 180 Tage oder länger überwacht. Anschließend wurden die Tumoren histologisch untersucht. Bis zu 90 Tage nach der Injektion zeigte sich eine deutliche Zunahme der Tumorgröße. Danach nahm das Tumorvolumen interessanterweise nicht mehr zu, sondern es zeigte sich vielmehr ein Rückgang des Tumorgewebes (siehe Abbildung 26).

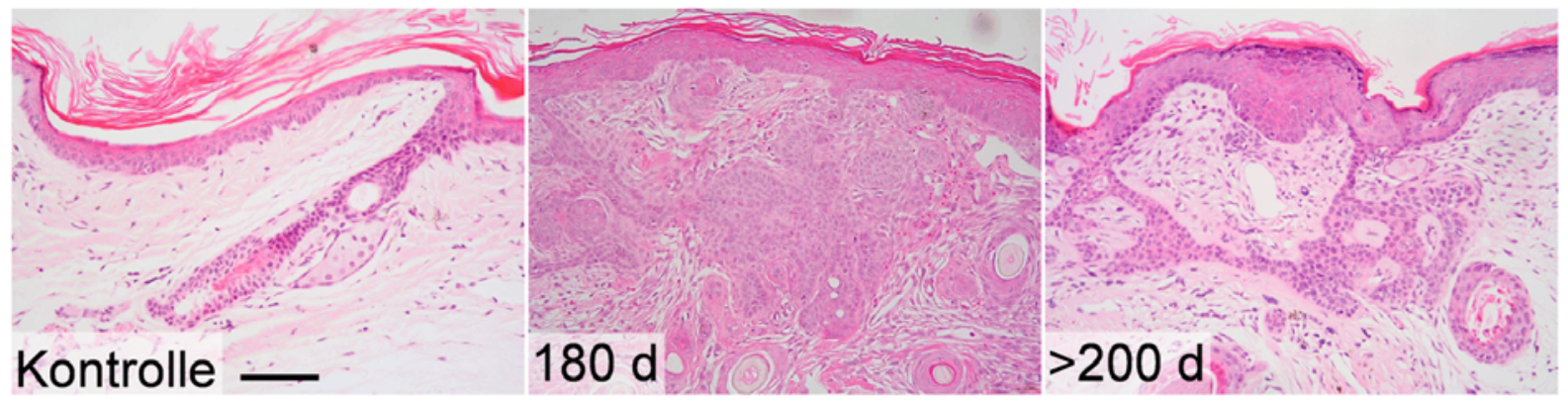

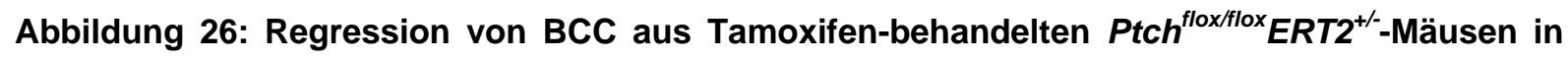

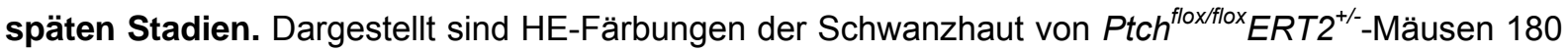
und mehr als 200 Tage nach der i.m. Tamoxifen-Injektion und einer Lösungsmittel-behandelten Ptch $^{\text {floxflox }} E_{R T 2}{ }^{+/}$-Maus (Kontrolle). Der Balken entspricht $1 \mathrm{~mm}$ im Präparat. Abkürzung: d, Tage.

Acht von zehn untersuchten BCC, die älter als 200 Tage waren, zeigten eine fast vollständige Tumorregression. Zwei weitere BCC bestanden nach 350 Tagen zwar noch aus soliden Tumorknötchen, jedoch waren auch diese Tumoren deutlich kleiner als BCC 90 Tage nach der Induktion. BCC dieser späten Stadien wurden mehreren erfahrenen Pathologen vorgelegt. Ihren Diagnosen zufolge handelt es sich um regrediente BCC, die 
einen hohen Differenzierungsgrad zeigen, so dass sie teilweise Ähnlichkeiten zu Trichoepitheliomen (TE) aufwiesen.

Zu keinem Zeitpunkt waren Anzeichen für eine Invasivität der BCC erkennbar. Dies konnte auch mittels p53-spezifischer Immunfärbungen gezeigt werden. So exprimieren invasive BCC, welche durch ionisierende Strahlung in $\mathrm{Ptch}^{\text {neo67/+ }}$-Mäusen induziert wurden (M Mancuso et al., 2004), sehr stark p53 (Abbildung 27). Wie in Abbildung 27 gezeigt, wurde p53 jedoch nur sehr fokal in BCC von Tamoxifen-induzierten $P_{t c h}^{f l o x / f l o x} E R T 2^{+/-}$-Mäusen exprimiert und weite Tumorbereiche zeigten überhaupt keine p53-Expression. Daher ist anzunehmen, dass die DNA-Integrität der Tumoren in $P t c h^{\text {flox/flox }} E R T 2^{+/-}$-Mäusen zu allen Zeitpunkten gewährleistet war.

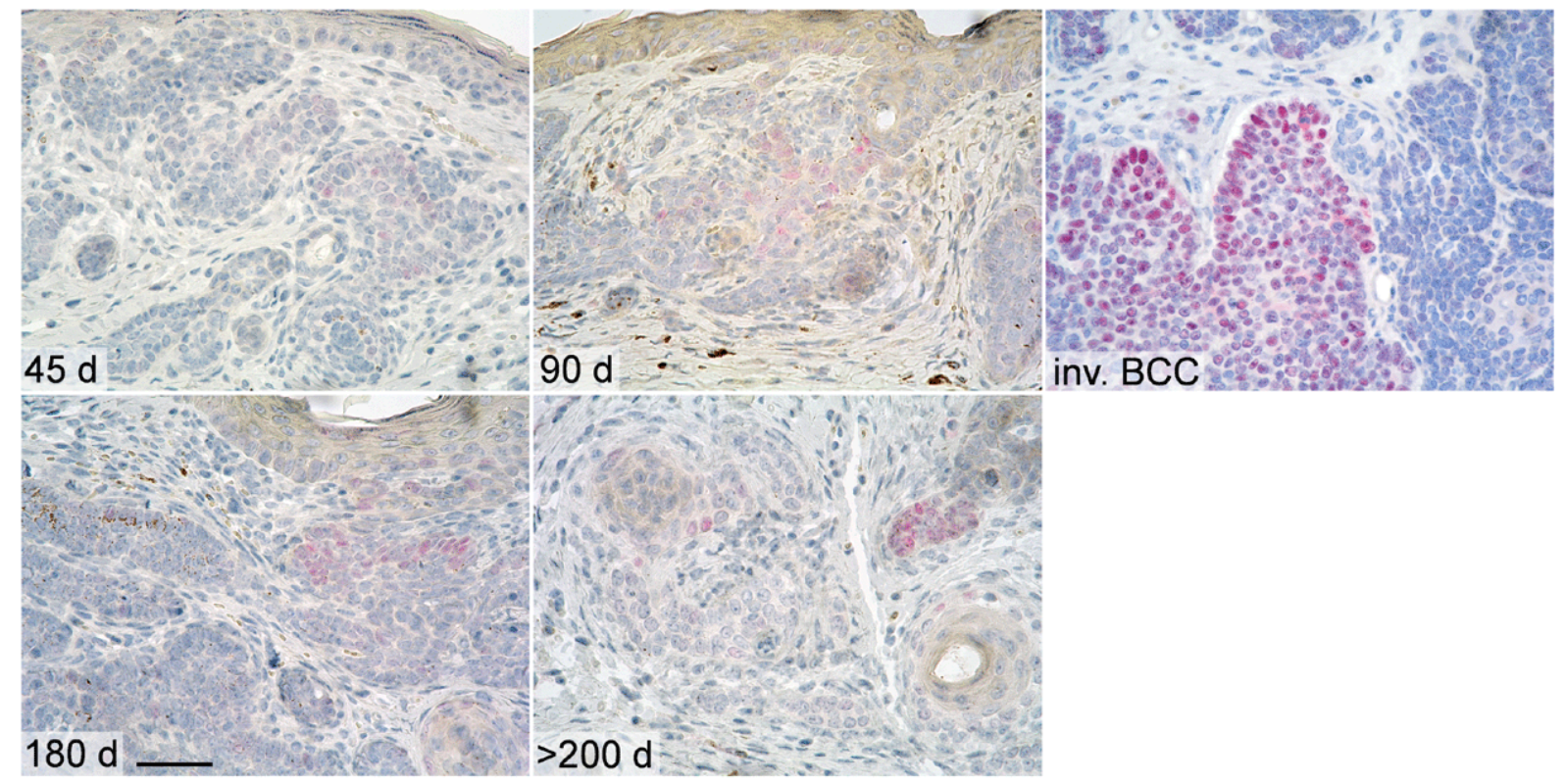

Abbildung 27: Fokale Expression von p53 in BCC. Gezeigt sind immunhistochemische Färbungen (Chromogen: Neufuchsin) für p53 an Paraffinschnitten von verschiedenen BCC-Stadien von $\mathrm{Ptch}^{\text {floxfllox}} \mathrm{ERT2}^{+/-}$-Mäusen und von einem invasiven BCC aus einer bestrahlten $\mathrm{Ptch}^{\text {neo67/+ }}$-Maus. Der Balken entspricht $0,5 \mathrm{~mm}$ im Präparat. Abkürzungen: $d$, Tage; inv. invasiv.

Um die Vorgänge der spontanen Regression der BCC näher zu charakterisieren, wurden Analysen zur Bestimmung der Apoptose- und Proliferationsraten durchgeführt. Zur Bestimmung der Proliferation wurde in den Tumoren die Expression von Ki-67, einem Markerprotein für proliferierende Zellen, bestimmt. Zur Ermittlung des Proliferationsindexes wurden für jeden analysierten Zeitpunkt Paraffinschnitte der

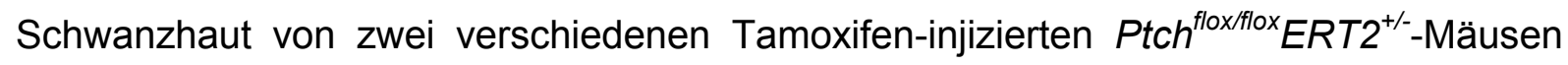
verwendet. Von jedem Tier wurden zwischen 650 und 2900 Tumorzellen ausgezählt, anhand des Anteils der Ki-67-positiven Zellen an den ausgezählten Tumorzellen wurde der Proliferationsindex berechnet. 
Wie in Abbildung 28 dargestellt, nahm der Proliferationsindex mit steigendem Tumoralter deutlich ab. Während BCC nach 45 Tagen ca. 72 \% Ki-67 positive Zellen enthielten, sank der Anteil in BCC nach $\sim 300$ Tagen auf $5 \%$. Abbildung 29 zeigt für jeden analysierten Zeitpunkt einen repräsentativen Ausschnitt der immunhistochemischen Färbung von Ki-67.

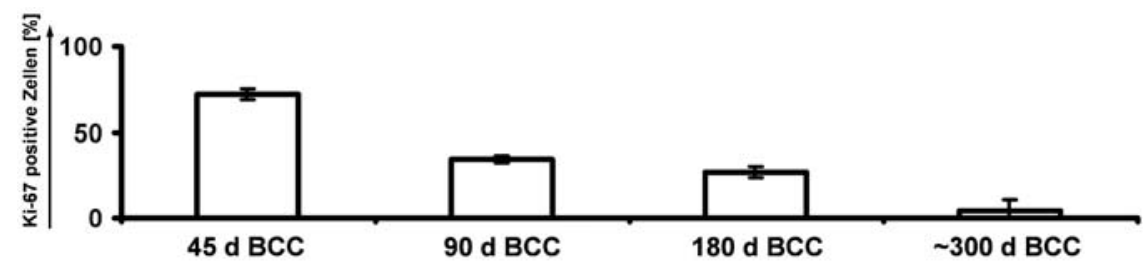

Abbildung 28: Abnahme des Proliferationsindexes bei zunehmendem Tumoralter. Gezeigt ist der Proliferationsindex von BCC 45, 90, 180 und 300 Tage nach der Tamoxifen-Injektion. Für jeden Zeitpunkt wurden zwei Tiere analysiert und jeweils zwischen 650 und 2900 Zellen ausgezählt. Abkürzung: $d$, Tage.

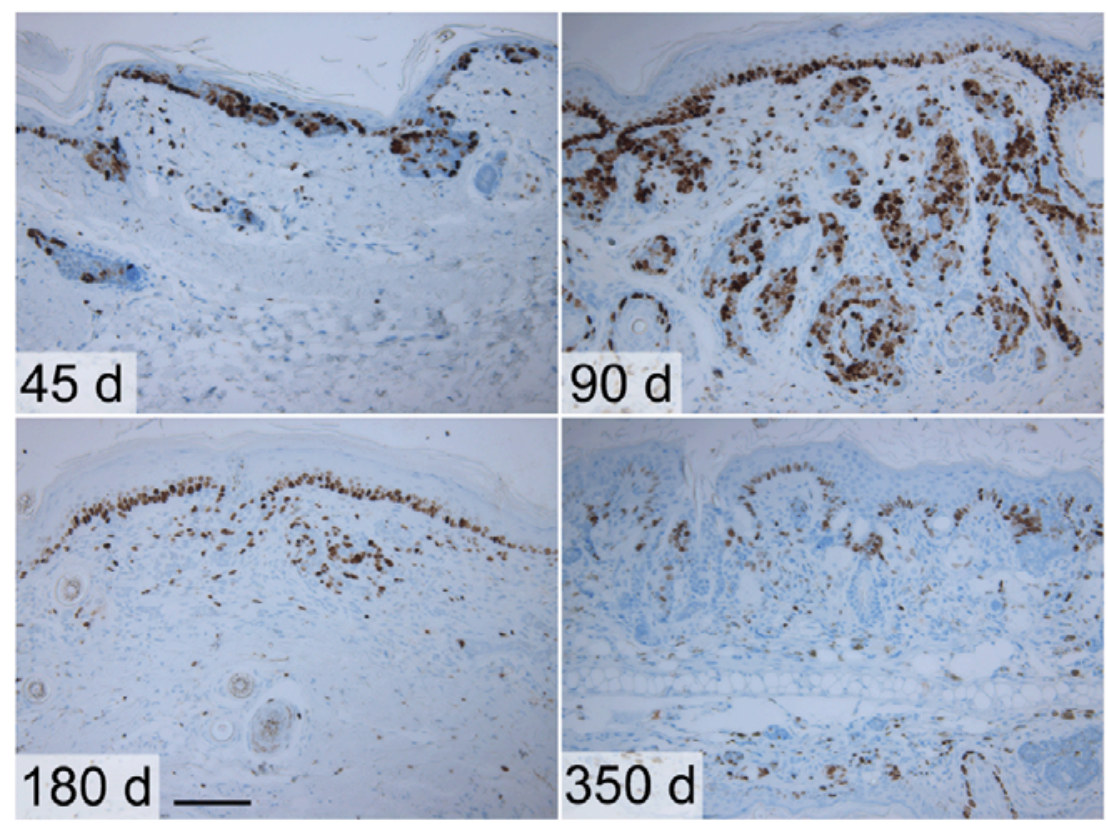

Abbildung 29: Abnahme der Proliferation bei zunehmendem Tumoralter. Dargestellt sind immunhistochemische Färbungen (Substrat: DAB) für den Proliferationsmarker Ki-67 an BCC von

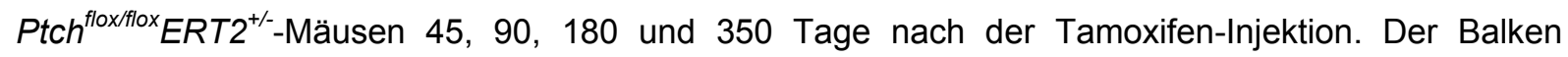
entspricht $1 \mathrm{~mm}$ im Präparat. Abkürzung: d, Tage.

Zusätzlich zur Proliferationsrate wurde die Apoptoserate der Tumoren ermittelt. Dies erfolgte durch immunhistochemische Färbungen zum Nachweis von aktiver Caspase-3, einem zentralen Enzym in der Signaltransduktion der Apoptose, und durch das sogenannte in situ end labeling (nicht gezeigt), wodurch die bei der Apoptose vorliegenden DNA-Strangbrüche dargestellt werden können. Für die Bestimmung der Apoptoserate wurden die Caspase-3 positiven Zellen ausgezählt. Anhand dieser 
Analysen wurde gezeigt, dass der Anteil Caspase-3 positiver Zellen in allen Tumorstadien zwischen 0 und 3 \% lag (nicht gezeigt). Dabei war die Apoptoserate unabhängig vom Tumoralter.

\subsubsection{Expressionsanalysen von Ptch in BCC}

Um zu überprüfen, ob die spontane Regression der BCC mit einer verminderten Aktivität des $\mathrm{Hh} /$ Ptch-Signalweges einhergehen könnte, wurde die Aktivität des Signalweges analysiert. Dazu wurden immunhistochemische Färbungen und in situ-Hybridisierungen an Paraffinschnitten sowie qRT-PCR-Analysen von Zielgenen des Signalweges in BCC durchgeführt.

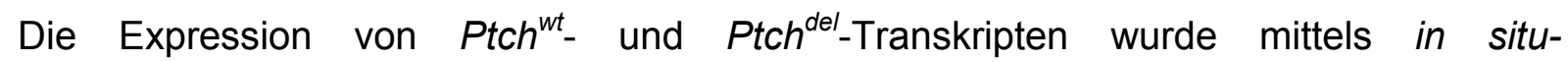
Hybridisierungen mit zwei unterschiedlichen Sonden von Mark Wijgerde (Erasmus Universität, Rotterdam) analysiert. Mit Hilfe der Sonde Ptch1-259 wurden aufgrund der Hybridisierung mit der Sequenz der Exone 8 und 9 ausschließlich Ptch ${ }^{\text {wt }}$-Transkripte detektiert. Zum Nachweis einer die Exone 2 bis 6 umfassenden Sequenz wurde die Sonde Ptch1-472 verwendet. Mit dieser Sonde konnten daher sowohl Ptch ${ }^{\text {wt }}$ - als auch Ptch $^{\text {del }}$-Transkripte detektiert werden. Daher musste es sich bei Signalen, die mit der Sonde Ptch1-472, nicht aber mit Sonde Ptch1-259 detektiert wurden, um $P t c h^{\text {del }}$-Transkripte handeln. Die verwendeten Sonden sind in Abbildung 30 dargestellt.

Ptch1-472

\begin{tabular}{|l|l|l|l|l|l|l|l|l|l}
\hline Exon 1 & Exon 2 & Exon 3 & Exon 4 & Exon 5 & Exon 6 & Exon 7 & Exon 8 & Exon 9 & Exon 10
\end{tabular}

Abbildung 30: Ptch-Sonden für die in situ-Hybridisierung. Gezeigt sind die ersten 10 Exone von Ptch und die Lage der Sonden Ptch1-472 und Ptch1-259 für in situ-Hybridisierung. Ptch1-472 umfasst die Exone 2 bis 6, während Ptch1-259 mit der Sequenz der Exone 8 und 9 hybridisiert. Die Exone 8 und 9, die durch Cre-ERT2-vermittelte Rekombination in Ptch $^{\text {floxflox }} E R T 2^{+/}$-Mäusen deletiert werden können, sind farbig hervorgehoben.

In Haarfollikeln von normaler Haut wurden mit beiden Sonden Ptch-Transkripte im unteren Abschnitt des Haarfollikels nachgewiesen. Dagegen wurden Ptch-Transkripte in allen analysierten BCC ausschließlich mit der Sonde Ptch1-472 detektiert (siehe Abbildung 31). Diese Ergebnisse zeigen, dass BCC Ptch überexprimieren und dass diese Überexpression ausnahmslos auf $P t c h^{d e l}$-Transkripte zurückzuführen war. Das Fehlen der Ptch ${ }^{\text {wt }}$-Transkripte zeigte, dass Ptch biallelisch in den Tumoren deletiert war. 


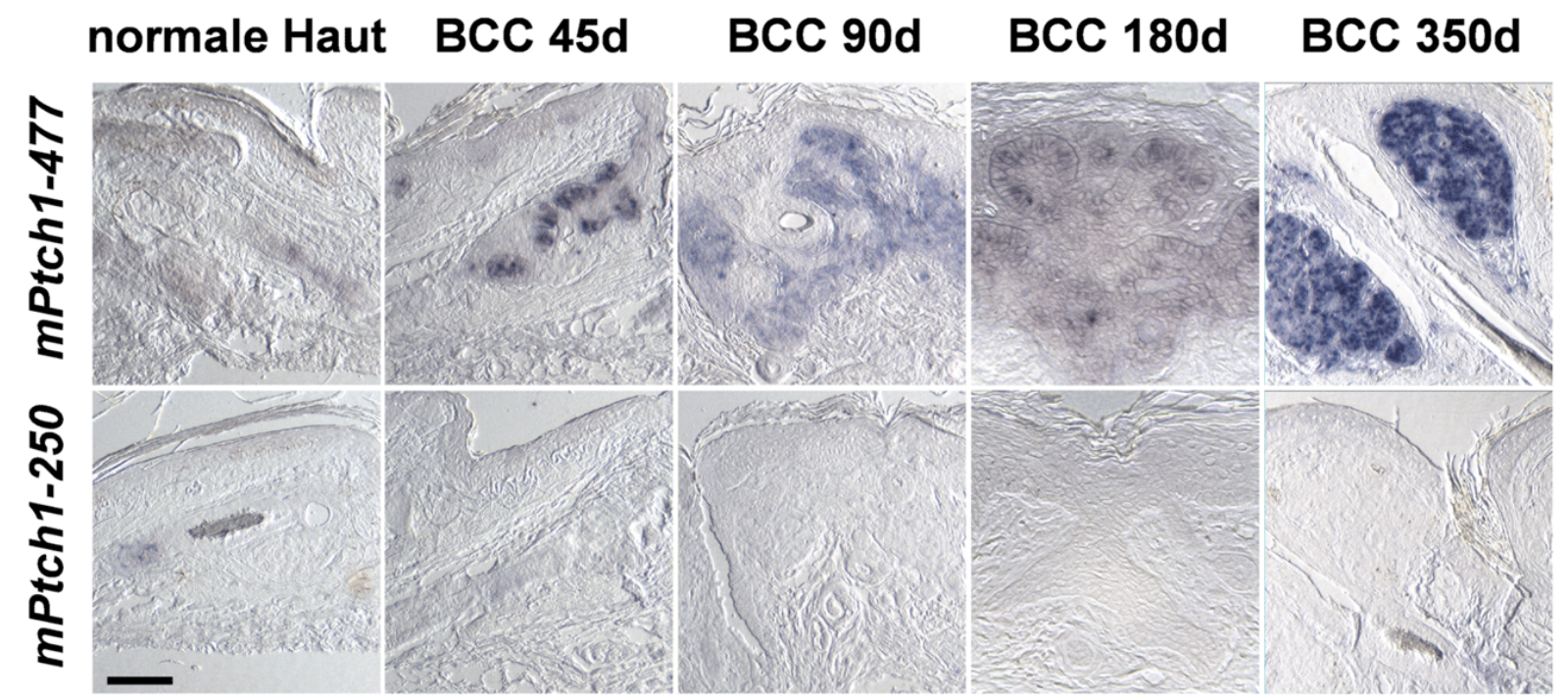

Abbildung 31: Biallelische Deletion von Ptch in BCC. Gezeigt sind in situ-Hybridisierungen an Paraffinschnitten von verschieden alten BCC und an normaler Haut mit den Ptch-spezifischen Sonden mPtch1-250 und mPtch1-477. Die Sonde mPtch1-477 dient dem Nachweis von Ptch ${ }^{\text {wt }}$ und Ptch ${ }^{\text {del }}$, mPtch1-250 hingegen ausschließlich der Detektion von tch $^{\text {wt }}$ (siehe auch Abbildung 30). Der Balken entspricht $1 \mathrm{~mm}$ im Präparat. Abkürzung: d, Tage.

\subsubsection{Expressionsanalysen von Gli1 und Gli2 in BCC}

Die Überexpression von Ptch in BCC ließ vermuten, dass die Hh/Ptch-Signalkaskade in diesen Tumoren aktiviert ist. Dies wurde durch Expressionsanalysen von Gli1 und Gli2 bestätigt (siehe Abbildung 32).

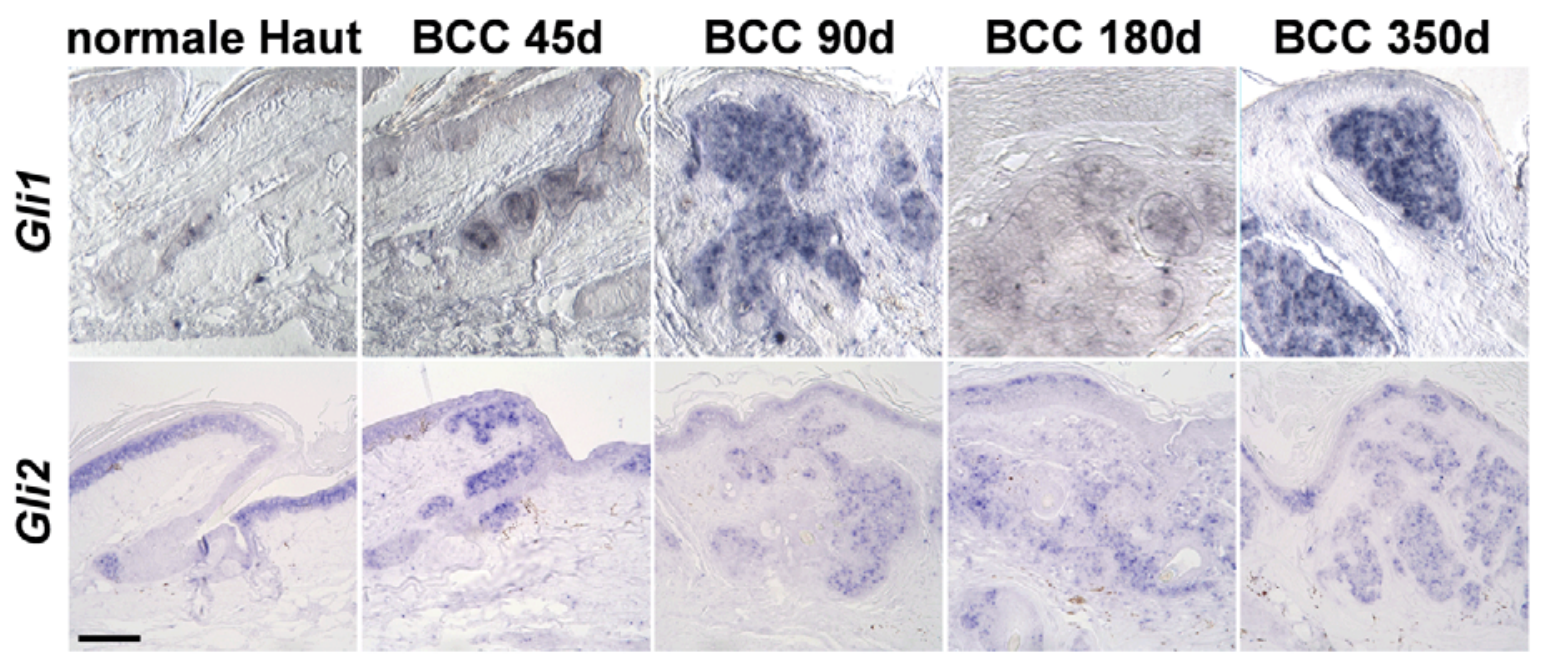

Abbildung 32: Expression von Gli1 und Gli2 in BCC. In situ-Hybridisierungen wurden mit Gli1- und Gli2-spezifischen Sonden an Paraffinschnitten von normaler Haut und verschieden alten BCC durchgeführt. Der Balken entspricht $1 \mathrm{~mm}$ im Präparat. Abkürzung: d, Tage.

So konnte von Mark Wijgerde (Erasmus Universität, Rotterdam) eine Gli1-Expression mittels in situ-Hybridisierungen in allen untersuchten Tumorstadien nachgewiesen 
werden. Die physiologische Expression von Gli1 in normaler Haut beschränkt sich auf die Haarfollikel. Auch Gli2 wurde in allen analysierten BCC überexprimiert. In normaler Haut wurde Gli2 in den Haarfollikeln und in der Epidermis exprimiert, wobei die Expression schwächer als im Tumorgewebe war.

Die Signalwegsaktivität wurde auch anhand von immunhistochemischen Färbungen für Gli1 und Bcl-2, einem Zielgen von Gli1, bestätigt. In allen Tumorstadien war eine zytoplasmatische Expression von Gli1 und Bcl-2 nachweisbar (siehe Abbildung 33).

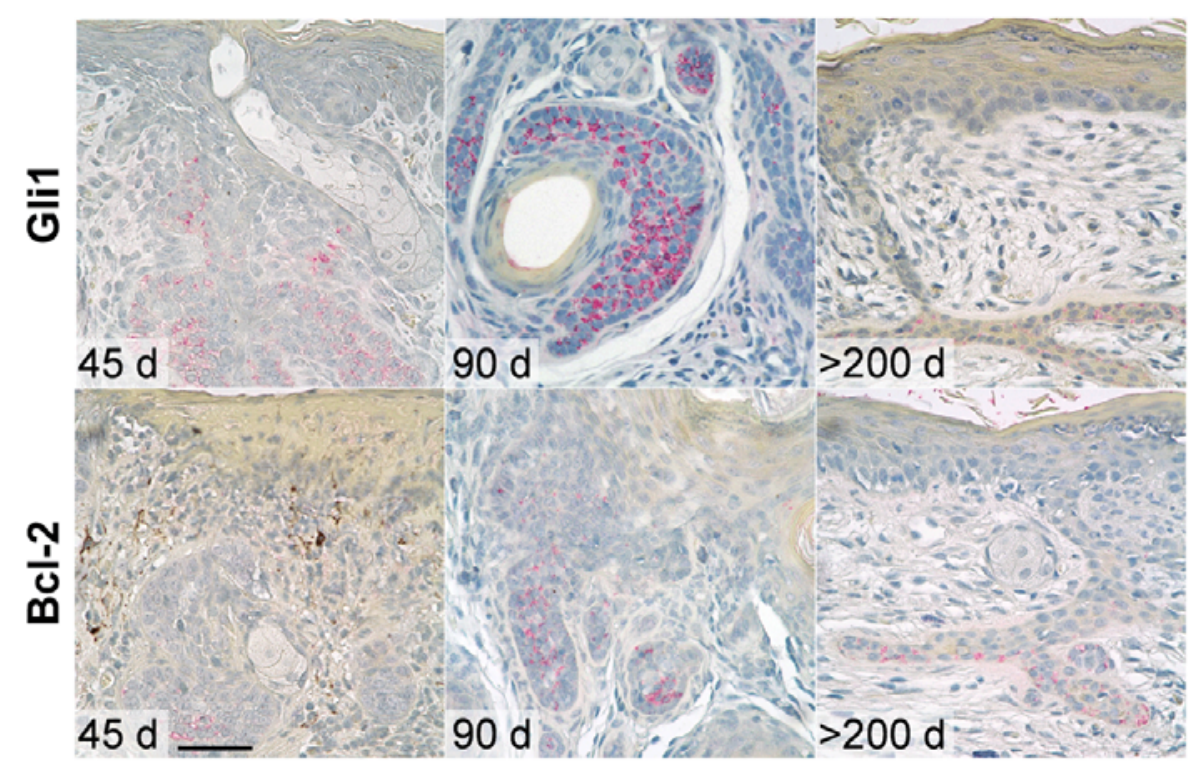

Abbildung 33: Gli1 und Bcl-2 sind in BCC fokal exprimiert. Gezeigt sind immunhistochemische Färbungen (Chromogen: Neufuchsin) für Gli1 und Bcl-2 an Paraffinschnitten von verschiedenen BCCStadien. Der Balken entspricht 0,5 mm im Präparat. Abkürzung: $d$, Tage.

Die Expression der Zielgene Gli1, Gli2 und Bcl-2 wurde auch mittels qRT-PCR in der Haut von Mäusen mit BCC-Vorläuferläsionen, voll-ausgebildeten und regredienten BCC analysiert. Dazu wurde RNA aus der Schwanzhaut von drei Tieren mit Vorläuferläsionen (24 Tage nach Tamoxifen-Gabe), vier mit voll-ausgebideten (90 Tage nach TamoxifenGabe) und acht mit regredienten BCC (>200 Tage nach Tamoxifen-Gabe) isoliert. Als

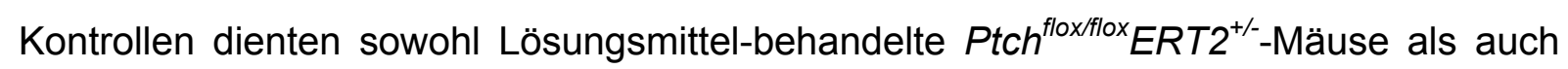

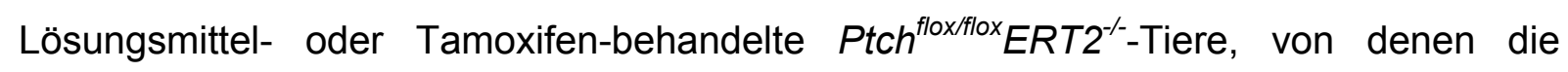
Hautproben 66 bis 365 Tage nach Tamoxifen-Gabe entnommen wurden.

Während die Expression von Gli1, Gli2 und $B c l-2$ in der Haut von Kontrolltieren, unabhängig von Alter, Genotyp oder Tamoxifen- bzw. Lösungsmittelgabe sehr niedrig war, war sie in der Haut von Tieren mit BCC erhöht (siehe Abbildung 34). Dabei war sie für alle drei Gene in BCC 90 Tage nach Tamoxifen-Injektion am höchsten (siehe Abbildung 34). 
Allerdings muss bei diesen Daten beachtet werden, dass der Anteil von Tumorgewebe in den entnommenen Proben von Tieren mit voll-ausgebildeten BCC wesentlich größer war als bei Mäusen mit Vorläuferläsionen oder regredienten Tumoren. Ein direkter Vergleich der Signalwegsaktivität anhand der Expression von Gli1, Gli2 und Bcl-2 ist aus diesem Grund nur zwischen Vorläuferläsionen und regredienten BCC möglich, da bei der histologischen Abklärung dieser Stadien anteilig gleichviel Tumorgewebe vorhanden war. Im Vergleich zu regredienten BCC wurden, wie in Abbildung 34 dargestellt, Gli1, Gli2 und $\mathrm{Bcl}$-2 in sehr viel stärkerem Ausmaß von den Proben mit BCCVorläuferläsionen exprimiert. So war die Expression der Gene Gli1 und Bcl-2 in Vorläuferläsionen teilweise mit derjenigen in voll-ausgebildeten BCC vergleichbar (siehe Abbildung 34). Dies lässt vermuten, dass die frühen Anfangsstadien von BCC eine hohe Hh/Ptch-Signalwegsaktivität aufweisen, die in voll-ausgebildeten Tumoren und auch im regredienten Stadium der Tumorentwicklung wieder abnimmt.
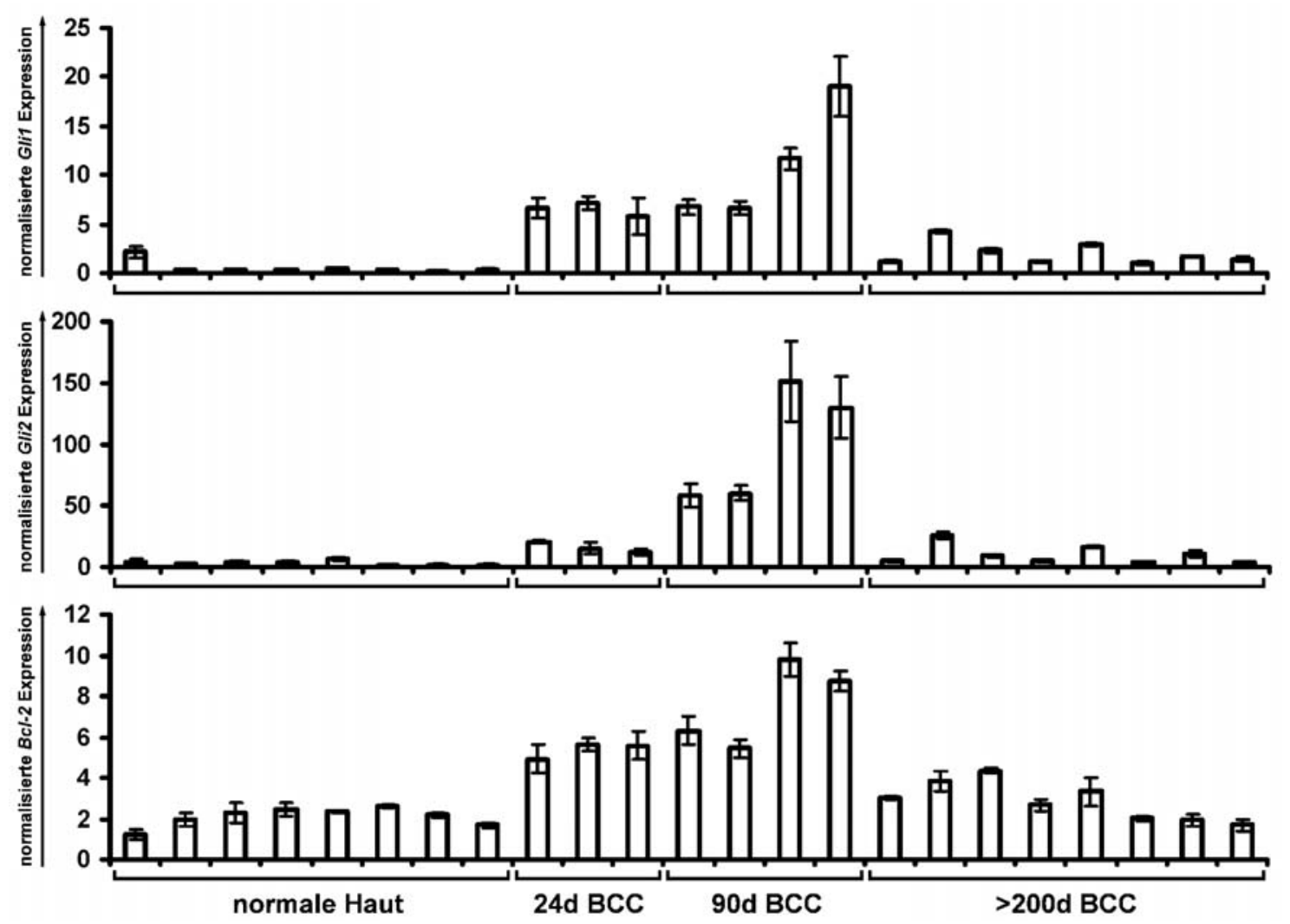

Abbildung 34: Verringerte Aktivität des Hh/Ptch-Signalweges in regredienten BCC. Mittels qRTPCR wurde die Expression von Gli1, Gli2 und Bcl-2 in normaler Haut von Kontrolltieren und in BCC 24, 90 und $>200$ Tage nach der Tamoxifen-Injektion analysiert. Dazu wurden die Oligonukleotidkombinationen mGli1-tq-f // mGli1-tq-r, RT-PCR-F // mGli2 RT-PCR-R und Bc/2-F1 // $B c / 2-R 1$ verwendet und die Expression anhand der 18S rRNA normalisiert. 


\subsubsection{Immunphänotyp von BCC}

Um einen möglichen Zusammenhang zwischen der Regression der BCC und dem Immunsystem zu untersuchen, erfolgten immunhistochemische Analysen zum Nachweis von B-Zellen, T-Zellen und Makrophagen. Wie in Abbildung 35 erkennbar, konnten die entsprechenden Zellpopulationen vereinzelt im Bindegewebe und in seltenen Fällen direkt im Tumor detektiert werden. In keinem der Tumorstadien bestand eine massive Infiltration von B-Zellen, T-Zellen oder Makrophagen, und es waren auch keine Unterschiede zwischen den einzelnen Stadien festzustellen. Daher kann eine Korrelation zwischen einer Reaktion des Immunsystems und der Regression von BCC ausgeschlossen werden.

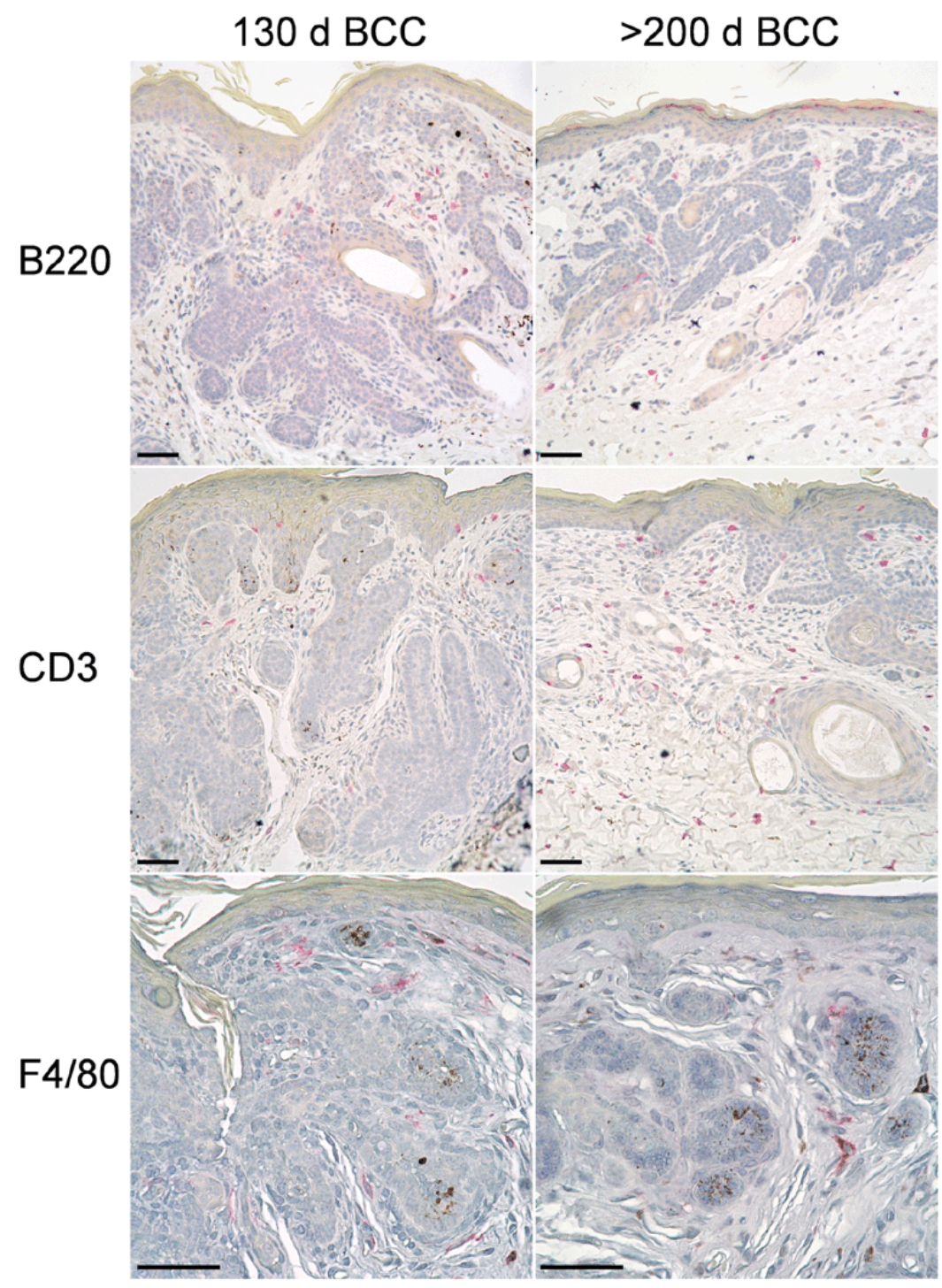

Abbildung 35: BCC werden nicht durch B-Zellen, T-Zellen oder Makrophagen infiltriert. Immunhistochemische Färbungen (Chromogen: Neufuchsin) für B220, CD3 und F4/80 zum Nachweis

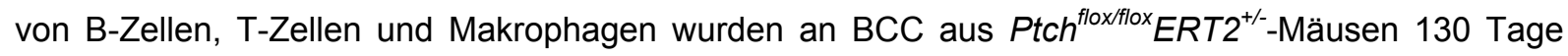
und >200 Tage nach der Tamoxifen-Injektion durchgeführt. Die Balken entsprechen 0,5 mm im Präparat. Abkürzung: d, Tage. 


\subsubsection{Analyse der kanonischen Wnt-Signalkaskade in BCC}

In der Literatur gibt es Hinweise, dass eine aktive kanonische Wnt-Signalkaskade in BCC (L Lo Muzio et al., 2002; M El-Bahrawy et al., 2003), die sich durch eine nukleäre Expression von $\beta$-Catenin auszeichnet, mit einem erhöhten Proliferationsindex der Tumoren einhergeht (G Saldanha et al., 2004). Daher war ein Zusammenhang zwischen einer Abnahme der Aktivität der kanonischen Wnt-Signalkaskade und der Regression von BCC denkbar. Unter dieser Annahme sollte die Wnt-Signalkaskade in frühen und voll-ausgebildeten BCC Stadien aktiviert sein, wohingegen die Aktivität in regredienten BCC abnehmen müsste. Zur Untersuchung dieser Hypothese wurde die Expression von $\beta$-Catenin in den Tumoren untersucht. Erst die nukleäre Translokation dieses Proteins bewirkt die Aktivierung von Zielgenen der kanonischen Wnt-Signalkaskade, deshalb ist die intrazelluläre Lokalisation von $\beta$-Catenin essentiell zur Bewertung der Aktivität dieses Signalweges. Wie in Abbildung 36 dargestellt, wurde $\beta$-Catenin in der Epidermis, im Haarfollikel und in BCC nachgewiesen. Unabhängig vom Tumoralter exprimierten alle analysierten BCC $\beta$-Catenin, das jedoch nicht nukleär, sondern ausschließlich zytoplasmatisch oder membran-assoziiert lokalisiert war. Daher wurde angenommen, dass der kanonische Wnt-Signalweg bei der Genese von BCC keine Rolle spielt und damit ebensowenig mit der beobachteten Tumorregression in Verbindung steht.

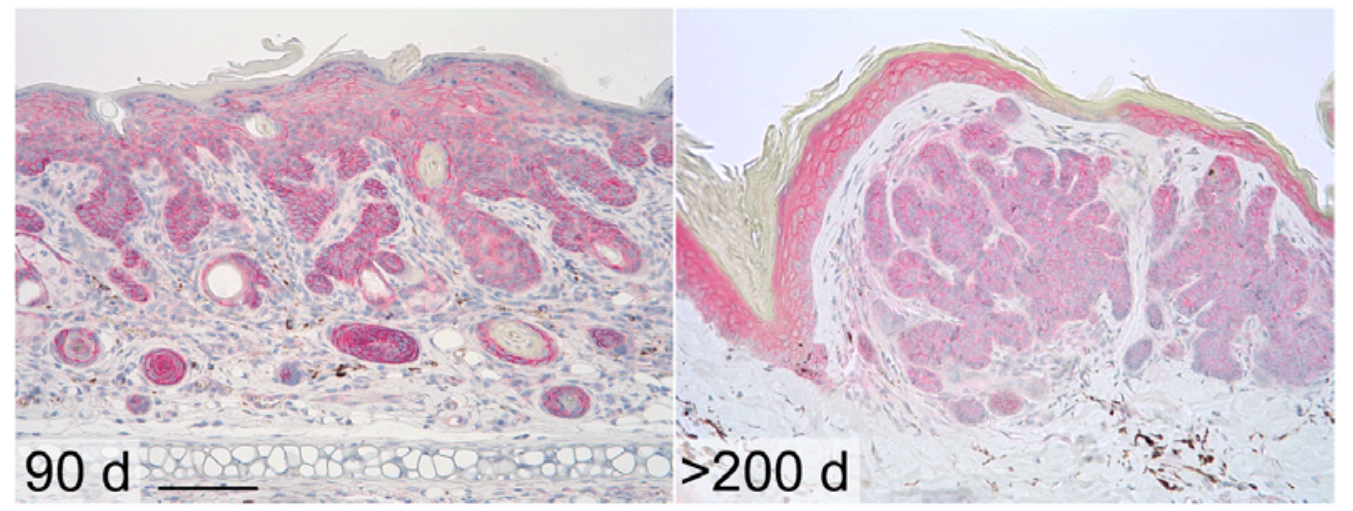

Abbildung 36: Zytoplasmatische und membranassoziierte Expression von $\beta$-Catenin in BCC. Gezeigt sind immunhistochemische Färbungen für $\beta$-Catenin an Paraffinschnitten von BCC aus

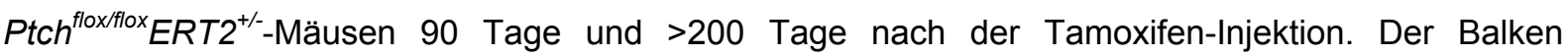
entspricht $1 \mathrm{~mm}$ im Präparat. Abkürzung: $d$, Tage.

\subsubsection{Expressionsanalysen von Differenzierungsmarkern in regredienten BCC}

Da die regredienten BCC histologisch einen wesentlich differenzierteren Phänotyp als Vorläuferläsionen oder voll-ausgebildete BCC aufwiesen (siehe 3.2.2.3 und Abbildung 
26), wurde auch bei diesen Tumoren die Expression von K1 und K10 untersucht. Neben der Expression in der IRS werden K1 und K10 auch in suprabasalen, differenzierten Schichten der Epidermis exprimiert und dienen daher als Differenzierungsmarker.

Wie unter 3.2.2.2 beschrieben, wurde keine K1- oder K10-Expression im Tumorgewebe der frühen BCC-Stadien nachgewiesen. Interessanterweise wurde im Gegensatz zu BCC 45 oder 90 Tage nach Tamoxifen-Injektion (siehe Abbildung 25) in regredienten Tumoren die Expression von K1 und K10 im Tumorgewebe detektiert. Abbildung 37 zeigt die K1- und K10-Expression in Tumorzellen und in suprabasalen Schichten der Epidermis von BCC am Tag 180 und 350 nach der Induktion.

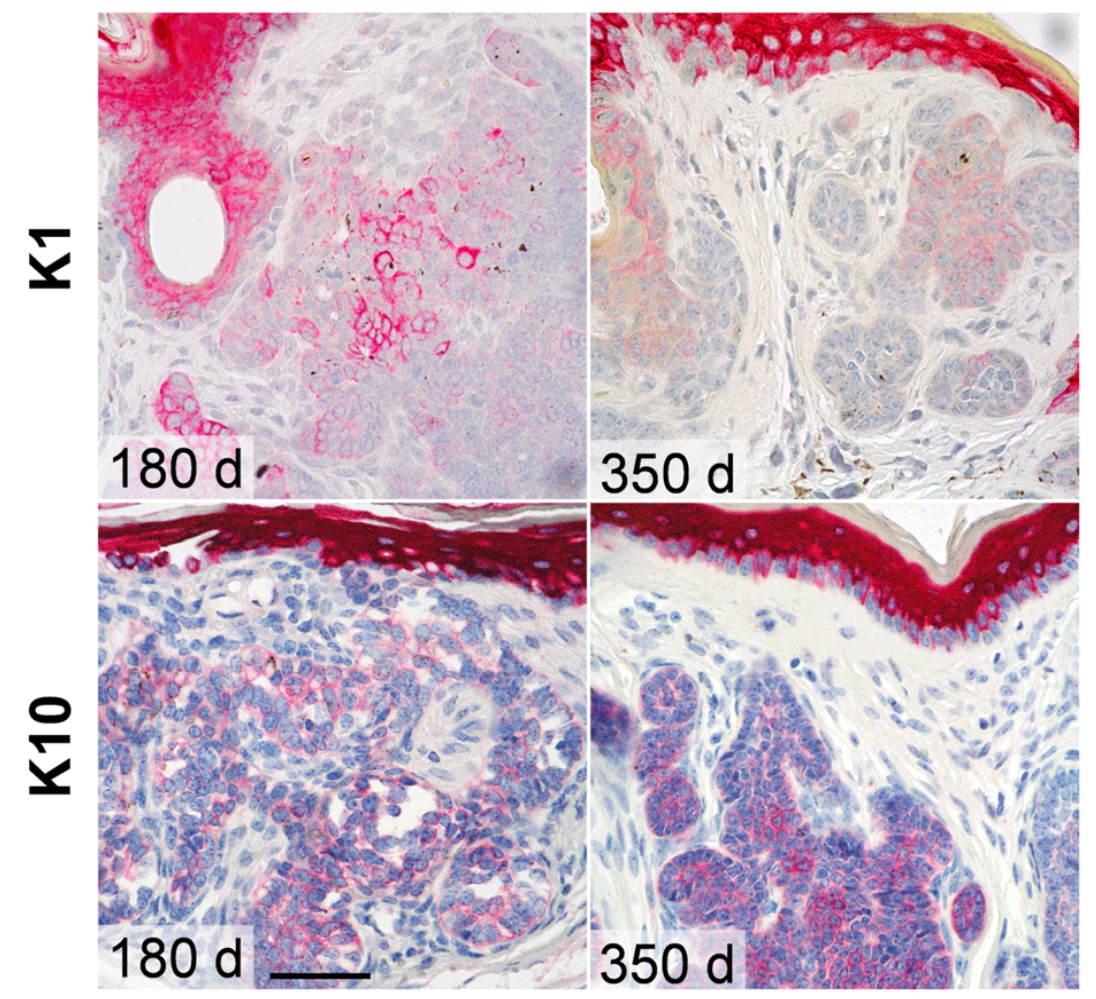

Abbildung 37: Expression von $\mathrm{K} 1$ und $\mathrm{K} 10$ in regredienten BCC. Immunhistochemische Färbungen (Chromogen: Neufuchsin) für die Differenzierungsmarker K1 und K10 wurden an BCC aus

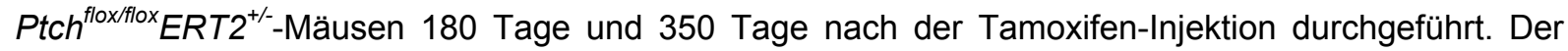
Balken entspricht 0,5 mm im Präparat. Abkürzung: $d$, Tage.

Um die Expression der beiden Differenzierungsmarker in regredienten Tumorstadien zu bestätigen, wurden qRT-PCR-Analysen für $K 1$ und $K 10$ an cDNA von Haut von Kontrolltieren, Vorläuferläsionen, voll-ausgebildeten und regredienten BCC durchgeführt. Während in der Haut von Kontrolltieren und Vorläuferläsionen kein wesentlicher Unterschied in der Expression von $K 1$ und $K 10$ erkennbar war, zeigten BCC ab einem Tumoralter von 90 Tagen eine deutliche Zunahme, wie in Abbildung 38 dargestellt. Interessanterweise blieb das Expressionsniveau in regredienten Stadien auf diesem 
erhöhten Niveau, obwohl diese sehr viel weniger Tumorzellen als BCC nach 90 Tagen aufweisen (siehe oben). Somit ist eine deutliche Steigerung der K1- und K10-Expression in den Tumorzellen regredienter BCC anzunehmen. Anhand dieser Daten wurden die immunhistochemischen Färbungen an Paraffinschnitten von BCC 180 und 350 Tage nach Induktion, in denen K1- und K10-Expression erkennbar war, bestätigt. Dies bedeutet, dass die Tumorzellen in regredienten Tumoren tatsächlich einen differenzierteren Phänotyp aufweisen.

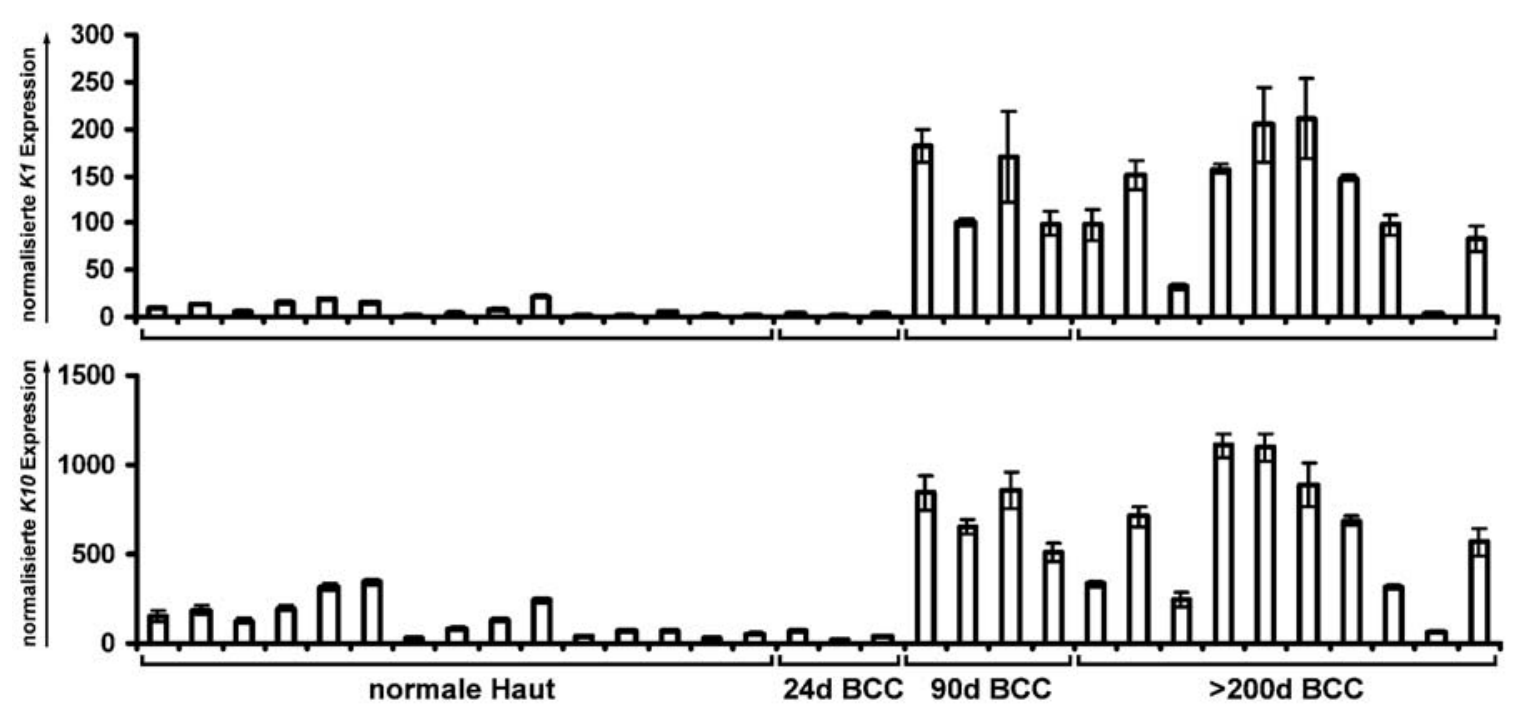

Abbildung 38: Expression von Differenzierungsmarkern in BCC. Mittels $\mathrm{qRT}-\mathrm{PCR}$ wurde die Expression von $K 1$ und $K 10$ in normaler Haut von Kontrolltieren und in BCC 24, 90 und $>200$ Tage nach der Tamoxifen-Injektion analysiert. Dazu wurden die Oligonukleotidkombinationen $m K 1-F / /$ $m K 1-R$ und $m K 10-F / / m K 10-R$ verwendet und die Expression anhand der 18S rRNA normalisiert. Abkürzung: $d$, Tage.

\subsubsection{Zusammenfassung der Charakteristika der induzierten BCC}

Zusammenfassend ist festzuhalten, dass sich in den Ohren und Schwänzen von

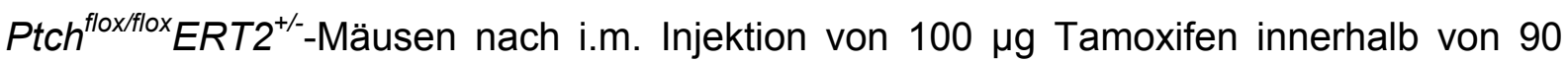
Tagen BCC aus Zellen der ORS und aus Basalzellen entwickeln. Überraschenderweise erfolgt eine spontane Regression von BCC nach mehr als 200 Tagen im Anschluss an die Induktion. Dies wird durch den Rückgang des Tumorvolumens mit gleichzeitiger Abnahme des Proliferationsindexes und völligem Fehlen von Invasivität deutlich. Die regredienten Tumoren zeigen interessanterweise histologisch eine Trichoblastomähnliche Morphologie.

Anhand von in situ-Hybridisierungen konnte gezeigt werden, dass Ptch biallelisch in allen Tumorstadien deletiert ist. Des Weiteren wurde nachgewiesen, dass sämtliche Tumoren eine aktive Hh/Ptch-Signalkaskade aufweisen, wobei die Aktivität jedoch möglicherweise 
in den regredienten Stadien abnimmt. Auf eine Reaktion des Immunsystems ist die Regression der BCC nicht zurückzuführen, da keine Infiltration des Tumorgewebes mit Immunzellen vorliegt. Paradoxerweise ist die Apoptoserate der regredienten Tumoren sehr niedrig und auch im Vergleich zu BCC-Vorläufern oder voll-ausgebildeten Tumoren nicht erhöht. Anhand der Expessionsanalyse von $\beta$-Catenin in BCC kann zudem ein Zusammenhang zwischen Regression und der kanonischen Wnt-Signalkaskade ausgeschlossen werden. Dagegen ist die Regression mit einer erhöhten K1- und K10mRNA- und Proteinexpression assoziiert, was auf einen Differenzierungsprozess in regredienten $\mathrm{BCC}$ hinweist.

\subsubsection{Induktion von BCC in unterschiedlichen Phasen des Haarzyklus}

Die Aktivität des $\mathrm{Hh} /$ Ptch-Signalweges ist essentiell für die Regulation des Haarzyklus (N Sato et al., 1999). Daher ist die Induktion von BCC im Zusammenhang mit den Haarzyklusphasen von besonderem Interesse. Die physiologische Aktivierung der Signalkaskade in adulter Haut ist im Wesentlichen auf das Anagen beschränkt (AE Oro und K Higgins, 2003). Möglicherweise reagieren die Zellen des Haarfollikels, die wie unter 3.2.2.2 beschrieben an der Ausbildung von BCC beteiligt sind, in verschiedenen Haarzyklusphasen unterschiedlich auf die Aktivität des Signalweges. So wurde bereits gezeigt, dass die Überexpression von Gli1 in transgenen K14-Gli1-Mäusen während des Anagens zur Bildung epithelialer Tumoren führt (AE Oro und K Higgins, 2003). Weiterhin weist Haut von Ptch ${ }^{\text {neo67/t }}$-Mäusen eine hohe Inzidenz von BCC auf, wenn sie während des Anagens bestrahlt wird. In diesen Tieren treten BCC sehr viel seltener auf, wenn die Bestrahlung der Haut während des Telogens erfolgt (M Mancuso et al., 2006).

Daher wurde im Rahmen dieser Arbeit ein Zusammenhang zwischen dem Haarzyklus und der Induktion von BCC in Ptch $^{\text {floxflox }} E R T 2^{+/}$-Mäusen untersucht. Dabei sollte geklärt werden, ob BCC nur in bestimmten Haarzyklusphasen entstehen können bzw. ob sich derart induzierte BCC abhängig von der Haarzyklusphase zum Zeitpunkt der Induktion voneinander unterscheiden.

\subsubsection{Synchronisierung des Haarzyklus}

Grundlegend für ein solches Experiment ist die Synchronisierung des Haarzyklus vor einer Tamoxifen-Induktion der Cre-ERT2. Durch Epilation, d. h. durch die Entfernung des Haares mitsamt Haarwurzel, kann der Eintritt des Haarzyklus in das Anagen hervorgerufen werden. Bei der Maus umfasst der Haarzyklus 25 Tage und kann sehr genau in die einzelnen Phasen Anagen, Katagen und Telogen eingeteilt werden ( $S$ 
Muller-Rover et al., 2001). Um BCC in einer bestimmten Phase zu induzieren, musste die Haut einer Maus mit Hilfe einer heißen 1:1 Mischung aus Bienenwachs und Kolophonium epiliert werden und die Behandlung mit Tamoxifen, abhängig von der gewünschten Haarzyklusphase, entsprechend später erfolgen.

\subsubsection{Aktivierung der Cre-ERT2}

Wie bereits oben beschrieben, bewirkt eine i.m. Injektion von Tamoxifen in

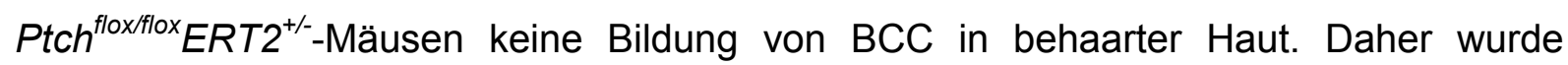
untersucht, ob sich BCC überhaupt in behaarter Haut durch Aktivierung der Cre-ERT2 induzieren lassen. Hierfür wurden zunächst doppelt heterozygote ROSA26ERT2 ${ }^{+/}$; ROSA26- $R^{+/-}$-Mäuse verwendet (siehe 3.2.2.1), denen zwei ca. $2 \mathrm{~cm}^{2}$ große Hautareale auf dem Rücken epiliert wurden. Anschließend wurden variable Mengen Tamoxifen in Ethanol/Sonnenblumenöl-Emulsion oder in DMSO auf die enthaarten Regionen aufgetragen und nach unterschiedlichen Zeiträumen gründlich mit Seife abgespült. Durch das Abspülen sollte verhindert werden, dass die Mäuse das Medikament während der Fellpflege oral und damit systemisch aufnehmen. Fünf Tage nach TamoxifenApplikation wurden die Tiere getötet und die behandelte Haut sowie innere Organe entnommen. Die Aktivität der Cre-ERT2 wurde durch eine X-Gal-Färbung an Kryoschnitten ermittelt. Dabei wurde die Cre-ERT2 mit Tamoxifen in DMSO besser aktiviert als mit Tamoxifen in einer Öl/Ethanol-Emulsion. Die stärkste lokale Blaufärbung ergab eine Applikation von $500 \mu \mathrm{g}$ Tamoxifen in $20 \mu \mathrm{l}$ DMSO auf einem $2 \mathrm{~cm}^{2}$ großen Hautareal für zweimal $10 \mathrm{~min}$, wobei beide Behandlungen mit einem zeitlichen Abstand von ca. $5 \mathrm{~h}$ erfolgten. Interessanterweise wurde durch diese lokale Applikation von Tamoxifen die Aktivität der Cre-ERT2 auch in Ohr- und Schwanzhaut, nicht aber in anderen Organen induziert (nicht gezeigt).

\subsubsection{Induktion von BCC in unterschiedlichen Haarzyklusphasen}

An Ptch $^{\text {flox/flox }} E R T 2^{+/-}$-Mäusen wurde nun untersucht, ob BCC nur in bestimmten Haarzyklusphasen entstehen. Bei den untersuchten Haarzyklusphasen handelt es sich um Anagen I, Anagen I-II, Anagen IV, Anagen VI, Katagen und Telogen. Zu diesem Zweck wurde der Haarzyklus im jeweiligen Hautareal 0 (d. h. am Tag der TamoxifenBehandlung), 2, 5, 8, 16 bzw. 24 Tage vor der lokalen Applikation von Tamoxifen durch Epilation synchronisiert. In Abbildung 39 ist dargestellt, in welchen Haarzyklusphasen die enthaarten Hautstellen zum Zeitpunkt der Tamoxifen-Applikation waren. 


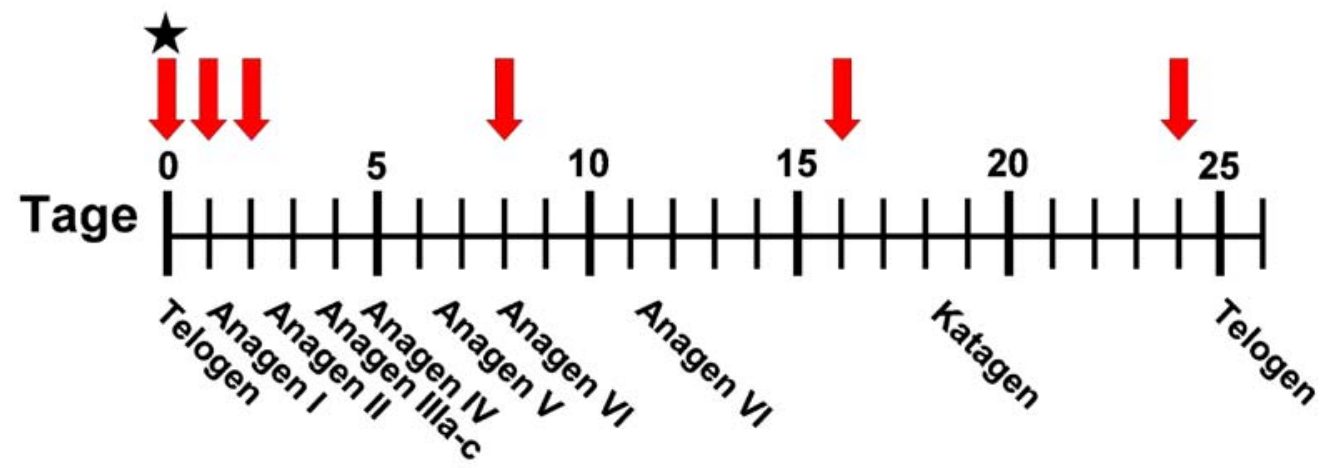

Abbildung 39: Tamoxifen-Applikation in definierten Haarzyklusphasen. Gezeigt ist der Verlauf eines Haarzyklus in Tagen, bei dem das Anagen durch eine Epilation (Stern) am Tag 0 induziert wurde. Die Pfeile markieren den Tag der Behandlung mit Tamoxifen 0, 1, 2, 8, 16 bzw. 24 Tage nach der Epilation. Unterhalb des Zeitstrahls ist die jeweilige Haarzyklusphase angegeben.

Die entsprechenden epilierten Hautstellen wurden dann, wie unter 2.15.4.1.6.1 beschrieben, zweimal für 10 min mit $500 \mu \mathrm{g}$ Tamoxifen in $20 \mu \mathrm{l}$ DMSO behandelt.

Nach 72 und 82 Tagen im Anschluss an die Tamoxifen-Applikation waren bei keinem der Tiere makroskopische Hautveränderungen sichtbar. Daher wurden drei Tiere abgetötet und HE-Färbungen von Paraffinschnitten der Haut erstellt. Anhand der HE-Färbungen waren bei diesen Tieren BCC an den lokal behandelten Hautarealen erkennbar, die sich jedoch völlig unabhängig von der jeweiligen Haarzyklusphase entwickelt hatten. Darüber hinaus wiesen diese Tiere BCC oder -Vorläuferläsionen an Ohren und Schwanz auf.

Die verbliebenen Tiere sollten länger beobachtet werden, da die Möglichkeit bestand, dass Tumoren, die zu den unterschiedlichen Zeitpunkten während des Haarzyklus induziert wurden, ein unterschiedliches Wachstumsverhalten zeigen. Leider konnten die Tiere nicht länger als 114 bis 140 Tage nach Tamoxifen-Applikation beobachtet werden, da bei einigen der Tiere durch starkes Kratzen Hautläsionen mit teilweise heftigen Entzündungsreaktionen entstanden waren. Auch bei diesen Tieren wurden BCC an beiden Hautarealen sowie an Ohren und Schwanz diagnostiziert, die sich aber weder in der Morphologie noch im Differenzierungszustand voneinander unterschieden. Zusätzlich wurde die Größe der einzelnen Tumoren bestimmt. Dazu wurden sie nach ihrer Größe in eine Kategorie von 1 bis 4 eingeteilt, wobei 1 die kleinsten und 4 die größten BCC umfasste. Sinnvollerweise sollten nur gleichalte BCC miteinander verglichen werden. Daher wurden jeweils nur BCC 72 - 82 Tage, 114 - 125 Tage und 140 Tage nach der Tamoxifen-Applikation untereinander verglichen (siehe Tabelle 23). Zwischen der Haarzyklusphase bei der Induktion und der Tumorgröße war jedoch keine Korrelation erkennbar. 
Tabelle 23: Entwicklung von BCC nach lokaler Applikation von Tamoxifen in definierten Haarzyklusphasen. Dargestellt ist ein Überblick der durch die lokale Applikation von Tamoxifen während unterschiedlicher Haarzyklusphasen induzierten BCC. In der linken Spalte ist der Zeitpunkt der Präparation nach der Tamoxifen-Applikation angegeben, die mittlere Spalte zeigt die jeweilige Haarzyklusphase des Hautareals bei der Applikation von Tamoxifen. In der rechten Spalte sind die Tumoren nach ihrer Größe in die Kategorien 1 bis 4 eingeteilt, wobei die Kategorie 1 kleine und die Kategorie 4 große Tumoren umfasst. Jeder analysierte Tumor ist mit einem $\mathrm{X}$ eingetragen, $\mathrm{XX}$ steht für zwei Tumoren.

\begin{tabular}{|c|c|c|c|c|c|}
\hline \multirow{2}{*}{$\begin{array}{l}\text { Präparation x Tage nach } \\
\text { der Tamoxifen-Applikation }\end{array}$} & \multirow{2}{*}{$\begin{array}{l}\text { Haarzyklusphase zum Zeitpunkt } \\
\text { der Tamoxifen-Applikation }\end{array}$} & \multicolumn{4}{|c|}{ Kategorie des Tumors } \\
\hline & & 1 & 2 & 3 & 4 \\
\hline \multirow[t]{6}{*}{ 72-82 Tage } & Anagen I & & $\mathrm{x}$ & & \\
\hline & Anagen I-II & & & & $x$ \\
\hline & Anagen IV & & $x$ & & \\
\hline & Anagen VI & & & & $x$ \\
\hline & Katagen & & & & $x$ \\
\hline & Telogen & & $x$ & & \\
\hline \multirow[t]{6}{*}{ 114-125 Tage } & Anagen I & $x$ & & & \\
\hline & Anagen I-II & & $x$ & & \\
\hline & Anagen IV & & & & $x$ \\
\hline & Anagen $\mathrm{VI}$ & & & $x X$ & \\
\hline & Katagen & $x$ & & $x$ & \\
\hline & Telogen & & & & $x$ \\
\hline \multirow[t]{6}{*}{140 Tage } & Anagen I & & & & $x$ \\
\hline & Anagen I-II & & & & $x$ \\
\hline & Anagen IV & \multicolumn{4}{|c|}{ kein Material vorhanden } \\
\hline & Anagen $\mathrm{VI}$ & \multicolumn{4}{|c|}{ kein Material vorhanden } \\
\hline & Katagen & \multicolumn{4}{|c|}{ kein Material vorhanden } \\
\hline & Telogen & \multicolumn{4}{|c|}{ kein Material vorhanden } \\
\hline
\end{tabular}

Zusammenfassend ist festzuhalten, dass die Induktion von BCC überraschenderweise zu jeder der analysierten Haarzyklusphasen möglich war. Ebenso wenig beeinflusst die Phase des Haarzyklus zum Zeitpunkt der Mutationsinduktion die Größe der BCC. Allerdings war die Anzahl der Tumorproben für eine Bewertung der Tumorgröße nach unterschiedlichen Zeiträumen sehr gering, so dass eine statistische Auswertung nicht möglich war.

\subsubsection{Etablierung stabiler Ptch ${ }^{\text {flox/flox }}$-, Ptch ${ }^{\text {flox/flox }}$ ERT2 $^{+/-}$- und Ptch $^{- \text {- }_{\text {-Zell- }}}$ linien}

Um in vitro-Analysen des hier beschriebenen konditionellen Ptch-knockout zu ermöglichen, wurden stabile Zelllinien aus $\operatorname{Ptch}^{\text {floxfllox}} E R T 2^{+/-}$- und Ptch $^{\text {flox/flox }}$-Mäusen 
etabliert. Mit diesen Zelllinien können Untersuchungen hinsichtlich der Funktion von Ptch relativ einfach durchgeführt werden. Dieses Modell bietet im Gegensatz zu in vivoAnalysen den Vorteil, dass einheitliche Zellpopulationen durch die direkte Modifikation des Hh/Ptch-Signalweges, beispielsweise mit spezifischen Inhibitoren, unmittelbar analysiert werden können und keine tierexperimentellen Methoden nötig sind.

Aus adulten unbehandelten $\mathrm{Ptch}^{\text {floxfflox}} E R T 2^{+/}$- und $\mathrm{Ptch}^{\text {floxfflox}}$-Mäusen wurden Fibroblasten zur Herstellung stabiler Zelllinien isoliert. Mittels PCR wurden drei Wochen nach der Isolierung, als stabiles Zellwachstum erreicht war, die Genotypen verifiziert.

\subsubsection{Herstellung der Ptch $^{\text {flox/flox }}$-Zelllinie}

Für die Etablierung der $P$ tch $h^{\text {floxfllox}}$-Zelllinie wurden Fibroblasten aus Ptch ${ }^{\text {floxfllox}}$-Mäusen isoliert und kultiviert. Die Analyse der Zellen erfolgte zusammen mit den anderen Zelllinien und ist in den Abschnitten 3.2.4.2 bis 3.2.4.6 detailliert dargestellt.

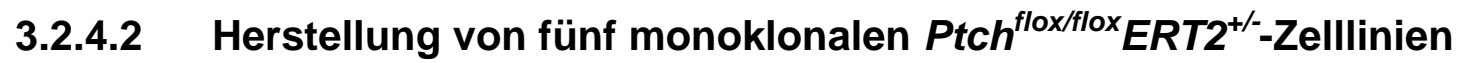

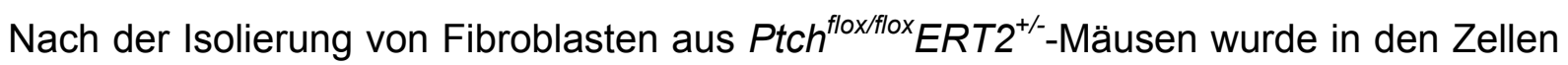
mit der Oligonukleotidkombination Exon7-F // neo-R ein geringer Anteil des $P t c h^{\text {del }}$-Allels nachgewiesen (siehe Abbildung 40). Dies beruht auf der gelegentlich auftretenden niedrigen Grundaktivität der Cre-ERT2 auch ohne Aktivierung durch Tamoxifen und führt wie in diesem Fall zur sogenannten „leakiness“.

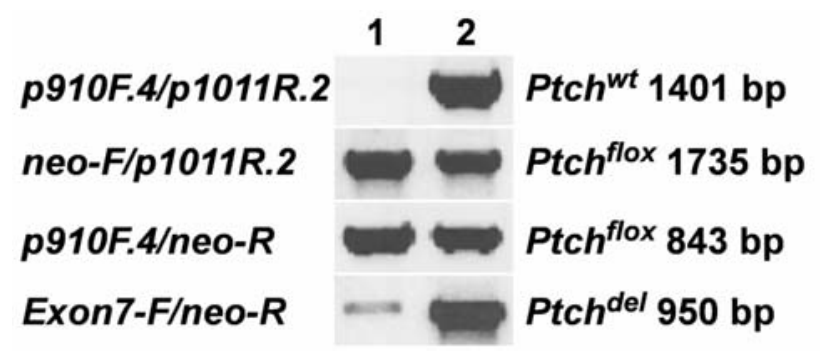

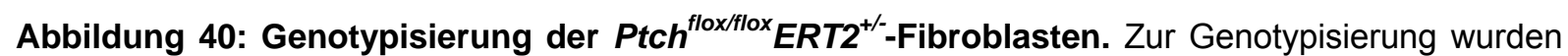
für das Ptch ${ }^{\text {wt }}$-Allel das Oligonukleotidpaar p910F.4//p1011R.2, für das Ptch ${ }^{\text {flox }}$-Allel die Oligonukleotidpaare Neo-F//p1011R.2 und p910F.4//Neo-R sowie für das Ptch ${ }^{\text {del-Allel das }}$ Oligonukleotidpaar Exon7-F// Neo-R verwendet. Die Anlagerungsstellen der Oligonukleotide sind

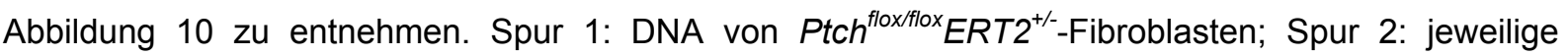
Positivkontrolle für die PCR-Reaktion.

Daher wurden fünf monoklonale Ptch $^{\text {floxfllox}} E R T 2^{+/}$-Zelllinien etabliert, die im Folgenden als B9, C6, D2, F4 und G2 bezeichnet werden. Hierfür wurden einzelne Zellen in einer 96-Loch Platte ausgesät und expandiert. Mittels PCR (nicht gezeigt) und TaqManAnalysen an gDNA wurde in allen fünf Zelllinien ausschließlich das Ptch flox-Allel 


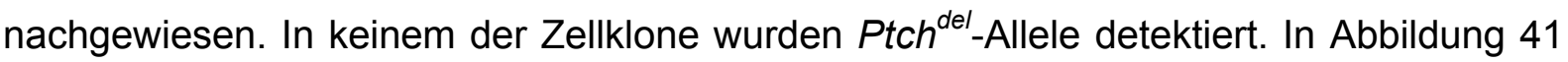
ist das Ergebnis der TaqMan-Analysen exemplarisch für die Zelllinie B9 im Vergleich zu Ptch $^{\text {floxflox }}$ - und Ptch ${ }^{-/}$-Fibroblasten (siehe unter 3.2.4.3) dargestellt. Während in Ptch $^{\text {floxflox }}$ - und B9-Zellen ausschließlich das Ptch ${ }^{\text {flox }}$-Allel, nicht aber das Ptch $^{\text {del }}$-Allel detektiert werden konnte, verhielt es sich in der Zelllinie Ptch $^{--}$umgekehrt (zur Etablierung dieser Zelllinie siehe 3.2.4.3). Daher war in den Zelllinien B9, C6, D2, F4 und G2 keine Grundaktivität der Cre-ERT2 vorhanden.
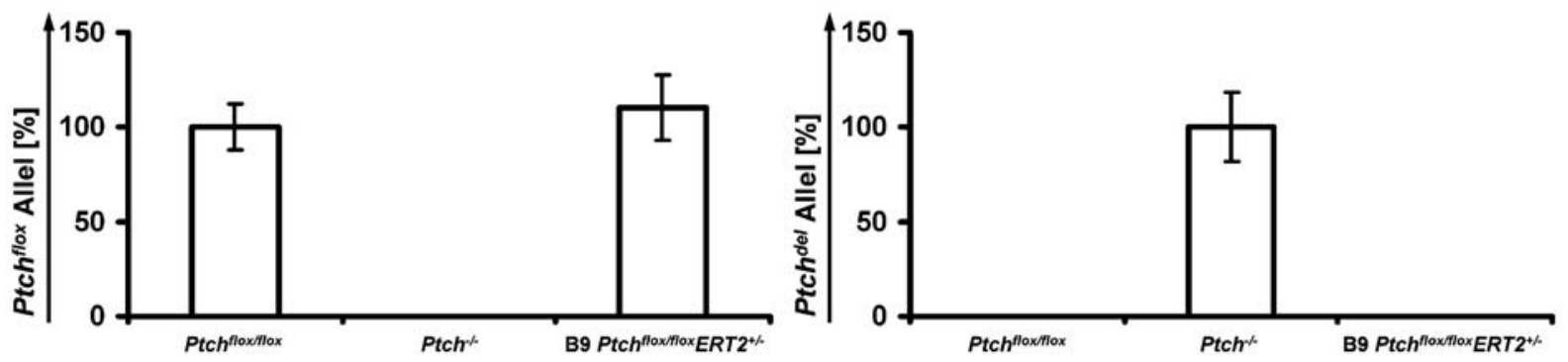

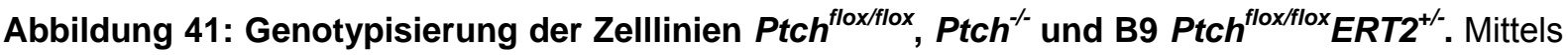
TaqMan-Analysen an gDNA erfolgte die Genotypisierung von $\operatorname{Ptch}^{\text {floxflox }}{ }_{-}, \operatorname{Ptch}^{-{ }_{-}}$und

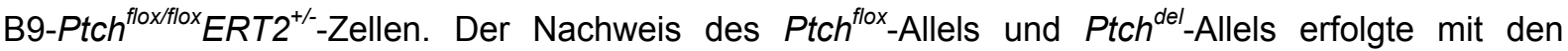
Oligonukleotiden mPTCNx_f // $m P T C N x_{-} r$ bzw. mPTCdeINx_f $/ / \quad m P T C N x_{-} r$ und den fluoreszenzmarkierten, spezifischen Sonden mPTCNx_S2 bzw. mPTCdelNx_S1. Für die Normalisierung wurde ein spezifischer Assay für Pelota verwendet.

\subsubsection{Herstellung einer $\boldsymbol{P t c h}^{-/}$-Zelllinie}

Nach einer Inkubation der Ptch ${ }^{\text {floxflox}} E R T 2^{+/}{ }^{+}$-Fibroblasten mit $10 \mu \mathrm{M}$ Tamoxifen war noch nach $120 \mathrm{~h}$ das Ptch $^{\text {flox}}$-Allel nachweisbar (siehe 3.2.4.4.1.1, Abbildung 43). Dies bedeutet, dass der Zeitraum von $120 \mathrm{~h}$ nicht ausreichte, um eine komplette Rekombination der loxP-Sequenzen in sämtlichen Zellen hervorzurufen. Für die Herstellung einer Ptch $^{-/}$-Zelllinie, in der die Exone 8 und 9 von Ptch komplett deletiert sind, wurden Ptch $^{\text {floxfflox}} E R T 2^{+/}$-Fibroblasten für ca. vier Wochen mit $10 \mu \mathrm{M}$ Tamoxifen inkubiert. Da die Zellen bei geringen Zelldichten unter Tamoxifen-Behandlung starben, wurde Tamoxifen nur zugegeben, wenn die Zellen mindestens $50 \%$ konfluent waren. Das tamoxifenhaltige Medium wurde alle zwei bis drei Tage erneuert.

Wie in Abbildung 42 gezeigt, konnte in den Zellen nach vier Wochen kein Amplifikat für das Ptch $^{\text {flox }}$-Allel nachgewiesen werden. Des Weiteren waren weder zu diesem Zeitpunkt noch später Ptch ${ }^{\text {wt }}$-Transkripte mit Hilfe der Oligonukleotide Exon7-F oder mPtc11 (Vorwärts-Oligonukleotide) und mPtc-tq Ex8R (Rückwärts-Oligonukleotid) mittels qRTPCR detektierbar. Das $P t c h^{\text {del }}$-Transkript war hingegen nachweisbar. Diese Ergebnisse zeigen, dass wahrscheinlich in allen Zellen eine vollständige Rekombination der loxP- 
Sequenzen stattgefunden hat. Dies konnte auch in sämtlichen Folgeexperimenten an höheren Passagen der Zelllinie verifiziert werden.

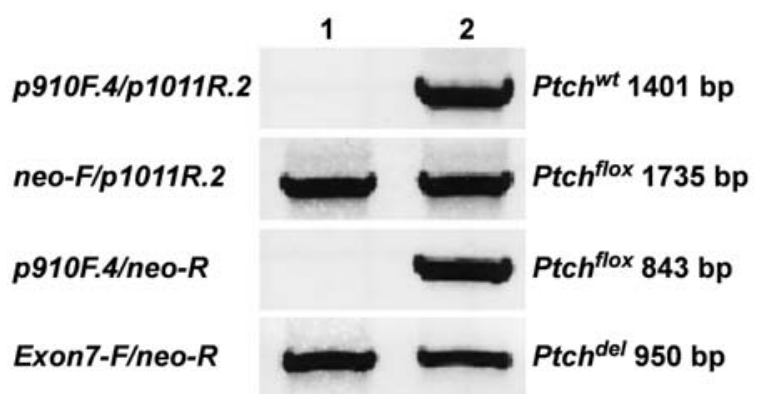

Abbildung 42: Genotypisierung der Ptch $^{-/}$-Fibroblasten. Zur Genotypisierung wurden für das Ptch ${ }^{\text {wt }}$-Allel das Oligonukleotidpaar p910F.4 // p1011R.2, für das Ptch ${ }^{\text {flox }}$-Allel die Oligonukleotidpaare

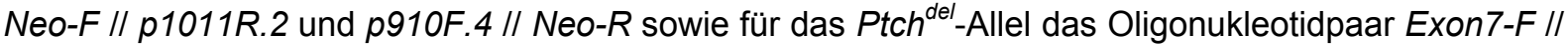
Neo- $R$ verwendet. Die Anlagerungsstellen der Oligonukleotide sind Abbildung 10 zu entnehmen. Spur 1: DNA von Ptch ${ }^{-/}$-Fibroblasten; Spur 2: jeweilige Positivkontrolle für die PCR-Reaktion.

\subsubsection{Charakterisierung der Ptch ${ }^{\text {flox/flox }}$ ERT2 $^{+/-}$-Fibroblasten (B9)}

\subsection{Aktivierung der Hh/Ptch-Signalkaskade durch Tamoxifen}

\subsection{Untersuchung der Rekombinationseffizienz am Ptch ${ }^{\text {flox }}$-Lokus}

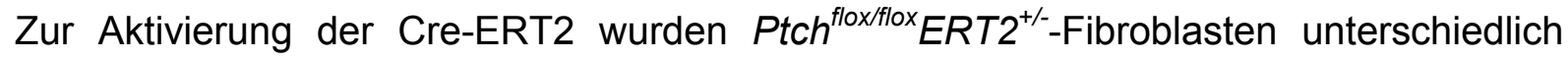
lange mit $10 \mu \mathrm{M}$ Tamoxifen stimuliert. Trotz „leakiness“ wurde für dieses Vorexperiment

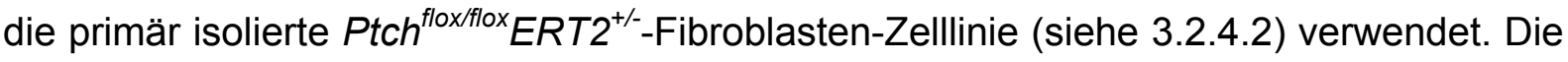
Analyse der Rekombination erfolgte mittels PCR an gDNA mit den Oligonukleotidkombinationen p910F.4 // neo- $R$ und Exon7-F // neo- $R$ (siehe Tabelle 3). Durch die Cre-ERT2-vermittelte Rekombination erfolgte die Deletion des von loxPSequenzen flankierten Abschnitts, in dem sich die Hybridisierungssequenz des Oligonukleotids p910F.4 befand. Somit sollte eine Stimulation mit Tamoxifen eine Abnahme des mit der Oligonukleotidkombination p910F.4// neo- $R$ amplifizierten Fragmentes (entspricht dem Ptch ${ }^{\text {wt }}$-Allel) bewirken und gleichzeitig das Ptch ${ }^{\text {del }}$-Allel (Oligonukleotidpaar Exon7-F// neo-R) detektiert werden. Abbildung 43 zeigt exemplarisch das Ergebnis der PCR an gDNA der primär isolierten Ptch $^{\text {flox/flox }} E R T 2^{+/}$Fibroblasten-Zellinie nach Behandlung mit Tamoxifen oder Lösungsmittel $(0,01 \%$ DMSO, v/v). Die Tamoxifen-behandelten Zellen wurden für eine Dauer zwischen $48 \mathrm{~h}$ und $120 \mathrm{~h}$ mit $10 \mu \mathrm{M}$ Tamoxifen stimuliert, wobei für jeden Zeitpunkt zwei Petrischalen mit Zellen verwendet wurden. Nach $48 \mathrm{~h}$ war nur in den Zellen einer Petrischale das

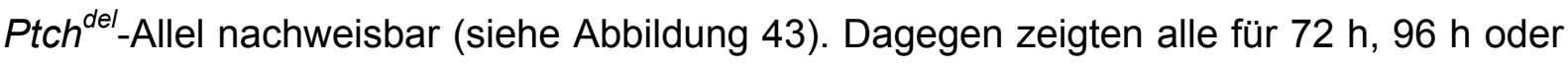




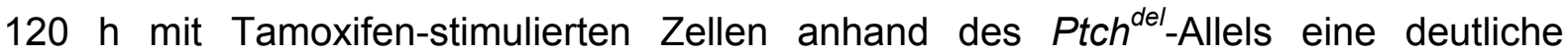
Rekombination. Aufgrund dieser Ergebnisse wurde für weitere Stimulationsexperimente stets eine Stimulationsdauer von $72 \mathrm{~h}$ gewählt.

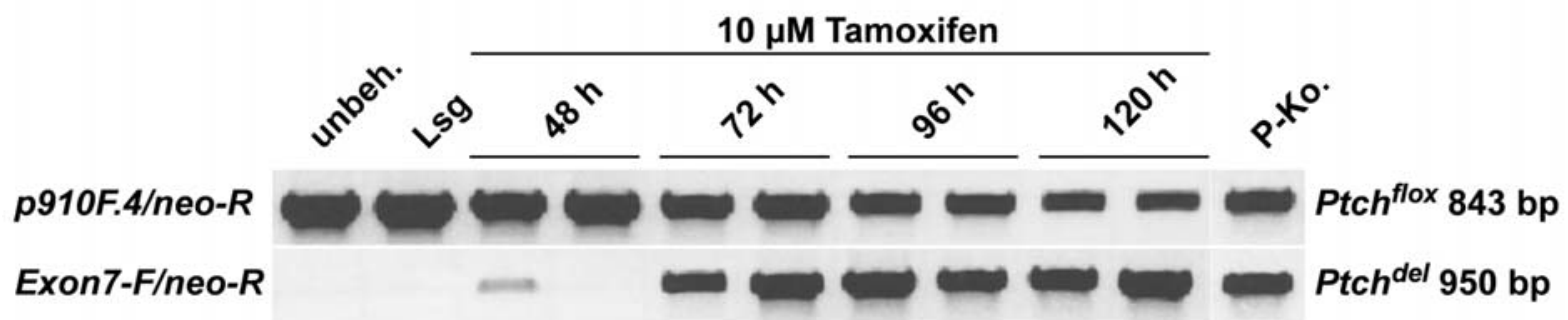

Abbildung 43: Tamoxifen-vermittelte Rekombination des Ptch $^{\text {flox }}$-Lokus in Ptch $^{\text {flox/flox }}{ }^{\text {ERT2 }}{ }^{\text {+/- }}$ Fibroblasten. Dargestellt sind die Ergebnisse von PCR-Analysen an unbehandelten, Lösungsmittel-

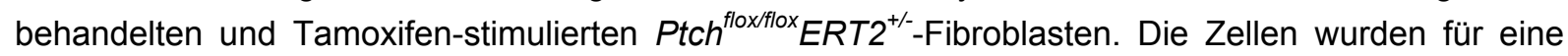
Dauer zwischen $48 \mathrm{~h}$ und $120 \mathrm{~h}$ mit $10 \mu \mathrm{M}$ Tamoxifen stimuliert und die Rekombination anhand der Oligonukleotidkombinationen p910F.4 // neo-R und Exon7-F // neo-R untersucht. Abkürzungen: Lsg, Lösungsmittel; P-Ko, Positivkontrolle; unbeh., unbehandelt.

In weiterführenden Experimenten wurde nun die Effizienz der Cre-ERT2-vermittelten Rekombination quantifiziert. Hierfür wurden die fünf etablierten monoklonalen Ptch $^{\text {floxfllox}}{ }^{\mathrm{E} R T 2^{+/}}{ }^{+-Z e l l l i n i e n}$ (siehe 3.2.4.2) verwendet. In diesen Zelllinen wurde zunächst die Tamoxifen-induzierte Rekombinationsrate am Ptch flox-Lokus mittels TaqManAnalysen ermittelt. Ein Pelota-spezifischer Assay diente der Normalisierung, anhand der Standardkurven-Methode erfolgte die Auswertung. Die Rekombinationseffizienz zeigt den Anteil des Ptch ${ }^{\text {del }}$-Allels von der Summe der detektierten Ptch ${ }^{\text {del }}$ - sowie Ptch $^{\text {flox }}$-Allele (Abbildung 44). Sie variierte in den fünf Zelllinien zwischen 57 und $73 \%$. Weder in Lösungsmittel-behandelten noch unbehandelten Zellen oder in Ptch floxflox-Zellen war eine Rekombination nachweisbar (nicht gezeigt). 


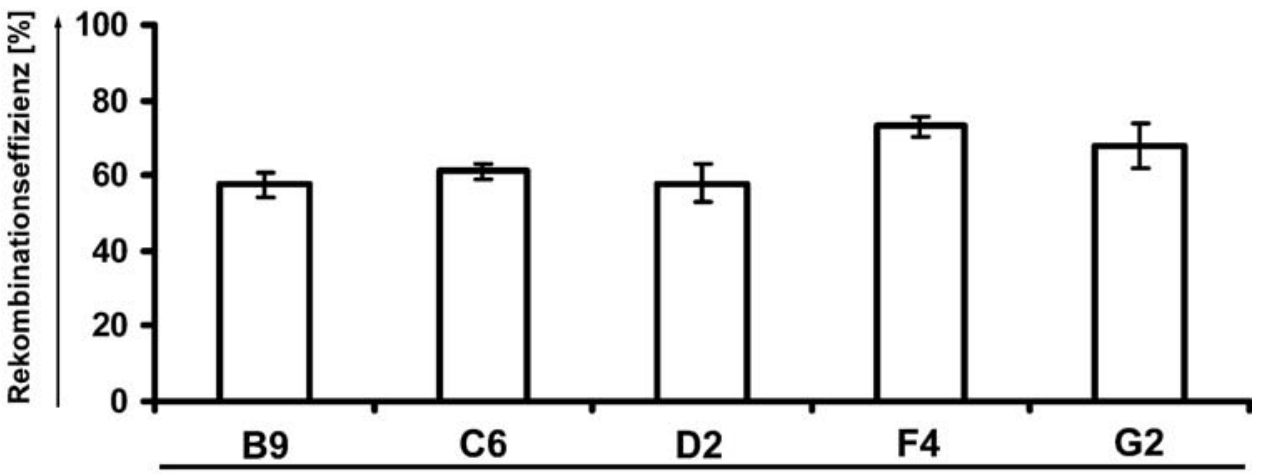

Ptch $^{\text {flox/flox }}$ ERT2 $^{\text {+/- }}$

Abbildung 44: Rekombinationseffizienz am Ptch ${ }^{\text {flox }}$-Lokus nach Stimulation mit Tamoxifen. Dargestellt sind die durch TaqMan-Analysen an gDNA ermittelten Rekombinationseffizienzen am Ptch $^{\text {flox }}$-Lokus in den Zelllinien B9, C6, D2, F4 und G2 nach 72 h Stimulation mit Tamoxifen. Der

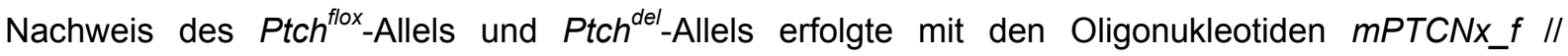
$m P T C N x_{-} r$ bzw. mPTCdelNx_f // mPTCNx_r und den fluoreszenzmarkierten, spezifischen Sonden mPTCNx_S2 bzw. mPTCdelNx_S1. Die Berechnung der Rekombinationseffizienz in Prozent erfolgte für jede Probe anhand der Formel $P t c h^{d e l} /\left(P t c h^{d e l}+P t c h{ }^{f l o x}\right) * 100 \%$. Für die Normalisierung wurde ein spezifischer Assay für Pelota verwendet.

\subsection{Untersuchung der Aktivität des Hh/Ptch-Signalweges}

Da angenommen wurde, dass die Ptch-Deletion zur Aktivierung der Hh/PtchSignalkaskade führt, wurde die Expression der Zielgene Ptch und Gli1 in den Tamoxifenbehandelten Zelllinien B9, C6, D2, F4, G2 und Ptch floxflox und den jeweiligen Kontrollen anhand von qRT-PCR quantifiziert (siehe Abbildung 45). Dabei wurden für den Nachweis von Ptch Oligonukleotide (mPtc10 // mPtc11R) verwendet, die aufgrund ihrer Lokalisation in den Exonen 5 und 6 sowohl Ptch $^{\text {wt }}$ - als auch Ptch ${ }^{d e l}$-Transkripte detektieren. Zum Nachweis von Gli1 mittels qRT-PCR dienten die Oligonukleotide mGli1tq-f und $m$ Gli1-tq-r.

Mit diesen Oligonukleotiden wurde in allen Zellen eine basale Ptch-Expression nachgewiesen, und es ergaben sich keine wesentlichen Unterschiede zwischen behandelten oder unbehandelten Zellen. Dagegen war in Tamoxifen-behandelten B9Zellen im Gegensatz zu den Kontrollen eine deutlich erhöhte Gli1-Expression nachweisbar. Bei den übrigen Zelllinien war keine Änderung des Gli1Expressionsniveaus erkennbar. 

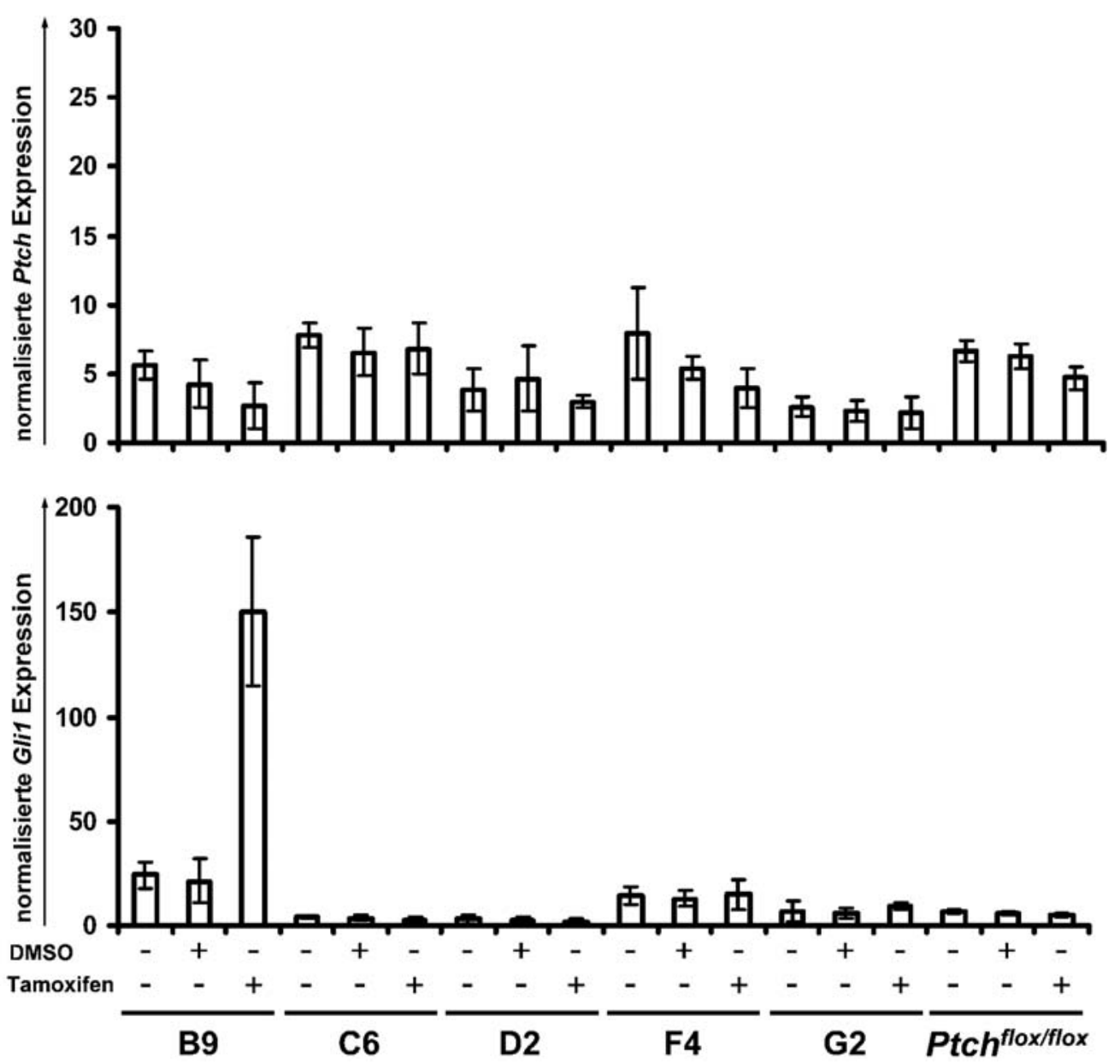

Abbildung 45: Erhöhte Gli1-Expression in B9 nach Stimulation mit Tamoxifen. Die Expression von Ptch und Gli1 in den Ptch ${ }^{\text {flox/lox }}$ ERT2 ${ }^{+/}$-Fibroblastenzelllinien B9, C6, D2, F4, G2 und Ptch ${ }^{\text {floxfllox }}$ Zellen nach Stimulation mit Tamoxifen und in unbehandelten oder Lösungsmittel-behandelten Zellen wurde mittels qRT-PCR analysiert. Dazu wurden die Oligonukleotidpaare mPtc10 // mPtc11R und $m$ Gli1-tq-f // mGli1-tq-r verwendet und eine Normalisierung anhand der Expression von 18S rRNA durchgeführt.

Zusammenfassend ist festzuhalten, dass keine der fünf monoklonalen Zelllinien B9, C6, D2, F4 und G2 eine Grundaktivität der Cre-ERT2 aufwies. Nach der Stimulation der CreERT2 mit Tamoxifen zeigte sich in keiner Zelllinie eine Änderung der Ptch-Expression. Jedoch wurde in der Zelllinie B9 im Vergleich zu allen anderen Zelllinien die Expression von Gli1 induziert. Dies zeigt, dass sich der Hh/Ptch-Signalweg in B9-Zellen durch das Ausschalten von Ptch aktivieren lässt. Daher wurden weitere Experimente zur Analyse des Hh/Ptch-Signalweges ausschließlich mit dieser Zelllinie durchgeführt.

\subsection{Untersuchung der Aktivität des Hh/Ptch-Signalweges in Abhängigkeit von der Konfluenz}

Bereits mehrfach wurde eine Korrelation zwischen der Aktivität des Hh/PtchSignalweges und der Zelldichte bei Zellkulturexperimenten gezeigt (J Taipale et al., 
2000; WJ Ingram et al., 2002). Daher wurde überprüft, ob dies auch für die Zelllinie B9 zutrifft. Hierfür wurde RNA aus unbehandelten B9-Zellen mit einer Konfluenz zwischen 35 und $100 \%$ isoliert und die Ptch- und Gli1-Expression mittels qRT-PCR analysiert. Zwischen Zelldichte und Ptch-Expression konnte keine Korrelation detektiert werden (nicht gezeigt). Dagegen wiesen Zellen, die zum Zeitpunkt des Aberntens in höherer Konfluenz gewachsen waren, eine gesteigerte Expression von Gli1 auf (Abbildung 46). Daher wurden die weiteren Versuche bei einer Konfluenz von ca. 80 \% durchgeführt, um eine Vergleichbarkeit der Daten zu ermöglichen.

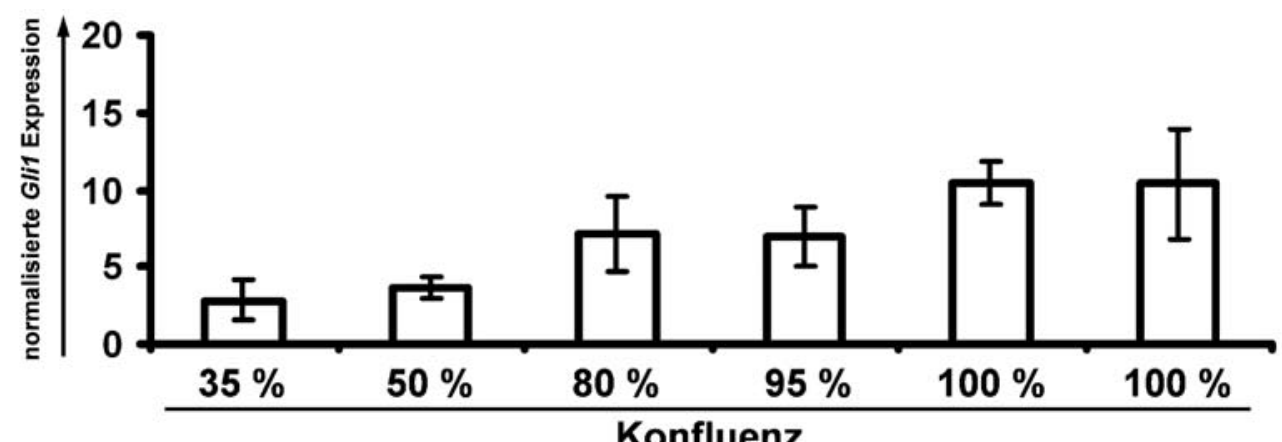

Abbildung 46: Dichteabhängige Expression von Gli1 in B9-Zellen. Dargestellt ist die Gli1Expression in B9-Zellen mit untschiedlicher Konfluenz beim Abernten der Zellen. Die Analyse erfolgte mit der Oligonukleotidkombination mGli1-tq-f // mGli1-tq- $r$ mittels qRT-PCR, die Proben wurden anhand der Expression der 18S rRNA normalisiert.

\subsection{Blockade der Hh/Ptch-Signalkaskade durch Cyclopamin}

Zur Überprüfung, ob die Aktivierung der Hh/Ptch-Signalkaskade in Tamoxifenstimulierten B9-Zellen (siehe 3.2.4.4.1.2) reversibel ist, wurde die Aktivität durch den spezifischen Smo-Inhibitor Cyclopamin (siehe 1.3) blockiert. Hierfür wurden Tamoxifenbehandelte Zellen zusätzlich mit $5 \mu \mathrm{M}$ Cyclopamin oder dem Lösungsmittel Ethanol (0,5 $\% \mathrm{v} / \mathrm{v}$ ) inkubiert. Als Kontrollen wurden die Zellen nur mit den entsprechenden Lösungsmitteln DMSO (0,01\% v/v; Lösungsmittel für Tamoxifen), Ethanol (0,5\% v/v, Lösungsmittel für Cyclopamin) oder Cyclopamin behandelt (siehe Abbildung 47).

Zur Analyse der Aktivität der Hh/Ptch-Signalkaskade wurde neben der Oligonukleotidkombination mGli1-tq-f // mGli1-tq-r die Kombination mPtc10 // mPtc11R verwendet, welche sowohl Ptch ${ }^{\text {wt }}$ als auch Ptch ${ }^{\text {del }}$ Transkripte detektiert (siehe 3.2.4.4.1.2). Zusätzlich wurden qRT-PCR Assays eingesetzt, die eine Unterscheidung von Ptch $^{\text {wt }}$ - und $P t c h^{d e l}$-Transkripten ermöglichen. Die Kombination der Oligonukleotide mPtc-tq-Ex7F und mPtc-tq Ex8R diente aufgrund der Lokalisation des Rückwärtsoligonukleotids in Exon 8 ausschließlich zur Detektion von tch $^{\text {wt }}$, wohingegen 
die Verwendung von mPtc-tq Ex7F und mPtc-tq Ex7/10R durch Hybridisierung des Übergangs von Exon 7 auf 10 den Nachweis des $P t c h^{d e l}$-Transkripts ermöglichte. Die Ergebnisse der Expressionsanalysen sind in Abbildung 47 gezeigt.

Nach Cyclopamin-Gabe wurde die Expression von Gesamt-Ptch (Ptch ${ }^{\text {wt }}$ - und Ptch ${ }^{\text {del }}$ Transkripte) unabhängig von der Behandlung blockiert. Diese Blockade war auch in Zellen erkennbar, die mit Tamoxifen behandelt wurden. Bei diesen Analysen war anhand der Oligonukleotidkombination $\mathrm{mPtc} 10 / / \mathrm{mPtc} 11 R$ jedoch nicht erkennbar, ob es sich bei den nachgewiesenen Transkripten um Ptch ${ }^{\text {wt }}$ oder Ptch ${ }^{\text {del }}$ handelte, wobei Ptch ${ }^{\text {del }}$ Transkripte ausschließlich in Tamoxifen-behandelten Zellen nachweisbar sein sollten. Analysen mit den Oligonukleotiden mPtc-tq-Ex7F// mPtc-tq Ex8R zeigten eine etwas höhere Expression von $\mathrm{Ptch}^{\text {wt }}$ in unbehandelten und Lösungsmittel-behandelten Zellen im Vergleich zu Cyclopamin-behandelten Zellen. Eine deutliche Abnahme dieser Transkripte war in Tamoxifen- und Cyclopamin/Tamoxifen-behandelten Zellen erkennbar. Wie erwartet war mit der Oligonukleotidkombination mPtc-tq Ex7F // mPtc-tq Ex7/10R in unbehandelten und Lösungsmittel-behandelten Zellen keine Expression von

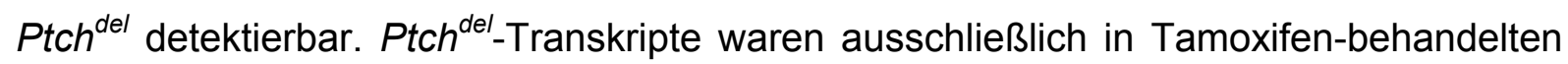
Zellen nachweisbar, wobei die mit Tamoxifen stimulierten Zellen die höchste Expression aufwiesen, die sich durch Cyclopamin blockieren ließ.

Eine erhöhte Gli1-Expression wurde nur in Tamoxifen-behandelten Zellen gefunden, sie ließ sich ebenfalls durch die Zugabe von Cyclopamin inhibieren.

Diese Daten zeigen, dass die Tamoxifen-induzierte Mutation von Ptch in B9-Zellen eine Induktion der Gli1-Expression hervorruft, während die Expression von Gesamt-Ptch überraschenderweise unverändert bleibt. Dabei zeigten genauere Analysen eine

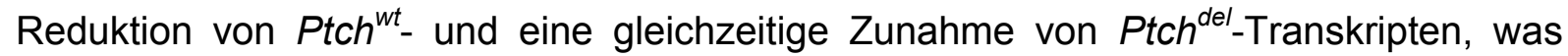
wahrscheinlich für die Aktivierung der $\mathrm{Hh} /$ Ptch-Signalkaskade und damit für die verstärkte Gli1-Expression verantwortlich ist. Wie erwartet, bewirkte die Zugabe von Cyclopamin hierbei eine Inhibition der Ptch- und Gli1-Expression. 

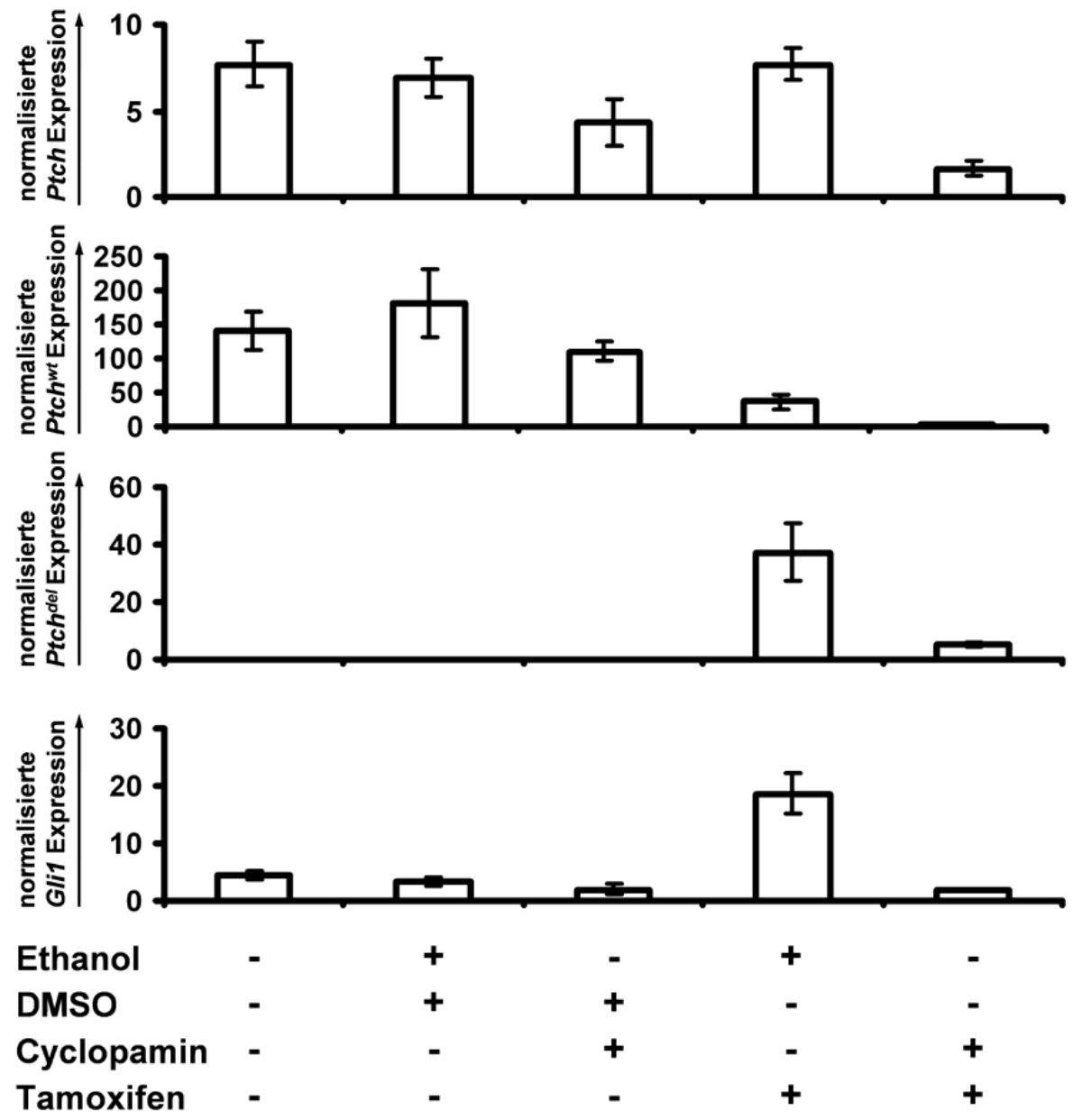

Abbildung 47: Blockade der Tamoxifen-induzierten erhöhten Gli1- und Ptch-Expression durch Cyclopamin. Die Expression von Ptch, Ptch ${ }^{\text {wt }}, \operatorname{Ptch}^{\text {del }}$ und Gli1 in unbehandelten, Lösungsmittelbehandelten und Cyclopamin- und/oder Tamoxifen-behandelten B9-Zellen wurde durch qRT-PCR an cDNA analysiert und auf die Expression von $18 S$ rRNA normalisiert. Dazu wurden die Oligonukleotidkombinationen mPtc10// mPtc11R, mPtc-tq-Ex7F// mPtc-tq Ex8R, mPtc-tq-Ex7F // $m P t c-t q E x 7 / 10 R$ und $m G$ li1-tq-f // mGli1-tq- $r$ verwendet.

\subsection{Aktivierung der Hh/Ptch-Signalkaskade durch Shh}

In vorhergegangenen Experimenten wurde gezeigt, dass die Induktion der Ptch-Mutation in der Ptch $^{\text {floxfllox}} E R T 2^{+/}$-Fibroblastenzelllinie B9 durch Gabe von Tamoxifen die Aktivierung des Hh/Ptch-Signalweges bewirkt. Analog hierzu wurde nun versucht, die Aktivierung der Signalkaskade mittels Zugabe von Shh für $72 \mathrm{~h}$ zu induzieren. Hierfür wurde Überstand von Hek293 Shh-Zellen verwendet, sog. konditioniertes Medium (siehe 2.15.3.5 und 2.15.3.6), das sezerniertes Shh enhält. Als Kontrollmedium diente entsprechend hergestellter Überstand der Zelllinie Hek293.

Die Aktivierung des $\mathrm{Hh} /$ Ptch-Signalweges wurde ebenfalls mittels qRT-PCR anhand der Expression von Gli1 und Ptch untersucht. Als Kontrolle wurden Tamoxifen-behandelte B9-Zellen mitgeführt. Im Gegensatz zu den vorher beschriebenen Analysen wurde für 
die Expressionsanalyse von Ptch ${ }^{w t}$ die Oligonukleotidkombination mPtc11// mPtc-tq Ex8R verwendet, da sich diese bei der qRT-PCR als beständiger als die Kombination mPtc-tq-Ex7F // mPtc-tq Ex8R erwiesen hatte.

Wie bereits vorher dargestellt, zeigten unbehandelte oder Lösungsmittel-behandelte B9Zellen (0,01 \% DMSO, v/v) eine moderate Expression von Ptch $^{\text {wt }}$ (siehe 3.2.4.4.1.2, Abbildung 45). Nach Shh-Stimulation dagegen war die Expression von Ptch ${ }^{\text {wt }}$ stark erhöht (Abbildung 48). Tamoxifen bewirkte wie erwartet eine deutliche Reduktion von Ptch $^{\text {wt }}$-Transkripten (siehe Abbildung 48) und einen Anstieg von Ptch ${ }^{\text {del }}$-Transkripten (siehe Abbildung 47).

Im Gegensatz zur Tamoxifen-Induktion, durch die sich ausschließlich die Expression von Gli1 und Gli2 stimulieren ließ (siehe Abbildung 49), wurde nach Gabe von Shh zusätzlich Gli3 vermehrt exprimiert. Sowohl nach Stimulation mit Shh als auch nach Zugabe von Tamoxifen war der Effekt auf Gli1 am größten (4,5-fache bzw. 1800-fache Zunahme nach Tamoxifen- bzw. Shh-Stimulation gegenüber Lösungsmittelzugabe). Tamoxifen bewirkte eine 6,4-fache und Shh eine 25-fache Zunahme der Gli2-Expression, wohingegen die Gli3-Expression nur nach Zugabe von Shh auf das 2-fache gegenüber Lösungsmittel-behandelten Zellen anstieg.

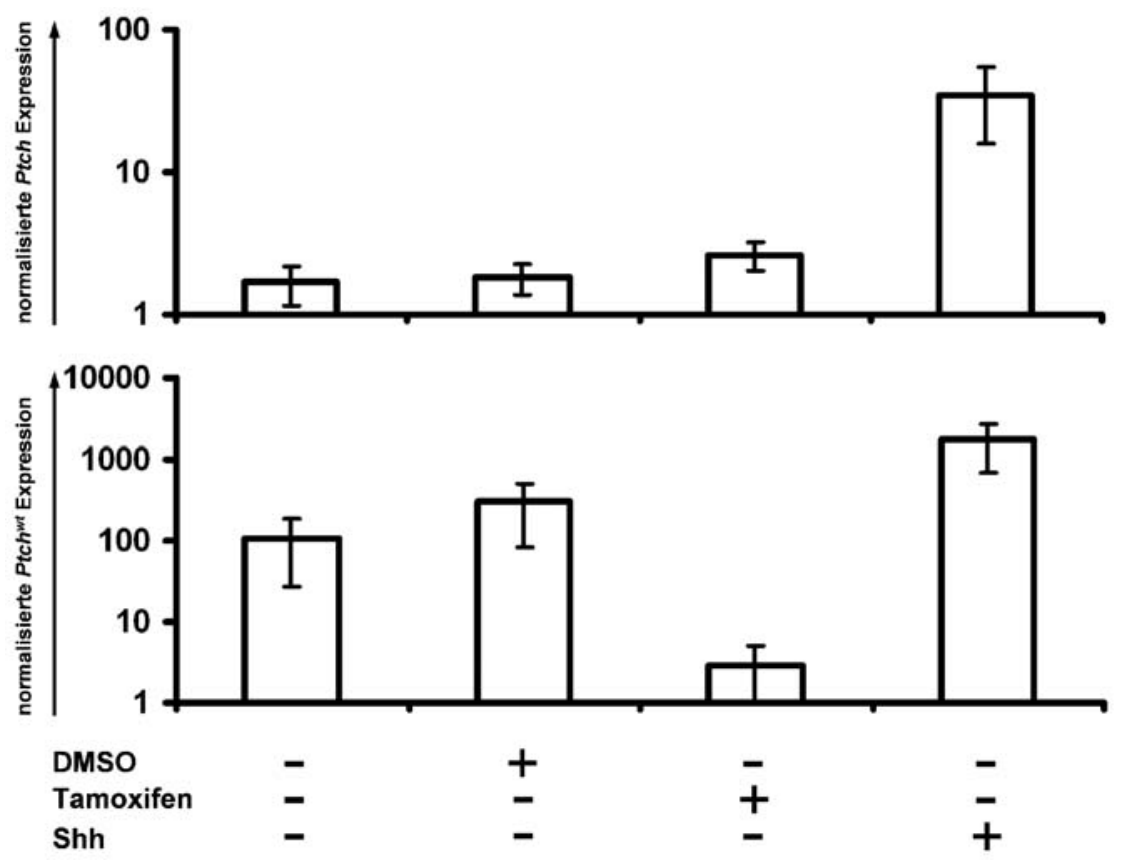

Abbildung 48: Erhöhte Ptch-Expression in B9-Zellen nach Stimulation mit Shh. Die Expression von Ptch und Ptch ${ }^{\text {wt }}$ in B9-Zellen nach Stimulation für $72 \mathrm{~h}$ mit Tamoxifen oder Shh und in unbehandelten oder Lösungsmittel-behandelten Zellen wurde mittels qRT-PCR an cDNA analysiert. Hierzu wurden die Oligonukleotidpaare mPtc10 // mPtc11R und mPtc11 // mPtc-tq Ex8R verwendet und eine Normalisierung anhand der Expression von $18 S$ rRNA durchgeführt. 

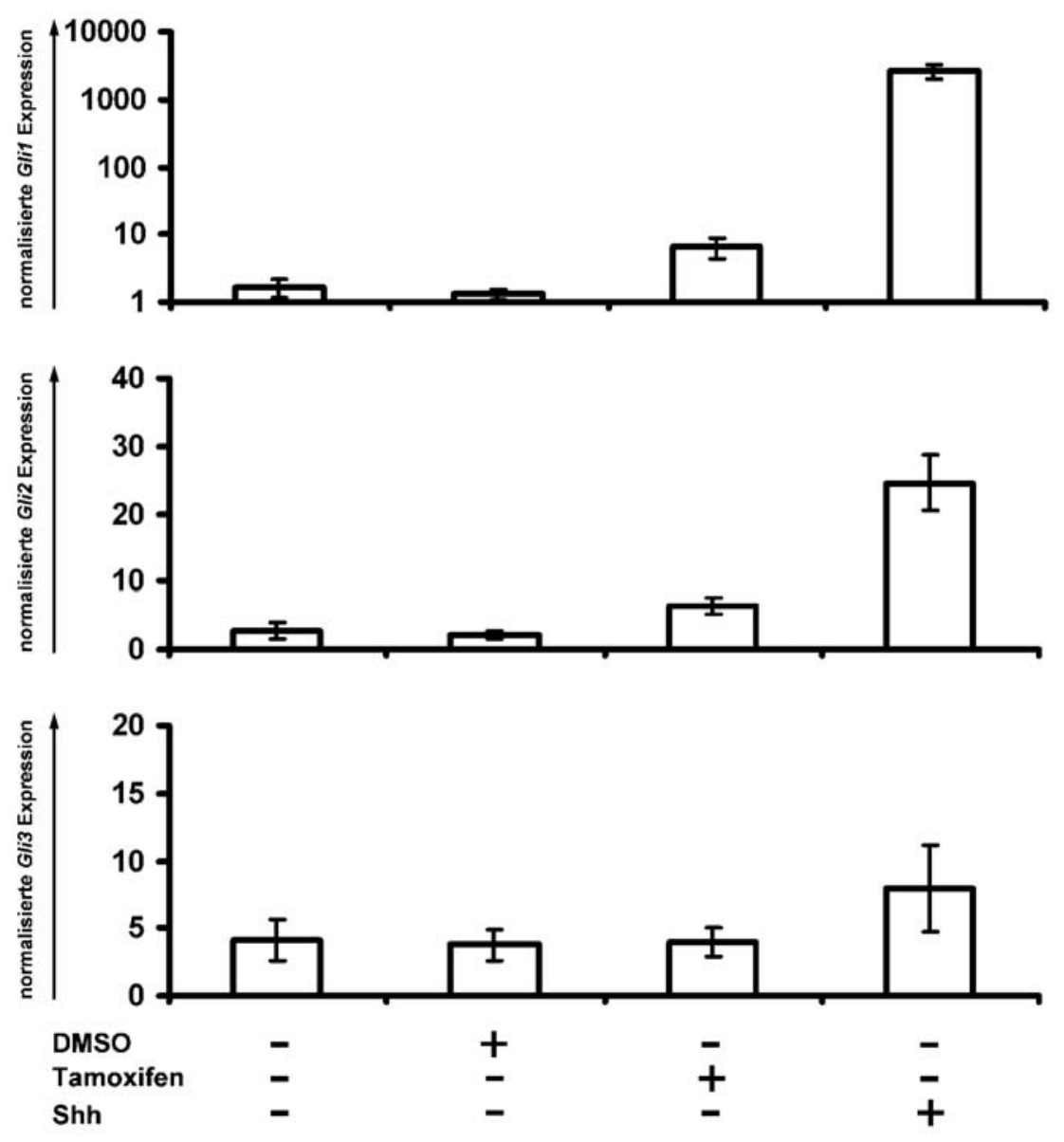

Abbildung 49: Erhöhte Expression von Gli1, Gli2 und Gli3 in B9-Zellen nach Stimulation mit Shh. Gezeigt ist die mittels qRT-PCR an cDNA analysierte Expression von Gli1, Gli2 und Gli3 in B9Zellen nach Stimulation für $72 \mathrm{~h}$ mit Tamoxifen oder Shh und in unbehandelten oder Lösungsmittelbehandelten Zellen. Dafür wurden die Oligonukleotidkombinationen mGli1-tq-f// mGli1-tq-r, mGli2 RT$P C R-F / / m G l i 2$ RT-PCR-R und $m$ Gli3 F2 // $m$ Gli3-SybrgreenR verwendet und eine Normalisierung anhand der Expression von 18S rRNA durchgeführt.

Zusätzlich zu diesen Experimenten konnte gezeigt werden, dass sich die Shh-induzierte Expression von Ptch und Gli1 durch gleichzeitige Zugabe von Cyclopamin hemmen lässt (nicht gezeigt).

Zusammengefasst wurde gezeigt, dass eine Inkubation der B9-Zellen mit Shh nach $72 \mathrm{~h}$ zu einer Aktivierung des $\mathrm{Hh} / \mathrm{Ptch}$-Signalweges führt, die noch effizienter ist als diejenige, die durch eine Tamoxifen-induzierte Rekombination am Ptch-Lokus hervorgerufen wird.

\subsubsection{Charakterisierung der Zelllinien Ptch $^{-/}$und Ptch $^{\text {flox/flox }}$}

\subsection{Expressionsprofile}

Auch in den Zelllinien Ptch ${ }^{-/}$und Ptch flox/flox wurde die Aktivität des Hh/Ptch-Signalweges durch qRT-PCR analysiert. Die Ptch ${ }^{\text {floxflox }}$-Zelllinie kann als eine „normale“ Ptch $^{\text {wt }}$ Zelllinie 
angesehen werden, da sie keine aberranten Ptch-Transkripte exprimiert (Daten nicht gezeigt). Wie in Abbildung 50 gezeigt, ist die Expression von Ptch, Gli1, Gli2 und Gli3 in der Zelllinie Ptch $^{-/}$im Vergleich zu Ptch floxflox-Zellen deutlich erhöht.
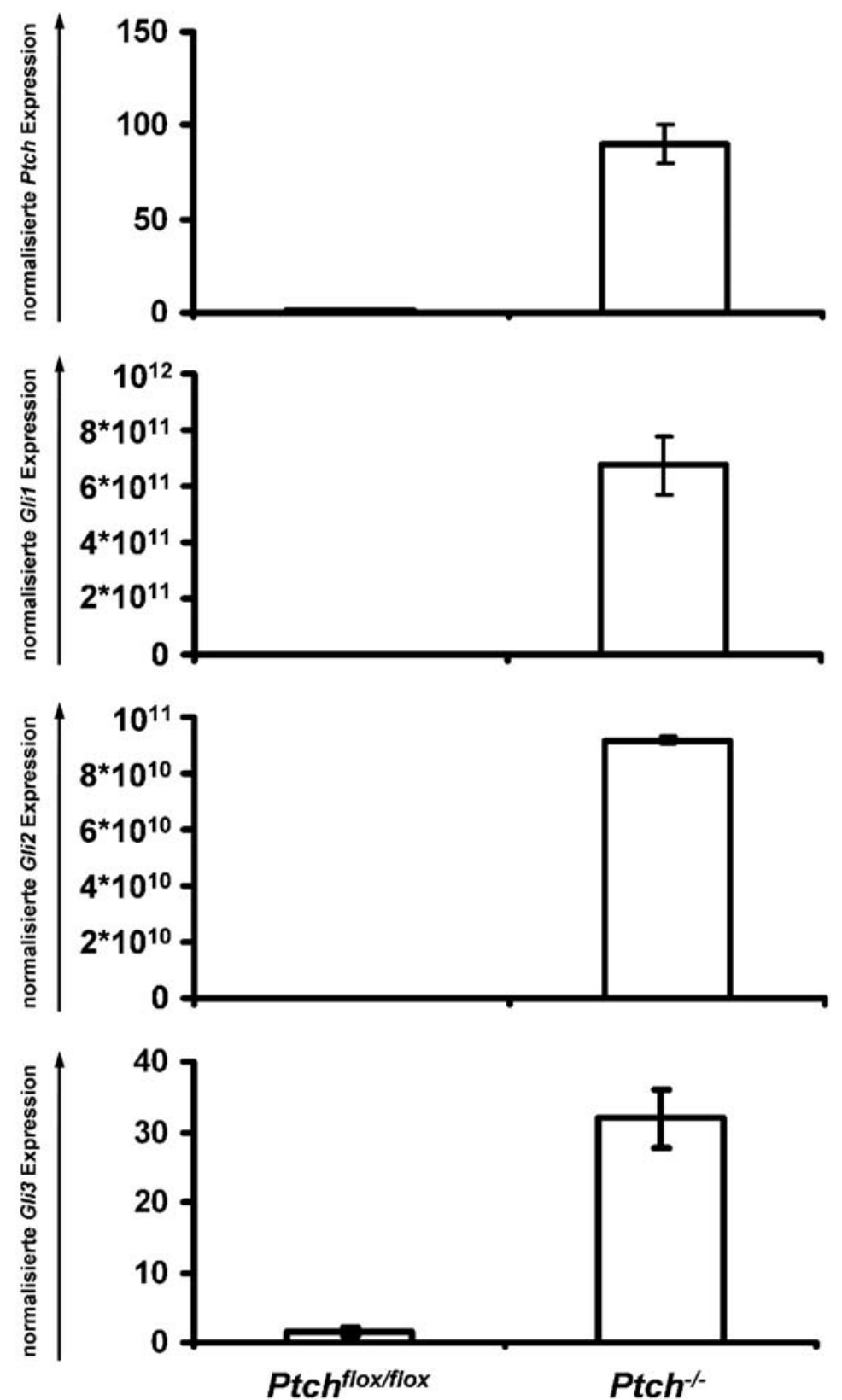

Abbildung 50: Erhöhte Aktivität der Hh/Ptch-Signalkaskade in Ptch $^{-/}$-Zellen. Mittels qRT-PCR wurde die Expression von Ptch, Gli1, Gli2 und Gli3 in Ptch floxflox - und Ptch ${ }^{-/-Z e l l e n ~ a n a l y s i e r t . ~ H i e r f u ̈ r ~}$ wurden die Oligonukleotidkombinationen mPtc10 // mPtc11R, mGli1-tq-f// mGli1-tq-r, RT-PCR-F// $m$ Gli2 RT-PCR-R und $m$ Gli3 F2 // mGli3-SybrgreenR verwendet und die Expression anhand der $18 S$ rRNA normalisiert.

Anhand der Ptch- und Gli1-Expression wurde überprüft, ob sich die Aktivität der Signalkaskade in der Zelllinie Ptch ${ }^{-/}$ebenso wie in B9-Zellen durch die Zugabe von Cyclopamin blockieren lässt. Hierfür wurden die Zellen wie unter 3.2.4.4.3 beschrieben 
mit $5 \mu \mathrm{M}$ Cyclopamin behandelt. Als Kontrollen dienten unbehandelte oder mit Lösungsmittel behandelte Zellen (0,5 \% v/v). Wie in Abbildung 51 gezeigt, war die Expression von Ptch und Gli1 nach Cyclopamin-Gabe deutlich reduziert.

In einem weiteren Experiment konnte gezeigt werden, dass bereits eine Konzentration von $1 \mu \mathrm{M}$ Cyclopamin ausreichte, um die Gli1-Expression zu hemmen (nicht gezeigt).

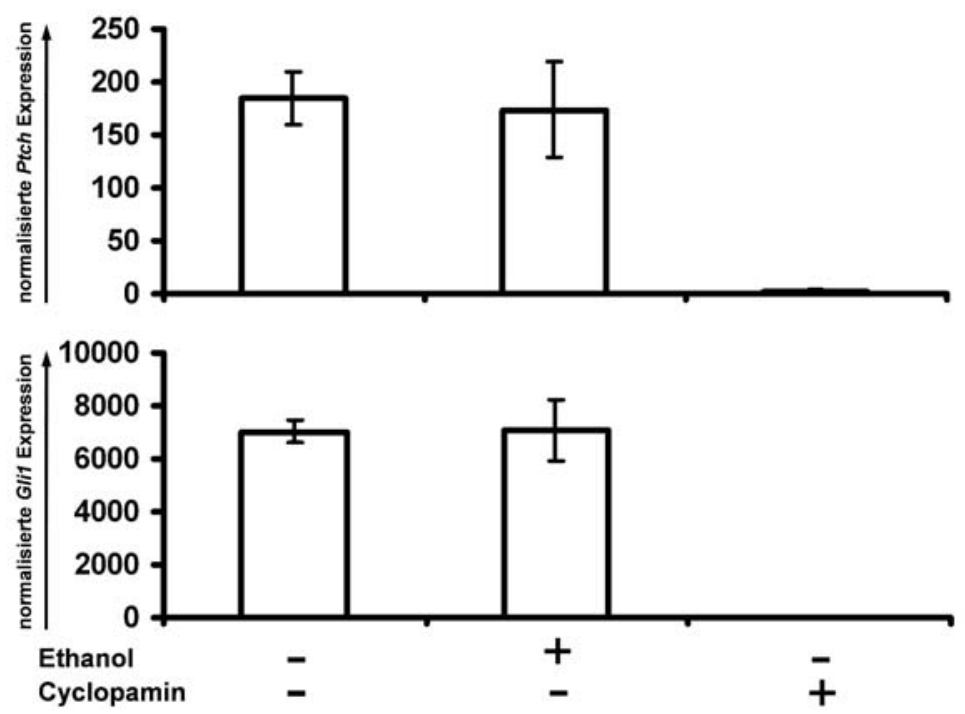

Abbildung 51: Blockade der Ptch- und Gli1-Expression in Ptch ${ }^{-/}$-Zellen durch Cyclopamin. Gezeigt ist die mittels qRT-PCR erhobene Expression von Ptch und Gli1 in Cyclopamin- $(5 \mu \mathrm{M})$ und Lösungsmittel- $\left(0,5 \%\right.$ Ethanol v/v) behandelten Ptch $^{-/}$-Zellen. Die Oligonukleotidkombinationen $m P t c 10 / / m P t c 11 R$ und $m$ Gli1-tq-f// mGli1-tq- $r$ wurden benutzt und die Expression anhand der 18S rRNA normalisiert.

\subsection{Untersuchung der Proliferationsraten}

Da die Zelllinie Ptch $^{-/}$im Vergleich zur Zelllinie Ptch ${ }^{\text {floxflox }}$ eine erhöhte Aktivität der Hh/Ptch-Signalkaskade aufwies, wurde die Proliferationsrate der beiden Zelllinien miteinander verglichen. Die Experimente wurden an zwei unterschiedlichen Passagen je Zelllinie durchgeführt. Dazu wurden 7000 Zellen pro Loch einer 96-Loch Platte ausgesät und $24 \mathrm{~h}$ später für $22 \mathrm{~h}$ mit BrdU inkubiert. Mit Hilfe eines Luminometers wurde die Inkorporation von BrdU gemessen; sie zeigte, wie in Abbildung 52 dargestellt, eine 1,6-fache Erhöhung in $\mathrm{Ptch}^{-/}$- gegenüber $\mathrm{Ptch}^{\text {floxflox }}$-Zellen. Dabei waren keine Unterschiede zwischen verschiedenen Passagen der jeweiligen Zelllinie erkennbar. 


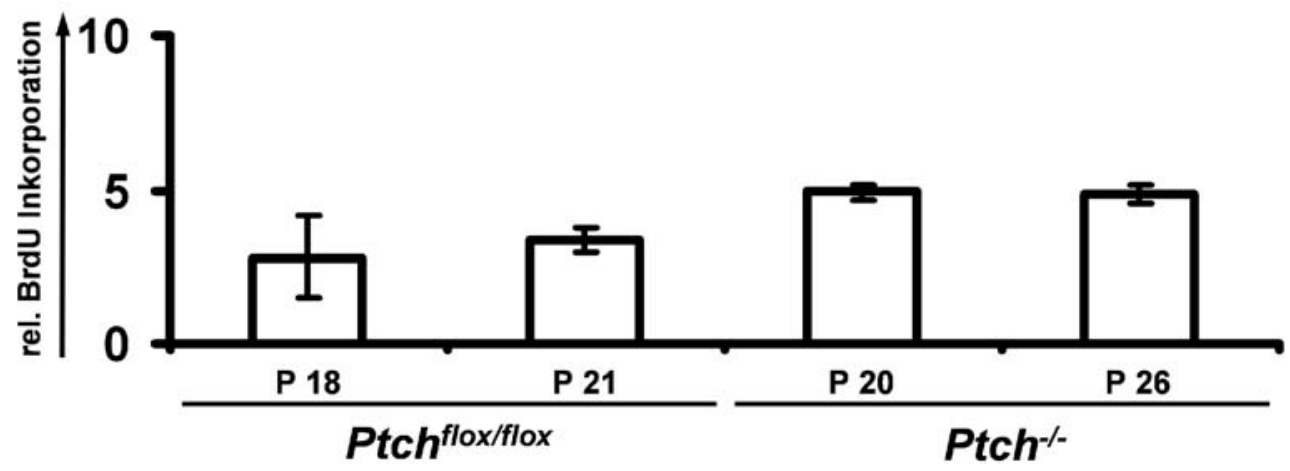

Abbildung 52: Erhöhte Proliferationsrate von Ptch $^{-/-}$-Zellen. Dargestellt ist die relative BrdU Inkorporation in Ptch $^{\text {floxfllox }}$ - und Ptch $^{-/-}$-Zellen nach $22 \mathrm{~h}$ Inkubation mit BrdU. Abkürzung: P, Passage.

Zusammenfassend zeigen die Daten eine stark erhöhte Expression von Ptch, Gli1, Gli2 und Gli3 in $P_{t c h}{ }^{-/}$-Zellen gegenüber Ptch ${ }^{\text {floxfllox}}$-Zellen. Nach Zugabe von Cyclopamin zu $\mathrm{Ptch}^{-/}$-Zellen für $72 \mathrm{~h}$ wurde eine deutliche Inhibition der Gli1-Expression nachgewiesen. Anhand des Vergleiches der Proliferation von Ptch $^{-/}$- und Ptch floxflox-Zellen war eine 1,6-fache Erhöhung der Proliferationsrate der $\mathrm{Ptch}^{-/}$-Zellen erkennbar.

\subsubsection{Zusammenfassung der Zellkulturexperimente}

Um die Funktion von Ptch in Zellkulturexperimenten besser analysieren zu können, wurden im Rahmen dieser Arbeit stabile Zellinien etabliert. Hierbei handelt es sich zum

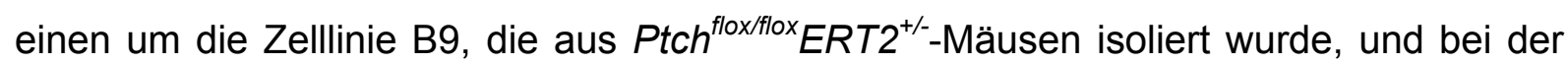
es möglich ist, nach Zugabe von Tamoxifen zum Kulturmedium Ptch zu deletieren. Zum anderen wurden die wt Ptch Zelllinie Ptch floxflox und die Ptch-defiziente Zelllinie Ptch ${ }^{-1-}$ hergestellt.

Die Analyse der Zelllinien zeigt, dass die Zugabe von Tamoxifen zu B9-Zellen innerhalb von $72 \mathrm{~h}$ eine deutliche Rekombination des Ptch ${ }^{\text {flox }}$-Lokus bewirkt. Dennoch bleibt die Expression von Ptch unverändert, wobei jedoch wesentlich mehr Ptch ${ }^{\text {del }}$ - als $P t c h^{\text {wt }}$ Transkripte exprimiert werden. Gli1 und Gli2 werden nach Tamoxifen-Gabe vermehrt exprimiert, wohingegen die Expression von Gli3 konstant bleibt. Durch die gleichzeitige Zugabe von Cyclopamin zu Tamoxifen-behandelten B9-Zellen wird die Tamoxifeninduzierte Erhöhung der Gli1-Expression blockiert.

Im Gegensatz zu Tamoxifen bewirkt die Zugabe von Shh zu B9-Zellen eine deutlich stärkere Induktion der Gli1- und Gli2-Expression sowie eine erhöhte Expression von Gli3.

Wie erwartet, weisen Ptch $^{-1}$-Zellen im Vergleich zu der Zelllinie Ptch floxflox , welche keines der untersuchten Gene exprimiert, eine stark erhöhte Expession von Ptch, Gli1, Gli2 und Gli3 auf. Weiterhin wurde gezeigt, dass die Zugabe von Cyclopamin zu Ptch ${ }^{-/}$-Zellen 
eine deutliche Reduktion der $\mathrm{Ptch}^{\text {del_ }}$ und der Gli1-Expression bewirkt. Die Gegenüberstellung der Proliferationsraten von $\mathrm{Ptch}^{\text {floxfllox }}$ - und $\mathrm{Ptch}^{-/}$-Zellen anhand der BrdU-Inkorporation zeigt eine erhöhte Proliferationsrate der Zelllinie Ptch ${ }^{-/}$. 


\section{Diskussion}

\subsection{BALB-Allele des Lokus Parms1 vermitteln Suszeptibilität für RMS}

Ein Funktionsverlust von Ptch oder andere Störungen des Hh/Ptch-Signalweges bewirken die Entwicklung diverser Tumoren, wie beispielsweise Rhabdomyosarkome (RMS), Medulloblastome (MB) und Basalzellkarzinome (BCC). Wie Vorarbeiten gezeigt haben, entwickeln $\mathrm{Ptch}^{\text {neo67/+}}$-Mäuse diese Tumoren abhängig vom genetischen Hintergrund (J Calzada-Wack et al., 2002). Diese Daten belegen, dass es neben dem Ptch-Lokus, der aufgrund seiner Schlüsselrolle bei Zellwachstum und -differenzierung den hauptsächlichen Tumorsuszepitbilitätslokus darstellt, weitere Genlozi geben muss, die die Suszeptibilität für Ptch-assoziierte Tumoren beeinflussen.

Eine Zielsetzung dieser Arbeit war die Kartierung solcher Gene. Für das Kartierungsprojekt wurden 89 B6x(BALBxB6)Ptch ${ }^{\text {neo67/+ }}$ N2-Mäuse verwendet, die aufgrund der Ptch-Defizienz mit hoher Wahrscheinlichkeit entweder RMS oder MB entwickeln. Für eine initiale genomweite Analyse wurden 97 Mikrosatellitenmarker verwendet. Der Abstand der Marker lag durchschnittlich bei $14 \mathrm{cM}$, was für eine erste genomweite Analyse genügt (A Darvasi et al., 1993). Anhand der Daten war erkennbar, dass multiple Lozi die MB-Suszeptililität beeinflussen. Allerdings waren die entsprechenden LOD-Scores sowie die p-Werte sehr niedrig und konnten daher nur als „hinweisend“ gewertet werden. Deshalb erfolgte keine detaillierte Analyse dieser Lozi.

Dagegen wiesen die Ergebnisse auf einen einzigen RMS-Suszeptibilitätslokus (Parms1) auf dem 2. Chromosom hin, der zwischen den Mikrosatellitenmarkern D2Mit37 und D2Mit102 lokalisiert ist. Aufgrund des signifikanten LOD-Scores von 2,44 für den Marker D2Mit42 erfolgte eine Analyse von elf weiteren Mikrosatellitenmarkern in der Umgebung dieses Markers. Die Auswertung einer Permutationsanalyse (GA Churchill und RW Doerge, 1994; RW Doerge und GA Churchill, 1996) zeigte eine signifikante Korrelation zwischen dem Genotyp B6/BALB in dieser Region und der Suszeptibilität für RMS. Durch das BALB Suszeptibilitäts-Allel verkürzt sich die Latenzzeit für RMS. Da sich weder Morphologie noch Differenzierung der RMS aus Tieren mit dem Genotyp B6/B6 oder B6/BALB an diesem Lokus unterscheiden, beeinflusst Parms1 vor allem die Tumorentstehung, nicht aber die Progression.

Der Abschnitt zwischen D2Mit37 und D2Mit102 ist synthen zu den humanen Chromosomen 2q31-33, 11p11-p13 und 15q14-q15, die mit der Entwicklung von RMS 
assoziiert wurden. So wurde gezeigt, dass in humanen RMS der Verlust oder Zugewinn von chromosomalem Material in diesen Bereichen vorkommt (JA Bridge et al., 2002).

In der Region Parms1, die 7,5 cM umfasst, sind 571 Gene lokalisiert, von denen einige (z. B. Wt1) tatsächlich als Kandidaten für eine Modifikation der RMS-Suszeptibilität in Betracht kommen. Wie unter 3.1.1.1 beschrieben, erfolgte eine SNP- und Expressionsanalyse verschiedener Kandidatengene, die in oder unmittelbar neben Parms1 lokalisiert sind.

Zusammengefasst weisen diese Daten auf die Existenz eines oder auch mehrerer Gene auf dem 2. Chromosom bei Mäusen hin, die die Tiere gegenüber RMS prädisponieren. Aufgrund dieser Daten sollte der Lokus Parms1 in dieser Arbeit mit einer größeren Anzahl an B6x(BALBxB6)Ptch ${ }^{\text {neo67/+ }}$ N2-Mäusen genauer analysiert und möglichst weiter eingeengt werden. Hierzu wurde eine Kolonie von 218 Tieren etabliert und auf die Entwicklung von RMS überwacht. Währenddessen erfolgte die Analyse von elf Kandidatengenen, die in oder unmittelbar neben der Region Parms1 lokalisiert sind.

\subsubsection{Analyse von potenziellen RMS-modifizierenden Genen im Lokus Parms1}

Unter der Annahme, dass Polymorphismen in den zu untersuchenden Kandidatengenen abhängig vom genetischen Hintergrund zu den unterschiedlichen Inzidenzen von RMS in

$\mathrm{Ptch}^{\text {neo67/+}}$-Mäusen führen können, wurden die kodierenden Regionen dieser Gene zwischen den Mausstämmen BALB und B6 miteinander verglichen. Neben SNPAnalysen erfolgte die Untersuchung der Expression von Kandidatengenen der Region Parms1 anhand von TaqMan-Analysen.

SNP-Analysen wurden für die Gene Wt1, Bmf, Disp2 und DIl4 durchgeführt. Zum Zeitpunkt der Analyse waren nur wenige Polymorphismen in diesen Genen bekannt. Mittlerweile sind sämtliche im Rahmen dieser Arbeit gefundenen SNP für den Mausstamm BALB und B6 in verschiedenen Datenbanken angegeben.

Im Mausstamm BALB wurden im Vergleich zu B6 in den Genen Bmf und Wt1 synonyme SNP gefunden, die ohne Auswirkungen auf die Aminosäuresequenz sind. Dagegen wurde in den Genen Disp2 und DIl4 neben synonymen SNP jeweils ein SNP detektiert, der eine Änderung der Aminosäuresequenz bewirkt. Dabei führt eine T-C Transition an der mRNA-Position 3697 im Exon 8 von Disp2 im Mausstamm BALB zu einem SerinProlin Austausch. Disp1 und Disp2 sind Homologe von Ptch, wobei Disp1 am zellulären 
Export von $\mathrm{Hh}$ beteiligt ist (M Evangelista et al., 2006). Laut Literaturangaben spielt Disp2 keine essentielle Rolle in der Hh/Ptch-Signalkaskade (Y Ma et al., 2002; Y Nakano et al., 2004). Dies schließt allerdings eine Funktion bei der Suszeptibilität für RMS nicht aus.

Bei DI/4 findet im Mausstamm BALB durch eine G-A Transition in Exon 9 an der mRNAPosition 1879 ein Glycin-Serin Austausch statt. Dll4 ist ein Aktivator des NotchSignalweges und in der Lage, das Wachstum von Tumoren zu fördern (JR Shutter et al., 2000; JL Li et al., 2007).

Sowohl bei Disp2 als auch DIl4 könnte der Austausch der jeweiligen Aminosäure einen Einfluss auf die entsprechende Proteinfunktion und -struktur nehmen. Disp2 verfügt wahrscheinlich wie Ptch über zwölf transmembrane Domänen (Y Ma et al., 2002). Der nicht-synonyme SNP ist nicht in einer dieser Domänen, sondern in der Nähe des CTerminus lokalisiert. Der Austausch von Serin (hydrophile Aminosäure) durch Prolin (hydrophobe Aminosäure) könnte zu Veränderungen der Proteinfunktion führen.

Bei Dll4 liegt der nicht-synonyme SNP auch in der C-terminalen Region. Interessanterweise verfügt DII4 über eine PDZ-Domäne (von PSD95/SAP90, Discs large und Zonula occludentes-1) (CP Ponting et al., 1997) am C-Terminus (A Pintar et al., 2007). PDZ-Domänen sind für die Interaktion von Proteinen wichtig ( $P$ Jemth und $S$ Gianni, 2007). Ein Funktionsverlust kann gravierende Folgen haben. So verliert z. B. das Gen „Tumor suppressor gene in lung cancer" nach einer Deletion der PDZ-Domäne seine Tumorsuppressoraktivität (X Mao et al., 2003). Der Austausch von Glycin durch Serin bei Dll4 könnte daher durchaus Auswirkungen auf dessen Funktion haben und möglicherweise eine erhöhte RMS-Suszeptibilität bewirken.

Zur weiteren Charakterisierung der Effekte der Kandidatengene Disp2 und DIl4 können auch andere im Rahmen dieser Arbeit erhobene Ergebnisse berücksichtigt werden. Wie im Ergebnisteil dargestellt, wurden Kohorten von DBA2JxB6Ptch ${ }^{\text {neo67/t }}$-, 129SvxB6Ptch ${ }^{\text {ne067/+ }}$ - und FVB/NxB6Ptch ${ }^{\text {neo67/+}}$-Mäusen etabliert. Diese Tiere sollten für eine weitere Eingrenzung des Lokus Parms1 herangezogen werden. Wie bereits unter 3.1.2 beschrieben, wurde erwartet, dass sich die verschiedenen F1-Tiere in den Tumorinzidenzen unterscheiden. Tatsächlich entwickelten $9 \%$ der 129SvxB6Ptch ${ }^{\text {neo67/t }}-$, $32 \%$ der FVB/NxB6Ptch ${ }^{\text {neo67/+ }}$ - und $50 \%$ der DBA2JxB6Ptch ${ }^{\text {neo67/+ }}$-Mäuse RMS. Im Vergleich dazu soll an dieser Stelle nochmals hervorgehoben werden, dass $63 \%$ der (BALBxB6)Ptch ${ }^{\text {neo67/+}-M a ̈ u s e, ~ a b e r ~ k e i n e ~ d e r ~ B 6 P t c h ~}{ }^{\text {neo67/+}}$-Mäuse ein RMS entwickelten. Aufgrund dieser Ergebnisse könnte der Mausstamm 129Sv auf Chromosom 2 Allele aufweisen, die im Vergleich zu B6 konserviert sind, d. h. mit B6 übereinstimmen. Dies 
resultiert aus der Tatsache, dass die RMS-Inzidenz sowohl bei 129SvxB6Ptch ${ }^{\text {neo67/+ }}$ - als auch bei B6Ptch ${ }^{\text {neo67/+ }}$-Mäusen sehr niedrig ist. Dagegen wäre anzunehmen, dass DBA2J-Allele in der Kandidatenregion denjenigen von BALB entsprechen, da beide Mausstämme eine hohe RMS Frequenz aufweisen. Falls kodierende Polymorphismen der Gene Disp2 und DII4 die BALB-vermittelte erhöhte RMS-Suszeptibilität verursachen, würde man annehmen, dass die cSNP von B6 und 129Sv bzw. BALB und DBA2J übereinstimmen.

Daher wurden die cSNP der Gene Disp2 und DIl4 aus der Datenbank MPD für die Mausstämme B6, 129, BALB und DBA2J verglichen. Für Disp2 sind lediglich zwei cSNP bekannt. Bei den Mausstämmen BALB und DBA2J, aber auch bei 129, sind die beiden cSNP gleich und kodieren für die Aminosäuren Prolin und Histidin. Dagegen kodieren diese SNP bei B6 für die Aminosäuren Serin und Arginin. Bei DIl4 existiert nur ein cSNP. Dieser kodiert in den Mausstämmen BALB, DBA2J und in 129 für die Aminosäure Serin, bei B6 dagegen für Glycin. Daher unterscheiden sich die Mauslinien 129 und B6 in der Aminosäuresequenz in Disp2 und DII4. Die niedrige Inzidenz für RMS in diesen beiden Mausstämmen sollte somit eher nicht auf funktionelle Unterschiede dieser Proteine zurückzuführen sein. Dennoch könnten unterschiedliche Expressionslevel von Disp2 oder DIl4 im SM der vier Mauslinien vorliegen und die RMS-Suszeptibilität beeinflussen.

Die Expression von acht weiteren Kandidatengenen aus der Region Parms1 wurde anhand von TaqMan-Analysen an cDNA aus SM von BALB- und B6-Mäusen untersucht. Während die Wt1-Expression zu gering für eine zuverlässige Messung war, zeigten Mdk, Api5, Ptprj und Ehf gleiche Expressionsniveaus in SM von BALB und B6. Hingegen wurde eine ca. 2-fach höhere Expression von Zfp289, Traf6 und Catns im SM von B6 gefunden. Die Expressionsunterschiede dieser Gene könnten daher mit der unterschiedlichen RMS-Suszeptibilität beider Mausstämme in Verbindung stehen. Über das Gen Zfp289 ist bisher wenig bekannt. Möglicherweise besitzt es eine Funktion in der S-Phase des Zellzyklus, da es bei in vitro Experimenten zu einem erhöhten S-Phase Index führt (J Singh et al., 2001). Somit wäre eine erhöhte Proliferation durch die Expression von Zfp289 denkbar. Allerdings wird im SM des Mausstammes BALB weniger Zfp289 als in B6 exprimiert.

Traf6 wird unter anderem in Zellen des Immunsystems exprimiert und dient bei der Signaltransduktion verschiedener Signalwege als Adapterprotein (T Kobayashi et al., 2004; LV Pham et al., 2008). Ein Signalweg, in den Traf6 integriert ist, wurde mit Tumorwachstum, -progression und -metastasierung assoziiert (J Inoue et al., 2007). Auch dieses Gen wird im SM des Mausstammes BALB weniger als in B6 exprimiert. 
Aufgrund der höheren Expression der Gene Zfp289 und Traf6 im SM des Mausstamms B6, der nicht zu RMS prädisponiert, ist ein Zusammenhang dieser Gene mit einer erhöhten RMS-Suszeptibilität unwahrscheinlich.

Die Defizienz von Catns ist mit der Progression von Tumoren assoziiert, und es gibt Hinweise, dass es als Tumorsuppressorgen wirken könnte (MA Davis und AB Reynolds, 2006). Weiterhin wurde sowohl der Verlust von Catns als auch eine verminderte oder anomale Expression in verschiedenen humanen Tumoren beobachtet (MA Thoreson und AB Reynolds, 2002). Daher könnte es als Tumorsuppressorgen durch eine geringere Expression im Mausstamm BALB im Vergleich zu B6 zur erhöhten RMS-Inzidenz beitragen.

Verminderte Expressionslevel von Catns im SM von BALB könnten demnach einen Effekt auf die Suszeptibilität ausüben. Die höhere Expression im SM von B6-Tieren überstieg jedoch nie das 2,5-fache. Trotz dieses geringen Unterschieds könnte Catns durchaus an der erhöhten Parms1-assoziierten RMS-Suszeptibilität beteiligt sein.

Aufgrund der RMS-Resistenz von 129Sv bzw. der RMS-Suszeptibilität von DBA2J hätte man zusätzlich noch die Expression des Gens Catns in diesen Mauslinien untersuchen können. Wenn es tatsächlich die RMS-Suszeptibilität beeinflusst, sollte die Expression im SM von DBA2J - analog zur Expression bei BALB und B6 - niedriger sein als bei 129Sv.

Leider wurden diese Daten jedoch nicht weiter verfolgt. Dies basiert auf der Tatsache, dass die B6-Mäuse für die Zucht der 129SvxB6Ptch ${ }^{\text {neo67/+ }}$, DBA2JxB6Ptch ${ }^{\text {neo67/+ }}$ - und FVB/NxB6Ptch ${ }^{\text {neo67 }}$-Mäuse und für die in 4.2 (s. u.) genannte B6x(BALBxB6)Ptch ${ }^{\text {neo67/+ }}$ N2-Kolonie genetisch kontaminiert waren. Die Generierung der entsprechenden Mauslinien mit neuen, nicht-kontaminierten B6-Mäusen hätte weitere ein bis zwei Jahre gedauert und damit den zeitlichen Rahmen dieser Doktorarbeit überschritten.

\subsubsection{Ausblick}

In dieser Arbeit wurde gezeigt, dass der genetische Hintergrund die Suszeptibilität für Ptch-assoziierte Tumoren stark beeinflusst. Durch eine Kopplungsanalyse wurde der Parms1-Lokus identifiziert, der eines oder mehrere RMS-modifizierende Gene umfasst. Aufgrund der genetischen Kontamination der B6-Mäuse (siehe 4.2) wurde dieses Projekt allerdings nicht abgeschlossen. Es soll an dieser Stelle jedoch festgehalten werden, dass es bei B6-Mäusen, die für die initiale genomweite Analyse benutzt wurden und zur Identifikation des Parms1-Lokus beigetragen haben, keinerlei Hinweise auf eine 
genetische Kontamination gab. Daher wäre es sinnvoll, bei zukünftigen Analysen zu Parms1 an nicht-kontaminierten Mauskreuzungen die Gene Catns, Disp2 und DIl4 weiterhin als Kandidatengene in Erwägung zu ziehen und zu analysieren.

\subsection{Detektion und Charakterisierung der genetischen Kontamina- tion im Mausstamm B6}

Während der Analyse von 97 Mikrosatellitenmarkern in 218 B6x(BALBxB6)Ptch ${ }^{\text {neo67/+ }}$ N2-Mäusen wurde bei $26 \%$ der Tiere eine genetische Kontamination festgestellt. Dabei wiesen die betroffenen Tiere bei einzelnen Markern scheinbar eine Homozygotie für BALB auf. Da N2-Mäuse aus einer Rückkreuzung von (BALBxB6)Ptch ${ }^{\text {neo67/+ }}$-Männchen mit B6-Weibchen stammten, hätten ausschließlich B6/B6- oder BALB/B6-Genotypen auftreten dürfen, keinesfalls jedoch der Genotyp BALB/BALB. Dennoch wurde eine scheinbare Homozygotie für BALB bei $38 \%$ der untersuchten 85 Marker gefunden.

Der Ursprung der scheinbaren BALB/BALB-Genotypen konnte auf eine genetische Kontamination von B6 von Charles River Laboratories zurückgeführt werden. Die Kontamination der B6-Mäuse trat wahrscheinlich im Frühjahr 2003 bei dieser Firma auf. Diese Annahme basiert auf unserer Beobachtung, dass (BALBxB6)Ptch ${ }^{\text {neo67/+ }}$-Mäuse, die vor dem Frühjahr 2003 generiert wurden, keine Kontamination aufwiesen. Alternativ wäre denkbar, dass die Kontamination bei Charles River Laboratories sogar schon früher auftrat, jedoch die für die Generierung der (BALBxB6)Ptch ${ }^{\text {neo67/+ }}$ Hybriden aus einem nicht kontaminierten Raum stammten.

Der Kontaminationsgrad zwischen verschiedenen Zuchträumen von Charles River Laboratories war unterschiedlich. So waren von den beiden Lieferungen von 200558 \% der Tiere aus Zuchtraum A kontaminiert, wohingegen Tiere des Zuchtraums B nur eine $8 \%$ ige Kontamination aufzeigten. Weiterhin war im Vergleich zwischen den Kohorten desselben Zuchtraumes ein Rückgang der Kontamination zwischen 2003 und 2005 erkennbar. So zeigten $67 \%$ der Tiere, die im Jahr 2003 erworben wurden, bei $55 \%$ der analysierten Marker eine Kontamination. Dagegen wurde bei 58 \% der Tiere, die 2005 erworben wurden, nur bei $14 \%$ der Marker eine Kontamination festgestellt.

Insgesamt zeigen die Daten, dass die Kontamination über mindestens zwei Jahre sehr hoch gewesen ist. 


\subsubsection{Identifikation von DBA-Inzuchtlinien als Ursprung der Kontami- nation}

Zur Bestimmung der kontaminierenden Mauslinie wurde eine SNP-Analyse durchgeführt. Anhand von 100 analysierten SNP wurde ein Vergleich zwischen 102 verschiedenen Inzuchtlinien ermöglicht.

Dabei stellte sich heraus, dass eine Kontamination der B6-Mäuse mit einer DBAInzuchtlinie am wahrscheinlichsten war. So stimmten 20 der 21 von B6 abweichenden Allele mit den Mausstämmen DBA/1J, DBA/1LacJ und DBA/2HaSmnJ des Jackson Laboratory überein. Das Allel, das nicht eindeutig einer dieser DBA-Inzuchtlinien zugeordnet werden konnte, könnte auf einem Gendrift zwischen den DBA-Inzuchtlinien des Jackson Laboratories und der kontaminierenden DBA-Mauslinie von Charles River Laboratories beruhen.

Aufgrund dieser Daten kam die Kontamination bei Charles River höchstwahrscheinlich durch eine Verpaarung von B6- und DBA-Mäusen zustande. Wahrscheinlich blieb dieser Zuchtfehler unerkannt, da die resultierende F1-Generation äußerlich wegen der schwarzen Fellfarbe nicht von der Linie B6 zu unterscheiden ist.

Wie uns Charles River Laboratories mitgeteilt hat, wurde die Reinheit der B6-Mäuse lediglich mit sechs Mikrosatellitenmarkern überprüft, dabei wurden keine Auffälligkeiten gefunden. Diese Daten zeigen, dass diese Anzahl von Markern keinesfalls ausreicht, um eine ausreichende Kontrolle von Inzuchtlinien zu gewährleisten.

\subsubsection{Ausblick}

Bei tierexperimentellen Arbeiten mit Mäusen erlauben Inzuchtlinien die Durchführung von Kartierungsexperimenten. Wie unsere Analysen zeigen, ist die hierfür essentielle Authentizität der Inzuchtlinien nicht immer gegeben. Dabei können spontane NeuMutationen, Gendrift oder Zuchtfehler die Ursache sein, wobei letzteres die gravierendsten Auswirkungen haben dürfte. Durch die versehentliche, unbemerkte Verpaarung mit einer anderen Mauslinie kommt es jedoch $\mathrm{zu}$ wesentlichen Veränderungen der Eigenschaften der betroffenen Mauslinie. So ist es möglich, dass Experimente scheinbar unerklärlicherweise nicht mehr reproduzierbar sind. Diese Problematik zeigt die Notwendigkeit einer regelmäßigen und ausreichend detaillierten Überwachung der verwendeten Inzuchtlinien. Im vorliegenden Fall wurde die B6Inzuchtlinie vom Anbieter durch die Analyse von sechs Mikrosatellitenmarkern überprüft, wobei keine Auffälligkeiten festgestellt wurden. Erst durch die Analyse von 29 bis 37 Markern in den betroffenen B6-Tieren im Rahmen dieser Arbeit wurde eine 
Kontamination bei bis zu 18 Markern gefunden. Diese Resultate weisen somit auf die Dringlichkeit einer besseren Überwachung der Erhaltung eines genetischen Hintergrundes, insbesondere bei darauf basierenden Experimenten, hin.

\subsection{Unterschiedliche Expressionsmuster von RMS aus $\mathrm{CD} \mathrm{Ptch}^{\text {neo67/+}}$ - und (BALBXB6)Ptch ${ }^{\text {neo67/+}}$-Mäusen}

Wie oben ausführlich diskutiert, nimmt der genetische Hintergrund Einfluss auf die Tumorprädisposition. Es ist daher zu erwarten, dass sich das Genexpressionsprofil einer Tumorentität unterscheidet, wenn der Tumor auf unterschiedlichem genetischen Hintergrund propagiert wird. Eine Mikroarray-Expressionsanalyse an RMS aus CD1Ptch ${ }^{\text {neo67/+ }}$ - und (BALBxB6)Ptch ${ }^{\text {neo67/+ }-M a ̈ u s e n ~ z e i g t, ~ d a s s ~ d a s ~ t a t s a ̈ c h l i c h ~ d e r ~ F a l l ~ i s t . ~}$ Eine erste hierarchische Clusteranalyse erlaubte eine eindeutige Zuordnung der Tumoren zum genetischen Hintergrund (CD1 und BALBxB6). Dagegen unterscheiden sich die Expressionsprofile von syn- oder metachronen Tumoren so stark voneinander, dass sie über die Clusteranalyse nicht einem Tier zugeordnet werden konnten.

Diese Daten sollen nun in ein Projekt einfließen, bei dem untersucht werden soll, ob die genetische Ausstattung eines Patienten den wichtigeren Aspekt bei einer Tumortherapieantwort ausmacht oder aber die somatischen, genetischen Veränderungen im Tumor den wichtigeren Aspekt darstellen. Hierzu sollen die RMS mit dem Anthrazyklin Doxorubicin behandelt werden. Wie aus anderen Vorversuchen bekannt ist, bleiben einige RMS gegenüber der Behandlung mit Doxorubicin resistent. Eine solche Therapieresistenz auf genetisch-identischem Hintergrund muss auf die genetische Tumorvariabilität zurückgeführt werden. Sollte die Variabilität beim Vergleich zweier Mausstämme weiter ansteigen, spielt das Wirtsgenom bei der Therapieantwort auf Doxorubicin eine Rolle. Über den Vergleich von Genexpressionsprofilen sollen der Anteil der genetischen Tumor-Variabilität sowie der genetischen Wirts-Variabilität am Therapieerfolg bestimmt werden. Zusätzlich sollen Gene identifiziert und charakterisiert werden, die beim Ansprechen der Tumoren auf Doxorubicin mitwirken.

\subsection{Charakterisierung der Ptch $^{\text {flox }}$-knockout-Maus und Induktion von BCC}

BCC sind die häufigsten Tumoren des Menschen und die Rate der Neuerkrankungen nimmt weiterhin zu. Eine Fehlregulation der Hh/Ptch-Signalkaskade in der Haut bewirkt auch in verschiedenen Mausmodellen die Bildung von BCC. So entstehen BCC in Shh transgenen Mäusen, die dieses Gen unter der Kontrolle des hautspezifischen K14- 
Promotors exprimieren (AE Oro et al., 1997). Ebenso entstehen BCC in K5 GLI-1-, K5-tTA;TRE-Gli2- und Krt6a-Cre:Ptch ${ }^{\text {neo/neo }}$-Mäusen (M Nilsson et al., 2000; ME Hutchin et al., 2005; C Adolphe et al., 2006).

In heterozygoten Ptch $^{\text {neo67/+ }}$-Mäusen dagegen können BCC erst durch eine Bestrahlung der Tiere hervorgerufen werden (M Mancuso et al., 2004; S Pazzaglia et al., 2004). Hierdurch werden natürlich viele unspezifische, strahlungsbedingte molekulare Veränderungen in der Haut verursacht. Die Entwicklung von BCC in diesen Tieren kann daher nicht unbedingt alleinig auf den Effekt einer Ptch-Mutation zurückgeführt werden. Um die exakte Rolle von Ptch bei der Initiation und Progression von BCC untersuchen zu können, wurde im Rahmen dieser Arbeit zunächst an der Analyse eines konditionellen $P t c h^{\text {flox }}$-knockout mitgewirkt und dann untersucht, ob sich in diesem Tiermodell BCC induzieren lassen.

\subsubsection{Phänotyp- und Transkriptanalysen}

$P t c h^{\text {flox/flox }}$-Tiere sind fertil und phänotypisch normal. Weiterhin entwickeln sie keine Tumoren. In allen untersuchten Organen wurden ausschließlich Ptch ${ }^{\text {wt }}$-Transkripte nachgewiesen, dementsprechend sind Transkription und Spleißen von Ptch mRNA nicht beeinträchtigt. Dies bedeutet, dass die loxP-Sequenzen in Intron 7 und 9 sowie die neoKassette keine Auswirkung auf das resultierende Ptch-Protein haben können.

Wird das Ptch $^{\text {flox }}$-Allel jedoch in der Keimbahn deletiert, weisen sowohl die resultierenden

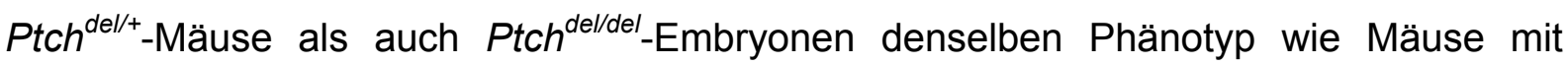
Ptch ${ }^{\text {neo67 }}$ - oder Ptch ${ }^{\text {neo12 }}$-Mutation auf (LV Goodrich et al., 1997; H Hahn et al., 1998). So

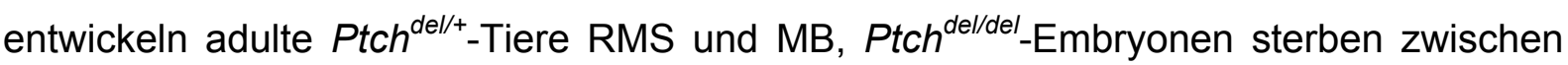
9,0 und 10,5 dpc nach der Befruchtung in utero aufgrund von Neuralrohrdefekten ab.

Transkriptanalysen an RMS von $\operatorname{Ptch}^{\text {del/+ }}$-Mäusen und an $P t c h^{\text {del/del }}$-Embryonen am Tag 9,5 bis 10,5 dpc zeigen, dass im Ptch ${ }^{\text {del }}$-Transkript Exon 7 in Exon 10 gespleißt wurde. Hierdurch entsteht eine Leserasterverschiebung, die zu einem vorzeitigen Stopcodon

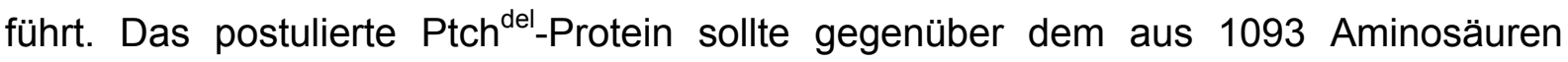
bestehenden Ptch $^{\text {wt }}$-Protein nur aus 341 Aminosäuren bestehen. Daher fehlt diesem Protein, das ein molekulares Gewicht von 38 kDa aufweisen sollte, die SSD, die zweite extrazelluläre Schleife und der C-Terminus. Obwohl der Nachweis eines solchen Proteins aufgrund des Fehlens eines geeigneten Antikörpers nicht möglich war, kann man anhand des Phänotyps von Ptch $^{\text {del/t+}}$-Mäusen annehmen, dass das Ptch ${ }^{\text {del }}$-Protein keine Funktion mehr hat. 


\subsubsection{Induktion von BCC}

Um eine Deletion von Ptch in der Haut zu ermöglichen, wurden Ptch ${ }^{\text {floxflox }}$-Mäuse mit ROSA26ERT2-Mäusen, die eine Tamoxifen-induzierbare Cre-ERT2 exprimieren, verpaart. Ptch ${ }^{\text {flox/flox }} E R T 2^{+/-}$-Nachkommen wurde zunächst eine kumulative Dosis von 5 mg Tamoxifen i.p. injiziert. Die als $t P t c h^{-/}$bezeichneten Tiere konnten aufgrund einer rapiden Verschlechterung der körperlichen Verfassung über höchstens 23 Tage beobachtet werden.

Wie molekulare Analysen zeigten, war Ptch in $\mathrm{Ptch}^{--}$-Mäusen in vielen der untersuchten Organe mit Ausnahme von Groß- und Kleinhirn deletiert (A Uhmann et al., 2007). Die fehlende Deletion von Ptch in Groß- und Kleinhirn beruht auf einer mangelnden oder geringen Expression der Cre-ERT2 in diesen Geweben (D Hameyer et al., 2007).

In den Ptch $^{-/}$-Mäusen wurde eine Hyperproliferation der Magenwand und des Mesenteriums festgestellt. Daher könnte Ptch an der Entstehung von Magentumoren oder mesenterialen Tumoren beteiligt sein. Tatsächlich wurde in Tumoren des Verdauungstraktes (DM Berman et al., 2003), z. B. des lleums (V Fendrich et al., 2007), sowie in kolorektalen Tumoren (R Douard et al., 2006; YH Bian et al., 2007) eine erhöhte Aktivität des Hh/Ptch-Signalweges nachgewiesen. Bisher wurde jedoch nicht gezeigt, ob Ptch-Mutationen an der Ausbildung dieser Tumoren beteiligt sind. Die in dieser Arbeit gezeigten Daten an Ptch $^{\text {floxfllox }}$ ERT2 ${ }^{+/-}$-Mäusen lassen dies aber vermuten.

Der Entwicklungsdefekt der allgemeinen lymphoiden Vorläuferzellen im Knochenmark bei diesen Mäusen wurde bereits in der Dissertation von Anja Uhmann (2005) ausführlich diskutiert.

Weiterhin wurden in $\mathrm{tPtch}^{-/}$-Mäusen proliferative Veränderungen in der interfollikulären und follikulären Epidermis detektiert, bei denen es sich um Vorläuferläsionen von BCC handelte.

\subsubsection{Entstehung von BCC nach i.m. Applikation von $100 \mu \mathrm{g}$ Tamoxifen}

Wie bereits erwähnt, mussten Ptch $^{-/}$-Tiere am Tag 23 nach der Applikation von $5 \mathrm{mg}$ Tamoxifen abgetötet werden (siehe 3.2.1.3.2). Die Progression der Vorläuferläsionen zu voll-ausgebildeten BCC war in diesem Modell daher nicht zu verfolgen. Interessanterweise war dies jedoch in Ptch $^{\text {floxfflox }} E R T 2^{+/-}$-Mäusen nach einer einmaligen i.m. Injektion von $100 \mu \mathrm{g}$ Tamoxifen möglich.

Etwa 45 Tage nach der Tamoxifen-Applikation waren hyperproliferative Veränderungen der Ohr- und Schwanzhaut erkennbar, die sich 90 Tage nach der Injektion zu massiven BCC ausgebildet haben. Zusätzlich wurden an den Fußsohlen Trichoblastome 
festgestellt. In der behaarten Haut entwickelten sich in Einzelfällen BCC-Vorläuferläsionen, aber keine BCC.

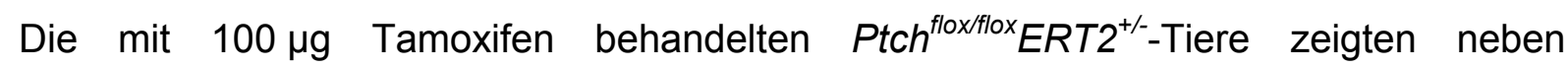
Hauttumoren keine weiteren Organveränderungen, obwohl in Experimenten mit ROSA26ERT2 ${ }^{+/} ;$ROSA26- $R^{+/-}$-Reportermäusen eine schwache Aktivierung der CreERT2 in Leber, Milz und Lunge detektiert wurde. Es kann daher angenommen werden, dass in diesen Organen die Ptch-Inaktivierung bei i.m. behandelten Ptch $^{\text {floxflox }}{ }^{\text {ERT2 }}{ }^{+/}$Mäusen für eine pathologische Aktivierung der Signalkaskade nicht ausreichend ist. Überraschenderweise entwickeln sich in diesen Tieren keine RMS. Wie Daten von Arne Zibat (AG Hahn) zeigen, wird Ptch jedoch effektiv durch die i.m. Gabe im injizierten Muskel deletiert. Diese Ergebnisse lassen vermuten, dass die Ursprungszellen für RMS nicht im adulten Muskel zu suchen sind.

Das Ausbleiben von BCC in behaarten Hautregionen lässt sich möglicherweise mit Hilfe der Reportermäuse erklären. In diesen Mäusen ließ sich die Cre-ERT2 durch eine i.m. Injektion von $100 \mu \mathrm{g}$ Tamoxifen sehr viel besser in Ohren und Schwänzen der Tiere, d. h. in unbehaarter Haut, als an behaarten Körperstellen aktivieren. Ursache dafür war jedoch nicht eine fehlende Expression oder fehlende Aktivierbarkeit der Cre-ERT2 in behaarter Haut. Eine mögliche Erklärung für die stärkere Cre-ERT2-Aktivität in unbehaarter Haut ist eine höhere Durchblutung der Ohren und Schwänze im Vergleich zu behaarten Hautarealen. Faktoren wie der Kontakt mit Einstreu könnten hierbei auch eine Rolle spielen. Durch eine bessere Durchblutung könnte mehr Tamoxifen anfluten und die Cre-ERT2 besser aktiviert werden.

Jedoch könnte auch ein Unterschied der BCC-Suszeptibilität zwischen behaarter und unbehaarter Haut vorliegen. So entwickeln beispielsweise $\triangle K 5-M 2 S M O-$ und K5-Gli2Mäuse, in denen mutantes SMO bzw. Gli2 unter der Kontrolle eines hautspezifischen Promotors exprimiert wird (M Grachtchouk et al., 2000; V Grachtchouk et al., 2003), BCC vorwiegend an der Schwanzhaut. Der K5-Promotor ist jedoch sowohl in unbehaarter als auch behaarter Haut aktiv (H Sheng et al., 2002). Weiterhin wird er nicht durch die i.p. oder i.m. Gabe von Induktoren aktiviert. Diese Daten sprechen für die Existenz von Faktoren, die eine erhöhte BCC-Suszeptibilität von unbehaarter Haut gegenüber behaarter Haut verursachen. 


\subsubsection{Initiation und Progression von BCC}

Aufgrund der Analysen von BCC aus K14-Shh-, K5-tTA;TRE-Gli2- und Krt6aCre:Ptch ${ }^{\text {neo/neo }}$-Mäusen wurde bisher angenommen, dass BCC aus Zellen des Haarfollikels (ME Hutchin et al., 2005), aus Basalzellen der Epidermis (AE Oro et al., 1997) oder aus beiden Strukturen entstehen (C Adolphe et al., 2006). In letzteren Tiermodellen wurde die Induktion von BCC durch eine gewebs- bzw. zellspezifische Fehlregulation des Hh/Ptch-Signalweges durch den K14-, K5- oder den Keratin 6a (K6a)-

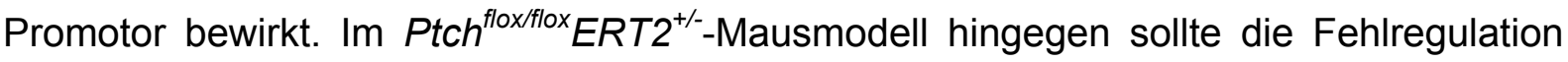
nicht auf einzelne Zelltypen der Haut beschränkt sein, obwohl dies bislang nicht explizit nachgewiesen wurde.

Zur Untersuchung, ob BCC aus der ORS des Haarfollikels oder aus Basalzellen der Epidermis entstehen, wurden in dieser Arbeit p63- und K17-Antikörperfärbungen an BCC-Vorläuferläsionen und späteren Stadien durchgeführt.

In der Epidermis werden p63 und K17 in der ORS exprimiert. Zudem wird p63 auch in den Basalzellen exprimiert. Falls BCC nun aus der ORS entstehen, würde man erwarten, dass BCC beide Marker exprimieren. Falls BCC nur aus Basalzellen entstehen, sollten

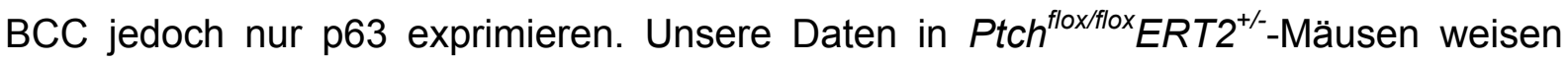
darauf hin, dass alle voll-ausgebildeten BCC sowohl p63 als auch K17 exprimieren. Weiterhin war p63 stets in sämtlichen interfollikulären Vorläuferläsionen exprimiert, wohingegen nicht alle dieser Läsionen K17 exprimierten. Dies ist ein Hinweis darauf, dass sich BCC neben der ORS auch aus Basalzellen entwickeln können.

Dagegen wurde die IRS als Ursprung für BCC ausgeschlossen, da weder K1 noch K10 in 45 oder 90 Tage alten BCC exprimiert wurden.

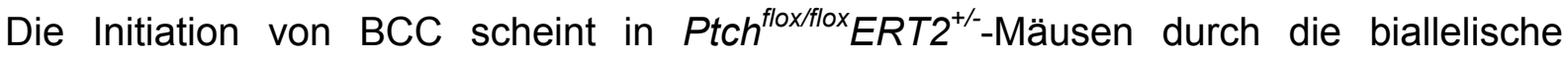
Deletion von Ptch ausgelöst zu werden. Dies wurde zunächst anhand von Tamoxifen-

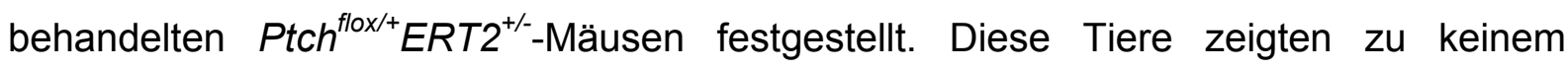
Zeitpunkt Hautveränderungen oder andere Anomalien. Somit scheint eine monoallelische Inaktivierung von Ptch nicht für eine Induktion von BCC auszureichen.

BCC ließen sich dagegen in $P_{t c h}{ }^{\text {flox/flox }} E R T 2^{+/-}$-Mäusen induzieren und die durchgeführten in situ-Hybridisierungen zeigten, dass diese Tumoren keine Ptch ${ }^{\text {wt }}$ Transkripte mehr exprimierten. Daher scheint eine biallelische Deletion von Ptch für die Initiation von BCC notwendig zu sein. 
Während ihrer Progression zu voll-ausgebildeten BCC zeigten die Tumoren von $\mathrm{Ptch}^{\text {floxfllox }} E R T 2^{+/-}$-Mäusen nur eine schwache, lokal begrenzte Expression von p53. Da die Expression von p53 durch genomische Instabilität aktiviert wird (DM Shin et al., 2001), bedeutet dies, dass in den Tumoren keine dramatischen somatischen Veränderungen stattgefunden haben können. Letzteres wird auch dadurch deutlich, dass die BCC zu keinem Zeitpunkt einen invasiven Charakter zeigten und regredient waren.

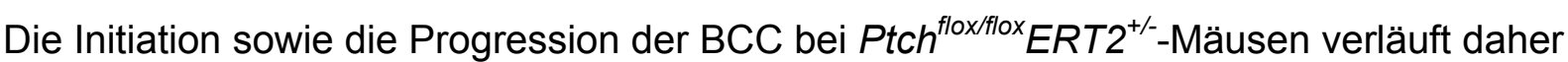
völlig anders als bei bestrahlen Ptch ${ }^{\text {neo67/+}}$-Mäusen.

In Ptch $^{\text {neo67/+}}$-Mäusen werden durch die Bestrahlung natürlich viele Mutationen in den verschiedensten Genen hervorgerufen, was zur Aktivierung und damit zur Expression von p53 führt (M Mancuso et al., 2004). Eine verstärkte Expression von p53 kann aber auch durch einen gestörten Abbau dieses Proteins beim Vorliegen von Mutationen hervorgerufen werden (J Gu et al., 2001). Tatsächlich wurden in $40 \%$ der BCC aus bestrahlten $\mathrm{Ptch}^{\text {neo67/+}}$-Mäusen p53-Mutationen gefunden (M Aszterbaum et al., 1999). Daher wird p53 sowohl in voll-ausgebildeten als auch infiltrativen BCC von bestrahlten $\mathrm{Ptch}^{\text {ne067/+}}$-Mäusen deutlich exprimiert (M Mancuso et al., 2004). Interessanterweise ist ein aggressiveres Wachstumsmuster dieser BCC nicht mit der Expression von p53, sondern mit dem Ptch-Status assoziiert. So zeigen ausschließlich invasive BCC einen biallelischen Verlust von Ptch (LOH des Ptch-Lokus), wohingegen nodulläre BCC lediglich einen monoallelischen Ptch-Verlust aufweisen. In diesem Modell wurde daher postuliert, dass ein biallelischer Verlust von Ptch nicht mit der Initiation, sondern mit der Tumorprogression und der Entstehung von aggressiven BCC in Verbindung steht.

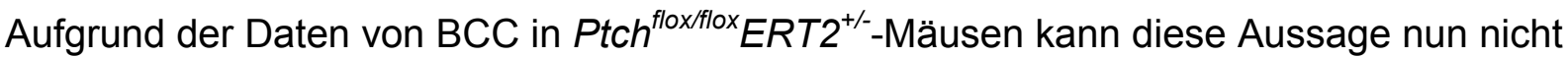
mehr gehalten werden. So scheint in Ptch $^{\text {floxflox }} E R T 2^{+/-}$-Mäusen die biallelische PtchInaktivierung die Voraussetzung für die BCC Initiation zu sein. Sie scheint aber nicht mit dem aggressiven Charakter der Tumoren in Verbindung zu stehen.

\subsubsection{Spontane Regression und Differenzierung von BCC}

BCC zeigten $\geq 200$ Tage nach ihrer Induktion eine spontane Regression, die sich durch eine Trichoblastom-ähnliche Morphologie, durch einen differenzierteren Phänotyp und in den meisten Fällen durch einen dramatischen Rückgang des Tumorvolumens auszeichnete. Wie bereits erörtert, erfolgte diese Regression, obwohl Ptch im Tumorgewebe in allen untersuchten Tumorstadien biallelisch deletiert war. 
Bisher wurde die Regression von Hh/Ptch-assoziierten BCC nur in K5-tTA;TRE-Gli2Mäusen beschrieben (ME Hutchin et al., 2005). In diesen Tieren entstehen BCC durch die Expression von Gli2, welches unter einem aktivierbaren K5-Promotor exprimiert wurde. Eine Regression der Tumoren erfolgt nach Inaktivierung des Promotors und damit der Inaktivierung der Gli2-Expression. In diesem Modell korreliert die Regression mit einer Inaktivierung der Aktivität der Hh/Ptch-Signalkaskade, was durch eine verminderte Expression von Ptch und Gli1 deutlich wird, sowie mit einer Abnahme der Proliferation und einer erhöhten Apoptoserate.

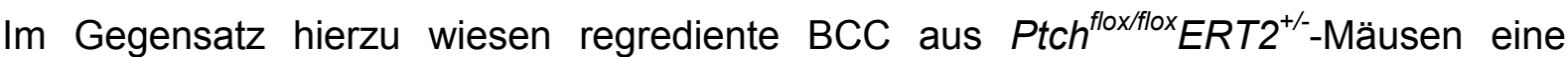
konstitutiv aktive Hh/Ptch-Signalkaskade auf. Möglicherweise erfolgte eine leichte Aktivitätsabnahme in den regredienten Stadien. Weiterhin korrelierte die Regression der BCC von Ptch ${ }^{\text {floxfllox }}$ ERT2 ${ }^{+-}$-Mäusen zwar mit einem Rückgang der Proliferation, nicht jedoch mit einer Zunahme der Apoptoserate. Letzteres wurde nicht nur durch fehlende Caspase-3-Aktivierung, sondern auch durch eine hohe Expression des antiapoptotischen Bcl-2 deutlich. An der Regression der BCC könnte natürlich auch ein Caspase- oder Bcl2-unabhängiger programmierter Zelltod beteiligt sein (G Kroemer und SJ Martin, 2005). Weiterhin sollte man Autophagie in Erwägung ziehen ( $Y$ Tsujimoto und $S$ Shimizu, 2005), zumal kürzlich gezeigt wurde, dass der autophagische Zelltod auch in Zellen erfolgt, die eine Expression antiapoptotischer Proteine wie $\mathrm{Bcl}-2$ aufweisen (S Shimizu et al., 2004).

Aufgrund verschiedener Publikationen ist auch ein Zusammenhang zwischen der Regression von BCC und der kanonischen Wnt-Signaltransduktion denkbar (F Yamazaki et al., 2001; G Saldanha et al., 2004; M Salto-Tellez et al., 2006). Demnach hätte eine Abnahme der Aktivität des kanonischen Wnt-Signalwegs eine Regression bewirkt. Eine Beteiligung dieses Signalweges bei der BCC Regression konnte jedoch eindeutig ausgeschlossen werden.

Des Weiteren wurde untersucht, ob regrediente BCC eine vermehrte Infiltration mit Zellen des Immunsystems aufweisen. Diese Untersuchung basierte auf den folgenden Sachverhalten: i) Es ist bekannt, dass eine Immunsuppression nach Organtransplantationen das Risiko für BCC erhöht (V Madan et al., 2006; J Rawlins et al., 2006). ii) Zu den wesentlichen BCC Risikofaktoren gehört UV-Strahlung, die neben der Induktion von Mutationen auch eine Suppression des Immunsystems bewirkt (S Beissert et al., 2001). iii) Weiterhin sind BCC mit dem Immunmodulator Imiquimod therapierbar (D Bilu und DN Sauder, 2003). iv) Bei humanen BCC wird eine spontane 
Regression mit einer Reaktion des Immunsystems assoziiert. Häufig werden hierbei inflammatorische Infiltrate von Lymphozyten (P Kaur et al., 2006) bzw. T-Zellen gefunden (PJ Lespi und SD Gregorini, 2000; HG Kaporis et al., 2007). v) Der Haarfollikel verfügt als einzige Struktur der Haut über ein Immunprivileg, das auf den Zeitraum des Anagens beschränkt ist. Dieses Immunprivileg äußert sich unter anderem durch eine niedrige Expression des Haupthistokompatibilitätskomplexes I, die Beeinträchtigung Antigen-präsentierender Zellen und die lokale Produktion von immunsupprimierenden Substanzen (R Paus et al., 2005). Möglicherweise kann daher das Immunsystem die Entstehung von Tumoren, die aus diesen Zellen zum Zeitpunkt des Anagens entstehen können (wie z. B. auch das BCC), nicht verhindern.

Die Analyse von BCC der Ptch flox/flox ERT2 ${ }^{+/}-$Mäuse zeigte, dass die Regression von BCC unabhängig von einer vermehrten Infiltration mit Immunzellen (einschließlich B- und TZellen sowie Makrophagen) stattfindet. Diese Analysen lassen jedoch keine Aussage zu, ob die infiltrierenden Immunzellen der regredienten BCC vermehrt anti-tumorale Zytokine, wie beispielsweise Gamma-Interferon, Interleukin-2 und Tumornekrosefaktor- $\beta$, ausschütten. Für diese Zytokine ist ein erhöhter Expressionslevel in regredienten BCC gezeigt worden (DA Wong et al., 2000). Auch eine vermehrte Sekretion von Interleukin12 käme in Betracht, weil im Mausmodell eine komplette Remission von Tumormetastasen durch dieses Zytokin gezeigt wurde (M Zabala et al., 2004).

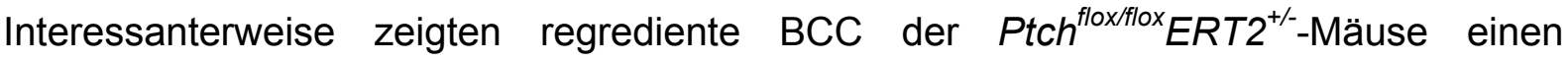
differenzierteren Phänotyp als voll-ausgebildeten BCC 90 Tage nach der Induktion. Dies war sowohl histologisch als auch molekular durch die Expression von $\mathrm{K} 1$ und $\mathrm{K} 10$ offensichtlich.

Bisher wurde über eine Expression von K1 oder K10 in BCC nur selten berichtet. Dabei wurden die Marker höchstens lokal sehr begrenzt oder in keratinhaltigen Zysten im Tumorgewebe exprimiert (O Yamamoto und M Asahi, 1999; F Remotti et al., 2001; ME Hutchin et al., 2005). Im Gegensatz dazu werden beide Marker in Plattenepithelkarzinomen (engl.: „squamous cell carcinoma“ - SCC) exprimiert (BK Bloor et al., 2001). SCC sind maligne Tumoren, die im Gegensatz zu den semimalignen BCC häufiger metastasieren. Daher wurde eine Metaplasie von BCC zu SCC angesichts der K1- und K10-Expression in späten Stadien in Erwägung gezogen. Die Histologie der Tumoren von Ptch $^{\text {floxflox }} E R T 2^{+/-}$-Mäusen spricht jedoch eindeutig dagegen. 
Der Auslöser für die Expression von $\mathrm{K} 1$ und $\mathrm{K} 10$ in den regredienten $\mathrm{BCC}$ der $\mathrm{Ptch}^{\text {floxfflox }} E R T 2^{+/-}$-Mäuse ist momentan unbekannt. Da jedoch eine inaktive Hh/PtchSignalkaskade die Expression von $K 10$ aktiviert (G Regl et al., 2004; S Tamiji et al., 2005), könnte eine Aktivitätsabnahme des Hh/Ptch-Signalwegs in den BCC der $\mathrm{Ptch}^{\text {flox/flox }} \mathrm{ERT2}^{+/-}$-Mäuse direkt mit der vermehrten $\mathrm{K} 10$-Expression in Verbindung stehen. Ob die Aktivität des Hh/Ptch-Signalwegs in regredienten BCC tatsächlich abnimmt, ist - wie bereits beschrieben - bisher nicht eindeutig bewiesen.

Weiterhin ist unbekannt, ob $\mathrm{K} 1$ oder $\mathrm{K} 10$ die Proliferation von BCC Tumorzellen hemmen. Dies ist jedoch für Keratinozyten gezeigt worden, deren Proliferation durch K10 gehemmt wird (JM Paramio et al., 1999; JM Paramio et al., 2001). Auch weisen transgene Mäuse, die K10 in der proliferativen Basalzellschicht exprimieren, nicht nur eine verminderte Proliferation von Keratinozyten auf, sondern zeigen ein erniedrigtes Risiko für Hauttumoren (M Santos et al., 2002). Weiterhin wurde spekuliert, dass K1 und/oder K10 den Prozess der Differenzierung von Keratinozyten beschleunigen, indem die Apoptose verhindert wird (J Chen et al., 2006). Aufgrund dieser Daten könnte man vermuten, dass es sich bei $K 10$ um ein Tumorsuppressorgen handelt. Daher könnte die K10-Expression in BCC von Ptch ${ }^{\text {floxflox }} E R T 2^{+/-}$-Mäusen direkt mit der Regression, oder auch mit der fehlenden Apoptose in den Tumoren (siehe oben) in Zusammenhang stehen.

Gegen die „Tumorsuppressorgen-Hypothese“ sprechen jedoch Analysen von $\mathrm{K} 10^{-/}$knockout-Mäusen. Mit Hilfe dieser Mäuse wurde gezeigt, dass K10 zwar die Proliferation von Basalzellen hemmt, die Prädisposition zu chemisch-induzierten Papillomen jedoch heraufsetzt (J Reichelt und TM Magin, 2002; J Reichelt et al., 2004). Weiterhin gibt es Mutmaßungen, dass K10 in Signaltransduktionsprozesse involviert ist. So wurde eine Inhibition des Notch-Signalweges durch K10 beschrieben (M Santos et al., 2005). Es ist daher möglich, dass die Regression der BCC von Ptch flox/flox ERT2 ${ }^{+/-}$-Mäusen auch mit einem solchen Signaltransduktionsprozess in Verbindung steht.

Bei voll-ausgebildeten BCC am Tag 90 nach der Induktion kann der mRNA Level von K1 und $\mathrm{K} 10$ nicht mit der $\mathrm{K} 1$ - und $\mathrm{K} 10$-Proteinexpression korreliert werden. In diesem Stadium wurde zwar $K 1$ und K10 mRNA exprimiert, jedoch war kein Protein detektierbar. Möglicherweise lagen in den voll-ausgebildeten BCC Proteinmodifikationen von K1 und K10 vor, die eine Bindung der verwendeten Antikörper verhinderten. Weiterhin könnte die Translation der mRNA in diesem BCC-Stadium verhindert sein. Beide Möglichkeiten müssten jedoch zeitlich auf 90 Tage alte BCC beschränkt sein, da in späteren Stadien eine Proteinexpression von K1 und K10 nachgewiesen wurde. 
Neben K1 oder K10 könnte auch p63 mit dem erhöhten Differenzierungsstaus und der niedrigeren Proliferationsrate der regredienten BCC in Verbindung gebracht werden. So wurde beschrieben, dass p63 für eine Differenzierung von Keratinozyten notwendig ist (AB Truong et al., 2006; MI Koster et al., 2007). Andererseits wurde jedoch gezeigt, dass p63 die Differenzierung von Keratinozyten blockiert (KE King et al., 2003; BC Nguyen et al., 2006). Diese unterschiedlichen Funktionen von p63 scheinen auf den verschiedenen p63-Isoformen zu beruhen (C Bamberger et al., 2005). So ist vor allem die $\Delta$ Np63Isoform - und weniger die TAp63-Isoform - an der Differenzierung und verminderten Proliferation von Keratinozyten beteiligt (AB Truong und PA Khavari, 2007). Nun wurde in BCC aus Ptch $^{\text {floxflox }}{ }^{\text {ERT2 }}{ }^{+-}$-Mäusen in jedem Stadium das p63-Protein nachgewiesen. Da der verwendete Antikörper alle p63-Isoformen erkennt, ist unklar, ob sich das Expressionsniveau der p63-Isoformen in BCC aus Ptch floxfllox $E R T 2^{+/-}$-Mäusen im Verlauf der Progression und Differenzierung zugunsten der $\Delta$ Np63-Isoformen verschiebt. Dies könnte eine Änderung des Differenzierungsgrades sowie einen Rückgang der Proliferationsrate bewirken. Zukünftige Analysen könnten sich anhand von mRNAExpressionsanalysen an mikrodissektiertem Material mit dieser Fragestellung befassen.

Auch ist es möglich, dass Faktoren aus dem Tumorstroma eine Rolle bei Differenzierung

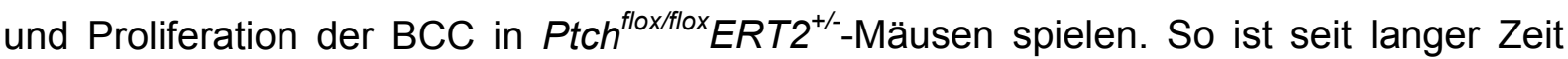
bekannt, dass Interaktionen zwischen BCC und dem assoziierten Bindegewebe bestehen, die beispielsweise eine Stimulation der Proliferation von stromalen Zellen bewirken. Weiterhin exprimieren stromale Zellen von BCC im Vergleich zu stromalen Zellen aus gesunder Haut vermehrt GREMLIN1, einen Antagonisten des „Bone morphogenic protein" (BMP)-Signalweges. Interessanterweise wird durch GREMLIN1 die Proliferation der Tumorzellen gefördert (JB Sneddon et al., 2006). Darüber hinaus wurde gezeigt, dass die Ko-Kultivierung von Keratinozyten und Fibroblasten aus BCC-Stroma in den Keratinozyten BCC-ähnliche Eigenschaften hervorruft (L Lacina et al., 2007). Daher ist es möglich, dass auch das BCC-Stroma in Ptch $^{\text {floxfllox }} E R T 2^{+/-}$-Mäusen Faktoren abgibt, die bei der Regression dieser Tumoren eine Rolle spielen könnten.

\subsubsection{Entstehung von BCC möglicherweise unabhängig vom Haar- zyklus}

In der Haut ist die Hh/Ptch-Signalkaskade essentiell für die Regulation des Haarzyklus. Bereits mehrfach wurden Zusammenhänge zwischen der Entstehung von BCC und den Haarzyklusphasen beschrieben. So entstehen epitheliale Tumoren in K14-Gli1-Mäusen 
erst während des ersten Anagens in 25 Tage alten Mäusen (AE Oro und $\mathrm{K}$ Higgins, 2003). Ebenso wird die BCC-Inzidenz und Latenzzeit in bestrahlten Ptch ${ }^{\text {neo67/+ }}$-Mäusen in Abhängigkeit des Haarzyklus moduliert (M Mancuso et al., 2006).

Auch in dieser Arbeit wurde untersucht, ob BCC nur in bestimmten Haarzyklusphasen entstehen können. Dazu wurde die Cre-ERT2 in behaarter Haut mit einem synchronisierten Haarzyklus zu verschiedenen Zeitpunkten des Haarzyklus induziert.

Interessanterweise konnten BCC unabhängig von der Haarzyklusphase induziert werden. Dies war aufgrund der oben genannten Ergebnisse von Mancuso et al. (M Mancuso et al., 2006) an bestrahlten Ptch ${ }^{\text {neo67/+ }}$-Mäusen ein unerwartetes Resultat. In letzterem Modell entwickelten sich BCC häufiger und schneller, wenn die Ptch ${ }^{\text {neo67/+ }}$ Mäuse während des Anages bestrahlt wurden. Zudem exprimierten einige dieser Tumoren glattes Muskel-Aktin und K14. Solche molekularen Veränderungen sind bei den

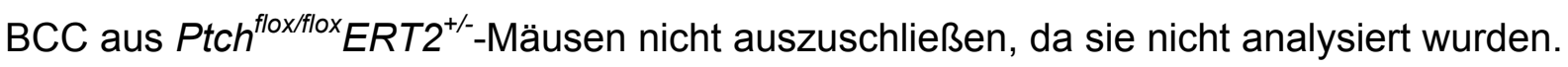
Aufgrund unserer Versuchsplanung war es leider auch nicht möglich, die Latenzzeit der BCC zu analysieren. So wurde in unserer Studie eine Endpunktanalyse vom 72. Tag an bis 140 Tage nach Tamoxifengabe durchgeführt. Innerhalb dieser Zeiträume hatten sich bereits in sämtlichen Mäusen BCC gebildet. Nichtsdestotrotz wurden in dieser Arbeit die Tumorgröße und, wenn möglich, die Tumormultiplizität analysiert. Die Analysen zeigen, dass sich diese Parameter zwischen den einzelnen Kohorten nicht unterscheiden. So waren sowohl Größe als auch Frequenz der BCC einheitlich und unabhängig davon, ob die Tumoren im Anagen oder aber im Telogen induziert wurden.

Natürlich sollte das Experiment mit einer größeren Anzahl an Tieren wiederholt werden. Um den Einfluss der jeweiligen Haarzyklusphase auf die Latenzzeit der BCC zu untersuchen, sollten sequenzielle Hautanalysen durchgeführt werden, die sofort nach der Induktion der Tumoren begonnen werden.

\subsubsection{Etablierung stabiler Zelllinien für in vitro-Analysen der Ptch-Funk- tion}

Ein weiteres Ziel dieser Arbeit war die Etablierung von Zelllinien zur Analyse der Funktion von Ptch. Vorteile von Zelllinien gegenüber tierexperimentellen Arbeiten sind die einfache Manipulierbarkeit, die Arbeit mit homogenem Material und die Möglichkeit der Durchführung diverser Experimente innerhalb kurzer Zeit.

Die Zelllinien wurden aus Fibroblasten der murinen Dermis von Ptch $^{\text {flox/flox }} E R T 2^{+/}$-, $P t c h^{\text {flox fllox }}$ - und Ptch ${ }^{\text {wt }}$-Mäusen hergestellt. Es wurden keine embryonalen Fibroblasten 
isoliert, da die Gefahr der Selektion von Zellklonen mit per se aktiver oder inaktiver Hh/Ptch-Signalkaskade bestanden hätte.

In der primär isolierten Ptch ${ }^{\text {floxflox }} E R T 2^{+/-}$-Zelllinie wurde zunächst das Ptch ${ }^{\text {del }}$-Allel nachgewiesen. Dies wurde auf eine basale Grundaktivität der Cre-ERT2 in den Zellen zurückgeführt, obwohl diese in vivo nicht aufgetreten ist (siehe 3.2.1.3.2). Um Zellen ohne Cre-ERT2-Aktivität zu gewinnen, wurden Einzelzellklone isoliert. Hierdurch konnten fünf monoklonale Ptch flox/flox ERT2 ${ }^{+/}$-Zelllinien ohne Basalaktivität der Cre-ERT2 hergestellt werden. In allen fünf Zelllinien konnte aber eine Rekombination des Ptch ${ }^{\text {flox }}$ Lokus nach Stimulation der Cre-ERT2 mit Tamoxifen induziert werden. Nur in einer der Zelllinien („B9“) ließ sich durch die Ptch-Mutation eine Aktivierung der Hh/PtchSignalkaskade hervorrufen. Die übrigen vier Zelllinien hatten diese Eigenschaft im Laufe der Kultivierung (möglicherweise durch Mutationen oder epigenetische Veränderungen) verloren.

Genauere Analysen der Ptch-Transkripte in B9-Zellen nach Tamoxifengabe zeigten einen deutlichen Rückgang von Ptch $^{\text {wt }}$ sowie die Zunahme von Ptch ${ }^{\text {del }}$-Transkripten. Da das postulierte Ptch $^{\text {del_}}$-Protein wegen eines vorzeitigen Abbruchs der Translation auf 341 Aminosäuren verkürzt ist, sollte es keine Inhibition von Smo bewirken können und dadurch die Hh/Ptch-Signalkaskade aktivieren (RL Johnson et al., 2000; S Makino et al., 2001). Dies war tatsächlich der Fall und neben Gli1 wurde auch Gli2 nach Stimulation mit Tamoxifen exprimiert. Weiterhin konnte die Erhöhung der Gli1-Expression durch den spezifischen Smo-Inhibitor Cyclopamin blockiert werden.

Obwohl es unter Tamoxifen-Behandlung in B9-Zellen zu einem Wechsel der Expression

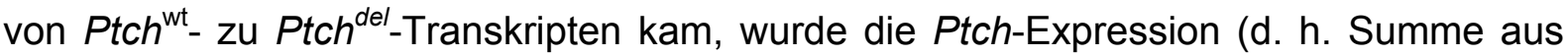

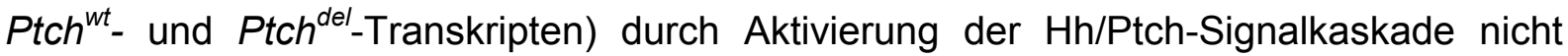
erhöht. Wie auch Gli1 ist Ptch ebenfalls ein Zielgen des Hh/Ptch-Signalweges (siehe Abbildung 1). Daher würde man annehmen, dass der Funktionsverlust von Ptch nicht nur zur Induktion der Gli1-Expression, sondern auch zu einem starken Anstieg von PtchTranskripten führen sollte.

Die fehlende Zunahme der Ptch-Expression in Tamoxifen-behandelten B9-Zellen könnte ein Anzeichen für eine nicht vollständig funktionierende Signalkaskade sein oder auf epigenetische Veränderungen am Ptch-Promotor hinweisen. Dagegen spricht jedoch, dass sich die Ptch-Expression durch die Zugabe von Shh in den B9-Zellen aktivieren ließ. Durch Shh-Stimulation wurde im Vergleich zu Tamoxifen-behandelten Zellen nicht nur vermehrt Ptch, sondern auch vermehrt Gli1 und Gli2 und Gli3 exprimiert.

Zusammengefasst kann man nun Folgendes festhalten: Sowohl Mutationen in Ptch als auch die Shh-Stimulation führen in B9-Zellen zur Aktivierung der Gli1-Expression. 
Begleitet wird dies in Shh-stimulierten Zellen durch eine Aktivierung der PtchTranskription. Die Aktivierung der Ptch-Transkription bleibt dagegen in den Ptchmutanten B9-Zellen aus. Diese Daten könnten für eine alternative Signaltransduktion durch Shh sprechen. Dieser alternative Weg könnte z. B. über Gli2 oder Gli3 laufen, da diese beiden Faktoren in Shh-stimulierten Zellen heraufreguliert werden. Alternativ dazu könnten weitere Faktoren durch Shh stimuliert werden, die für eine Gli-unabhängige Ptch-Transkription verantwortlich sind. Ein solcher alternativer, nicht-kanonischer Signalweg ist in Abbildung 53 dargestellt.

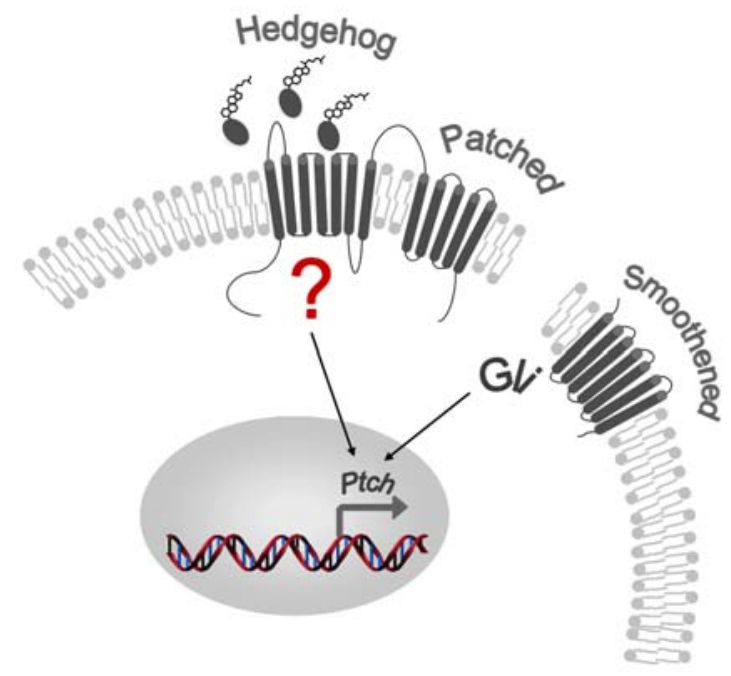

\begin{abstract}
Abbildung 53: Modell einer nicht-kanonischen Hh/Ptch-Signaltransduktion. Gezeigt ist ein Modell für einen nicht-kanonischen Hh/Ptch-Signalweg. Die Aktivierung durch die Bindung des Liganden Hh führt zur Aktivierung von Gli oder anderen Faktoren (?) in den Nukleus. Dort wird die Transkription von Ptch ausgelöst.
\end{abstract}

Es gibt jedoch noch eine weitere Erklärungsmöglichkeit. Nach Shh-Stimulation kann die erhöhte Ptch-Expression in B9-Zellen nur durch Ptch ${ }^{\text {wt }}$-Transkripte bedingt sein. Im Gegensatz dazu werden nach Tamoxifen-Behandlung in den Zellen aufgrund der unvollständigen Rekombinationseffizienz (ca. $60 \%$ ) sowohl Ptch ${ }^{\text {wt }}$ - als auch Ptch ${ }^{\text {del }}$ Transkripte exprimiert.

Nun ist bekannt, dass bereits ein Ptch ${ }^{\text {wt }}$-Molekül die Aktivität von 45 Smo-Molekülen um fast 80 \% hemmen kann (J Taipale et al., 2002). Daher ist es möglich, dass der Level an Ptch $^{\text {wt }}$-Transkripten in Tamoxifen-behandelten B9-Zellen nicht hoch genug ist, um die Smo-Aktivität vollständig zu inhibieren. Dies resultiert in einer Restaktivität der Signalkaskakde, die gerade ausreicht, um eine vermehrte Gli1-Expression auszulösen. Die Aktivierung der Kaskade reicht jedoch nicht aus, um eine Deregulation der PtchExpression hervorzurufen. Eine solche Hypothese wird auch durch Expressionsanalysen von Ptch $^{-/}$-Zellen gestützt. Im Gegensatz zu Tamoxifen-behandelten B9-Zellen 


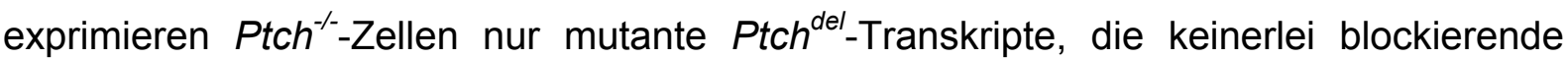
Wirkung auf Smo haben. Hierdurch ist die Signalkaskade hochaktiv, was in einer sehr starken Transkription sowohl von Gli1 als auch von Ptch resultiert.

Wie soeben beschrieben, zeigen B9-Zellen einen Anstieg der Gli3-Expression nach ShhStimulation. Auch Ptch ${ }^{-/}$-Zellen exprimieren sehr stark Gli3. Heutzutage besteht jedoch die Auffassung, dass die Gli3-Transkription durch eine aktive Hh/Ptch-Signalkaskade negativ reguliert wird. Die negative Regulation der Gli3-Transkription durch $\mathrm{Hh}$ wurde jedoch während der Embryonalentwicklung beschrieben (V Marigo et al., 1996b; A Ruiz i Altaba, 1999). Bei B9- und Ptch ${ }^{-/}$-Zellen dagegen handelt es sich um adulte Fibroblasten.

Es ist daher möglich, dass adulte Zellen im Gegensatz zu embryonalen Zellen in der Lage sind, Gli3 nach Stimulation der Hh/Ptch-Signalkaskade zu exprimieren. Eine solche Beobachtung wurde auch schon von anderen Gruppen gemacht ( $\mathrm{J}$ Motoyama et al., 1998).

Schließlich sei noch angemerkt, dass die Aktivierung der Hh/Ptch-Signalkaskade in $\mathrm{Ptch}^{-/}$-Zellen in einer erhöhten Proliferationsrate resultiert. Dies zeigt ein Vergleich zu Ptch $^{\text {floxflox }}$-Zellen. Die erhöhte Proliferationsrate der Ptch ${ }^{-/}$-Zellen ist darauf zurückzuführen, dass inaktivierende Ptch-Mutationen über die konstitutiv aktive Hh/PtchSignalkaskade eine Progression des Zellzyklus hervorrufen (EA Barnes et al., 2005).

\subsubsection{Ausblick}

Zusammengefasst zeigen die Ergebnisse, dass die Zelllinien B9 und Ptch ${ }^{-/}$für Analysen der Ptch-Funktion in vitro hervorragend geeignet sind. B9- können genauso wie $P t c h^{\text {flox/flox }}$-Zellen als „Wildtyp Ptch-Zelllinien“ verwendet werden. In B9-Zellen kann der Hh/Ptch-Signalweg durch Zugabe von Shh oder von Tamoxifen ins Kulturmedium aktiviert werden. In $\mathrm{Ptch}^{-/}$-Zellen ist der Signalweg aufgrund von mutiertem Ptch per se aktiv.

Diese Zelllinien können in der Zukunft für verschiedene Experimente benutzt werden. So wird heute vermutet, dass Ptch als Pumpe für den Transport von Cholesterolderivaten fungieren könnte (MF Bijlsma et al., 2006). Es ist jedoch nicht bekannt, um welche Derivate es sich hierbei handelt.

Weiterhin gibt es Hinweise, dass es sich bei Ptch um einen so genannten „Dependence“ Rezeptor handelt (C Thibert et al., 2003; P Mehlen et al., 2005), der in Gegenwart seines Liganden Shh ein Überleben von Zellen ermöglicht. Durch Abwesenheit von Shh wird 
dagegen der programmierte Zelltod induziert ( $P$ Mehlen und DE Bredesen, 2004). Die genauen molekularen Abläufe, die sich nach Bindung von Shh an Ptch abspielen, sind unbekannt.

Ferner wurde gezeigt, dass Ptch als Lipoproteinrezeptor fungieren kann. Was hierbei auf molekularer Ebene genau passiert und welche Rolle diese Bindung für die Zelle spielt, ist ebenfalls unklar (TE Willnow et al., 2007; A Callejo et al., 2008). Solche Fragestellungen können nun anhand dieser Zelllinien überprüft werden.

Auch können diese Zelllinien zur Analyse der Tumor-Stroma Interaktion beim BCC verwendet werden. Unter der Annahme, dass stromale Faktoren tatsächlich eine Rolle bei der Regression von BCC spielen (siehe 4.4.2.3), könnte man BCC-Zelllinien mit Ptch $^{\text {flox/flox }}$ - bzw. B9-Zellen kokultivieren und die molekularen Veränderungen sowohl in Tumorzellen (z. B. Kontrolle des Differenzierungstatus über K1- und K10-Analysen; Untersuchung des Proliferationsverhaltens über BrdU Assays etc.) als auch den „stromalen“ Fibroblasten (z. B. über Mikroarrayanalysen) untersuchen. 


\section{$5 \quad$ Zusammenfassung}

Mutationen im Patched-Gen (Ptch), welches für eine Komponente der Hedgehog (Hh)/Ptch-Signalkaskade kodiert, werden häufig bei Basalzellkarzinomen (BCC), Medulloblastomen (MB) und Rhabdomyosarkomen (RMS) gefunden. Wie Daten aus dem Ptch ${ }^{\text {neo67/+ }}$-Tiermodell zeigen, ist die Tumorinzidenz vom genetischen Hintergrund abhängig. Der Hintergrund C57BL/6N (B6) prädisponiert die Tiere zu MB, wohingegen der BALB/c (BALB)-Hintergrund zu RMS prädisponiert. Dies weist auf die Existenz von Modifikatorgenen hin. Ein Ziel dieser Arbeit war die Kartierung und Identifikation dieser Gene.

Im Rahmen dieses Projektes wurde an der Charakterisierung des RMS-SuszeptibilitätsLokus Parms1 (Patched-Associated RMS 1) mitgewirkt. Dieser Lokus liegt auf Chromosom 2 im Intervall zwischen den Mikrosatellitenmarkern D2Mit37 und D2Mit102. In dieser Region begünstigen dominante BALB-Allele die Entstehung von RMS. Diese Daten wurden in der Zeitschrift Genomics publiziert (H Hahn et al., 2004).

In den Mauslinien B6 und BALB wurden für elf Kandidatengene SNP- oder Genexpressions-Analysen durchgeführt. Aufgrund der Überexpression von Catenin src im Skelettmuskel von B6-Mäusen und seiner tumorsuppressorischen Funktion könnte dieses Gen in die Modulation der RMS-Suszeptibilität involviert sein.

Zusätzlich wurde für Feinkartierungsuntersuchungen des Lokus Parms1 in 218 B6x(BALBxB6)Ptch ${ }^{\text {neo67/+ }}$ N2-Mäusen eine genomweite Kopplungsanalyse mit 97 polymorphen Mikrosatellitenmarkern durchgeführt. Weiterhin wurden Nachkommen aus Kreuzungen von B6Ptch ${ }^{\text {neo67/+ }}$-Mäusen mit den Inzuchtstämmen 129Sv, DBA2J und FVB/N generiert und auf die Entwicklung von Tumoren untersucht. In den F1Generationen sollte dann auf der Basis der Korrelation von Segmentidentität und Phänotyp eine weitere Kartierung der RMS-Suszeptibilität durchgeführt werden.

Im Laufe der Untersuchungen wurde eine genetische Kontamination bei B6-Mäusen, die im Zeitraum von Herbst 2003 bis Frühjahr 2005 von der Firma Charles River Laboratories zur Etablierung der entsprechenden Kreuzungen zugekauft worden waren, festgestellt. Die SNP-Analyse ließ auf eine Kontamination mit einer DBA-Inzuchtlinie schließen (F Nitzki et al., 2007). Aufgrund dieser Tatsache wurde das Kartierungsprojekt abgebrochen.

In einem zweiten Projekt wurde die in unserem Labor generierte Mauslinie Ptch ${ }^{\text {flox/flox }}$ charakterisiert. Mittels einer Tamoxifen-induzierbaren Cre-Rekombinase wurde in diesem konditionellen Ptch-knockout-Mausmodell eine Ptch-Mutation induziert. Neben 
hyperproliferativen Veränderungen der Magenwand und des Mesenteriums sowie einem Entwicklungsdefekt der allgemeinen lymphoiden Vorläuferzellen im Knochenmark konnten in diesen Mäusen BCC hervorgerufen werden (A Uhmann et al., 2007).

Die BCC wurden durch eine biallelische Deletion von Ptch initiiert und entstehen wahrscheinlich unabhängig von der Haarzyklusphase aus sowohl Basalzellen der Epidermis als auch der äußeren Wurzelscheide des Haarfollikels.

Interessanterweise wurden die BCC nach 200 Tagen regredient, zeigten einen differenzierteren Phänotyp und eine verminderte Proliferation. Da in jedem BCC-Stadium die Hh/Ptch-Signalkaskade aktiv war, kann die Regression nicht durch eine Inaktivierung des Signalweges bedingt sein. Von regredienten Tumorstadien wurden die Differenzierungsmarker Keratin 1 (K1) und Keratin 10 (K10) exprimiert, wohingegen K1 und $\mathrm{K} 10$ in den frühen Tumorstadien nicht detektiert wurden. Daher steht die Expression von $\mathrm{K} 1$ und $\mathrm{K} 10$ vermutlich im direkten Zusammenhang mit der Regression der BCC. Diese Daten leisten einen wichtigen Beitrag zum besseren Verständnis der Pathogenese dieser Tumorentität und könnten in der Zukunft eventuell zur Etablierung neuer Therapieansätze beisteuern.

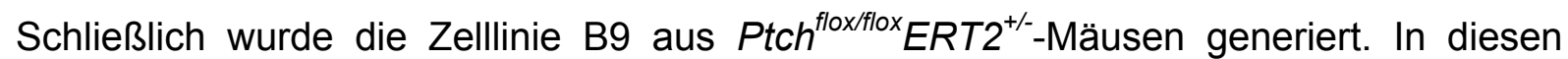
Zellen lässt sich eine Ptch-Mutation durch Behandlung mit Tamoxifen induzieren. Die resultierende Ptch-Deletion bewirkt eine Aktivierung der Hh/Ptch-Signalkaskade, was auch durch Inkubation der Zellen mit Shh hervorgerufen werden kann. Zusätzlich wurden die Ptch-defiziente Zelllinie $\mathrm{Ptch}^{-/}$, die eine pathologisch aktivierte Hh/Ptch-Signalkaskade aufweist, und die Wildtyp-Ptch Zelllinie Ptch ${ }^{\text {floxflox }}$ etabliert. Ptch ${ }^{-/}$ -Zellen zeigen im Vergleich zur Zelllinie $P t c h^{\text {floxfllox }}$ eine stark erhöhte Aktivität der Hh/Ptch-Signalkaskade sowie eine erhöhte Proliferationsrate. Sowohl in B9- als auch Ptch $^{-/}$-Zellen lässt sich die physiologisch bzw. pathologisch aktivierte Hh/Ptch-Signalkaskade durch die Zugabe von Cyclopamin inhibieren. Diese Zellinien können dazu beitragen, die Funktion von Ptch besser zu verstehen. 


\section{Abkürzungsverzeichnis}

${ }^{32} \mathrm{P}$

6-FAM

AP

Api5

B6

$\mathrm{BCC}$

Bcl-2

$B m f$

BMP/Bmp

$\mathrm{Bp}$

$\mathrm{Bq}$

BrdU

BSA

$C$

c

c

Catns

$C D$

cDNA

Chr.

$\mathrm{Ci}$

$\mathrm{CM}$

Cre-ERT2

CRNA

cSNP

C-terminal

Ct-Wert

d

DAB

$\mathrm{Db}$

dCTP

DEPC

DISP/Disp

Disp2

DII4

DMEM

DMSO

DNA

dNTPS

$d p c$

DTT

E

E

EDTA radioaktives Phosphorisotop

6-Carboxyfluoreszein

alkalische Phosphatase

Apoptosis inhibitor $\underline{5}$

C57므/ 6 N

Basal cell carcinoma - Basalzellkarzinom

B cell leukemia/lymphoma $\underline{2}$

B $c 1-2$ modifying factor

Bone morphogenetic proteins

Basenpaare

Becquerel

5-Bromo-2-Deoxyuridin

bovine serum albumine - Rinderserumalbumin)

Nukleinsäure-spezifischer Koeffizient

Konzentration von Nukleinsäuren

cortex (Kortex)

Catenin $\underline{s} r c$

cluster of differentiation

copyDNA

Chromosom

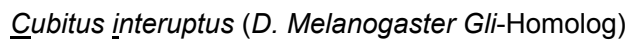

centiMorgan

Tamoxifen-induzierbare Cre-Rekombinase

copy RNA

coding single nucleotide polymorphism - kodierende Einzelpunktmutation

carboxyteriminal

cycle treshold (Schwellenwert)

days - Tage

Diamino-B̈enzidin

Dot blot

Deoxycytidintriphosphat

Diethylpyrocarbonat

Dispatched

Dispatched homolog $\underline{2}$

Delta-like 4

Dulbecco's Modified Eagle Medium

N.N.-Dimethylsulfoxid

Desoxyribonukleinsäure

Desoxyribonukleotidtriphosphate

days post coitum (Tage nach der Kopulation)

Dithiothreitol

Extinktion

Exon

Éthylen-diamin-tetraacetat 


\begin{tabular}{|c|c|}
\hline Ehf & Éts homologous factor \\
\hline ERT2 & Mauslinie ROSA26CreERT2 \\
\hline$f$ & Verdünnungsfaktor \\
\hline Fab & antigenbindendes Fragment \\
\hline FCS & fetal calf serum (fötales Kälberserum) \\
\hline frt & frt Sequenz (DNA-Konsensussequenz zur Bindung der FLPase) \\
\hline Fu/FU & Fused \\
\hline g & grandulärer, musköser Magen \\
\hline G418 & Geneticinsulfat \\
\hline Gapdh & Glycerinaldehyd-3-phosphatase-dehydrogenase \\
\hline gDNA & genomische DNA \\
\hline Gh & Großhirn \\
\hline $\mathrm{Ha}$ & Haut \\
\hline $\mathrm{He}$ & $\underline{\text { Herz }}$ \\
\hline HE & Hämatoxylin/Ëosin \\
\hline$H h$ & $\underline{H}$ edgehogog \\
\hline HRP & horseradish peroxidase (Meerrettich Peroxidase) \\
\hline I & Immunglobulin \\
\hline i.m. & intramuskulär \\
\hline i.p. & intraperitoneal \\
\hline $\operatorname{lgf2}$ & insulin-like growth factor $\underline{2}$ \\
\hline $\mathrm{IHC}$ & Immunhistochemie \\
\hline inv. & invasiv \\
\hline IRS & inner root sheath - innere Wurzelscheide \\
\hline ISH & in situ- $\underline{H}$ ybridisierung \\
\hline K1 & Keratin 1 \\
\hline K10 & $\underline{\text { Keratin }} \underline{10}$ \\
\hline K14 & $\underline{\text { Keratin }} \underline{14}$ \\
\hline K17 & Keratin $\underline{17}$ \\
\hline K6a & $\underline{\text { Keratin }} \underline{6 \mathrm{a}}$ \\
\hline $\mathrm{kDa}$ & Kilodalton \\
\hline $\mathrm{Kh}$ & Kleinhirn \\
\hline $\mathrm{KI}$ & knockin-Allel \\
\hline Kif7 & $\underline{K}$ Kinesin family member $\underline{7}$ \\
\hline LacZ & $\beta$-Galactosidase \\
\hline LB-Medium & lysogeny broth Medium \\
\hline Le & Leber \\
\hline LMS & Leiomyosarkom \\
\hline LOD-Score & logarithm of the odds - Logarithmus der Wahrscheinlichkeit \\
\hline $\mathrm{LOH}$ & loss of heterozygosity (Verlust beider Genallele) \\
\hline loxP & loxP Sequenz (DNA-Konsensussequenz zur Bindung der Cre-Rekombinase) \\
\hline LRS & likelihood ratio statistic \\
\hline Lsg. & Löösungsmittel \\
\hline Lu & Lunge \\
\hline MB & $\underline{\text { Medulloblastom }}$ \\
\hline $\mathrm{Mb}$ & Megabasen \\
\hline
\end{tabular}




\begin{tabular}{|c|c|}
\hline MBSTL & Maleinsäure/Natriumchlorid/Levamisol/Tween-20-haltiger Puffer \\
\hline Mdk & $\underline{\text { Midkine }}$ \\
\hline me & $\underline{\text { Mesenterium }}$ \\
\hline $\mathrm{Mi}$ & $\underline{\text { Milz }}$ \\
\hline MPD & Mouse Phenome ㅁatabase \\
\hline M-Phase & Mitose \\
\hline mRNA & $\underline{\text { messenger } \underline{\mathrm{RNA}}}$ \\
\hline N2 & $\mathrm{B} 6 x(\mathrm{BALBxB}) \mathrm{Ptch}^{\text {neo67/+ }} \mathrm{N} 2$ \\
\hline NBCCS & Nevoid $\underline{B}$ asal $\underline{\text { Cell }}$ Carcinoma Syndrome \\
\hline neoR & 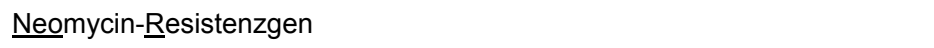 \\
\hline $\mathrm{ng}$ & nicht-grandulärer, kutaner Mage \\
\hline $\mathrm{Ni}$ & Niere \\
\hline NT & Natriumchlorid/ㅍris-haltiger Puffer \\
\hline N-terminal & aminoterminal \\
\hline NTMLT & Natriumchlorid/Tris/Magnesiumchlorid/L_evamisol/Iwween-20-haltiger Puffer \\
\hline OD & optische Dichte \\
\hline ORS & outer root sheath - äußere Wurzelscheide \\
\hline$P$ & Passage \\
\hline$p 53$ & Transformation related protein $\underline{53}$ \\
\hline p63 & Transformation related protein $\underline{63}$ \\
\hline Parms1 & Patched-asssociated $\underline{R M S} 1$ \\
\hline PBS & Phosphate buffered saline (Phoshat-gepufferte Natriumchlorid Lösung) \\
\hline PCR & Polymerase chain reaction - Polymerasekettenreaktion \\
\hline PDZ-Domäne & 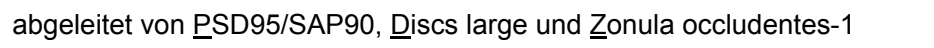 \\
\hline P-Ko. & Positivkontrolle \\
\hline PS & Penicillin/吕treptomycin \\
\hline Ptch & Patched \\
\hline Ptch $^{\text {del }}$ & Ptch Allel mit Cre-vermittelter Deletion der Exone 8 und 9 \\
\hline $\operatorname{Ptch}^{f l o x}$ & Ptch Allel zur Cre-vermittelten Deletion der Exone 8 und 9 \\
\hline $\operatorname{Ptch}^{\text {neo12 }}$ & Ptch Allel mit der Deletion der Exone 1 und 2 \\
\hline $\operatorname{Ptch}^{\text {neo67 }}$ & Ptch Allel mit Deletion der Exone 6 und 7 \\
\hline $\operatorname{Ptch}^{\text {wt }}$ & Wildtyp Ptch Allel \\
\hline $\operatorname{Ptch}^{\Delta 10}$ & Ptch-Spleißvariante ohne Exon 10 \\
\hline Ptprj & Protein tyrosine phosphatase, receptor type, $\underline{J}$ \\
\hline qRT-PCR & quantitative real time $\underline{\mathrm{PCR}}$ \\
\hline QTL & quantitative trait locus \\
\hline RMS & Rhabdomyosarkom \\
\hline RNA & Ribonukleinsäure \\
\hline RZPD & Ressourcenzentrum für Genomforschung \\
\hline SCC & Sqamous cell carcinoma - Plattenepithelkarzinom \\
\hline SDS & Natriumdodecylsulfat \\
\hline Shh & $\underline{\text { Sonic }} \underline{h}$ edgehog \\
\hline SM & $\underline{\text { Skelettmuskel }}$ \\
\hline Smo & Smoothened \\
\hline SNP & single nucleotide polymorphism - Einzelpunktmutation \\
\hline S-Phase & Synthesephase \\
\hline
\end{tabular}




\begin{tabular}{|c|c|}
\hline SSC & standard saline citrate (Standard Natriumcitrat Lösung) \\
\hline SSD & sterol sensing domain \\
\hline STE & SDS/Tris/EDTA-haltiger Puffer \\
\hline Sufu & Suppressor of fused \\
\hline $\mathrm{T}$ & transgenes Allel \\
\hline Taq & Thermus aquaticus \\
\hline TBE & Iris-B̈orsäure-ËDTA Lösung \\
\hline TBS & $\underline{\text { tris-b} u f f e r e d ~ s a l i n e ~(T r i s-g e p u f f e r t e ~ N a t r i u m c h l o r i d ~ L o ̈ s u n g) ~}$ \\
\hline Th & Thymus \\
\hline $\operatorname{tPtch}^{-/}$ & Tamoxifen-induzierte $\operatorname{Ptch}^{\text {delNX}}$ Mutation \\
\hline Traf6 & $\underline{\text { Tnf }}$ receptor-associated factor $\underline{6}$ \\
\hline$U$ & unit (Enzymaktivitätseinheit) \\
\hline UV-Licht & Ultraviolettes Licht \\
\hline $\mathrm{v} / \mathrm{v}$ & volume/volume (Volumen/Volumen) \\
\hline Vol & $\underline{\text { Volumen }}$ \\
\hline$w / v$ & weight/volume (Gewicht/Volumen) \\
\hline$W n t / W N T$ & Wingless \\
\hline wt & Wildtyp \\
\hline Wt1 & Wilms tumor homolog \\
\hline $\mathrm{xg}$ & -fache Erdbeschleunigung \\
\hline X-Gal & 5-Bromo-4-chloro-3-indolyl- $\beta$-Galaktosid \\
\hline $\mathrm{XI}$ & $\underline{X} h o l$ \\
\hline YYE & Yakima Yellow \\
\hline Zfp289 & ADP-ribosylation factor GTPase activating protein 2 \\
\hline
\end{tabular}




\section{$7 \quad$ Literaturverzeichnis}

Adolphe C, Hetherington R, Ellis T und Wainwright B, 2006. 'Patched1 functions as a gatekeeper by promoting cell cycle progression.' Cancer Res 66(4): 2081-8.

Alcedo J, Ayzenzon M, Von Ohlen T, Noll M und Hooper JE, 1996. 'The Drosophila smoothened gene encodes a seven-pass membrane protein, a putative receptor for the hedgehog signal.' Cell 86(2): 221-32.

Aszterbaum M, Epstein J, Oro A, Douglas V, LeBoit PE, Scott MP und Epstein EH, Jr., 1999. 'Ultraviolet and ionizing radiation enhance the growth of BCCs and trichoblastomas in patched heterozygous knockout mice.' Nat Med 5(11): 1285-91.

Bamberger C, Hafner A, Schmale H und Werner S, 2005. 'Expression of different p63 variants in healing skin wounds suggests a role of p63 in reepithelialization and muscle repair.' Wound Repair Regen 13(1): 41-50.

Barnes EA, Heidtman KJ und Donoghue DJ, 2005. 'Constitutive activation of the shh-ptc1 pathway by a patched1 mutation identified in BCC.' Oncogene 24(5): 902-15.

Barnes EA, Kong M, Ollendorff $V$ und Donoghue DJ, 2001. 'Patched1 interacts with cyclin B1 to regulate cell cycle progression.' Embo J 20(9): 2214-23.

Beissert S, Ruhlemann D, Mohammad T, Grabbe S, El-Ghorr A, Norval M, Morrison H, Granstein RD und Schwarz T, 2001. 'IL-12 prevents the inhibitory effects of cis-urocanic acid on tumor antigen presentation by Langerhans cells: implications for photocarcinogenesis.' J Immunol 167(11): 6232-8.

Berman DM, Karhadkar SS, Maitra A, Montes De Oca R, Gerstenblith MR, Briggs K, Parker AR, Shimada Y, Eshleman JR, Watkins DN und Beachy PA, 2003. 'Widespread requirement for Hedgehog ligand stimulation in growth of digestive tract tumours.' Nature 425(6960): 846-51.

Bian YH, Huang SH, Yang L, Ma XL, Xie JW und Zhang HW, 2007. 'Sonic hedgehog-Gli1 pathway in colorectal adenocarcinomas.' World J Gastroenterol 13(11): 1659-65.

Bijlsma MF, Spek CA, Zivkovic D, van de Water S, Rezaee F und Peppelenbosch MP, 2006. 'Repression of smoothened by patched-dependent (pro-)vitamin D3 secretion.' PLoS Biol 4(8): e232.

Bilu D und Sauder DN, 2003. 'Imiquimod: modes of action.' Br J Dermatol 149 Suppl 66: 5-8.

Bloor BK, Seddon SV und Morgan PR, 2001. 'Gene expression of differentiation-specific keratins in oral epithelial dysplasia and squamous cell carcinoma.' Oral Oncol 37(3): 251-61. 
Botchkarev VA, Botchkareva NV, Nakamura M, Huber O, Funa K, Lauster R, Paus R und Gilchrest BA, 2001. 'Noggin is required for induction of the hair follicle growth phase in postnatal skin.' Faseb J 15(12): 2205-14.

Bridge JA, Liu J, Qualman SJ, Suijkerbuijk R, Wenger G, Zhang J, Wan X, Baker KS, Sorensen P und Barr FG, 2002. 'Genomic gains and losses are similar in genetic and histologic subsets of rhabdomyosarcoma, whereas amplification predominates in embryonal with anaplasia and alveolar subtypes.' Genes Chromosomes Cancer 33(3): 310-21.

Bridge JA, Liu J, Weibolt V, Baker KS, Perry D, Kruger R, Qualman S, Barr F, Sorensen P, Triche T und Suijkerbuijk R, 2000. 'Novel genomic imbalances in embryonal rhabdomyosarcoma revealed by comparative genomic hybridization and fluorescence in situ hybridization: an intergroup rhabdomyosarcoma study.' Genes Chromosomes Cancer 27(4): 337-44.

Bukhardt Perez MP, Ruiz-Villaverde R, Naranjo Diaz MJ, Blasco Melguizo J und Naranjo Sintes R, 2007. 'Basal cell carcinoma: treatment with imiquimod.' Int J Dermatol 46(5): 539-42.

Burke R, Nellen D, Bellotto M, Hafen E, Senti KA, Dickson BJ und Basler K, 1999. 'Dispatched, a novel sterol-sensing domain protein dedicated to the release of cholesterol-modified hedgehog from signaling cells.' Cell 99(7): 803-15.

Callejo A, Culi J und Guerrero I, 2008. 'Patched, the receptor of Hedgehog, is a lipoprotein receptor.' Proc Natl Acad Sci U S A 105(3): 912-7.

Calzada-Wack J, Kappler R, Schnitzbauer U, Richter T, Nathrath M, Rosemann M, Wagner SN, Hein $\mathrm{R}$ und Hahn H, 2002. 'Unbalanced overexpression of the mutant allele in murine Patched mutants.' Carcinogenesis 23(5): 727-734.

Carpentieri DF, Nichols K, Chou PM, Matthews M, Pawel B und Huff D, 2002. 'The expression of WT1 in the differentiation of rhabdomyosarcoma from other pediatric small round blue cell tumors.' Mod Pathol 15(10): 1080-6.

Chen J, Cheng X, Merched-Sauvage M, Caulin C, Roop DR und Koch PJ, 2006. 'An unexpected role for keratin 10 end domains in susceptibility to skin cancer.' J Cell Sci 119(Pt 24): 5067-76.

Chen JK, Taipale J, Young KE, Maiti T und Beachy PA, 2002. 'Small molecule modulation of Smoothened activity.' Proc Natl Acad Sci U S A 99(22): 14071-6.

Chen X, Horiuchi A, Kikuchi N, Osada R, Yoshida J, Shiozawa T und Konishi I, 2007. 'Hedgehog signal pathway is activated in ovarian carcinomas, correlating with cell proliferation: it's inhibition leads to growth suppression and apoptosis.' Cancer Sci 98(1): 68-76.

Chiang C, Swan RZ, Grachtchouk M, Bolinger M, Litingtung Y, Robertson EK, Cooper MK, Gaffield W, Westphal H, Beachy PA und Dlugosz AA, 1999. 'Essential role for Sonic hedgehog during hair follicle morphogenesis.' Dev Biol 205(1): 1-9. 
Churchill GA und Doerge RW, 1994. 'Empirical threshold values for quantitative trait mapping.' Genetics 138(3): 963-71.

Clement V, Sanchez P, de Tribolet N, Radovanovic I und Ruiz i Altaba A, 2007. 'HEDGEHOG-GLI1 signaling regulates human glioma growth, cancer stem cell self-renewal, and tumorigenicity.' Curr Biol 17(2): 165-72.

Cohen MM, Jr., 2003. 'The hedgehog signaling network.' Am J Med Genet A 123(1): 5-28.

Coventry S, Kapur RP und Siebert JR, 1998. 'Cyclopamine-induced holoprosencephaly and associated craniofacial malformations in the golden hamster: anatomic and molecular events.' Pediatr Dev Pathol 1(1): 29-41.

Crowson AN, 2006. 'Basal cell carcinoma: biology, morphology and clinical implications.' Mod Pathol 19 Suppl 2: S127-47.

Dahmane N, Lee J, Robins P, Heller P und Ruiz i Altaba A, 1997. 'Activation of the transcription factor Gli1 and the Sonic hedgehog signalling pathway in skin tumours.' Nature 389(6653): 876-81.

Darvasi A, Weinreb A, Minke V, Weller JI und Soller M, 1993. 'Detecting marker-QTL linkage and estimating QTL gene effect and map location using a saturated genetic map.' Genetics 134(3): 943-51.

Davis MA und Reynolds AB, 2006. 'Blocked acinar development, E-cadherin reduction, and intraepithelial neoplasia upon ablation of p120-catenin in the mouse salivary gland.' Dev Cell 10(1): 2131.

Daya-Grosjean L und Couve-Privat S, 2005. 'Sonic hedgehog signaling in basal cell carcinomas.' Cancer Lett 225(2): 181-92.

de Vries E, van de Poll-Franse LV, Louwman WJ, de Gruijl FR und Coebergh JW, 2005. 'Predictions of skin cancer incidence in the Netherlands up to 2015.' Br J Dermatol 152(3): 481-8.

Doerge RW und Churchill GA, 1996. 'Permutation tests for multiple loci affecting a quantitative character.' Genetics 142(1): 285-94.

Douard R, Moutereau S, Pernet P, Chimingqi M, Allory Y, Manivet P, Conti M, Vaubourdolle M, Cugnenc PH und Loric S, 2006. 'Sonic Hedgehog-dependent proliferation in a series of patients with colorectal cancer.' Surgery 139(5): 665-70.

Echelard Y, Epstein DJ, St-Jacques B, Shen L, Mohler J, McMahon JA und McMahon AP, 1993. 'Sonic hedgehog, a member of a family of putative signaling molecules, is implicated in the regulation of CNS polarity.' Cell 75(7): 1417-30.

El-Bahrawy M, El-Masry N, Alison M, Poulsom R und Fallowfield M, 2003. 'Expression of beta-catenin in basal cell carcinoma.' Br J Dermatol 148(5): 964-70. 
Endo H, Oikawa A, Utani A und Shinkai H, 2004. 'Plexiform neurofibromas express the transcription factor Gli1.' Dermatology 209(4): 284-7.

Evangelista M, Tian H und de Sauvage FJ, 2006. 'The hedgehog signaling pathway in cancer.' Clin Cancer Res 12(20 Pt 1): 5924-8.

Evans DG, Farndon PA, Burnell LD, Gattamaneni HR und Birch JM, 1991. 'The incidence of Gorlin syndrome in 173 consecutive cases of medulloblastoma.' Br J Cancer 64(5): 959-61.

Fan H und Khavari PA, 1999. 'Sonic hedgehog opposes epithelial cell cycle arrest.' J Cell Biol 147(1): 71-6.

Feldmann G, Dhara S, Fendrich V, Bedja D, Beaty R, Mullendore M, Karikari C, Alvarez H, lacobuzioDonahue C, Jimeno A, Gabrielson KL, Matsui W und Maitra A, 2007. 'Blockade of hedgehog signaling inhibits pancreatic cancer invasion and metastases: a new paradigm for combination therapy in solid cancers.' Cancer Res 67(5): 2187-96.

Fendrich V, Waldmann J, Esni F, Ramaswamy A, Mullendore M, Buchholz M, Maitra A und Feldmann G, 2007. 'Snail and Sonic Hedgehog activation in neuroendocrine tumors of the ileum.' Endocr Relat Cancer 14(3): 865-74.

Frohlich L, Liu Z, Beier DR und Lanske B, 2002. 'Genomic structure and refined chromosomal localization of the mouse Ptch2 gene.' Cytogenet Genome Res 97(1-2): 106-10.

Fuchs E, 1993. 'Epidermal differentiation and keratin gene expression.' J Cell Sci Suppl 17: 197-208.

Gailani MR, Bale SJ, Leffell DJ, DiGiovanna JJ, Peck GL, Poliak S, Drum MA, Pastakia B, McBride OW, Kase R und et al., 1992. 'Developmental defects in Gorlin syndrome related to a putative tumor suppressor gene on chromosome 9.' Cell 69(1): 111-7.

Gailani MR, Leffell DJ, Ziegler A, Gross EG, Brash DE und Bale AE, 1996. 'Relationship between sunlight exposure and a key genetic alteration in basal cell carcinoma [see comments].' J Natl Cancer Inst 88(6): 349-54.

Giglia-Mari G und Sarasin A, 2003. 'TP53 mutations in human skin cancers.' Hum Mutat 21(3): 217-28.

Goodrich LV, Milenkovic L, Higgins KM und Scott MP, 1997. 'Altered neural cell fates and medulloblastoma in mouse patched mutants.' Science 277(5329): 1109-13.

Goodrich LV und Scott MP, 1998. 'Hedgehog and patched in neural development and disease.' Neuron 21(6): 1243-57.

Gorlin RJ, 1987. 'Nevoid basal-cell carcinoma syndrome.' Medicine (Baltimore) 66(2): 98-113.

Grachtchouk M, Mo R, Yu S, Zhang X, Sasaki H, Hui CC und Dlugosz AA, 2000. 'Basal cell carcinomas in mice overexpressing Gli2 in skin.' Nat Genet 24(3): 216-7. 
Grachtchouk V, Grachtchouk M, Lowe L, Johnson T, Wei L, Wang A, de Sauvage F und Dlugosz AA, 2003. 'The magnitude of hedgehog signaling activity defines skin tumor phenotype.' Embo J 22(11): 2741-51.

Gu J, Kawai H, Wiederschain D und Yuan ZM, 2001. 'Mechanism of functional inactivation of a LiFraumeni syndrome p53 that has a mutation outside of the DNA-binding domain.' Cancer Res 61(4): 1741-6.

Hahn H, Nitzki F, Schorban T, Hemmerlein B, Threadgill D und Rosemann M, 2004. 'Genetic mapping of a Ptch1-associated rhabdomyosarcoma susceptibility locus on mouse chromosome 2.' Genomics 84(5): 853-8.

Hahn H, Wicking C, Zaphiropoulous PG, Gailani MR, Shanley S, Chidambaram A, Vorechovsky I, Holmberg E, Unden AB, Gillies S, Negus K, Smyth I, Pressman C, Leffell DJ, Gerrard B, Goldstein AM, Dean M, Toftgard R, Chenevix-Trench G, Wainwright B und Bale AE, 1996. 'Mutations of the human homolog of Drosophila patched in the nevoid basal cell carcinoma syndrome.' Cell 85(6): 84151.

Hahn H, Wojnowski L, Miller G und Zimmer A, 1999. 'The patched signaling pathway in tumorigenesis and development: lessons from animal models [In Process Citation].' J Mol Med 77(6): 459-68.

Hahn H, Wojnowski L, Specht K, Kappler R, Calzada-Wack J, Potter D, Zimmer A, Muller U, Samson E und Quintanilla-Martinez L, 2000. 'Patched target lgf2 is indispensable for the formation of medulloblastoma and rhabdomyosarcoma.' J Biol Chem 275(37): 28341-4.

Hahn H, Wojnowski L, Zimmer AM, Hall J, Miller G und Zimmer A, 1998. 'Rhabdomyosarcomas and radiation hypersensitivity in a mouse model of Gorlin syndrome.' Nature Med 4: 619-622.

Hamed S, LaRue H, Hovington H, Girard J, Jeannotte L, Latulippe E und Fradet Y, 2004. 'Accelerated induction of bladder cancer in patched heterozygous mutant mice.' Cancer Res 64(6): 1938-42.

Hameyer D, Loonstra A, Eshkind L, Schmitt S, Antunes C, Groen A, Bindels E, Jonkers J, Krimpenfort P, Meuwissen R, Rijswijk L, Bex A, Berns A und Bockamp E, 2007. 'Toxicity of ligand-dependent Cre recombinases and generation of a conditional Cre deleter mouse allowing mosaic recombination in peripheral tissues.' Physiol Genomics 31(1): 32-41.

Hanahan D und Weinberg RA, 2000. 'The hallmarks of cancer.' Cell 100(1): 57-70.

Hooper JE und Scott MP, 2005. 'Communicating with Hedgehogs.' Nat Rev Mol Cell Biol 6(4): 306-17.

Huang S, He J, Zhang X, Bian Y, Yang L, Xie G, Zhang K, Tang W, Stelter AA, Wang Q, Zhang H und Xie J, 2006. 'Activation of the hedgehog pathway in human hepatocellular carcinomas.' Carcinogenesis 27(7): 1334-40. 
Huangfu D und Anderson KV, 2006. 'Signaling from Smo to Ci/Gli: conservation and divergence of Hedgehog pathways from Drosophila to vertebrates.' Development 133(1): 3-14.

Humphreys RP, 1982. 'Posterior cranial fossa brain tumors in children.' In: J. R. Youmans (ed), Neurological Surgery. W. B. Saunders, Philadelphia: pp. 2733-2752.

Hunter KW und Williams RW, 2002. 'Complexities of cancer research: mouse genetic models.' llar J 43(2): 80-8.

Hutchin ME, Kariapper MS, Grachtchouk M, Wang A, Wei L, Cummings D, Liu J, Michael LE, Glick A und Dlugosz AA, 2005. 'Sustained Hedgehog signaling is required for basal cell carcinoma proliferation and survival: conditional skin tumorigenesis recapitulates the hair growth cycle.' Genes Dev 19(2): 214-23.

Ingham PW und McMahon AP, 2001. 'Hedgehog signaling in animal development: paradigms and principles.' Genes Dev 15(23): 3059-87.

Ingram WJ, Wicking CA, Grimmond SM, Forrest AR und Wainwright BJ, 2002. 'Novel genes regulated by Sonic Hedgehog in pluripotent mesenchymal cells.' Oncogene 21(53): 8196-205.

Inoue J, Gohda J, Akiyama T und Semba K, 2007. 'NF-kappaB activation in development and progression of cancer.' Cancer Sci 98(3): 268-74.

Jemth P und Gianni S, 2007. 'PDZ domains: folding and binding.' Biochemistry 46(30): 8701-8.

Johnson RL, Milenkovic L und Scott MP, 2000. 'In vivo functions of the patched protein: requirement of the $C$ terminus for target gene inactivation but not Hedgehog sequestration.' Mol Cell 6(2): 467-78.

Johnson RL, Rothman AL, Xie J, Goodrich LV, Bare JW, Bonifas JM, Quinn AG, Myers RM, Cox DR, Epstein EH, Jr. und Scott MP, 1996. 'Human homolog of patched, a candidate gene for the basal cell nevus syndrome.' Science 272(5268): 1668-71.

Kaporis HG, Guttman-Yassky E, Lowes MA, Haider AS, Fuentes-Duculan J, Darabi K, Whynot-Ertelt J, Khatcherian A, Cardinale I, Novitskaya I, Krueger JG und Carucci JA, 2007. 'Human basal cell carcinoma is associated with Foxp3+ $T$ cells in a Th2 dominant microenvironment.' J Invest Dermatol 127(10): 2391-8.

Kappler R, Calzada-Wack J, Schnitzbauer U, Koleva M, Herwig A, Piontek G, Graedler F, Adamski J, Heinzmann U, Schlegel J, Hemmerlein B, Quintanilla-Martinez L und Hahn H, 2003. 'Molecular characterization of Patched-associated rhabdomyosarcoma.' J Pathol 200(3): 348-56.

Karagas MR, Stukel TA, Greenberg ER, Baron JA, Mott LA und Stern RS, 1992. 'Risk of subsequent basal cell carcinoma and squamous cell carcinoma of the skin among patients with prior skin cancer. Skin Cancer Prevention Study Group.' Jama 267(24): 3305-10. 
Karhadkar SS, Steven Bova G, Abdallah N, Dhara S, Gardner D, Maitra A, Isaacs JT, Berman DM und Beachy PA, 2004. 'Hedgehog signalling in prostate regeneration, neoplasia and metastasis.' Nature.

Kasper M, Regl G, Frischauf AM und Aberger F, 2006. 'GLI transcription factors: mediators of oncogenic Hedgehog signalling.' Eur J Cancer 42(4): 437-45.

Katoh Y und Katoh M, 2004. 'KIF27 is one of orthologs for Drosophila Costal-2.' Int J Oncol 25(6): 1875-80.

Katoh $\mathrm{Y}$ und Katoh M, 2006. 'Hedgehog signaling pathway and gastrointestinal stem cell signaling network (review).' Int J Mol Med 18(6): 1019-23.

Kaur P, Mulvaney M und Carlson JA, 2006. 'Basal cell carcinoma progression correlates with host immune response and stromal alterations: a histologic analysis.' Am J Dermatopathol 28(4): 293-307.

Kawakami T, Kawcak T, Li YJ, Zhang W, Hu Y und Chuang PT, 2002. 'Mouse dispatched mutants fail to distribute hedgehog proteins and are defective in hedgehog signaling.' Development 129(24): 575365.

Kimonis VE, Goldstein AM, Pastakia B, Yang ML, Kase R, DiGiovanna JJ, Bale AE und Bale SJ, 1997. 'Clinical manifestations in 105 persons with nevoid basal cell carcinoma syndrome.' Am J Med Genet 69(3): 299-308.

King KE, Ponnamperuma RM, Yamashita T, Tokino T, Lee LA, Young MF und Weinberg WC, 2003. 'deltaNp63alpha functions as both a positive and a negative transcriptional regulator and blocks in vitro differentiation of murine keratinocytes.' Oncogene 22(23): 3635-44.

Knudson AG, Jr., 1971. 'Mutation and cancer: statistical study of retinoblastoma.' Proc Natl Acad Sci U $S$ A 68(4): 820-3.

Kobayashi T, Walsh MC und Choi Y, 2004. 'The role of TRAF6 in signal transduction and the immune response.' Microbes Infect 6(14): 1333-8.

Koster MI, Dai D, Marinari B, Sano Y, Costanzo A, Karin M und Roop DR, 2007. 'p63 induces key target genes required for epidermal morphogenesis.' Proc Natl Acad Sci U S A 104(9): 3255-60.

Kraemer KH, Lee MM, Andrews AD und Lambert WC, 1994. 'The role of sunlight and DNA repair in melanoma and nonmelanoma skin cancer. The xeroderma pigmentosum paradigm.' Arch Dermatol 130(8): 1018-21.

Kraemer KH, Lee MM und Scotto J, 1987. 'Xeroderma pigmentosum. Cutaneous, ocular, and neurologic abnormalities in 830 published cases.' Arch Dermatol 123(2): 241-50.

Kroemer G und Martin SJ, 2005. 'Caspase-independent cell death.' Nat Med 11(7): 725-30. 
Kruger K, Blume-Peytavi U und Orfanos CE, 1999. 'Basal cell carcinoma possibly originates from the outer root sheath and/or the bulge region of the vellus hair follicle.' Arch Dermatol Res 291(5): 253-9.

Kuwabara PE und Labouesse M, 2002. 'The sterol-sensing domain: multiple families, a unique role?' Trends Genet 18(4): 193-201.

Lacina L, Smetana K, Jr., Dvorankova B, Pytlik R, Kideryova L, Kucerova L, Plzakova Z, Stork J, Gabius HJ und Andre S, 2007. 'Stromal fibroblasts from basal cell carcinoma affect phenotype of normal keratinocytes.' Br J Dermatol 156(5): 819-29.

Lacour JP, 2002. 'Carcinogenesis of basal cell carcinomas: genetics and molecular mechanisms.' $\mathrm{Br} \mathrm{J}$ Dermatol 146 Suppl 61: 17-9.

Lakso M, Pichel JG, Gorman JR, Sauer B, Okamoto Y, Lee E, Alt FW und Westphal H, 1996. 'Efficient in vivo manipulation of mouse genomic sequences at the zygote stage.' Proc Natl Acad Sci U S A 93(12): 5860-5.

Lam CW, Xie J, To KF, Ng HK, Lee KC, Yuen NW, Lim PL, Chan LY, Tong SF und McCormick F, 1999. 'A frequent activated smoothened mutation in sporadic basal cell carcinomas.' Oncogene 18(3): 833-6.

Lespi PJ und Gregorini SD, 2000. 'Folliculotropic T cells in regressive basal cell carcinoma of skin.' Am J Dermatopathol 22(1): 30-3.

Li J, Meyer AN und Donoghue DJ, 1997. 'Nuclear localization of cyclin B1 mediates its biological activity and is regulated by phosphorylation.' Proc Natl Acad Sci U S A 94(2): 502-7.

Li JL, Sainson RC, Shi W, Leek R, Harrington LS, Preusser M, Biswas S, Turley H, Heikamp E, Hainfellner JA und Harris AL, 2007. 'Delta-like 4 Notch ligand regulates tumor angiogenesis, improves tumor vascular function, and promotes tumor growth in vivo.' Cancer Res 67(23): 11244-53.

Lindstrom E, Shimokawa T, Toftgard R und Zaphiropoulos PG, 2006. 'PTCH mutations: distribution and analyses.' Hum Mutat 27(3): 215-9.

Lo Celso C, Prowse DM und Watt FM, 2004. 'Transient activation of beta-catenin signalling in adult mouse epidermis is sufficient to induce new hair follicles but continuous activation is required to maintain hair follicle tumours.' Development 131(8): 1787-99.

Lo Muzio L, Pannone G, Staibano S, Mignogna MD, Grieco M, Ramires P, Romito AM, De Rosa G und Piattelli A, 2002. 'WNT-1 expression in basal cell carcinoma of head and neck. An immunohistochemical and confocal study with regard to the intracellular distribution of beta-catenin.' Anticancer Res 22(2A): 565-76. 
Ma Y, Erkner A, Gong R, Yao S, Taipale J, Basler K und Beachy PA, 2002. 'Hedgehog-mediated patterning of the mammalian embryo requires transporter-like function of dispatched.' Cell 111(1): 6375.

Madan V, Hoban P, Strange RC, Fryer AA und Lear JT, 2006. 'Genetics and risk factors for basal cell carcinoma.' Br J Dermatol 154 Suppl 1: 5-7.

Makino S, Masuya H, Ishijima J, Yada $\mathrm{Y}$ und Shiroishi T, 2001. 'A spontaneous mouse mutation, mesenchymal dysplasia (mes), is caused by a deletion of the most C-terminal cytoplasmic domain of patched (ptc).' Dev Biol 239(1): 95-106.

Maloney ME, 1995. 'Histology of basal cell carcinoma.' Clin Dermatol 13(6): 545-9.

Mancuso M, Leonardi S, Tanori M, Pasquali E, Pierdomenico M, Rebessi S, Di Majo V, Covelli V, Pazzaglia S und Saran A, 2006. 'Hair cycle-dependent basal cell carcinoma tumorigenesis in Ptc1neo67/+ mice exposed to radiation.' Cancer Res 66(13): 6606-14.

Mancuso M, Pazzaglia S, Tanori M, Hahn H, Merola P, Rebessi S, Atkinson MJ, Di Majo V, Covelli V und Saran A, 2004. 'Basal cell carcinoma and its development: insights from radiation-induced tumors in Ptch1-deficient mice.' Cancer Res 64(3): 934-41.

Mao X, Seidlitz E, Ghosh K, Murakami Y und Ghosh HP, 2003. 'The cytoplasmic domain is critical to the tumor suppressor activity of TSLC1 in non-small cell lung cancer.' Cancer Res 63(22): 7979-85.

Marigo V, Davey RA, Zuo Y, Cunningham JM und Tabin CJ, 1996a. 'Biochemical evidence that patched is the Hedgehog receptor [see comments].' Nature 384(6605): 176-9.

Marigo V, Johnson RL, Vortkamp A und Tabin CJ, 1996b. 'Sonic hedgehog differentially regulates expression of GLI and GLI3 during limb development.' Dev Biol 180(1): 273-83.

McFerren MA, 2006. 'Useful plants of dermatology. VIII. The false hellebore (Veratrum californicum).' J Am Acad Dermatol 54(4): 718-20.

Mehlen P und Bredesen DE, 2004. 'The dependence receptor hypothesis.' Apoptosis 9(1): 37-49.

Mehlen P, Mille F und Thibert C, 2005. 'Morphogens and cell survival during development.' J Neurobiol 64(4): 357-66.

Mentzel T und Kuhnen C, 2006. 'Spindle cell rhabdomyosarcoma in adults: clinicopathological and immunohistochemical analysis of seven new cases.' Virchows Arch 449(5): 554-60.

Millar SE, 2002. 'Molecular mechanisms regulating hair follicle development.' J Invest Dermatol 118(2): 216-25.

Miller DL und Weinstock MA, 1994. 'Nonmelanoma skin cancer in the United States: incidence.' J Am Acad Dermatol 30(5 Pt 1): 774-8. 
Mizuno T, Tokuoka S, Kishikawa M, Nakashima E, Mabuchi K und Iwamoto KS, 2006. 'Molecular basis of basal cell carcinogenesis in the atomic-bomb survivor population: p53 and PTCH gene alterations.' Carcinogenesis 27(11): 2286-94.

Motoyama J, Liu J, Mo R, Ding Q, Post M und Hui CC, 1998. 'Essential function of Gli2 and Gli3 in the formation of lung, trachea and oesophagus.' Nat Genet 20(1): 54-7.

Muller-Rover S, Handjiski B, van der Veen C, Eichmuller S, Foitzik K, McKay IA, Stenn KS und Paus $\mathrm{R}, 2001$. 'A comprehensive guide for the accurate classification of murine hair follicles in distinct hair cycle stages.' J Invest Dermatol 117(1): 3-15.

Nagao K, Togawa N, Fujii K, Uchikawa H, Kohno Y, Yamada M und Miyashita T, 2005a. 'Detecting tissue-specific alternative splicing and disease-associated aberrant splicing of the PTCH gene with exon junction microarrays.' Hum Mol Genet 14(22): 3379-88.

Nagao K, Toyoda M, Takeuchi-Inoue K, Fujii K, Yamada M und Miyashita T, 2005b. 'Identification and characterization of multiple isoforms of a murine and human tumor suppressor, patched, having distinct first exons.' Genomics 85(4): 462-71.

Nakano Y, Kim HR, Kawakami A, Roy S, Schier AF und Ingham PW, 2004. 'Inactivation of dispatched 1 by the chameleon mutation disrupts Hedgehog signalling in the zebrafish embryo.' Dev Biol 269(2): 381-92.

Nguyen BC, Lefort K, Mandinova A, Antonini D, Devgan V, Della Gatta G, Koster MI, Zhang Z, Wang J, Tommasi di Vignano A, Kitajewski J, Chiorino G, Roop DR, Missero C und Dotto GP, 2006. 'Crossregulation between Notch and p63 in keratinocyte commitment to differentiation.' Genes Dev 20(8): 1028-42.

Nilsson M, Unden AB, Krause D, Malmqwist U, Raza K, Zaphiropoulos PG und Toftgard R, 2000. 'Induction of basal cell carcinomas and trichoepitheliomas in mice overexpressing GLI-1 [In Process Citation].' Proc Natl Acad Sci U S A 97(7): 3438-43.

Nitzki F, Kruger A, Reifenberg K, Wojnowski L und Hahn H, 2007. 'Identification of a genetic contamination in a commercial mouse strain using two panels of polymorphic markers.' Lab Anim 41(2): 218-28.

Nusslein-Volhard C und Wieschaus E, 1980. 'Mutations affecting segment number and polarity in Drosophila.' Nature 287(5785): 795-801.

Nybakken K und Perrimon N, 2002. 'Hedgehog signal transduction: recent findings.' Curr Opin Genet Dev 12(5): 503-11.

Oro AE und Higgins K, 2003. 'Hair cycle regulation of Hedgehog signal reception.' Dev Biol 255(2): 238-48. 
Oro AE, Higgins KM, Hu Z, Bonifas JM, Epstein EH, Jr. und Scott MP, 1997. 'Basal cell carcinomas in mice overexpressing sonic hedgehog.' Science 276(5313): 817-21.

Paladini RD, Saleh J, Qian C, Xu GX und Rubin LL, 2005. 'Modulation of hair growth with small molecule agonists of the hedgehog signaling pathway.' J Invest Dermatol 125(4): 638-46.

Paramio JM, Casanova ML, Segrelles C, Mittnacht S, Lane EB und Jorcano JL, 1999. 'Modulation of cell proliferation by cytokeratins K10 and K16.' Mol Cell Biol 19(4): 3086-94.

Paramio JM, Segrelles C, Ruiz S und Jorcano JL, 2001. 'Inhibition of protein kinase B (PKB) and PKCzeta mediates keratin K10-induced cell cycle arrest.' Mol Cell Biol 21(21): 7449-59.

Paus R und Cotsarelis G, 1999. 'The biology of hair follicles.' N Engl J Med 341(7): 491-7.

Paus R, Nickoloff BJ und Ito T, 2005. 'A 'hairy' privilege.' Trends Immunol 26(1): 32-40.

Pazzaglia S, Mancuso M, Atkinson MJ, Tanori M, Rebessi S, Majo VD, Covelli V, Hahn H und Saran A, 2002. 'High incidence of medulloblastoma following X-ray-irradiation of newborn Ptc1 heterozygous mice.' Oncogene 21(49): 7580-4.

Pazzaglia S, Mancuso M, Tanori M, Atkinson MJ, Merola P, Rebessi S, Di Majo V, Covelli V, Hahn H und Saran A, 2004. 'Modulation of patched-associated susceptibility to radiation induced tumorigenesis by genetic background.' Cancer Res 64(11): 3798-806.

Petkov PM, Ding Y, Cassell MA, Zhang W, Wagner G, Sargent EE, Asquith S, Crew V, Johnson KA, Robinson P, Scott VE und Wiles MV, 2004. 'An efficient SNP system for mouse genome scanning and elucidating strain relationships.' Genome Res 14(9): 1806-11.

Pham LV, Zhou HJ, Lin-Lee YC, Tamayo AT, Yoshimura LC, Fu L, Darnay BG und Ford RJ, 2008. 'Nuclear Tumor Necrosis Factor Receptor-associated Factor 6 in Lymphoid Cells Negatively Regulates c-Myb-mediated Transactivation through Small Ubiquitin-related Modifier-1 Modification.' J Biol Chem 283(8): 5081-9.

Pietsch T, Waha A, Koch A, Kraus J, Albrecht S, Tonn J, Sorensen N, Berthold F, Henk B, Schmandt N, Wolf HK, von Deimling A, Wainwright B, Chenevix-Trench G, Wiestler OD und Wicking C, 1997. 'Medulloblastomas of the desmoplastic variant carry mutations of the human homologue of Drosophila patched.' Cancer Res 57(11): 2085-8.

Pintar A, De Biasio A, Popovic M, Ivanova N und Pongor S, 2007. 'The intracellular region of Notch ligands: does the tail make the difference?' Biol Direct 2: 19.

Ponting CP, Phillips C, Davies KE und Blake DJ, 1997. 'PDZ domains: targeting signalling molecules to sub-membranous sites.' Bioessays 19(6): 469-79. 
Pritchard JI und Olson JM, 2008. 'Methylation of PTCH1, the Patched-1 gene, in a panel of primary medulloblastomas.' Cancer Genet Cytogenet 180(1): 47-50.

Raffel C, Jenkins RB, Frederick L, Hebrink D, Alderete B, Fults DW und James CD, 1997. 'Sporadic medulloblastomas contain PTCH mutations.' Cancer Res 57(5): 842-5.

Rawlins J, Platt A und Gowda P, 2006. 'Regression of BCC following immunosuppression withdrawal in a renal transplant recipient.' Clin Exp Dermatol 31(5): 717-8.

Regl G, Kasper M, Schnidar H, Eichberger T, Neill GW, Ikram MS, Quinn AG, Philpott MP, Frischauf AM und Aberger F, 2004. 'The zinc-finger transcription factor GLI2 antagonizes contact inhibition and differentiation of human epidermal cells.' Oncogene 23(6): 1263-74.

Reichelt J, Furstenberger G und Magin TM, 2004. 'Loss of keratin 10 leads to mitogen-activated protein kinase (MAPK) activation, increased keratinocyte turnover, and decreased tumor formation in mice.' J Invest Dermatol 123(5): 973-81.

Reichelt $\mathrm{J}$ und Magin TM, 2002. 'Hyperproliferation, induction of c-Myc and 14-3-3sigma, but no cell fragility in keratin-10-null mice.' J Cell Sci 115(Pt 13): 2639-50.

Reifenberger J, Wolter M, Knobbe CB, Kohler B, Schonicke A, Scharwachter C, Kumar K, Blaschke B, Ruzicka T und Reifenberger G, 2005. 'Somatic mutations in the PTCH, SMOH, SUFUH and TP53 genes in sporadic basal cell carcinomas.' Br J Dermatol 152(1): 43-51.

Reifenberger J, Wolter M, Weber RG, Megahed M, Ruzicka T, Lichter P und Reifenberger G, 1998. 'Missense mutations in $\mathrm{SMOH}$ in sporadic basal cell carcinomas of the skin and primitive neuroectodermal tumors of the central nervous system.' Cancer Res 58(9): 1798-803.

Remotti F, Fetsch JF und Miettinen M, 2001. 'Keratin 1 expression in endothelia and mesenchymal tumors: an immunohistochemical analysis of normal and neoplastic tissues.' Hum Pathol 32(8): 873-9.

Roberts WM, Douglass EC, Peiper SC, Houghton PJ und Look AT, 1989. 'Amplification of the gli gene in childhood sarcomas.' Cancer Res 49(19): 5407-13.

Robinson JK und Dahiya M, 2003. 'Basal cell carcinoma with pulmonary and lymph node metastasis causing death.' Arch Dermatol 139(5): 643-8.

Rossi A, Caracciolo V, Russo G, Reiss K und Giordano A, 2008. 'Medulloblastoma: From Molecular Pathology to Therapy.' Clin Cancer Res 14(4): 971-976.

Rubin Al, Chen EH und Ratner D, 2005. 'Basal-cell carcinoma.' N Engl J Med 353(21): 2262-9.

Ruiz i Altaba A, 1999. 'Gli proteins and Hedgehog signaling: development and cancer.' Trends Genet 15(10): 418-25. 
Saldanha G, Ghura V, Potter L und Fletcher A, 2004. 'Nuclear beta-catenin in basal cell carcinoma correlates with increased proliferation.' $\mathrm{Br} J$ Dermatol 151(1): 157-64.

Salto-Tellez M, Peh BK, Ito K, Tan SH, Chong PY, Han HC, Tada K, Ong WY, Soong R, Voon DC und Ito $Y, 2006$. 'RUNX3 protein is overexpressed in human basal cell carcinomas.' Oncogene 25(58): 7646-9.

Santos M, Paramio JM, Bravo A, Ramirez A und Jorcano JL, 2002. 'The expression of keratin k10 in the basal layer of the epidermis inhibits cell proliferation and prevents skin tumorigenesis.' J Biol Chem 277(21): 19122-30.

Santos M, Rio P, Ruiz S, Martinez-Palacio J, Segrelles C, Lara MF, Segovia JC und Paramio JM, 2005. 'Altered $T$ cell differentiation and Notch signaling induced by the ectopic expression of keratin K10 in the epithelial cells of the thymus.' J Cell Biochem 95(3): 543-58.

Sato N, Leopold PL und Crystal RG, 1999. 'Induction of the hair growth phase in postnatal mice by localized transient expression of Sonic hedgehog.' J Clin Invest 104(7): 855-64.

Sheng H, Goich S, Wang A, Grachtchouk M, Lowe L, Mo R, Lin K, de Sauvage FJ, Sasaki H, Hui CC und Dlugosz AA, 2002. 'Dissecting the oncogenic potential of Gli2: deletion of an NH(2)-terminal fragment alters skin tumor phenotype.' Cancer Res 62(18): 5308-16.

Shimizu S, Kanaseki T, Mizushima N, Mizuta T, Arakawa-Kobayashi S, Thompson CB und Tsujimoto $\mathrm{Y}$, 2004. 'Role of Bcl-2 family proteins in a non-apoptotic programmed cell death dependent on autophagy genes.' Nat Cell Biol 6(12): 1221-8.

Shin DM, Charuruks N, Lippman SM, Lee JJ, Ro JY, Hong WK und Hittelman WN, 2001. 'p53 protein accumulation and genomic instability in head and neck multistep tumorigenesis.' Cancer Epidemiol Biomarkers Prev 10(6): 603-9.

Shutter JR, Scully S, Fan W, Richards WG, Kitajewski J, Deblandre GA, Kintner CR und Stark KL, 2000. 'DII4, a novel Notch ligand expressed in arterial endothelium.' Genes Dev 14(11): 1313-8.

Sidransky D, 1996. 'Is human patched the gatekeeper of common skin cancers? [news; comment].' Nat Genet 14(1): 7-8.

Singh J, Itahana Y, Parrinello S, Murata K und Desprez PY, 2001. 'Molecular cloning and characterization of a zinc finger protein involved in Id-1-stimulated mammary epithelial cell growth.' J Biol Chem 276(15): 11852-8.

Smyth I, Narang MA, Evans T, Heimann C, Nakamura Y, Chenevix-Trench G, Pietsch T, Wicking C und Wainwright BJ, 1999. 'Isolation and characterization of human Patched 2 (PTCH2), a putative tumor suppressor gene in basal cell carcinoma and medulloblastoma on chromosome 1p32.' Hum Mol Gen 6(2): 291-297. 
Sneddon JB, Zhen HH, Montgomery K, van de Rijn M, Tward AD, West R, Gladstone H, Chang HY, Morganroth GS, Oro AE und Brown PO, 2006. 'Bone morphogenetic protein antagonist gremlin 1 is widely expressed by cancer-associated stromal cells and can promote tumor cell proliferation.' Proc Natl Acad Sci U S A 103(40): 14842-7.

Soriano P, 1999. 'Generalized lacZ expression with the ROSA26 Cre reporter strain.' Nat Genet 21(1): 70-1.

St-Jacques B, Dassule HR, Karavanova I, Botchkarev VA, Li J, Danielian PS, McMahon JA, Lewis PM, Paus R und McMahon AP, 1998. 'Sonic hedgehog signaling is essential for hair development.' Curr Biol 8(19): 1058-68.

Strutt H, Thomas C, Nakano Y, Stark D, Neave B, Taylor AM und Ingham PW, 2001. 'Mutations in the sterol-sensing domain of Patched suggest a role for vesicular trafficking in Smoothened regulation.' Curr Biol 11(8): 608-13.

Taipale J, Chen JK, Cooper MK, Wang B, Mann RK, Milenkovic L, Scott MP und Beachy PA, 2000. 'Effects of oncogenic mutations in Smoothened and Patched can be reversed by cyclopamine.' Nature 406(6799): 1005-9.

Taipale J, Cooper MK, Maiti T und Beachy PA, 2002. 'Patched acts catalytically to suppress the activity of Smoothened.' Nature 418(6900): 892-7.

Tamiji S, Beauvillain JC, Mortier L, Jouy N, Tual M, Delaporte E, Formstecher P, Marchetti P und Polakowska R, 2005. 'Induction of apoptosis-like mitochondrial impairment triggers antioxidant and Bcl-2-dependent keratinocyte differentiation.' J Invest Dermatol 125(4): 647-58.

Thayer SP, di Magliano MP, Heiser PW, Nielsen CM, Roberts DJ, Lauwers GY, Qi YP, Gysin S, Fernandez-del Castillo C, Yajnik V, Antoniu B, McMahon M, Warshaw AL und Hebrok M, 2003. 'Hedgehog is an early and late mediator of pancreatic cancer tumorigenesis.' Nature 425(6960): 851-6.

Thibert C, Teillet MA, Lapointe F, Mazelin L, Le Douarin NM und Mehlen P, 2003. 'Inhibition of neuroepithelial patched-induced apoptosis by sonic hedgehog.' Science 301(5634): 843-6.

Thoreson MA und Reynolds AB, 2002. 'Altered expression of the catenin p120 in human cancer: implications for tumor progression.' Differentiation 70(9-10): 583-9.

Tian H, Jeong J, Harfe BD, Tabin CJ und McMahon AP, 2005. 'Mouse Disp1 is required in sonic hedgehog-expressing cells for paracrine activity of the cholesterol-modified ligand.' Development 132(1): 133-42.

Tiet TD, Hopyan S, Nadesan P, Gokgoz N, Poon R, Lin AC, Yan T, Andrulis IL, Alman BA und Wunder JS, 2006. 'Constitutive hedgehog signaling in chondrosarcoma up-regulates tumor cell proliferation.' Am J Pathol 168(1): 321-30. 
Tostar U, Malm CJ, Meis-Kindblom JM, Kindblom LG, Toftgard R und Unden AB, 2006. 'Deregulation of the hedgehog signalling pathway: a possible role for the PTCH and SUFU genes in human rhabdomyoma and rhabdomyosarcoma development.' J Pathol 208(1): 17-25.

Truong AB und Khavari PA, 2007. 'Control of keratinocyte proliferation and differentiation by p63.' Cell Cycle 6(3): 295-9.

Truong AB, Kretz M, Ridky TW, Kimmel R und Khavari PA, 2006. 'p63 regulates proliferation and differentiation of developmentally mature keratinocytes.' Genes Dev 20(22): 3185-97.

Tsujimoto Y und Shimizu S, 2005. 'Another way to die: autophagic programmed cell death.' Cell Death Differ 12 Suppl 2: 1528-34.

Uhmann A, Dittmann K, Nitzki F, Dressel R, Koleva M, Frommhold A, Zibat A, Binder C, Adham I, Nitsche M, Heller T, Armstrong V, Schulz-Schaeffer W, Wienands J und Hahn H, 2007. 'The hedgehog receptor patched controls lymphoid lineage commitment.' Blood 110(6): 1814-23.

Uhmann A, Ferch U, Bauer R, Tauber S, Arziman Z, Chen C, Hemmerlein B, Wojnowski L und Hahn $\mathrm{H}$, 2005. 'A model for PTCH1/Ptch1-associated tumors comprising mutational inactivation and gene silencing.' Int J Oncol 27(6): 1567-75.

Unden AB, Zaphiropoulos PG, Bruce K, Toftg ard R und St ahle-Backdahl M, 1997. 'Human patched (PTCH) mRNA is overexpressed consistently in tumor cells of both familial and sporadic basal cell carcinoma.' Cancer Res 57(12): 2336-40.

Vorechovsky I, Tingby O, Hartman M, Stromberg B, Nister M, Collins VP und Toftgard R, 1997a. 'Somatic mutations in the human homologue of Drosophila patched in primitive neuroectodermal tumours.' Oncogene 15(3): 361-6.

Vorechovsky I, Unden AB, Sandstedt B, Toftgard R und Stahle-Backdahl M, 1997b. 'Trichoepitheliomas contain somatic mutations in the overexpressed PTCH gene: support for a gatekeeper mechanism in skin tumorigenesis.' Cancer Res 57(21): 4677-81.

Wade CM, Kulbokas EJ, 3rd, Kirby AW, Zody MC, Mullikin JC, Lander ES, Lindblad-Toh K und Daly MJ, 2002. 'The mosaic structure of variation in the laboratory mouse genome.' Nature 420(6915): 5748.

Wang LC, Liu ZY, Gambardella L, Delacour A, Shapiro R, Yang J, Sizing I, Rayhorn P, Garber EA, Benjamin CD, Williams KP, Taylor FR, Barrandon Y, Ling L und Burkly LC, 2000. 'Regular articles: conditional disruption of hedgehog signaling pathway defines its critical role in hair development and regeneration.' J Invest Dermatol 114(5): 901-8.

Watkins DN, Berman DM, Burkholder SG, Wang B, Beachy PA und Baylin SB, 2003. 'Hedgehog signalling within airway epithelial progenitors and in small-cell lung cancer.' Nature 422(6929): 313-7. 
Wetmore C, Eberhart DE und Curran T, 2000. 'The normal patched allele is expressed in medulloblastomas from mice with heterozygous germ-line mutation of patched.' Cancer Res 60(8): 2239-46.

Willnow TE, Hammes A und Eaton S, 2007. 'Lipoproteins and their receptors in embryonic development: more than cholesterol clearance.' Development 134(18): 3239-49.

Wolter M, Reifenberger J, Sommer C, Ruzicka T und Reifenberger G, 1997. 'Mutations in the human homologue of the Drosophila segment polarity gene patched (PTCH) in sporadic basal cell carcinomas of the skin and primitive neuroectodermal tumors of the central nervous system.' Cancer Res 57(13): 2581-5.

Wong DA, Bishop GA, Lowes MA, Cooke B, Barnetson RS und Halliday GM, 2000. 'Cytokine profiles in spontaneously regressing basal cell carcinomas.' $\mathrm{Br} \mathrm{J}$ Dermatol 143(1): 91-8.

Xie J, Johnson RL, Zhang X, Bare JW, Waldman FM, Cogen PH, Menon AG, Warren RS, Chen LC, Scott MP und Epstein EH, Jr., 1997. 'Mutations of the PATCHED gene in several types of sporadic extracutaneous tumors.' Cancer Res 57(12): 2369-72.

Xie J, Murone M, Luoh SM, Ryan A, Gu Q, Zhang C, Bonifas JM, Lam CW, Hynes M, Goddard A, Rosenthal A, Epstein EH, Jr. und de Sauvage FJ, 1998. 'Activating Smoothened mutations in sporadic basal-cell carcinoma.' Nature 391(6662): 90-2.

Yamamoto O und Asahi M, 1999. 'Cytokeratin expression in trichoblastic fibroma (small nodular type trichoblastoma), trichoepithelioma and basal cell carcinoma.' Br J Dermatol 140(1): 8-16.

Yamazaki F, Aragane Y, Kawada A und Tezuka T, 2001. 'Immunohistochemical detection for nuclear beta-catenin in sporadic basal cell carcinoma.' Br J Dermatol 145(5): 771-7.

Yang A, Kaghad M, Wang Y, Gillett E, Fleming MD, Dotsch V, Andrews NC, Caput D und McKeon F, 1998. 'p63, a p53 homolog at 3q27-29, encodes multiple products with transactivating, death-inducing, and dominant-negative activities.' Mol Cell 2(3): 305-16.

Yoon JW, Kita Y, Frank DJ, Majewski RR, Konicek BA, Nobrega MA, Jacob H, Walterhouse D und lannaccone P, 2002. 'Gene expression profiling leads to identification of GLI1-binding elements in target genes and a role for multiple downstream pathways in GLI1-induced cell transformation.' J Biol Chem 277(7): 5548-55.

Zabala M, Wang L, Hernandez-Alcoceba R, Hillen W, Qian C, Prieto J und Kramer MG, 2004. 'Optimization of the Tet-on system to regulate interleukin 12 expression in the liver for the treatment of hepatic tumors.' Cancer Res 64(8): 2799-804.

Zhang H, Ping XL, Lee PK, Wu XL, Yao YJ, Zhang MJ, Silvers DN, Ratner D, Malhotra R, Peacocke $M$ und Tsou HC, 2001. 'Role of PTCH and p53 genes in early-onset basal cell carcinoma.' Am J Pathol 158(2): 381-5. 
Zurawel RH, Allen C, Chiappa S, Cato W, Biegel J, Cogen P, de Sauvage F und Raffel C, 2000a. 'Analysis of PTCH/SMO/SHH pathway genes in medulloblastoma.' Genes Chromosomes Cancer 27(1): 44-51.

Zurawel RH, Allen C, Wechsler-Reya R, Scott MP und Raffel C, 2000b. 'Evidence that haploinsufficiency of Ptch leads to medulloblastoma in mice.' Genes Chromosomes Cancer 28(1): 7781. 


\section{Danksagung}

Diese Arbeit wurde an der Universität Göttingen am Institut für Humangenetik (Leitung Prof. Dr. W. Engel) angefertigt.

Mein besonderer Dank gilt Frau Prof. Dr. H. Hahn für die Bereitstellung der interessanten Themen, der intensiven Betreuung und Unterstützung sowie für die vielen Gespräche und Anregungen.

Herzlich bedanken möchte ich mich bei Herrn Prof. Dr. W. Engel für die Übernahme des Referats und für die Möglichkeit, diese Arbeit am Institut für Humangenetik anfertigen zu können.

Herrn Prof. Dr. R. Hardeland danke ich für die sofortige Bereitschaft, das Korreferat zu übernehmen.

Bei Herrn PD Dr. W. Schulz-Schaeffer bedanke ich mich für viele wertvolle Ratschläge und die Unterstützung zur Durchführung und Interpretation von histologischen Färbungen.

Für die umfassende Einweisung in die Methode der in situ-Hybridisierung, die Hilfestellung und die Durchführung von Färbungen danke ich Herrn Dr. M. Wijgerde.

Herr Dr. M. Rosemann, der die statistische Auswertung der Kopplungsanalysen durchgeführt hat, hatte auch bei Fragen zu diesen Analysen stets ein offenes Ohr. Für die Auswertung und viele einleuchtende Erklärungen möchte ich inm herzlich danken.

Frau Dr. B. Kulle danke ich für die Clusteranalyse.

Weiterhin möchte ich Herrn Dr. F. Brembeck sowie allen anderen, die mir freundlicherweise Antikörper zur Verfügung gestellt haben, herzlich danken.

Danke auch an Tatjana Pfander, die mich in immunhistochemische Methoden eingearbeitet hat.

An unsere gesamte Arbeitsgruppe vielen Dank für die angenehme Atmosphäre. Besonders möchte ich mich bei Ina Heß, Astrid Herwig und Anke Frommhold für die großartige technische Unterstützung und Zusammenarbeit bedanken. Außerdem möchte ich Ines Ecke, Dr. Arne Zibat und ganz besonders meiner lieben Dr. Anja Uhmann für ihre Unterstützung und viele gute Ratschläge danken. Es ist toll, mit Euch allen zu arbeiten.

Auch den Mitarbeitern der Tierhaltung, insbesondere Kerstin Beyer und Stefan Wolf, gilt mein besonderer Dank.

Schließlich möchte ich mich auch bei meiner Familie, Dennis, Anneliese und allen anderen bedanken, die mich während der Erstellung dieser Arbeit unterstützt haben. 


\section{$9 \quad$ Lebenslauf}

\section{Persönliche Angaben}

geboren am 04. Dezember 1978 in Hannover

Staatsangehörigkeit: deutsch

\section{Ausbildung}

Juli 2003 bis März 2008

Promotion am Institut für Humangenetik, Arbeitsgruppe Prof. Dr. H. Hahn, Universität Göttingen

,Patched-assoziierte Tumoren: Modifikatorgene und Pathogenese'

Juli 2003

Diplom in Biologie (Note: sehr gut)

2002-2003

Diplomarbeit in der Abteilung für Immunologie, Prof. Dr. O. Götze, Universität Göttingen

'Expressionsregulation des Komplementproteins Faktor $\mathrm{H}$ in KupfferZellen durch das C5a-Anaphylatoxin'

Okt 2000 Vordiplom in Biologie (Note: sehr gut)

1998-2002

Studium der Biologie, Universität Göttingen

Juni 1998

Abitur (Note: gut), Johannes-Kepler-Gymnasium Garbsen

\section{Berufserfahrung und Praktika}

Mai-Sept 2001

März-Mai 2002

Sept-Nov 2002

Aug-Okt 2001

Aug 2000
Studentische Hilfskraft am Zoologischen Institut in den Abteilungen Morphologie und Neurobiologie: Betreuung von Praktika

Praktikum beim US Fish and Wildlife Service im National Wildlife Refuge Bosque del Apache, New Mexico

Praktikum beim Verein Jordsand zum Schutze der Seevögel und der Natur e.V., Ahrensburg im Vogelschutzgebiet Oehe-Schleimünde

\section{Publikationen}

Uhmann A und Dittmann K, Nitzki F, Dressel R, Koleva M, Frommhold A, Zibat A, Binder C, Adham I, Nitsche M, Heller T, Armstrong V, Schulz-Schaeffer W, Wienands J und Hahn H. The hedgehog receptor patched controls lymphoid lineage commitment. Blood. 2007 Sep 15;110(6):1814-23.

Nitzki F, Kruger A, Reifenberg K, Wojnowski L und Hahn H. Identification of a genetic contamination in a commercial mouse strain using two panels of polymorphic markers. Lab Anim. 2007 Apr;41(2):21828.

Hahn H, Nitzki F, Schorban T, Hemmerlein B, Threadgill D und Rosemann M. Genetic mapping of a Ptch1-associated rhabdomyosarcoma susceptibility locus on mouse chromosome 2. Genomics. 2004 Nov;84(5):853-8. 
Schlaf G und Nitzki F, Heine I, Hardeland R, Schieferdecker HL, Götze O. C5a anaphylatoxin as a product of complement activation up-regulates the complement inhibitory factor $\mathrm{H}$ in rat Kupffer cells. Eur J Immunol. 2004 Nov;34(11):3257-66.

Burkhardt S, Poeggeler B, Tan D-X, Rosner C, Gruetzner T, Nitzki F, Schoenke M, Thuermann S, Reiter RJ, Hardeland R. Oxidation products formed from melatonin in various radical-generating systems. In: Hardeland R., editor. Actions and Redox Properties of Melatonin and Other Aromatic Amino Acid Metabolites, Göttingen: Cuvillier, 2001. pp. 9-22.

\section{Poster und Präsentationen}

Sept 2007

Sept 2006

März 2005

Juni 2004
Horizons in Molecular Biology 2007, Göttingen

Posterpräsentation: Interaction between Hedgehog/Patched and Wnt5a

Signalling in BCC'

Horizons in Molecular Biology 2006, Göttingen

Vortrag und Posterpräsentation: ,Induction of Basal Cell Carcinoma by conditional Ptch ablation', Auszeichnung mit dem Student talk Preis Horizons in Molecular Biology 2005, Göttingen

Posterpräsentation: ,Genetic mapping of rhabdomyosarcoma susceptibility loci in Ptch1-deficient mice'

Europäische Humangenetikerkonferenz (ESHG), München Posterpräsentation: ,Genetic mapping of a Ptch1-associated rhabdomyosarcoma susceptibility locus on mouse Chromosome 2' 
